\title{
Aplicação de práticas de usabilidade ágil em software livre
}

\author{
Ana Paula Oliveira dos Santos
}

\author{
DisSERTAÇÃO APRESENTADA \\ $\mathrm{AO}$ \\ Instituto DE MATEMÁticA E EstatísticA \\ DA \\ UNIVERSIDADE DE SÃo PAUlO \\ PARA \\ OBTENÇÃO DO TÍTULO \\ $\mathrm{DE}$ \\ Mestre em CiênCIAS
}

\author{
Programa: Ciência da Computação \\ Orientador: Prof. Dr. Fabio Kon
}

Durante o desenvolvimento deste trabalho a autora recebeu auxílio financeiro do projeto Qualipso financiado pela Comissão Européia

São Paulo, março de 2012 


\section{Aplicação de práticas de usabilidade ágil em software livre}

Esta versão da dissertação contém as correções e alterações sugeridas pela Comissão Julgadora durante a defesa da versão original do trabalho, realizada em 22/03/2012. Uma cópia da versão original está disponível no

Instituto de Matemática e Estatística da Universidade de São Paulo.

Comissão Julgadora:

- Prof. Dr. Fabio Kon (orientador) - IME-USP

- Prof. Dr. Alfredo Goldman vel Lejbman - IME-USP

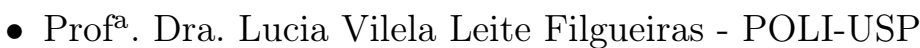




\section{Agradecimentos}

Agradeço primeiramente a Deus por ter me proporcionado a possibilidade de realizar este mestrado e por todas as oportunidades que trouxe para minha vida. À minha querida mãe e familiares só tenho a agradecer todo amparo, compreensão e força com que sempre me incentivaram. Ao meu noivo Leonardo Bertholdo pelo amor, amizade e companheirismo em todos os momentos.

Ao meu orientador, o professor Fabio Kon, pelo apoio, acompanhamento, confiança e compreensão durante todo o mestrado. Agradeço também às professoras Lucia Filgueiras, Maria Laura Martinez e Rebecca Bates pelas conversas sobre usabilidade e assuntos relacionados, as quais me ajudaram a melhor definir e aprofundar este estudo.

Muitas pessoas fizeram parte do desenvolvimento desta pesquisa. Em particular, agradeço a todos os membros dos projetos do Centro de Competência em Software Livre nos quais tivemos a possibilidade de aplicar práticas de usabilidade. Agradeço aos membros do projeto Arquigrafia-Brasil, especialmente aos professores Artur Rozestraten, Marco Aurélio Gerosa e Maria Laura Martinez e a Straus Michalsky, pela oportunidade de realizar uma pesquisa-ação durante o desenvolvimento do projeto e por todo apoio oferecido durante o trabalho. Também agradeço a todos os membros do projeto Mezuro, na disciplina de Programação Extrema do IME-USP. Em especial, agradeço ao professor Alfredo Goldman e a Paulo Meirelles, pela oportunidade de vivenciar o contexto de desenvolvimento de projetos XP. Obrigada a João Miranda, Lucianna Almeida, Marcio Rocha, Thiago Colucci, Vinícius Daros e Viviane Santos, pelas tardes de desenvolvimento, regadas com boas risadas e muito aprendizado.

Agradeço a todos os membros do projeto Balcão de Dúvidas em especial, a Carlos Herrera e Edith Sonco; do projeto CogrOO, especialmente Wesley Seidel e William Collen; do projeto Borboleta, especialmente Edwin Triana e Rafael Correia; e membros da Agilcoop, especialmente Claudia Melo.

Às varias pessoas que em algum momento estiveram envolvidas no desenvolvimento deste mestrado, muito obrigada. Em especial quero agradecer aos amigos do IME, pelos almoços filosóficos, pelas conversas animadas, pelo apoio, entre eles: Alvaro Mamani, Claudia Melo, Edith Sonco, Edwin Triana, Erika Guetti, Fabio Franco, Juliana Yamashita, Maysa Macedo, Paulo de Tarso, Paulo Meirelles, Simone Hanazumi, Sirley Vitorio, Straus Michalsky, Viviane Menezes e Viviane Santos. A todos os amigos que muito contribuíram com seus incentivos.

Muito obrigada também aos professores e demais funcionários do IME e da USP em geral. Finalmente quero agradecer a Comissão Européia, por meio do projeto Qualipso, pelo apoio financeiro para o desenvolvimento da pesquisa. 


\section{Resumo}

SANTOS, A. P. O. Aplicação de práticas de usabilidade ágil em software livre. 2012. 131 p. Dissertação (Mestrado) - Instituto de Matemática e Estatística, Universidade de São Paulo, São Paulo, 2012.

Esta dissertação de mestrado fez parte do projeto Qualipso (Quality Platform for Open Source Software) que teve como principal objetivo melhorar a confiabilidade de sistemas de software livre. Nesse contexto, o enfoque desta pesquisa é um dos atributos de qualidade de software: usabilidade. As práticas de usabilidade no desenvolvimento de software livre, são aplicadas na maioria das vezes, em projetos patrocinados por grandes empresas ou que possuam especialistas em usabilidade como membros da equipe. Mas, em projetos menores da comunidade, compostos geralmente por desenvolvedores, raramente ela é considerada. Porém, a usabilidade é um atributo fundamental para a qualidade durante o uso de um sistema.

Com base em valores compartilhados entre as comunidades de métodos ágeis e de software livre, esta dissertação propõe a adaptação de práticas de usabilidade no contexto de métodos ágeis para o contexto de comunidades de software livre. Por meio de pesquisa bibliográfica, levantamos as principais práticas de usabilidade tanto no âmbito de métodos ágeis, quanto no âmbito de software livre, e as classificamos de acordo com as fases do Design Centrado em Usuário, descrevendo cada uma com o formato nome-contexto-problema-solução-exemplos. As práticas foram exploradas em projetos de software livre, o que possibilitou maior entendimento de problemas enfrentados em contextos reais. Essa experiência resultou na proposta de adaptação de práticas de usabilidade ágil no contexto de comunidades de software livre. Dessa forma, descrevemos a realização de uma pesquisaação no projeto Arquigrafia-Brasil, um estudo de caso no projeto Mezuro e a aplicação de práticas de usabilidade em quatro projetos do Centro de Competência em Software Livre do IME-USP.

Palavras-chave: usabilidade, design centrado em usuário, DCU, experiência do usuário, UX, software livre, métodos ágeis, usabilidade ágil, DCU ágil, teste de aceitação, melhores práticas, padrão de uso. 


\section{Abstract}

\section{SANTOS, A. P. O. Application of agile usability practices in free and open source soft-}

ware. 2012. 131 p. Thesis (Master) - Institute of Mathematics and Statistics, University of São Paulo, São Paulo, 2012.

This Masters thesis was part of the Qualipso project (Quality Platform for Open Source Software) whose main objective was to improve the reliability of free and open source software systems. Within such context, the focus of this research is one of the attributes of software quality: usability. The usability practices in free and open source software development are applied most often in projects sponsored by large companies or employing usability experts as team members. But on smaller projects in the community, generally composed by developers, it is rarely considered. However, usability is an essential attribute to the quality in use of a system.

Based on values shared between the communities of agile methods and free and open source software, this thesis proposes the adaptation of usability practices in the context of agile methods to the context of free and open source software communities. Through the study of the literature in the field, we gathered the main usability practices both within agile methods, as in free and open source software, and we classified according to User-Centered Design phases, describing each one with the format name-context-problem-solution-examples. The practices were explored in free and open source software projects, which enabled greater understanding of problems faced in real contexts. This experience resulted in the adaptation proposal of agile usability practices into the context of free and open source software communities. We describe the implementation of an action research in the Arquigrafia-Brazil project, a case study in the Mezuro project and the application of usability practices in four projects of the IME-USP FLOSS Competence Center.

Keywords: usability, user-centered design, UCD, user experience, UX, free and open source software, agile methods, agile usability, agile UCD, acceptance testing, best practices, usage pattern. 


\section{Sumário}

Lista de Abreviaturas $\quad$ xi

Lista de Figuras $\quad$ xiii

1 Introdução $\quad 1$

1.1 Considerações preliminares . . . . . . . . . . . . . . . . . . . . . 1

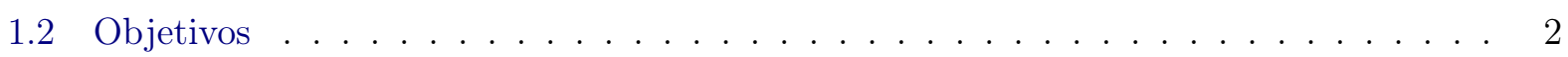

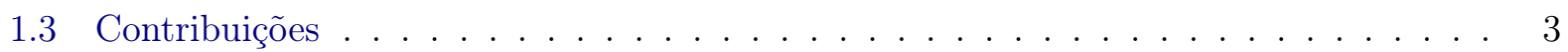

1.4 Organização do trabalho . . . . . . . . . . . . . . . . . . . . . 3

2 Metodologia de pesquisa $\quad 5$

2.1 Contexto: Fatores de influência . . . . . . . . . . . . . . . . . . . 5

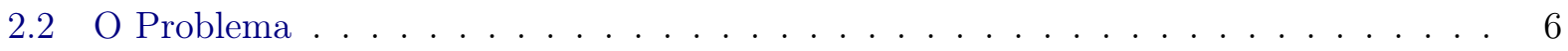

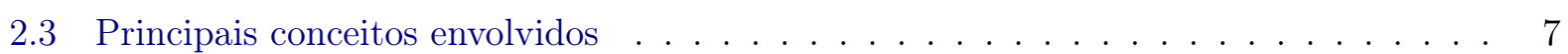

2.3 .1 Pesquisa-ação . . . . . . . . . . . . . . . . . . . . . . 7

2.3 .2 Estudo de caso . . . . . . . . . . . . . . . . . . . . . . . . 8

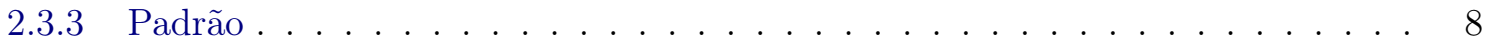

2.4 Revisão da literatura . . . . . . . . . . . . . . . . . . . . . . . . . 10

2.4 .1 Formulação do problema . . . . . . . . . . . . . . . . . . . . 11

2.4 .2 Coleta de dados . . . . . . . . . . . . . . . . . . . . . . . . . 11

2.4 .3 Avaliação, análise e apresentação dos dados . . . . . . . . . . . . . . . . . 12

3 Principais conceitos relacionados a usabilidade $\quad 13$

3.1 O que é usabilidade? . . . . . . . . . . . . . . . . . . . . . . . . . . 13

3.2 Experiência do Usuário ou User eXperience (UX) . . . . . . . . . . . . . . . . . . 14

3.3 IHC - Interação Humano-Computador . . . . . . . . . . . . . . . . . . . . . 15

3.4 Design de Interação . . . . . . . . . . . . . . . . . . . . . . . . 15

3.4.1 Metas do design de interação . . . . . . . . . . . . . . . . . . . . 17

3.4 .2 DCU - Design Centrado no Usuário . . . . . . . . . . . . . . . . . . 18

3.5 Engenharia de usabilidade de desconto . . . . . . . . . . . . . . . . . . 20

3.6 Notas do Capítulo . . . . . . . . . . . . . . . . . . . . . . . . . . . . 21

4 Métodos de usabilidade utilizados na comunidade de software livre $\quad 23$

4.1 Ecossistema FLOSS (Free/Libre Open Source Software) . . . . . . . . . . . . . . 23

4.1.1 Contexto de desenvolvimento FLOSS . . . . . . . . . . . . . . . 25

4.1 .2 Participantes de comunidades . . . . . . . . . . . . . . 26 
4.2 Principais práticas de usabilidade utilizadas no desenvolvimento de software livre . . 28

4.2.1 Especificar contexto de uso . . . . . . . . . . . . . . . . . . . . . 29

4.2 .2 Especificar requisitos . . . . . . . . . . . . . . . . . . . . . . . . . . 31

4.2.3 Criar soluções de design . . . . . . . . . . . . . . . . . . . . . . . . . 33

4.2.4 Avaliar designs . . . . . . . . . . . . . . . . . . . . . . . . . . 36

4.3 Notas do capítulo . . . . . . . . . . . . . . . . . . . . . . . 38

5 Práticas de usabilidade utilizadas na comunidade de métodos ágeis 39

5.1 Métodos ágeis . . . . . . . . . . . . . . . . . . . . . . . . . . . . . . 39

5.1.1 Scrum ........................... 41

5.1 .2 Programação extrema $(\mathrm{XP})$. . . . . . . . . . . . . . . . . . . . . 42

5.2 Métodos de usabilidade utilizados durante o desenvolvimento com métodos ágeis . . 42

5.2 .1 DCU e XP .......................... 45

5.3 Padrões de uso de práticas de usabilidade na comunidade de métodos ágeis . . . . 46

5.3.1 Identificar necessidades para design centrado em humano . . . . . . . . . . . 46

5.3.2 Especificar contexto de uso . . . . . . . . . . . . . . . . . . . . 52

5.3.3 Especificar requisitos . . . . . . . . . . . . . . . . . . . . . . 54

5.3.4 Criar soluções de design . . . . . . . . . . . . . . . . . . . . . . . . . 58

5.3.5 Avaliar designs ... . . . . . . . . . . . . . . . . . . . . . 62

5.4 Notas do Capítulo . . . . . . . . . . . . . . . . . . . . . . 67

6 Pesquisas qualitativas $\quad \mathbf{6 9}$

6.1 Pesquisa-ação no projeto Arquigrafia-Brasil . . . . . . . . . . . . . . . . . . . 69

6.1.1 Ciclo 1: Aplicação de métodos de usabilidade tradicionais . . . . . . . . . . . 71

6.1.2 Ciclo 2: Primeiro teste de usabilidade . . . . . . . . . . . . . . . . . . 75

6.1.3 Ciclo 3: Workshop de usabilidade e Card Sorting . . . . . . . . . . . . . . . . 77

6.1.4 Ciclo 4: Redesign de interfaces e testes de usabilidade remotos . . . . . . . . . 77

6.1.5 Ciclo 5: Avaliação e nova coleta de requisitos . . . . . . . . . . . . . . . . 79

6.1.6 Ciclo 6: Integração do HTML com o código Java . . . . . . . . . . . . . . . . 82

6.2 Estudo de caso no Projeto Mezuro . . . . . . . . . . . . . . . . . . . . . 85

6.3 Aplicação de práticas de usabilidade em projetos de software livre . . . . . . . . . . 87

6.3.1 Projeto Borboleta ......................... 87

6.3 .2 Projeto Balcão de Dúvidas . . . . . . . . . . . . . . . . . . . . . . 87

6.3.3 Projeto CoGrOO ........................... 88

6.3 .4 AgilCoop ............................ 88

6.4 Notas do Capítulo . . . . . . . . . . . . . . . . . . . . . . . . . . . . . . . . . . 89

7 Práticas de Usabilidade Ágil em Software Livre 91

7.1 Síntese de práticas de usabilidade ágil em contexto de software livre . . . . . . . . . . . . . . . . . . . . . . . . . . . 91

7.1.1 Fase: Identificar necessidades para design centrado em humano . . . . . . . . 92

7.1.2 Fase: Especificar contexto de uso . . . . . . . . . . . . . . . . . . . . 92

7.1.3 Fase: Especificar requisitos . . . . . . . . . . . . . . . . . . . . 93

7.1.4 Fase: Criar soluções de design . . . . . . . . . . . . . . . . . . . . . . . . . . 94 
7.1 .5 Fase: Avaliar designs . . . . . . . . . . . . . . . . . . . . . . 94

7.2 Adaptação de práticas de usabilidade ágil para o contexto de software livre . . . 96

7.2.1 Identificar necessidades para design centrado em humano . . . . . . . . . . 96

7.2 .2 Especificar contexto de uso . . . . . . . . . . . . . . . . . . . . . 98

7.2 .3 Especificar requisitos . . . . . . . . . . . . . . . . . . . . . . . . . 98

7.2 .4 Avaliar designs . . . . . . . . . . . . . . . . . . . . . . . . . . . . 99

7.3 Notas do Capítulo . . . . . . . . . . . . . . . . . . . . . . . 100

8 Conclusões $\quad 101$

8.1 Artigos publicados . . . . . . . . . . . . . . . . . . . . 102

8.2 Premiação do projeto Arquigrafia-Brasil na Olimpíada USP de inovação . . . . . . . 102

8.3 Trabalhos Futuros . . . . . . . . . . . . . . . . . . . . 103

$\begin{array}{ll}\text { Referências Bibliográficas } & 105\end{array}$ 


\section{Lista de Abreviaturas}

IHC Interação Humano-Computador (Human-Computer Interaction)

DCU Design Centrado no Usuário (User-Centered Design)

UX Experiência do Usuário (User eXperience)

UI Interface de Usuário (User Interface)

UPA Associação dos Profissionais de Usabilidade (Usability Professionals' Association)

XP Programação Extrema (eXtreme Programming)

FLOSS Free/Libre/Open Source Software

FDD Desenvolvimento guiado por características (Feature Driven Development)

BDD Desenvolvimento guiado por comportamento (Behavior Driven Development)

TDD Desenvolvimento guiado por testes (Test Driven Development)

AHT Análise Hierárquica de Tarefas

GOMS Goals, Operations, Methods, and Selection rules

RITE Rapid Iterative Testing and Evaluation 


\section{Lista de Figuras}

3.1 Relação entre design de interação, IHC e outras áreas [SRP07b] . . . . . . . . . . . . 16

3.2 Relacionamento entre as metas de usabilidade e de UX [SRP07a] . . . . . . . . . . . 18

3.3 Ciclo de vida do DCU $[$ Ass10b] . . . . . . . . . . . . . . . . . . . . . . . 19

4.1 Apresentação de funcionalidade implementada por desenvolvedor para aprovação da comunidade KDE [For11a]. . . . . . . . . . . . . . . . . . . . . 32

4.2 Registros para solicitação de novas características feitas por usuários do sistema KDE

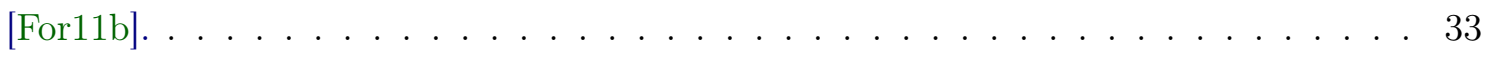

4.3 Visão geral do sistema ArgoUML [Col09]. . . . . . . . . . . . . . . . . . 34

5.1 Manifesto Ágil II por Mike Beedle . . . . . . . . . . . . . . . . . . . . . 41

5.2 Contexto: Características do projeto e da organização são importantes. . . . . . . . . . 41

5.3 Processo do Scrum [Blo11]. . . . . . . . . . . . . . . . . . . . . . . 42

5.4 Relacionamento entre valores, princípios e práticas de XP [BG11] . . . . . . . . . . . 43

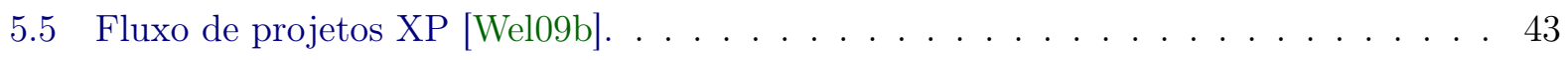

5.6 Ciclo do DCU ágil [SY07]. . . . . . . . . . . . . . . . . . . . . . . . . 44

5.7 Principais problemas durante a aplicação de DCU ágil [MS09] . . . . . . . . . . . . . . . . . . . . . . . . . . . . .

5.8 Um exemplo de cartão de história de usuário [Pri11] . . . . . . . . . . . . . . . . 55

5.9 Lousa contendo ideias dos participantes do estúdio [Dub11] . . . . . . . . . . . 60

6.1 Método de usabilidade proposto por Martinez [Mar02] . . . . . . . . . . . . . . 70

6.2 Registro fotográfico dos grupos focais presenciais de fotógrafos, arquitetos e estudantes 72

6.3 Personas definidas para o sistema Arquigrafia-Brasil. . . . . . . . . . . . . . 73

6.4 Teste presencial de usabilidade sobre a Versão Alfa do primeiro protótipo funcional . 76

6.5 Registro fotográfico do Workshop de usabilidade . . . . . . . . . . . . . 77

6.6 Interface da ferramenta WebSort.net utilizada para ordenação de cartões. . . . . . . 78

6.7 Relatório com resultados do teste sobre o wireframe da interface Home. . . . . . . . 79

6.8 Reuniões para discussão sobre os protótipos e resultados de testes remotos de usabilidade com usuários típicos. . . . . . . . . . . . . . . . . . . . . 79

6.9 Exemplo de imagem gerada com os resultados do teste para comparação do leiaute de uma interface com o fundo escuro e com o fundo claro. . . . . . . . . . . . . 80

6.10 Exemplos de telas usadas no teste remoto de usabilidade com usuários típicos. . . . . 80

6.11 Reunião para apresentação da análise dos testes remotos . . . . . . . . . . . . . . 81

6.12 Grupo focal presencial específico para discussão de avaliação de imagens por meio de aspectos plástico-espaciais . . . . . . . . . . . . . . . . 81 
6.13 Grupo focal remoto e entrevista remota com usuários típicos do sistema.

6.14 Arquivo usability_goals.story que contém as metas de usabilidade definidas para o

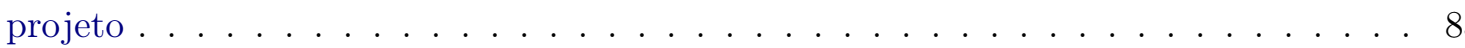

6.15 Classe UsabilityGoals.java que associa cada cenário descrito no arquivo .story a uma classe java que o implementa . . . . . . . . . . . . . . . . . . . . . . 83

6.16 Exemplo de classe que implementa o cenário Login realizado com sucesso descrito em um arquivo .story, que contém as metas de usabilidade da história de usuário Realizar $\operatorname{login} \ldots \ldots \ldots \ldots$. . . . . . . . . . . . . . 84

6.17 Protótipos de baixa fidelidade expostos na Área de trabalho informativa do projeto. 86

6.18 Diagrama de navegação do Borboleta [Gí1] . . . . . . . . . . . . . . . . . 88 


\section{Capítulo 1}

\section{Introdução}

A maioria dos projetos de software livre não possui, em seu processo de desenvolvimento, práticas para melhoria da usabilidade. Isso se deve pela mentalidade de parte dos desenvolvedores de software, voltada mais para a funcionalidade do que para os usuários do sistema [Tho08].

Métodos de usabilidade são utilizados por empresas especialistas em projeto de interação e, em menor ou maior grau, são inseridos nos processos de desenvolvimento de projetos de software fechado, o que garante, em geral, uma melhor usabilidade quando comparados à maioria dos sistemas de software livre.

Esse cenário é um dos fatores que ainda limita a expansão de uso e aceitação de sistemas livres, pois, perdendo-se em usabilidade, perde-se também em confiança dos usuários. Dessa forma, o uso desse tipo de sistema limita-se a usuários mais experientes em computação e tecnologia, configurando-se em uma grande perda para usuários inexperientes. Muitos sistemas de software livre possuem código de qualidade, o que lhes confere algoritmos eficientes e de bom desempenho, pois foram produzidos, na maioria das vezes, por indivíduos motivados a resolverem voluntariamente desafios ou problemas no sistema. A perda de usuários potenciais devido a baixa usabilidade configura, portanto, um desperdício de recursos para a sociedade.

Apesar desse cenário, o desenvolvimento de sistemas de código aberto vem mudando nos últimos anos com a crescente preocupação com a usabilidade, ainda que esteja normalmente limitada a projetos de grande visibilidade, geralmente patrocinados por grandes empresas. Porém, no âmbito das comunidades, a usabilidade raramente é considerada no processo [NT06]. Contudo, é importante que seja considerada porque a maioria dos projetos de software livre surge a partir das comunidades $\left[\mathrm{SFF}^{+}\right.$06, How08, DWA04] e existe um número crescente de novos usuários interessados em utilizar sistemas de software livre [Hed07].

Inserindo-se práticas para melhoria da usabilidade no ciclo de desenvolvimento de software livre, não só se consegue aumentar a aceitação desse tipo de software na sociedade, como também esse processo favorece o surgimento de novas ideias para interfaces. Afinal, o próprio modelo aberto de software livre possibilita uma maior exploração de um dos conceitos de métodos de usabilidade: a recepção de várias ideias de design e interação, de modo a promover a possibilidade de abertura à contribuição para qualquer pessoa interessada em participar.

\subsection{Considerações preliminares}

É comum em programas de software livre que haja pouco incentivo (ou interesse) na usabilidade, dado que a implementação das funcionalidades geralmente é a prioridade dos desenvolvedores. Essa cultura leva o desenvolvedor a iniciar o projeto pelo código, deixando o design de interfaces em segundo plano [Tho08].

Em aplicações de código aberto, também existe uma tendência para o crescimento em complexidade, muitas vezes em detrimento da usabilidade. Embora aplicações não livres também cresçam em complexidade, a competitividade do mercado faz com que existam alguns fatores moderadores desse crescimento, incluindo o custo direto do desenvolvimento de características extras e a própria 
preocupação com o possível impacto negativo sobre a usabilidade [NT03].

Desenvolvedores de software livre não costumam notar a baixa usabilidade de seus sistemas, por serem geralmente usuários experientes e acostumados a interfaces de baixo nível como, por exemplo, a linha de comando. Em contrapartida, empresas que produzem software comercial muitas vezes possuem funcionários especialistas em usabilidade, o que é raro em equipes de desenvolvimento de software livre [NT06].

Esse tema é importante na medida em que, ao perder em usabilidade, programas de código aberto perdem usuários. Isso ocorre porque a escolha entre dois produtos com funcionalidades similares leva fortemente em conta a usabilidade, já que o melhor software nesse aspecto propicia maior credibilidade ao sistema. Uma evidência dessa importância pode ser observada na existência de diversos sistemas que, a despeito de possuírem todas as funcionalidades necessárias, não obtiveram sucesso porque os usuários não conseguiam entender como utilizá-los.

Em boa parte dos casos, pode-se dizer que, para o usuário, a interface é o próprio sistema. Sendo assim, a interface torna-se parte fundamental para o sucesso de um projeto, porque o produto final não será utilizado por seus desenvolvedores e projetistas, ao menos na maioria das vezes, e, sim, por usuários que não participaram do seu processo de desenvolvimento e que provavelmente não tiveram contato anterior com tal tecnologia.

\subsection{Objetivos}

O objetivo deste trabalho é a melhoria da usabilidade de sistemas de software livre, através da inserção de métodos de usabilidade durante o desenvolvimento deste tipo de sistema. Para tanto, buscamos entender o contexto de desenvolvimento de software livre, cujas características são ambientes de desenvolvimento distribuídos, abertos e colaborativos, nos quais existe a predominância de contribuição por desenvolvedores de software [SFF ${ }^{+}$06, How08, DWA04].

Esse caráter impossibilita a utilização integral de métodos de usabilidade, pois estes foram pensados para aplicação por equipes de designers e/ou especialistas em usabilidade. Estudos realizados com pequenos e grandes projetos de software livre demonstram que o tempo médio de participação nos projetos é de 1,2 anos [DWA04], de acordo com a atratividade do projeto, sendo assim, métodos de usabilidade que se baseiam em investigações detalhadas antes do início do desenvolvimento não estão em conformidade com a realidade de ambientes de desenvolvimento de software livre, uma vez que esse tempo médio representa o tempo de desenvolvimento completo do projeto.

As práticas de usabilidade apoiadas em métodos ágeis facilitam a integração da preocupação com a usabilidade, durante o desenvolvimento, pois possibilitam menor granularidade de pesquisa de usabilidade e aplicação mais rápida dos resultados no sistema. Métodos ágeis priorizam o ser humano e sua comunicação e consideram o cliente como parte da equipe, o que demonstra a importância do feedback nesse tipo de desenvolvimento e a sua relação com métodos de design centrado no usuário (DCU).

Por esse motivo, pensou-se que a utilização de práticas de usabilidade, adaptadas de acordo com valores de métodos ágeis, poderia ser uma boa opção para inserir a preocupação com a usabilidade em equipes de desenvolvimento de software livre. Dessa forma, foram estudadas as práticas de usabilidade, já utilizadas em equipes de desenvolvimento de software livre e em equipes de métodos ágeis. O intuito era possibilitar o entendimento do contexto em que os métodos eram aplicados. Com isto, seria possível analisar como melhor explorar os "métodos de usabilidade ágil" (métodos de usabilidade integrados com valores de métodos ágeis) no contexto de desenvolvimento de software livre.

O objetivo geral desta pesquisa é a adaptação de práticas de usabilidade utilizadas no contexto de métodos ágeis para o contexto de comunidades de software livre, em particular, equipes que não possuem especialistas em usabilidade, compostas em sua maioria por desenvolvedores.

Os objetivos específicos da pesquisa são:

- levantar o perfil de membros de comunidades de software livre e o seu contexto de desenvolvimento de sistemas; 
- levantar as práticas de usabilidade utilizadas no contexto de software livre;

- levantar as práticas de usabilidade utilizadas no contexto de métodos ágeis; e

- analisar a aplicação de práticas de usabilidade em contextos reais de desenvolvimento de software livre.

\subsection{Contribuições}

As principais contribuições científicas são as seguintes:

- Classificação de práticas de usabilidade no contexto de comunidades de software livre de acordo com as fases de Design Centrado em Usuário e seguindo o formato: nome, contexto, problema, solução e exemplos.

- Classificação dos principais padrões de uso de práticas de usabilidade no contexto de comunidades de métodos ágeis de acordo com as fases de Design Centrado em Usuário e seguindo o formato: nome, contexto, problema, solução e exemplos.

- Adaptação de padrões de uso de práticas de usabilidade ágil para o contexto de comunidades de software livre, em particular, equipes que não possuem especialistas em usabilidade, compostas em sua maioria por desenvolvedores.

Nesta pesquisa, entende-se padrões de uso de práticas de usabilidade, não como o conjunto de práticas de usabilidade comumente utilizados em uma comunidade, mas sim, como a forma em que cada prática de usabilidade é aplicada em uma comunidade, tendo como base as melhores práticas de usabilidade da comunidade. Assim, por exemplo, para a prática de teste de usabilidade com usuários, nos interessa saber que tipo de problema se espera resolver, em que contexto e qual solução é aplicada ao utilizá-la.

\subsection{Organização do trabalho}

O Capítulo 2 tem como objetivo apresentar as motivações e questões de pesquisa que direcionaram este estudo. Neste capítulo também são definidos os métodos utilizados para responder as questões de pesquisa.

Uma explicação dos principais conceitos para entendimento do que são métodos de usabilidade e situá-los em sua área de pesquisa é apresentando no Capítulo 3.

O Capítulo 4 apresenta quem são os membros de projetos de software livre, quais são as suas necessidades em relação ao desenvolvimento de software e em que contexto eles desenvolvem esse tipo de sistema. Dessa forma, este capítulo utiliza-se da filosofia de Design Centrado no Usuário (DCU) para entender quem seriam os usuários dos métodos de usabilidade durante o desenvolvimento de software livre, no âmbito das comunidades. Em seguida, são apresentadas as principais práticas de usabilidade utilizadas por equipes de desenvolvimento de software livre e em que contexto tais métodos são realizados atualmente.

No Capítulo 5 são apresentadas as principais definições de métodos ágeis de desenvolvimento de software e na sequência, a integração deles com a área de usabilidade ou User eXperience ou UX, que neste contexto recebeu o nome de UX ágil ou Design Centrado no Usuário (DCU) ágil, que muitas vezes são usados como sinônimos de métodos de usabilidade. Embora uma distinção entre eles seja definida no Capítulo 3. Sendo assim, as principais práticas de usabilidade utilizadas por equipes de métodos ágeis são apresentadas.

O Capítulo 6 apresenta os estudos qualitativos realizados durante a pesquisa. Foram utilizados um projeto como estudo de caso, para exploração de práticas de usabilidade e um projeto como pesquisa-ação, para aplicação de adaptações para atender o contexto de desenvolvimento de software livre, de modo a descrever o refinamento sucessivo das adaptações através de ciclos durante o 
desenvolvimento do sistema. Também são descritas as práticas de usabilidade aplicadas em quatro projetos de software livre.

O Capítulo 7 apresenta uma reflexão sobre os principais padrões de uso de práticas de usabilidade no contexto de métodos ágeis, e sua aplicação no contexto de desenvolvimento de software livre, considerando suas particularidades. Desse modo, apresenta-se possíveis adaptações das práticas de usabilidade ágil para o contexto de desenvolvimento de software livre.

Por fim, o Capítulo 8 apresenta as conclusões obtidas com esta pesquisa, bem como os artigos resultantes, a premiação do projeto Arquigrafia-Brasil, projeto no qual realizou-se a pesquisa-ação, além de trabalhos futuros. 


\section{Capítulo 2}

\section{Metodologia de pesquisa}

Este capítulo possui como objetivo apresentar a metodologia de pesquisa através do contexto em que ela foi realizada, mostrando quais foram os fatores externos a esta pesquisa que a direcionaram; o problema que se pretende resolver, incluindo evidências de sua existência e em quais situações; além da proposta de solução, definindo as questões de pesquisa. Descreve-se também como a pesquisa bibliográfica foi realizada, apresentando o que foi preciso estudar e quais foram as buscas realizadas para obtenção dos resultados.

\subsection{Contexto: Fatores de influência}

Esta pesquisa iniciou-se dentro do projeto Qualipso (Quality Platform for Open Source Software) [Mem09], (http://www.qualipso.org), que propôs "definir e implementar tecnologias, procedimentos e políticas com o objetivo de potencializar as práticas de desenvolvimento de software livre, tornando-as confiáveis, reconhecidas e estabelecidas na indústria. Para viabilizar o projeto e a sustentação do software livre como uma solução confiável para a indústria, foi criado um consórcio formado por indústrias, academia e governo" [IU10].

Nesse contexto, o tópico de pesquisa relaciona-se com a melhoria da qualidade de software livre, com o foco mais específico em um dos atributos de qualidade de software, a usabilidade, com a meta de aumentar a confiança dos usuários em software livre através da possibilidade de melhoria da usabilidade desse tipo de sistema.

Como fator de influência, o grupo de pesquisa no qual esta dissertação está inserida, possui pesquisas sobre métodos ágeis de desenvolvimento de software e sua proximidade com desenvolvimento de software livre, pois existem valores compartilhados nesses dois ambientes de desenvolvimento e a integração entre eles pode ser facilitada, o que pode resultar na melhoria da qualidade de sistemas de software livre [CG11]. Além disso, modelos de desenvolvimento de software tradicionais como waterfall [Roy70], realizam a coleta de requisitos antes do início da implementação do sistema, o que não é compatível com o contexto de desenvolvimento de projetos de software livre, nos quais os requisitos são baseados na distribuição do software o mais cedo possível aos usuários para obter feedback [Rob03, Wik11].

Por esse motivo, a aplicação de práticas de usabilidade com valores de métodos ágeis tornou-se uma opção para melhoria da usabilidade de sistemas de software livre, uma vez que métodos de usabilidade apoiados na engenharia de software tradicional pressupõem uma fase de investigação detalhada de usuários antes do início do desenvolvimento.

Durante a pesquisa, foram aplicadas práticas de usabilidade com valores ágeis em projetos do Centro de Competência em Software Livre (CCSL) do IME-USP, de modo a explorar as práticas em contextos reais de desenvolvimento de software livre.

O tema desta pesquisa é portanto: utilização de práticas de usabilidade ágil (práticas de usabilidade com valores, princípios ou práticas de métodos ágeis) durante o desenvolvimento de software livre. 


\subsection{O Problema}

O problema a ser tratado nesta pesquisa é a integração de práticas de usabilidade ágil durante o desenvolvimento de sistemas em comunidades de software livre. O problema deriva-se das limitações de se utilizar práticas de usabilidade tradicionais no contexto de desenvolvimento de software livre. Além das evidências do problema, apontadas no Capítulo 1, existem algumas outras também baseadas na literatura:

- Os pequenos projetos da comunidade de desenvolvimento de software livre são compostos geralmente por um ou dois desenvolvedores $\left[\mathrm{SFF}^{+} 06\right.$, How08, DWA04] sem conhecimentos especializados em usabilidade.

- A maior parte do processo de desenvolvimento de software ocorre em isolamento [Gho05, KS02] (ambiente distribuído).

- Software livre tem grande potencial para ser usado por todos os tipos de usuários, uma vez que em geral, são distribuídos gratuitamente, mas para atingir todos os perfis, inclusive usuários novatos, é necessário maior preocupação com a usabilidade dos sistemas distribuídos.

- Ferramentas centradas em texto, presentes em ambientes de desenvolvimento de software livre, dificultam discussões sobre design de interação [Twi05], sendo assim existe a dificuldade na comunicação de problemas de usabilidade [NT06].

- Sistemas para que usuários apontem os erros encontrados em projetos de software livre, geralmente, exigem que os erros sejam descritos seguindo um formato específico, o que dificulta a participação de usuários não técnicos nesse tipo de ambiente.

O problema em questão existe majoritariamente no âmbito dos projetos de comunidades de desenvolvimento de software livre, uma vez que os projetos iniciados e/ou controlados por empresas, geralmente possuem especialistas em usabilidade contratados para cuidar da interação do usuário com o sistema. Porém, os projetos desenvolvidos por pequenos grupos de desenvolvedores voluntários, normalmente, ainda não incluem práticas para melhoria da usabilidade. Em termos de usabilidade, existe uma clara divisão entre pequenos e grandes projetos de software livre [Ben04].

O desenvolvimento de software livre, no âmbito das comunidades, possui as seguintes peculiaridades: são ambientes de desenvolvimento distribuídos, abertos, colaborativos, compostos majoritariamente por desenvolvedores, que geralmente não possuem especialistas em usabilidade como membros da equipe e que possuem contribuidores esporádicos que entram durante o desenvolvimento para resolver algum problema específico e saem após sua resolução, podendo ou não retornar em fases posteriores do desenvolvimento.

A relevância do problema se deve ao fato que dezenas de milhares de projetos de software livre estão funcionando em todo o mundo e milhões de usuários finais dependem cada vez mais de sistemas baseados em software livre. Números crescentes de projetos de pesquisa em ciências humanas, sociais e físicas tão bem quanto em artes e atividades culturais estão agora esperando desenvolver ou usar sistemas de software livre para melhor atender suas necessidades. Similarmente números crescentes de organizações comerciais e de governo estão agora procurando desenvolver e usar aplicações de software críticas que são construídas com componentes open source [Sca10].

Sendo assim, existem alternativas de solução para o problema de integração de práticas de usabilidade em ambientes de desenvolvimento de software livre, entre elas destacam-se:

- Definição de um modelo de maturidade de usabilidade para software livre [Raz11].

- Incentivo para atrair a contribuição de especialistas de usabilidade para projetos de software livre, por exemplo, através do projeto Open Usability (http://www.openusability.org). Segundo o site do projeto, consiste de uma iniciativa que promove usabilidade em desenvolvimento Free/Libre Open Source Software (FLOSS), contendo um grupo de pessoas que compartilha a 
ideia de fazer usabilidade transparente, compartilhar métodos e melhores práticas e suportar software de código aberto [Usa10].

- Pesquisa realizada para levantamento das principais práticas de usabilidade utilizadas no desenvolvimento de software livre [Pau09].

Esta pesquisa busca o entendimento do ponto de vista da comunidade na qual as práticas serão aplicadas, antes de utilizar uma abordagem existente. Dessa forma, buscou-se o entendimento da comunidade de possíveis usuários das práticas de usabilidade, no caso, desenvolvedores de comunidades de software livre.

As comunidades de software livre e de métodos ágeis utilizam práticas mais "leves" para o desenvolvimento de software, onde o termo leve refere-se a ter uma menor quantidade de tarefas obrigatórias para se chegar à implementação. Sendo assim, na aplicação de práticas de usabilidade ágil, as tarefas de pesquisa, design e avaliação de usabilidade também são mais "leves", e ocorrem de modo a trabalhar sobre pedaços menores do sistema, de acordo com os requisitos para a próxima iteração de desenvolvimento e não com todos os requisitos definidos antes do início da implementação.

Contudo, as práticas de usabilidade a serem utilizadas em um projeto dependem do contexto, ou seja, da equipe que está trabalhando no projeto, o ambiente de desenvolvimento e o próprio projeto, que pode conter especificidades que impedem o uso de determinada prática. Por esse motivo, os resultados desta pesquisa serão apresentados em termos de padrões de uso de práticas de usabilidade, de modo a definir o que cada padrão pode resolver, de acordo com o formato: nome, contexto, problema, solução e exemplos. Dessa forma, a seguinte questão de pesquisa (QP1), que será respondida no Capítulo 7, foi definida:

- QP1: São possíveis adaptações em práticas de usabilidade integradas aos valores, princípios ou práticas ágeis para o contexto de comunidades de desenvolvimento de software livre, mantendo as particularidades dessas comunidades?

\subsection{Principais conceitos envolvidos}

Para responder a questão (QP1) foram realizados um estudo de caso exploratório e a inserção de adaptações iterativamente em um projeto utilizado como pesquisa-ação, além da aplicação de práticas específicas de usabilidade em projetos de software livre. Uma breve definição para pesquisaação e estudo de caso é apresentada nas subseções 2.3.1 e 2.3.2, respectivamente. Além disso, para facilitar a organização das práticas levantadas na literatura, utilizou-se o formato de um padrão, que é definido na subseção 2.3.3.

\subsubsection{Pesquisa-ação}

A pesquisa-ação ou action-research surgiu na década de 1940, no contexto de críticas ao uso de procedimentos clássicos de ciências naturais na pesquisa social por razões de ordem prática (conhecimento teórico gerado teria pouca aplicabilidade na prática) ou ideológica (pesquisas estariam sendo realizadas como uma forma de controle social) [FF08, Gil06]. Estas críticas explicam o foco do método em aproximar a teoria da prática ao buscar soluções para um problema específico no contexto de uma organização [FF08]. Sendo assim, pesquisa-ação possui um duplo objetivo: fazer pesquisa para ampliar o conhecimento científico e realizar uma ação para promover uma melhoria na organização ou comunidade onde a pesquisa está sendo realizada, ou seja teoria e prática andam juntas através de pesquisa e ação. Por esse motivo, o pesquisador age e se envolve com a pesquisa [Dic93, KMS97].

Conforme Filippo [FF08], "na pesquisa-ação busca-se avançar na teoria atuando na prática, o que é feito através de ações no contexto de uma organização específica. O foco do pesquisador é na compreensão do problema e das ações realizadas para solucioná-lo dentro de um ambiente real particular e não na verificação de uma hipótese de caráter geral num ambiente de laboratório." 
O pesquisador adota um posicionamento não-neutro, ou seja não é apenas um observador, mas sim interfere com ações e integra-se aos membros da equipe ou organização onde a pesquisa é realizada [MM01]. Ainda conforme Filippo: "Pesquisadores e pesquisados colaboram visando compreender um problema, as ações propostas para solucioná-lo adequadamente e o efeito destas ações. A pesquisa é conduzida num processo cíclico de agir e refletir criticamente sobre as ações: o pesquisador, fazendo uso de seu arcabouço teórico; os membros do grupo, a partir do conhecimento prático do contexto em que trabalham." O pesquisador também pode atuar como profissional no ambiente da pesquisa, o que é o caso desta dissertação, onde utiliza-se o método de pesquisa-ação "canônico", que consiste em realizar ações para intervir em problemas identificados dentro de um contexto particular.

O pesquisador pode ter uma visão de insider ou outsider, na realização de uma pesquisa-ação. A visão de um insider ocorre quando o pesquisador vivencia o problema e o traz para a pesquisa, ou seja leva seus problemas para realizar a pesquisa, já a visão de outsider é quando a instituição tem um problema e chama um pesquisador ou o pesquisador vai atrás de uma empresa ou cenário real que tenha o problema. No caso deste estudo, a pesquisa-ação realizada no projeto ArquigrafiaBrasil, é do tipo outsider, pois existia a necessidade de pesquisa de usabilidade no projeto em um contexto de desenvolvimento de software livre utilizando métodos ágeis, que consiste no cenário ideal para esta pesquisa.

A pesquisa-ação é tipicamente realizada em ciclos iterativos que sucessivamente refinam o conhecimento adquirido nos ciclos anteriores [FF08], dessa forma ao fim de cada ciclo é possível refletir sobre o que funcionou bem, o que não funcionou e o que funcionou parcialmente. Basicamente, os ciclos podem ser descritos em refletir e agir, onde a reflexão é um estágio de diagnóstico e a ação é um estágio terapêutico. Nesta pesquisa, foi adotado o ciclo com as 4 etapas Planejar, Agir, Observar, Refletir [KM05], o qual será usado para descrever a pesquisa-ação realizada durante o desenvolvimento do projeto Arquigrafia-Brasil no Capítulo 6.

\subsubsection{Estudo de caso}

Com base em seus objetivos, esta pesquisa é classificada como uma pesquisa exploratória, que visa a proporcionar maior familiaridade com o problema, ou seja o aprimoramento de ideias ou a descoberta de intuições. Na maioria dos casos, a pesquisa exploratória assume a forma de pesquisa bibliográfica ou de estudo de caso [Gil07]. Um estudo de caso tem sido um método adequado para uma série de questões de pesquisa, já que oferece uma abordagem flexível, que não exige uma fronteira rigorosa entre o objeto estudado e seu ambiente [Yin03], além disso o estudo de caso é um método empírico que favorece o realismo sobre o nível de controle [PH08].

O processo de investigação de um estudo de caso envolve cinco etapas principais [PH08]: (i) o projeto de estudo de caso, em que os objetivos são definidos e o estudo de caso é planejado; (ii) a preparação para a coleta de dados, em que procedimentos e protocolos para coleta de dados são definidos; (iii) a coleta de evidências, que envolve a execução e coleta de dados sobre o caso estudado; (iv) análise dos dados coletados; e (v) relatórios, o que significa escrever e comunicar os resultados do estudo de caso.

O projeto Mezuro foi utilizado como estudo de caso desta pesquisa onde foram aplicadas práticas específicas de usabilidade que foram analisadas em um contexto real e é descrito no Capítulo 6 .

\subsubsection{Padrão}

As práticas de usabilidade utilizadas no contexto de desenvolvimento de software livre e de métodos ágeis são descritas por meio de padrões de uso. Dessa forma, relaciona-se cada uma das melhores práticas levantadas a um contexto de uso, a um problema que esta prática soluciona, a solução propriamente dita e exemplos. Ou seja, como uma determinada prática de usabilidade é aplicada em cada comunidade. Por esse motivo, uma breve definição do que são padrões é apresentada a seguir. 
Segundo Cukier e Kon [CK09], podemos definir um padrão de acordo com a definição dos seguintes autores:

- Christopher Alexander: cada padrão é uma regra de três partes que expressa a relação entre um certo contexto, um problema e uma solução.

- Richard Gabriel: cada padrão é uma regra de três partes que expressa a relação entre um certo contexto, um certo sistema de forças que ocorre repetidamente neste contexto e uma certa configuração de software que permita que essas forças se resolvam.

- Martin Fowler: um padrão é uma ideia que foi útil em algum contexto prático e provavelmente será util em outros.

O conceito de padrão de projeto foi criado na década de 1970 pelo arquiteto Christopher Alexander, que estabelece que um padrão deve ter, idealmente, as seguintes características:

- Encapsulamento: um padrão encapsula um problema/solução bem definida. Ele deve ser independente, específico e formulado de maneira a ficar claro onde ele se aplica.

- Generalidade: todo padrão deve permitir a construção de outras realizações a partir deste padrão.

- Equilíbrio: quando um padrão é utilizado em uma aplicação, o equilíbrio dá a razão, relacionada com cada uma das restrições envolvidas, para cada passo do projeto. Uma análise racional que envolva uma abstração de dados empíricos, uma observação da aplicação de padrões em artefatos tradicionais, uma série convincente de exemplos e uma análise de soluções ruins ou fracassadas pode ser a forma de encontrar este equilíbrio.

- Abstração: os padrões representam abstrações da experiência empírica ou do conhecimento cotidiano.

- Abertura: um padrão deve permitir a sua extensão para níveis mais baixos de detalhe.

- Combinatoriedade: os padrões são relacionados hierarquicamente. Padrões de alto nível podem ser compostos ou relacionados com padrões que endereçam problemas de nível mais baixo.

Além da definição das características de um padrão, Alexander definiu o formato que a descrição de um padrão deve ter. Ele estabeleceu que um padrão deve ser descrito em cinco partes:

- Nome: uma descrição da solução, mais do que do problema ou do contexto.

- Contexto: a descrição das situações sob as quais o padrão se aplica.

- Problema: uma descrição das forças e restrições envolvidos e como elas interagem.

- Solução: relacionamentos estáticos e regras dinâmicas descrevendo como construir artefatos de acordo com o padrão, freqüentemente citando variações e formas de ajustar a solução segundo as circunstâncias. Inclui referências a outras soluções e o relacionamento com outros padrões de nível mais baixo ou mais alto.

- Exemplo: uma ou mais figuras, diagramas ou descrições que ilustrem um protótipo de aplicação.

O Capítulo 7 tem o objetivo de ser uma síntese das práticas de usabilidade das comunidades de métodos ágeis e de software livre, de modo a adaptar padrões de uso no âmbito de métodos ágeis, para o contexto de software livre considerando suas especificidades. 


\subsection{Revisão da literatura}

Cooper [Coo88] propôs uma taxonomia de revisões da literatura, na qual sugere que elas podem ser classificadas de acordo com as seguintes cinco características: enfoque, meta, perspectiva, cobertura, organização e audiência.

Para determinar o enfoque da revisão, Cooper identifica quatro potenciais categorias: resultados de pesquisa, métodos de pesquisa, teorias e práticas ou aplicações. Esta pesquisa tem como enfoque práticas de usabilidade em ambientes de desenvolvimento de software livre e de métodos ágeis. Dessa forma, existe a intenção de se entender como uma certa intervenção, práticas de usabilidade, tem sido aplicadas em determinados grupos de pessoas, no caso comunidades de software livre ou de métodos ágeis. Dessa forma, pretende-se exibir as necessidades práticas que não são atualmente realizadas em comunidades de software livre, de modo a adaptá-las para esse contexto de acordo com práticas de usabilidade da comunidade de métodos ágeis.

A segunda característica apontada por Cooper [Ran09], a meta, diz respeito a se o autor deseja integrar e generalizar descobertas através de unidades, tratamentos, resultados e configurações; com o objetivo de resolver um debate dentro de um campo; ou ainda para conectar a linguagem usada através dos campos. Em outras revisões, a meta pode ser analisar criticamente a pesquisa anterior, identificar questões centrais, ou explicar uma linha de argumento dentro de um campo. Dessa forma, esta pesquisa tem como meta integrar e conectar a linguagem usada para práticas de usabilidade utilizadas nas comunidades de métodos ágeis e de software livre, através de uma formato-padrão para descrever as práticas nas duas comunidades, por meio da definição de nome, contexto, problema, solução e exemplos para cada uma das principais práticas.

A terceira característica, perspectiva, refere-se a adotar uma representação neutra ou com a exposição de posição sobre o assunto, na qual esta pesquisa adotará uma representação neutra dos resultados da revisão da literatura, de modo a apenas apresentar reflexões no capítulo no qual se pretende sintetizar as práticas de usabilidade de comunidades de métodos ágeis que possam ser aplicadas em comunidades de software livre.

A cobertura, quarta característica, trata da decisão de quão ampla será a rede de pesquisa. Cooper propõe quatro cenários de cobertura: exaustiva, exaustiva com citação seletiva, representativa e central ou essencial. Esta pesquisa utilizou a cobertura central ou essencial.

Quanto à característica de organização, Cooper propôs as seguintes categorias: histórica, conceitual e metodológica. Em alguns casos, pode-se associar esses formatos de organização do texto, por exemplo, iniciar com uma introdução, definir o método, apresentar os resultados em um formato conceitual e finalizar com uma discussão dos resultados. Este último formato será o utilizado nesta pesquisa, de modo que os resultados da revisão da literatura, ou seja as melhores práticas de usabilidade, serão apresentados conceitualmente em um formato-padrão para as duas comunidades - nome, contexto, problema, solução e exemplos - junto com uma tabela que sintetiza as principais práticas, e por fim, uma discussão dos resultados será apresentada.

Finalmente, a quinta característica proposta por Cooper, audiência, refere-se ao público-alvo da revisão da literatura. Para uma dissertação, o supervisor e revisores são a audiência primária e os estudantes dentro do campo de pesquisa da dissertação compõem a audiência secundária.

Ainda conforme Cooper, existem cinco passos básicos para se realizar uma revisão da literatura:

1. Formulação do problema;

2. Coleta de dados;

3. Avaliação dos dados;

4. Análise e interpretação dos dados; e

5. Apresentação pública. 


\subsubsection{Formulação do problema}

Por meio de levantamento bibliográfico e conversas com especialistas, foi realizado o estudo de comunidades de software livre, de modo a compreender as suas especificidades para o desenvolvimento de software, além das principais práticas de usabilidade já utilizadas, encontradas na literatura. A partir da definição da proposta de pesquisa, baseada na integração de práticas de usabilidade com métodos ágeis, existiu a necessidade de entender quais são as práticas de usabilidade aplicadas no ambiente de métodos ágeis, de modo a analisar se elas poderiam ser aplicadas em contextos de desenvolvimento de comunidades de software livre.

Como o intuito é entender como as práticas são aplicadas, surgiu a necessidade de entender o contexto, problema e solução de cada uma das práticas de usabilidade aplicadas em cada comunidade - de métodos ágeis e de software livre - e a partir desse entendimento analisar a possibilidade de adaptações de práticas de usabilidade ágil para o contexto de software livre.

Conforme Randolph [Ran09], a formulação do problema inicia-se com a determinação das questões que guiarão a revisão da literatura, sendo assim a pesquisa bibliográfica foi baseada nas seguintes questões:

- Q1: Quais são as práticas de usabilidade utilizadas atualmente na comunidade de software livre, descritas sob o formato nome, contexto, problema, solução e exemplos?

- Q2: Quais são as melhores práticas de usabilidade utilizadas atualmente na comunidade de métodos ágeis, descritas sob o formato nome, contexto, problema, solução e exemplos?

As questões Q1 e Q2 são respondidas respectivamente nos Capítulos 4 e 5, de acordo com as características de Cooper apontadas acima.

O segundo passo na formulação do problema é explicitamente determinar os critérios de inclusão e exclusão de estudos na pesquisa bibliográfica. Nesta pesquisa, os estudos foram incluídos se reunissem os seguintes critérios:

1. O estudo relatou como as práticas de usabilidade foram aplicadas em comunidades de software livre, de modo a levantar pelo menos uma das seguintes informações para cada prática descrita: contexto, problema e solução.

2. O estudo relatou como as práticas de usabilidade foram aplicadas em comunidades de métodos ágeis, de modo a levantar pelo menos uma das seguintes informações para cada prática descrita: contexto, problema e solução.

3. Conforme Randolph, para estudos separados que usaram os mesmos dados, por exemplo dissertação e um artigo, somente o estudo com o relatório mais abrangente foi incluído para evitar a sobrecarga de um conjunto particular de dados.

4. Estudos escritos em inglês.

Os estudos foram excluídos se:

1. Não apresentaram dados claros de como cada prática de usabilidade foi realizada dentro de uma comunidade, de software livre ou de métodos ágeis, impossibilitando o levantamento de pelo menos uma das seguintes informações: contexto, problema e solução de cada prática.

\subsubsection{Coleta de dados}

A coleta de dados inicia-se com uma busca eletrônica de bancos de dados acadêmicos e Internet. Registros devem ser mantidos dos dados de cada busca, os bancos de dados pesquisados, as palavraschave, as combinações de palavras-chave e o número de registros resultantes de cada busca [Ran09].

Os critérios de busca utilizados para pesquisa são divididas em três tipos: (1) Características de comunidades de software livre; (2) práticas de usabilidade utilizadas na comunidade de software livre; e (3) práticas de usabilidade utilizadas na comunidade de métodos ágeis. Cada um dos critérios de busca é apresentado abaixo, conforme o seu tipo: 
1. (("free software" OR "open source" OR "open source software" OR "Free/Libre Open Source Software" OR "Free Open Source Software") AND ("systematic review" OR "research review" OR "research synthesis" OR "research integration" OR "systematic overview" OR "systematic research synthesis" OR "integrative research review" OR "integrative review" OR "community features" OR "community" OR "particularities")).

2. (("usability" OR "usability methods" OR "User Centered Design" OR "User eXperience" OR "Human-Computer Interaction" OR "Computer-Human Interaction") AND ("free software" OR "open source" OR "open source software" OR "Free/Libre Open Source Software" OR "Free Open Source Software")).

3. (("usability" OR "usability methods" OR "User Centered Design" OR "User eXperience" OR "Human-Computer Interaction" OR "Computer-Human Interaction") AND ("agile methods" OR "agile development" OR "eXtreme Programming" OR "Scrum" OR "agile")).

O processo utilizado para filtragem consistia em: (1) Leitura do título; (2) Leitura do resumo; e (3) Leitura completa do estudo. Para cada uma dessas fases, os estudos que não estavam de acordo com os critérios de inclusão foram excluídos. Nesta pesquisa, a coleta de dados foi realizada através do sistema de buscas do Google acadêmico, e após a filtragem de acordo com os critérios de inclusão e exclusão, realizava-se a coleta de novos estudos a partir das referências bibliográficas dos artigos ou dissertações filtrados.

\subsubsection{Avaliação, análise e apresentação dos dados}

No estágio de avaliação dos dados, inicia-se a extração e avaliação dos estudos recuperados que atendem aos critérios de inclusão. Elabora-se um sistema para extração dos dados, que é baseado no enfoque e meta da revisão. Neste ponto, os dados que foram extraídos de cada estudo foram: nome, contexto, problema, solução e exemplos de cada uma das práticas de usabilidade utilizadas em comunidades de software livre e em comunidades de métodos ágeis.

A fase de análise e interpretação dos dados tem como objetivo obter o significado dos dados extraídos, ou seja, é a fase onde a meta da revisão da literatura é aplicada. Neste caso, a meta é integrar e conectar a linguagem usada para práticas de usabilidade utilizadas nas comunidades de métodos ágeis e de software livre. Sendo assim, as práticas de cada comunidade serão descritas através de um formato-padrão, de modo a facilitar a identificação de práticas de usabilidade ágil que possam ser úteis nas comunidades de software livre, de acordo com suas características. Os dados são analisados e interpretados segundo uma síntese qualitativa, de acordo com o método fenomenológico para conduzir uma revisão da literatura qualitativa [Ran09], que tem como objetivo alcançar a essência das experiências empíricas de pesquisadores com um fenômeno.

Para o estágio de apresentação pública são determinadas quais informações são mais importantes e serão apresentadas e quais informações não são relevantes e não entram na apresentação. Para esta pesquisa, as informações que serão apresentadas serão as práticas de usabilidade utilizadas em comunidades de métodos ágeis e de software livre, seguindo o formato nome, contexto, problema, solução e exemplos para cada prática descrita. Dessa forma, cada descrição de uma prática nesse formato, ou padrão de uso, reúne a integração dos dados coletados a respeito de cada prática de usabilidade. O texto será estruturado conforme as características de organização de Cooper descritas na Seção 2.4. O Capítulo 4 e o Capítulo 5 apresentam cada padrão de uso a partir das práticas de usabilidade de cada comunidade. O Capítulo 7 apresenta a síntese realizada a partir da discussão dos resultados obtidos com a revisão da literatura e da experiência obtida por meio da aplicação de práticas de usabilidade em projetos do Centro de Competência em Software Livre (CCSL). 


\section{Capítulo 3}

\section{Principais conceitos relacionados a usabilidade}

Este capítulo tem como objetivo definir alguns dos principais termos relacionados à usabilidade, de modo a situar a sua definição dentro da área de pesquisa que a aborda.

\subsection{O que é usabilidade?}

Conforme Nielsen [NL08], usabilidade é um atributo de qualidade relacionado à facilidade do uso de algo. Mais especificamente, refere-se à rapidez com que os usuários podem aprender a usar alguma coisa, a eficiência deles ao usá-la, o quanto lembram daquilo, seu grau de propensão a erros e o quanto gostam de utilizá-la. Se as pessoas não puderem ou não utilizarem um recurso, ele pode muito bem não existir.

A definição da International Standards Organization (ISO 9241-11 e da ISO 25010) para usabilidade é: "Medida pela qual um produto pode ser usado por usuários específicos para alcançar metas específicas com eficácia, eficiência e satisfação em um contexto específico de uso." A ISO 25010 define um modelo de qualidade de produto e um modelo de qualidade em uso. O modelo de qualidade de produto é composto de oito características - adequação funcional, confiabilidade, eficiência de desempenho, operabilidade, estabilidade, compatibilidade, manutenibilidade e portabilidade - que estão relacionadas com propriedades estáticas do software e propriedades dinâmicas do sistema de computador. O modelo de qualidade em uso é composto de cinco características - eficácia, eficiência, satisfação, segurança e usabilidade - que estão relacionadas com o resultado da interação, quando um produto é usado em um contexto particular e real de uso. Este modelo é aplicável tanto para sistemas de computador em uso quanto produtos de software em uso [OLDB11, Des11].

A Associação dos Profissionais de Usabilidade (UPA) [Ass10a], define usabilidade com o enfoque sobre o processo de desenvolvimento do produto: "Usabilidade é uma abordagem para desenvolvimento de produtos que incorpora feedback direto do usuário através do ciclo de desenvolvimento com o objetivo de reduzir custos e criar produtos e ferramentas que reúnam as necessidades do usuário."

Segundo Tullis e Albert [TA08], existem várias definições para usabilidade, mas todas compartilham alguns temas comuns:

- um usuário está envolvido;

- esse usuário faz alguma coisa; e

- esse usuário faz alguma coisa com um produto, sistema ou outra coisa.

Douglas et al. [DL11] divide a usabilidade em três conceitos:

1. usabilidade como adjetivo: ou a usabilidade é uma feature da tecnologia. É a definição mais básica onde usabilidade é simplesmente a forma substantiva para o adjetivo usável e refere-se a uma propriedade de um artefato tecnológico - um sistema é ou não é usável. 
2. usabilidade como verbo: ou conjunto de métodos e técnicas desenvolvidas para ajudar na produção ou avaliação de sistemas usáveis. A usabilidade torna-se uma ação, ou verbo. Ao olhar usabilidade como verbo, Douglas et al. demonstram a necessidade de se avaliar o contexto no qual os métodos de usabilidade são aplicados, por meio das seguintes dimensões: (1) ambiente físico; (2) normas culturais; (3) grau de instrução ou alfabetização; (4) distância; e (5) diversidade linguística. Também apresentam como meio de acesso aos principais métodos de usabilidade definidos no hemisfério norte, o site usability.gov, que é uma fonte central do governo americano para informação de usabilidade. O site lista um conjunto de métodos padronizados e conhecidos, incluindo card sorting, entrevistas, grupos focais, avaliação heurística, personas, prototipação, surveys, análise de tarefas, testes de usabilidade e casos de uso.

3. usabilidade como substantivo: ou a comunidade de indivíduos e organizações que reúnem-se para desenvolver e empregar métodos de usabilidade e produzir sistemas usáveis. As comunidades incluem associações profissionais, como a Usability Professional's Association ou UPA, grupos de interesse acadêmico, companhias privadas e outros. A usabilidade torna-se um substantivo, de modo que é possível encontrar um emprego no campo de usabilidade.

Dessa forma, é necessário confrontar a palavra usabilidade através de todos os seus papeis sintáticos: adjetivo, verbo e substantivo.

Nielsen propôs os seguintes atributos de usabilidade, com o objetivo de fornecer as características básicas que um produto precisa ter para conseguir melhor usabilidade. São eles:

- ser fácil de aprender, o que requer pouco treinamento e processamento cognitivo, pois são produtos intuitivos;

- ser fácil de lembrar, o que indica que, em uma segunda utilização, o usuário lembrará o que precisa fazer para atingir um determinado objetivo;

- maximizar produtividade, permitindo que a atividade seja realizada de forma rápida e eficiente (uso eficaz);

- minimizar erros, ao impossibilitar erros previamente analisados e para erros não previstos, avisar o usuário através de mensagens que possibilitem que ele os corrija;

- maximizar satisfação, pois ao fornecer uma interação mais rápida e eficiente, os usuários ganham confiança e segurança no sistema, fornecendo-lhes uma experiência satisfatória.

Os atributos de usabilidade descritos nesta pesquisa, fornecem uma visão geral do que um produto precisa ter para possuir melhor usabilidade. Mas, além destes, existem também atributos específicos para um determinado tipo de sistema, por exemplo, sistemas Web ou sistemas móveis.

Embora tantas razões tenham sido apresentadas para se considerar usabilidade como algo fundamental no processo de planejamento e desenvolvimento de um software, ainda hoje muitos projetistas costumam considerá-la como atividade secundária, a ser feita se houver tempo hábil. No entanto, tal característica é desejada pelo componente mais importante de todo o processo: o usuário que utilizará o sistema. Seja porque produtos com boa usabilidade são de mais fácil acesso às informações desejadas, seja pela simplicidade na interação com o sistema, o que realmente importa é que a usabilidade precisa ser considerada em todas as ações executadas pelo usuário, possibilitando a ele uma interação livre de problemas de usabilidade. Esses problemas são quaisquer características, observadas em determinada situação, que possam retardar, prejudicar ou inviabilizar a realização de uma tarefa e que aborrecem, constrangem ou traumatizam o usuário [FN08].

\subsection{Experiência do Usuário ou User eXperience (UX)}

Tullis e Albert relatam a diferença, descrita por vários pesquisadores, entre os termos usabilidade e experiência do usuário (User eXperience ou UX): "Usabilidade é geralmente considerada 
a habilidade do usuário na utilização de alguma coisa para realizar uma tarefa com sucesso, enquanto experiência do usuário possui uma visão mais ampla, olhando para a interação completa do indivíduo, além de seus pensamentos, sentimentos e percepções que resultam dessa interação."

A ISO 9241-210 define User eXperience como "percepções e respostas de uma pessoa que resultam do uso ou uso antecipado de um produto, sistema ou serviço". Então, a experiência do usuário é subjetiva e seu enfoque é no uso. As notas adicionais da ISO explicam que UX incluem todas as emoções dos usuários, crenças, preferências, percepções, respostas físicas e psicológicas, comportamentos e realizações que ocorrem antes, durante e depois do uso. As notas também listam os três fatores que influenciam a experiência do usuário: sistema, usuário e contexto de uso.

A Experiência do Usuário vai além da usabilidade, pois observa muitos outros fatores da interação do usuário com o sistema, envolvendo diversas disciplinas, incluindo engenharia de usabilidade, arquitetura de informação, design de interação e interface, design de persuasão, fatores humanos e design gráfico.

Para Douglas et al. [DL11], alguns pesquisadores tem ido além das medidas mais mecânicas para dar enfoque sobre os impactos emocionais do design. A experiência dos praticantes possui uma influência aqui, e muitos agora preferem dar ênfase no que é denominado User eXperience (UX) ou Experiência do Usuário, mais do que somente em usabilidade. Nesse caso, visualiza-se que enquanto usabilidade é importante e uma parte frequentemente negligenciada do design, a natureza holística do design é tal que um design de sucesso requer o balanceamento de todos os aspectos diferentes do design (usabilidade, funcionalidade, estética, etc.) e não somente concentrar-se em um para negligenciar os outros. Sendo assim, em UX define-se que um design finalizado é um gestalt - o todo é maior do que a soma de suas partes. Ainda segundo os autores, é comum confundirem usabilidade como se esta fosse sinônimo do campo completo de UX ou Design Centrado no Usuário (DCU). A pesquisa de campo da usabilidade, usada para compreender melhor os usuários típicos de um produto ou sistema, tem o papel principal desta definição expandida de usabilidade.

\subsection{IHC - Interação Humano-Computador}

IHC (Interação Humano-Computador) é um campo multidisciplinar no qual psicologia e outras ciências sociais unem-se à ciência da computação e campos técnicos relacionados, com o objetivo de fazer sistemas de computadores que são tanto úteis quanto usáveis [0003]. A Figura 3.1 mostra a relação entre IHC, design de interação e outras áreas.

A experiência da interação humano-computador é individual, na medida em que cada pessoa é única em sua bagagem de conhecimento e expectativas. Dificilmente uma mesma interface significará a mesma coisa para dois usuários distintos. Menor ainda é a chance de ela ter um significado integralmente compartilhado entre usuários e projetistas.

Tecnologias modernas continuamente desafiam os pesquisadores de IHC com novas opções, demandas de públicos e usos. Uma variedade de métodos de usabilidade tem sido desenvolvida, usando princípios psicológicos. A pesquisa nessa área tem se expandido além de suas raízes no processo cognitivo de usuários individuais para incluir processos sociais e organizacionais envolvidos no uso do computador em ambientes reais e no uso de computadores em colaboração.

\subsection{Design de Interação}

Design de interação foi definido por Sharp, Rogers e Preece [SRP07a] como: "Design de produtos interativos que fornecem suporte às atividades cotidianas das pessoas, seja no lar ou no trabalho" ${ }^{1}$. Ou seja, significa criar experiências que melhorem e estendam a maneira como as pessoas trabalham, comunicam-se e interagem.

O processo de design de interação envolve, essencialmente, quatro atividades básicas:

\footnotetext{
${ }^{1}$ Todas as traduções foram realizadas pela autora.
} 


\section{$\mathrm{HCI}$ and interaction design}

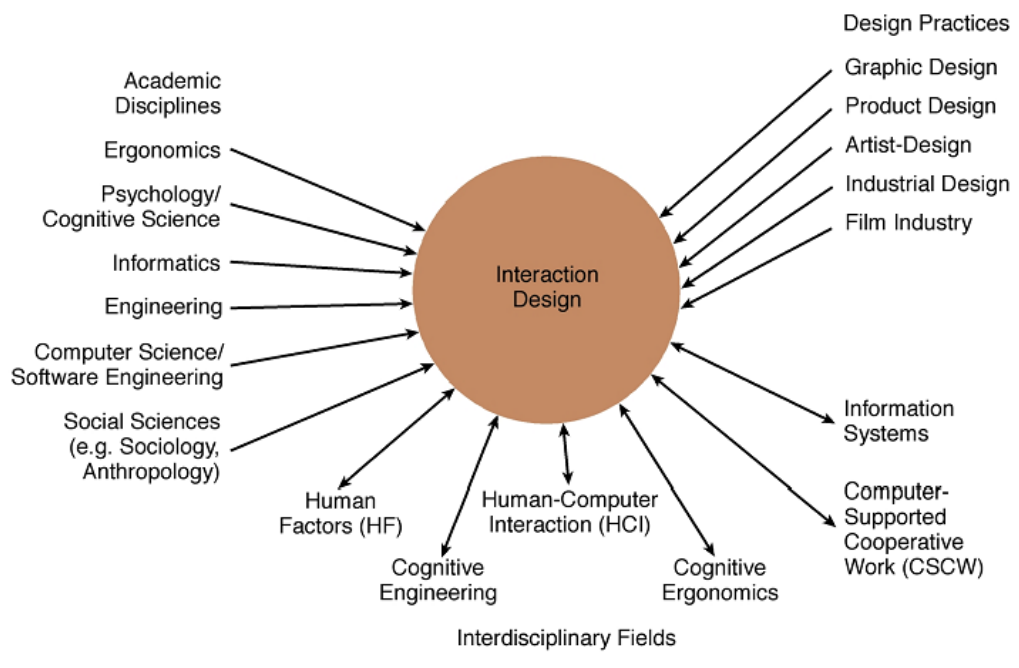

Figura 3.1: Relação entre design de interação, IHC e outras áreas [SRP0־b].

\section{Identificar necessidades e estabelecer requisitos}

É necessário conhecer quem são seus usuários-alvo e em que um sistema interativo pode ajudálos de maneira útil. Essas necessidades são a base dos requisitos do produto e sustentam o design e o desenvolvimento subsequentes.

\section{Desenvolver designs alternativos que preencham esses requisitos}

Esta atividade resume-se em sugerir ideias que atendam aos requisitos e é dividida em: design conceitual e design físico. A primeira produz um modelo conceitual para o produto, que descreve o que ele deveria fazer, como se comportar e com o que parecer. A segunda considera detalhes como cores, sons, imagens e designs do menu e dos ícones.

3. Construir versões interativas dos designs, de maneira que possam ser comunicados e analisados

A melhor maneira de usuários avaliarem o design de produtos interativos é através da utilização deles. Para tanto, é necessária uma versão das interfaces a serem construídas que possibilite a interação; por exemplo, pode-se simular o uso através de protótipos em papel, possibilitando que os usuários tenham uma noção de como será interagir com o produto.

\section{Avaliar o que está sendo construído durante o processo}

A avaliação tem como objetivo determinar a usabilidade e a aceitabilidade do produto ou design. É medida por meio de vários critérios, incluindo o número de erros que os usuários cometem e se o produto preenche os requisitos, entre outros.

As quatro atividades descritas são complementares, sendo realizadas repetidamente. A avaliação do que está sendo construído possui papel central no design de interação, com o objetivo de assegurar que o produto seja usável. Para realizar essa avaliação, geralmente, utiliza-se uma abordagem centrada no usuário, onde se envolve usuários em todo o processo de design, o que aumenta as chances de se entregar um produto usável. 
Sharp et al. também ressaltam três características-chave quanto ao processo de design de interação:

1. os usuários devem estar envolvidos no desenvolvimento do projeto;

2. a usabilidade específica e as metas decorrentes da experiência do usuário devem ser identificadas, claramente documentadas e acordadas no início do projeto; e

3. a iteração em todas as quatro atividades é inevitável.

\subsubsection{Metas do design de interação}

Ainda conforme Sharp et al., "parte do processo de entender as necessidades do usuário, no que diz respeito a projetar um sistema interativo que as atenda, consiste em ser claro quanto ao objetivo principal".

As preocupações principais quanto a projetar um sistema que permita aos usuários serem produtivos ou um sistema que seja motivador e que facilite o aprendizado, entre tantas outras preocupações, são denominadas metas de usabilidade e metas decorrentes da experiência do usuário. Essas metas são também chamadas, de acordo com o autor, de atributos de usabilidade e atributos decorrentes da experiência do usuário e diferem quanto ao modo como podem ser atingidas.

Metas de usabilidade preocupam-se com o preenchimento de critérios específicos de usabilidade, como eficiência, enquanto que as metas decorrentes da experiência do usuário preocupam-se com a qualidade da experiência, como ser esteticamente agradável.

\section{Metas de usabilidade}

A usabilidade é dividida nas seguintes metas ou atributos:

- ser eficaz no uso (eficácia): refere-se a quanto um sistema é bom em fazer o que se espera dele;

- ser eficiente no uso (eficiência): refere-se à maneira como o sistema auxilia os usuários na realização de suas tarefas;

- ser segura no uso (segurança): implica a proteção do usuário quanto às condições perigosas e situações indesejadas;

- ser útil (utilidade): refere-se à medida na qual o sistema propicia o tipo certo de funcionalidade, de maneira que os usuários possam realizar aquilo que precisam ou que desejam;

- ser fácil de aprender (learnability ou facilidade de aprendizagem): refere-se a quão fácil é aprender a usar o sistema;

- ser fácil de lembrar como se usa (memorability ou facilidade de memorização): refere-se à facilidade de lembrar como utilizar um sistema, depois de já ter aprendido como operá-lo. Importante para sistemas pouco utilizados.

Os atributos de usabilidade transformam-se em critérios ou métricas de usabilidade, que permitem que a usabilidade de um produto seja avaliada em termos quantitativos. São exemplos destas métricas, o tempo para completar uma tarefa (eficiência), o tempo para aprender uma tarefa (learnability) e o número de erros cometidos quando se realiza uma tarefa, já aprendida anteriormente, após um determinado tempo sem realizá-la (memorability). 


\section{Metas decorrentes da experiência do usuário}

O surgimento de tecnologias como realidade virtual, Web, computação móvel, entre outras, inseridas em uma diversidade de áreas de aplicação, como, por exemplo, entretenimento e educação, trouxe à tona um conjunto maior de interesses. Agora, além de se preocupar com a melhoria da eficiência e da produtividade no trabalho, precupa-se também com a criação de sistemas que sejam satisfatórios, interessantes, motivadores, esteticamente agradáveis, entre outros. O objetivo de criar sistemas com essas qualidades está na experiência que proporcionarão aos usuários, ou seja, como o usuário se sentirá na interação com o sistema.

\section{Comparação entre os dois tipos de metas}

Metas decorrentes da experiência do usuário diferem das metas de usabilidade, que são mais objetivas, no sentido de que estão preocupadas com a maneira como os usuários lidam com um produto interativo; enquanto as metas de usabilidade preocupam-se com a produtividade do usuário ao interagir com o sistema, de modo a melhorar e a aperfeiçoar a interação.

A relação entre esses dois tipos de metas é mostrada na Figura 3.2, onde, no círculo maior, estão as metas de experiência do usuário (User eXperience ou UX), e as de usabilidade são representadas pelo círculo menor.

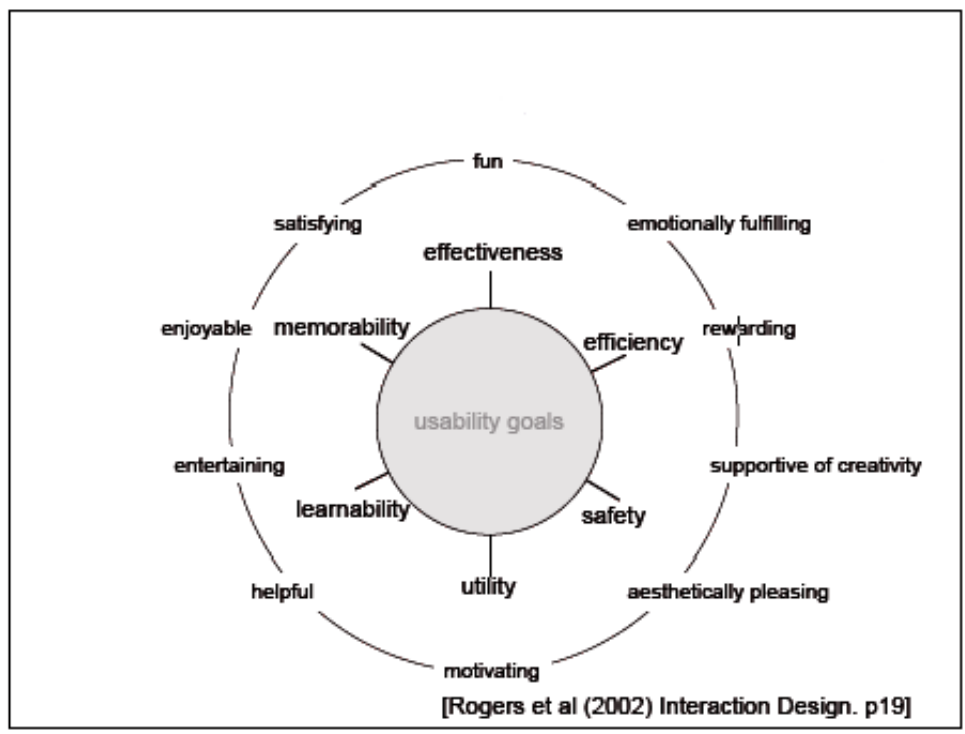

Figura 3.2: Relacionamento entre as metas de usabilidade e de UX [SRP0\%a].

É importante destacar que nem todas as metas de usabilidade e as decorrentes da experiência do usuário são aplicáveis a qualquer produto interativo. Além disso, algumas combinações são incompatíveis, já que dependem do contexto de uso, da tarefa a ser realizada e de quem são os usuários pretendidos.

\subsubsection{DCU - Design Centrado no Usuário}

Design Centrado no Usuário (DCU) é definido pela Associação dos Profissionais de Usabilidade (UPA) [Ass10b], como "uma abordagem para projeto que racionaliza o processo de informação sobre as pessoas que usarão o produto. O processo de DCU focaliza em usuários através do planejamento, design e desenvolvimento de um produto."

A International Standards Organization (ISO 13407: Human-centred design process) define um processo geral para incluir atividades centradas em humano através do ciclo de vida de desenvolvimento, sem especificar métodos exatos. A Figura 3.3 exibe as principais atividades envolvidas.

Identificar necessidades para design centrado em humano, refere-se a identificação da necessidade de usar algum processo para design centrado em usuário. Especificar o contexto de uso, refere-se a 


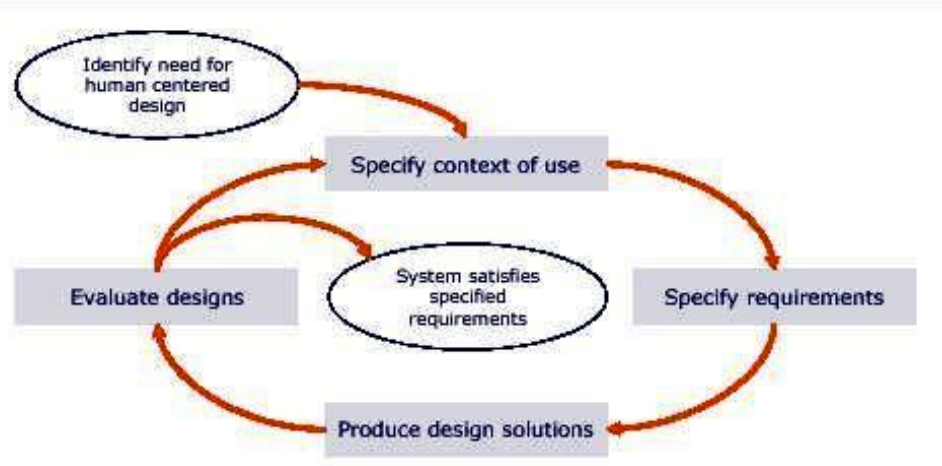

Figura 3.3: Ciclo de vida do DCU [Ass10b].

identificação das pessoas que usarão o produto, o que elas usarão para isto e sob quais condições elas o usarão. Especificar requisitos, refere-se a identificação de requisitos de negócios ou metas de usuários que devem ser cumpridas para que o produto tenha sucesso. Criar soluções de design refere-se aos estágios de construção do design a partir de um conceito bruto até alcançar o design completo. Avaliar designs, considerada a parte mais importante do processo, é realizada idealmente por meio de testes de usabilidade com usuários reais e é tão importante quanto teste de qualidade é para o bom desenvolvimento de software [Ass10b].

\section{Mas quem são os usuários?}

Segundo Preece, Rogers e Sharp, a definição mais óbvia para usuário diz respeito "àqueles indivíduos que interagem diretamente com o produto a fim de realizar uma tarefa". Porém, complementam que existe distinção de categorias de usuários, que podem ser: primários, secundários, terciários e stakeholders.

- Primários: usuários diretos que interagem com o sistema para realizar uma tarefa, ou mesmo que não tenham uma tarefa definida, a interação passa a ser o objetivo.

- Secundários: usuários ocasionais ou que usam o sistema através de um intermediário, por exemplo: chefes de usuários diretos.

- Terciários: usuários afetados pelo sistema ou que influenciam sua compra, por exemplo: recebem produtos do sistema, compram o sistema, utilizam sistemas concorrentes.

- Stakeholders: usuários terciários especiais, pois além das características dos terciários também são pessoas ou organizações afetadas pelo produto e que têm uma participação (stake) direta ou indireta sobre seus requisitos, o que contribui para o desenvolvimento de produtos bemsucedidos.

Dix et al. [DFAB93] observam que "geralmente o cliente formal que encomenda o sistema é um dos últimos da lista dos que serão afetados por ele. Tenha muito cuidado com mudanças que diminuam o poder, a influência ou o controle de alguns stakeholders sem colocar nada tangível no lugar". O grupo de stakeholders inclui a própria equipe de desenvolvimento e seus gestores, os usuários diretos e seus gerentes, os que irão receber os resultados do produto, entre outros.

Com relação ao perfil de usuário, eles podem ser [SRP07a]:

- Novatos ou Aprendizes: necessitam de interfaces passo a passo, restritas e com informações claras;

- Casuais ou Infrequentes: necessitam de interfaces com instruções claras, por exemplo: menus;

- Frequentes: necessitam de interfaces que possuam atalhos e que permitam criar comandos para ações frequentes; e 
- Experientes: necessitam de interfaces que lhes possibilite maior flexibilidade, eficiência, rapidez, liberdade e poder.

É importante ressaltar que para se projetar algo para pessoas, é preciso saber a que tipo de indivíduos o sistema deve dar suporte e entender que as pessoas possuem capacidades e necessidades distintas que precisam ser atendidas pelos requisitos do sistema.

\subsection{Engenharia de usabilidade de desconto}

O método de engenharia de usabilidade de desconto Discount Usability Engineering foi definido por Nielsen [Nie9b, Nie0a, Nie93] e é baseado no uso das seguintes três técnicas: cenários, método pensando alto simplificado e avaliação heurística, os quais Nielsen define conforme descrição abaixo [Nie94].

1. Cenários: um tipo especial de prototipação, onde são reduzidos tanto o nível de funcionalidades quanto a quantidade de features sendo analisadas, de modo a realizar mais rapidamente a representação de uma pequena parte do sistema. Por reduzir a parte do sistema sendo considerada a menor parte possível, cenários tornam-se baratos para projetar e implementar. Porém Nielsen reforça que cenários só são capazes de simular as interfaces de usuário, desde que usuários de teste sigam um caminho previamente planejado. Além disso, como o cenário é pequeno é possível mudá-lo várias vezes e se são utilizados estudos com o método pensando em voz alta, também é possível testar cada uma das versões. Portanto, cenários são uma maneira de obter feedback rápido e frequente dos usuários. Cenários podem ser implementados com mock-ups em papel ou em ambientes de prototipação simples. Sendo assim, cenários podem representar uma economia adicional quando comparados com protótipos mais complexos que requerem o uso de ferramentas de software avançadas.

2. Método Pensando em voz alta simplificado: Tradicionalmente, os estudos com o método pensando em voz alta ou thinking aloud studies são conduzidos por psicólogos ou especialistas em interface de usuário como experimentadores que gravam os temas e realizam uma análise de protocolo detalhada. Contudo, é possível rodar testes com usuários sem laboratórios sofisticados, simplesmente por trazer alguns usuários reais, lhes fornecer algumas tarefas de teste típicas e pedir a eles que pensem em voz alta enquanto realizam as tarefas. Nielsen ainda declara que em seus estudos [Nie2b] percebeu que cientistas da computação estão aptos para aplicar o método pensando em voz alta simplificado com eficiência, com o mínimo de treinamento. Em seus estudos [NL93], Nielsen descobriu que se consegue a relação custo-benefício máxima quando usando entre três e cinco usuários por teste, pois além de ser uma forma de simplificar o teste com usuários, também ganha-se quase os mesmos benefícios de um teste mais elaborado com grande número de usuários. Ainda segundo Nielsen, outra grande diferença entre a versão tradicional e a com desconto do método pensando em voz alta é que a análise dos dados pode ser feita com base nas anotações do testador ao invés da gravação de vídeos. Registrar, assistir e analisar os vídeos é caro e gasta muito tempo que poderia ser usado para rodar mais testes com usuários e iterações de redesign de interfaces. O autor sugere que gravações de vídeo sejam feitas apenas em casos onde certeza absoluta é necessária, como estudos de pesquisa. Na engenharia de usabilidade de desconto não se espera perfeição, mas apenas o suficiente para encontrar mais problemas de usabilidade.

3. Avaliação Heurística: Tipicamente, padrões de interfaces de usuário e coleções de diretrizes de usabilidade possuem milhares de regras e por isso são vistos como intimidadores por desenvolvedores. Para o método de desconto, Nielsen defende o corte da complexidade ao recorrer a um pequeno grupo de heurísticas, como os dez princípios básicos de usabilidade [Nie05]. Essas heurísticas podem explicar uma grande proporção de problemas observados em designs de interface. Nielsen declara que é necessário possuir alguma experiência com elas para aplicá-las suficientemente, por isso, sugere a contratação de consultores de usabilidade para ajudar com 
a avaliação heurística. Porém destaca que mesmo não especialistas podem encontrar muitos problemas de usabilidade com a avaliação heurística e muitos dos problemas remanescentes seriam revelados por meio do teste Pensando em voz alta simplificado. Também recomenda deixar várias pessoas diferentes realizarem a avaliação, porque pessoas diferentes localizam problemas de usabilidade diferentes.

Adicionalmente, o princípio básico do foco desde cedo no usuário deve ser seguido, o que pode ser alcançado de várias formas, inclusive por meio de visitas simples aos ambientes do cliente. Nielsen declara que especialistas em usabilidade frequentemente propõem o uso da melhor metodologia possível, pois foram treinados para fazer isso em muitas universidades. Porém, baseando-se em uma frase de Voltaire, em 1764, que "o melhor é o inimigo do bom", diz que insistir em apenas usar os melhores métodos, pode resultar em não ter métodos utilizados. Sendo assim, ele prefere alcançar o bom, tendo algum trabalho de usabilidade sendo realizado, mesmo sabendo que esses não são os melhores métodos e nem alcançarão resultados perfeitos. Contudo, Nielsen reforça que vários aspectos importantes da usabilidade são perdidos utilizando-se apenas os métodos da usabilidade de desconto, mas lembra que métodos mais cuidadosos são mais caros, frequentememte em termos de dinheiro e sempre em termos de competências necessárias, o que conduz ao fator de intimidação para aplicar métodos de usabilidade. Sendo assim, argumenta que métodos mais simples possuem uma chance maior de realmente serem usados em situações práticas e por isso devem ser vistos como uma forma de servir a comunidade de usuários.

\subsection{Notas do Capítulo}

Este capítulo teve como objetivo a apresentação dos principais conceitos relacionados a área de usabilidade, de modo a propiciar o entendimento das definições que são utilizadas em capítulos posteriores para expor as práticas de usabilidade aplicadas em comunidades de software livre e de métodos ágeis. O próximo capítulo apresenta o contexto de desenvolvimento de comunidades de softare livre e as práticas de usabilidade que são aplicadas nesse tipo de ambiente. 


\section{Capítulo 4}

\section{Métodos de usabilidade utilizados na comunidade de software livre}

O objetivo deste capítulo é apresentar a dinâmica de desenvolvimento de comunidades de software livre. Dessa forma, pretende-se responder quais são as características centrais do desenvolvimento em comunidades de software livre. Além disso, serão apresentadas as principais práticas de usabilidade utilizadas nessa comunidade, contextualizando como elas são aplicadas durante o desenvolvimento.

\subsection{Ecossistema FLOSS (Free/Libre Open Source Software)}

Software de código aberto, ou software livre, é simultaneamente um meio de produção, organização social e, para muitos, uma manifestação política ou cultural. Projetos FLOSS partilham um compromisso comum de ampla divulgação e disseminação do código fonte para as suas produções coletivas. Software livre é um meio de organizar a divisão de trabalho que se baseia na escolha voluntária de indivíduos que desejam oferecer seu tempo e habilidades a uma atividade de produção. Nesse sentido, possui semelhanças com as mais recentes formas de colaboração e produção que existem na Internet. Além disso, a colaboração entre membros de equipes de desenvolvimento contribui para a troca de informações, aprendizado e motivação para construir produtos de melhor qualidade [DDBS08].

Segundo Dalle et al., "O que está claro é que FLOSS representa um modelo viável para recrutamento e mobilização de esforços de pessoas com talento e imaginação, que fornece uma oportunidade ímpar para uma nova geração de indivíduos se tornarem intrigados por e engajados com a arte e ciência da programação de computadores, e que é capaz de produzir resultados que são comparáveis ou superiores aos métodos existentes de produção de software. É menos claro que a divisão futura de trabalho e concepção de software será de competência exclusiva de métodos de software de código aberto" [DDBS08].

Sistemas de software livre precisam contar com a atração dos participantes pelo projeto e com a sua disponibilidade para contribuir com partes específicas do código, ao contrário de sistemas de desenvolvimento proprietário tradicional, onde alocação de esforço é determinada por decisões gerenciais [BDG08].

Além disso, esses sistemas baseiam-se na modularidade dos métodos de engenharia de software moderna, na qual blocos específicos ou módulos de código podem ser criados independentemente e associados através de interfaces bem definidas. Assim como em métodos ágeis, a preocupação com a qualidade do código-fonte está disseminada na cultura de desenvolvimento de software livre, sendo este um dos motivos para a boa combinação entre software livre e métodos ágeis [CG11]. Já em relação à experiência do usuário, o desenvolvimento de código proprietário tradicional leva vantagens na preocupação com a usabilidade dos sistemas, pois em software livre esta preocupação ocorre geralmente em projetos patrocinados por empresas. No entanto, nas comunidades, a usabilidade raramente é considerada [NT06]. 
Embora em desenvolvimento de software livre exista interação com os usuários durante o desenvolvimento, a comunidade de usuários que guia o projeto não representa a comunidade de usuários como um todo, pois é formada, geralmente, por desenvolvedores e/ou pessoas experientes em tecnologia.

As definições de free software e open source software (ambas traduzidas para o português como software livre) são originadas a partir de filosofias diferentes oriundas da mesma comunidade. Software livre é definido pela Free Software Foundation [Fou10], fundada em 1985 por Richard Stallman, como "uma questão de liberdade dos usuários para executar, copiar, distribuir, estudar, mudar e melhorar o software. Mais precisamente, isto significa que os usuários do programa possuem quatro liberdades essenciais:

0. A liberdade de executar o programa, para qualquer propósito (liberdade 0).

1. A liberdade de estudar como o programa funciona e alterá-lo para que ele faça sua computação como você deseja (liberdade 1). Acesso ao código-fonte é um pré-requisito para isso.

2. A liberdade de redistribuir cópias de modo que você possa ajudar o seu próximo (liberdade 2 ).

3. A liberdade de distribuir cópias de suas versões modificadas para outros (liberdade 3). Ao fazer isto você pode dar a toda comunidade a oportunidade de se beneficiar de suas mudanças.

Um programa é software livre se os usuários possuem todas essas liberdades. Assim, você deve ser livre para redistribuir cópias, com ou sem modificações, de graça ou cobrando uma taxa pela distribuição, para qualquer lugar. Ser livre para fazer essas coisas significa (entre outras coisas) que você não tem que pedir ou pagar por permissão para fazê-las".

Já segundo a Open Source Initiative (OSI) [Ini11], "Open source não significa apenas acesso ao código-fonte. Os termos de distribuição de software open source devem obedecer aos seguintes critérios:

1. Redistribuição livre

A licença não deve restringir nenhuma parte de vender ou doar o software como um componente de uma distribuição agregada de software contendo programas de várias fontes diferentes. A licença não deve exigir um royalty ${ }^{1}$ ou outra taxa para tal venda.

2. Código Fonte

O programa deve incluir código fonte e deve permitir a distribuição em código fonte, bem como em formato compilado. Onde alguma parte de um produto não é distribuída com o código fonte, deve haver um meio bem divulgado de obter o código fonte para não mais do que um custo de reprodução razoável, preferencialmente, o download via Internet sem custos. O código fonte deve ser a forma preferida na qual um programador modificaria o programa. Código fonte deliberadamente ofuscado não é permitido. Formas intermediárias como a saída de um pré-processador ou tradutor não são permitidas.

3. Obras derivadas

A licença deve permitir modificações e trabalhos derivados e deve permitir que estes sejam distribuídos sob os mesmos termos que a licença do software original.

4. Integridade do Código Fonte do Autor

A licença pode restringir código fonte de ser distribuído em forma modificada somente se a licença permitir a distribuição de patch files ${ }^{2}$ com o código fonte para o propósito de modificar o programa em tempo de compilação. A licença deve permitir explicitamente a distribuição de software construído a partir do código fonte modificado. A licença pode exigir que trabalhos derivados tenham um nome ou número de versão diferente do software original.

\footnotetext{
${ }^{1}$ Importância paga pelos direitos de exploração, uso, distribuição ou comercialização de um determinado produto.

${ }^{2}$ Arquivos para atualização de código-fonte para uma versão mais nova do sistema.
} 
5. Sem Discriminação Contra Pessoas ou Grupos

A licença não deve discriminar nenhuma pessoa ou grupo de pessoas.

6. Sem Discriminação Contra Campos de Trabalho

A licença não deve restringir ninguém de fazer uso do programa em um campo específico de atuação. Por exemplo, ela não pode restringir o programa de ser usado em um negócio, ou de ser usado para pesquisa genética.

7. Distribuição da Licença

Os direitos associados ao programa devem ser aplicados a todos a quem o programa é redistribuído, sem a necessidade de execução de uma licença adicional por aquelas pessoas.

8. Licença Não Deve Ser Específica a um Produto

Os direitos associados ao programa não devem depender do programa ser parte de uma distribuição de software particular. Se o programa for extraído dessa distribuição e usado ou distribuído dentro dos termos da licença do programa, todas as partes para quem o programa é redistribuído devem ter os mesmos direitos que aqueles que são garantidos em conjunção com a distribuição de software original.

9. Licença não deve restringir outro software

A licença não deve colocar restrições em outro software que é distribuído junto com o software licenciado. Por exemplo, a licença não deve insistir para que todos os outros programas distribuídos na mesma mídia sejam open source software.

10. Licença deve ser tecnologicamente neutra

Nenhuma disposição da licença pode ser baseada em qualquer tecnologia individual ou estilo de interface".

\subsubsection{Contexto de desenvolvimento FLOSS}

Para todos os fins práticos, free software e open source são equivalentes. Nesta dissertação, utilizamos os termos software livre ou FLOSS para nos referirmos a este tipo de software.

As características mais marcantes de ambientes de desenvolvimento de software livre resumem-se em ambientes distribuídos, abertos e colaborativos, onde o produto resultante é o sistema de software com o código aberto compartilhado com a comunidade. Sendo assim, as principais diferenças entre desenvolvimento de software proprietário e software livre de acordo com cada uma dessas três características, são descritos nas próximas subseções.

\section{Ambientes de desenvolvimento distribuídos}

Ambientes de desenvolvimento distribuídos [Pri03] referem-se a membros de uma equipe de desenvolvimento de software que não estão situados no mesmo local de trabalho. Desse modo, o desenvolvimento do software é realizado à distância e a possibilidade de exploração da comunicação face a face fica prejudicada.

Além disso, as equipes precisam se adaptar a variáveis não presentes no ambiente de desenvolvimento tradicional, como horário para conversas online (se forem países com fusos horários diferentes), definição de um idioma para comunicação da equipe, geralmente o inglês, além da necessidade de ferramentas que suportem a colaboração e o compartilhamento de informações entre todos os membros envolvidos com o projeto.

\section{Ambientes de desenvolvimento abertos}

Ambientes de desenvolvimento abertos [Gar08] referem-se ao aspecto não proprietário (ou não fechado) de sistemas de software livre, onde o produto intelectual de desenvolvedores é compartilhado juntamente com o sistema funcionando. O código é disponibilizado a todos e todos podem se 
beneficiar não apenas do sistema pronto, mas também do conhecimento nele presente, de modo a aprender como ele funciona e disseminá-lo, podendo, inclusive, modificá-lo, adaptá-lo e redistribuílo.

Esse aspecto possui como consequência a abertura não apenas do código-fonte, mas da participação no processo de desenvolvimento a qualquer indivíduo interessado em colaborar, aprender e também disseminar conhecimento.

Esses indivíduos motivados por fatores como atratividade do projeto, necessidade de aprender alguma nova tecnologia ou mesmo pela necessidade de resolver algum problema ou bug que perturbe pessoalmente o seu uso de determinada ferramenta, resolvem de forma livre e espontânea contribuir com projetos de software livre.

Por seu caráter voluntário, não se pode prever se esses indivíduos continuarão a dedicar seu tempo livre ao desenvolvimento do software. Por isso, o ambiente de desenvolvimento aberto ainda traz à tona o fato que participantes podem entrar ou sair da equipe de desenvolvimento em qualquer momento durante o processo de desenvolvimento do software. Nesse caso, são chamados contribuidores esporádicos. Portanto não é possível, em ambientes de desenvolvimento aberto, garantir que os mesmos desenvolvedores continuarão a trabalhar na mesma equipe ou no mesmo projeto, pois pode ser apenas uma participação pontual para ajudar a resolver um bug, por exemplo. Menos ainda se pode garantir com relação às habilidades dos contribuidores, ou seja, não se pode assegurar que serão especialistas em usabilidade que entendem e podem aplicar métodos de usabilidade durante o desenvolvimento. Também não se pode prever que pessoas preocupadas com a melhoria da usabilidade terão interesse em participar de um projeto.

\section{Ambientes de desenvolvimento colaborativos}

Ambientes de desenvolvimento colaborativos [BB03] referem-se à colaboração existente entre membros da equipe com o objetivo de produzir software com melhor qualidade e disseminar o conhecimento para todos os envolvidos no processo. Em software livre, a colaboração com os usuários se dá através da disponibilização de versões do sistema em produção, para que os usuários, ao utilizarem-no, possam reportar problemas ou bugs encontrados e assim contribuírem para melhoria do sistema.

A colaboração também ocorre pela vontade de participar de um projeto e o produto desta ajuda - código-fonte, reporte de bugs, testes, documentação ou versões de design de interface (em alguns sistemas maiores) - são disponibilizados integralmente com o sistema, de modo que qualquer indivíduo possa utilizar, aprender, modificar e também distribuir o sistema para outros interessados.

Entre os desenvolvedores, a colaboração exige ferramentas que automatizam a integração do código de diversos desenvolvedores dispostos em locais distintos e ferramentas para relato da utilização do sistema e sugestões de melhorias. Wikis, portal do projeto, redes sociais, listas de e-mail, ou, ainda, ferramentas que possibilitam conversa em tempo real, ajudam na criação de comunidades em torno do desenvolvimento de um determinado sistema e, consequentemente, possibilitam a colaboração entre os seus membros e usuários.

A colaboração, em desenvolvimento de software livre, está aberta para um número muito maior de pessoas do que para apenas uma equipe co-localizada, podendo alcançar pessoas de várias nacionalidades e com perspectivas e necessidades diferentes. Sendo assim, a distância existente entre os membros pode impossibilitar a colaboração e a comunicação face a face.

\subsubsection{Participantes de comunidades}

Lakhani e Wolf [LW05] aplicaram um questionário via Web, no qual coletaram a resposta de 684 desenvolvedores de software que participavam de 287 projetos de software livre para aprender sobre esforços e motivações dos indivíduos que contribuem para a criação de FLOSS. O objetivo principal era responder a seguinte pergunta: "O que dirige desenvolvedores de software livre para contribuir com seu tempo e esforço para a criação de produtos de software livre?" 
Os autores encontraram que motivações intrínsecas baseadas em satisfação pessoal são o principal motor dos contribuidores. Ou seja, quão criativa uma pessoa se sente ao trabalhar em um projeto, é a motivação mais forte. Além disso, também encontraram que a necessidade de estimulação intelectual vinda da escrita de código e a melhoria de habilidades de programação são motivações principais para participação no projeto. A maioria dos respondentes do questionário eram profissionais experientes trabalhando com TI e aproximadamente $40 \%$ eram pagos para participar de projetos de software livre.

Hippel [Hip05] descreve em seu livro Democratizar a inovação, um sistema que denomina "inovação centrada em usuário", no qual explica por que usuários motivam-se para propor novas ideias para melhoria de um determinado produto que utilizam e por que compartilham tal conhecimento ou inovação com outros usuários livremente, para uso de todos. Ele chama a atenção para essa tendência na comunidade de software livre. Segundo Hippel, usuários que inovam podem desenvolver exatamente o que eles querem, ao invés de confiar em empresas para agir como agentes deles. Além disso, os demais usuários podem se beneficiar das inovações livremente compartilhadas pelos usuários inovadores.

Estudos empíricos revelam que de 10 a $40 \%$ dos usuários engajam-se em desenvolver ou modificar produtos e estudos sobre usuários inovadores mostram que eles apresentam características de "usuários líderes". Isto é, eles estão à frente da maioria dos usuários em suas populações com respeito a uma tendência de mercado importante e esperam obter relativamente altos beneficíos a partir de uma solução para as necessidades que eles encontraram [Hip05]. Esse perfil de usuário é encontrado em participantes da equipe núcleo de um projeto de software livre, ou seja, os fundadores ou participantes mais engajados com o desenvolvimento do sistema.

Hippel também explora os benefícios de se revelar inovações abertamente, uma vez que, geralmente existem outras pessoas que sabem algo muito próximo do seu segredo, o que torna a probabilidade de mantê-lo muito baixa. Além disso, um dos maiores valores de se revelar abertamente inovações, ocorre quando outras pessoas a usam. Hippel [Hip05] exemplifica com o resultado de estudos empíricos para o caso de artigos que possuem acesso aberto, ou seja, artigos disponíveis para download livre a partir do website do autor, por exemplo, são muito mais referenciados do que artigos que precisam ser comprados.

Hippel explica que inovação de usuário é um processo amplamente distribuído e, por isso, pode ser útil que seja reunido em comunidades de inovação. Quando necessidades dos usuários são heterogêneas e a informação desenhada pelos inovadores é diferente, é provável que atividades de desenvolvimento do produto sejam distribuídas entre usuários, ao invés de ser produzida por poucos inovadores. É o que está por trás da base lógica em depuração de software, onde Eric Raymond argumenta que a mesma tarefa pode ser muito reduzida em custo e também feita de forma mais rápida e com maior eficácia quando é aberta para uma grande comunidade de usuários de software, onde cada um pode ter a informação necessária para identificar e corrigir alguns bugs [Ray99]. Raymond diz: "Dada uma grande base de beta-testers e codesenvolvedores, quase todos os problemas serão caracterizados rapidamente e a solução será óbvia para alguém." Ou menos formalmente: "Dados olhos suficientes, todos os bugs são superficiais". Ele explica que "mais usuários encontram mais bugs, porque ao adicionar mais usuários adiciona-se mais formas de se testar o programa. Cada usuário aborda a tarefa de caracterização do bug com um conjunto perceptivo e um kit de ferramentas analíticas ligeiramente diferentes, um ângulo diferente sobre o problema. Então ao adicionar mais beta-testers aumenta-se a probabilidade do kit de ferramentas de alguém ir de encontro ao problema, de tal forma que o bug seja trivial para esta pessoa".

Os usuários descritos por Hippel são tipicamente participantes de comunidades de software livre que engajam-se em projetos, como desenvolvedores, documentadores, testadores ou simplesmente usuários que ajudam outros usuários por meio de fóruns ou levantando a possibilidade de novas funcionalidades que ainda não foram implementadas para o sistema.

Hippel define comunidades de inovação como nós (nodes), consistindo de indivíduos ou empresas interconectados por linhas de transferência de informações que podem se comunicar face a face, eletronicamente ou por meio de outra forma de comunicação. Essas comunidades frequente- 
mente, mas não necessariamente, incorporam qualidades das comunidades para os participantes e podem se desenvolver quando ao menos alguém inova e voluntariamente revela suas inovações, e quando outros encontram a informação revelada como de seu interesse. Comunidades de inovação são frequentemente especializadas, servindo como pontos de coleta e repositórios para informações relacionadas a categorias específicas de inovação. Também podem fornecer funções adicionais para participantes como salas de bate-papo e listas de email com postagem pública para que contribuidores possam trocar ideias e fornecer assistência mútua. Ferramentas para ajudar os participantes a desenvolver, avaliar e integrar seu trabalho podem ser fornecidas para membros da comunidade e tais ferramentas são frequentemente desenvolvidas pelos próprios membros da comunidade [Hip05].

Segundo Walt Scacchi [Sca02], embora participantes possam utilizar pseudônimos para identificação em comunidades, eles não utilizam identificadores anônimos, como é comum em outras comunidades. Desenvolvedores de software livre ou contribuidores tendem a agir de maneiras pelas quais possam construir confiança e reputação, "fama geek"; e ser generoso com seu tempo, experiência e código fonte são características valorizadas pelos participantes da comunidade. Eles contribuem para o desenvolvimento do software de uma comunidade. Fazer contribuições e ser reconhecido por outros membros da comunidade como tendo feito contribuições substanciais, é frequentemente um pré-requisito para avançar tecnicamente e socialmente dentro de uma comunidade. Ou seja, existe uma cultura de "meritocracia". Como uma consequência, participantes dentro dessas comunidades frequentemente participam em diferentes papeis dentro de redes tanto técnicas quanto sociais durante o curso do desenvolvimento.

Os participantes regularmente usam fóruns de discussão online ou mensagens de email como uma maneira central de observar, participar e contribuir para discussões públicas sobre assuntos de interesse da comunidade. Contudo, essas pessoas também engajam-se em discussões online ou offline privadas que não são publicamente divulgadas, devido ao seu conteúdo percebido como sensível. Scacchi comenta que nas comunidades que estudou, os participantes publicavam relatórios técnicos ou artigos científicos sobre seus esforços de desenvolvimento de software, os quais eram publicamente disponíveis para exame, revisão e análises.

\subsection{Principais práticas de usabilidade utilizadas no desenvolvimento de software livre}

Nesta seção são descritas as principais práticas de usabilidade existentes para o contexto de desenvolvimento de software livre utilizando o seguinte formato: nome, contexto, problema, solução e exemplos. Porém, este formato não indica que a prática faça parte de um padrão de uso comum na comunidade, uma vez que práticas de usabilidade ainda não são largamente disseminadas na cultura de desenvolvimento de software livre. A escolha do formato, para apresentação das práticas, foi feita apenas para facilitar a comparação com as práticas que serão descritas no Capítulo 5 , as quais pretendem reunir os padrões de uso mais comuns de práticas de usabilidade em comunidades de métodos ágeis.

Ainda com o mesmo intuito, as práticas são classificadas conforme as fases do Design Centrado no Usuário, de acordo com a definição da Associação dos Profissionais de Usabilidade (Usability Professionals' Association ou UPA) [Ass10b], o que mantém a padronização para descrição das práticas. Para a fase de DCU "Identificar necessidades para design centrado em humano" não foram encontradas práticas específicas da comunidade de software livre. A seleção e classificação das práticas de usabilidade da comunidade de software livre encontradas na literatura, por meio do formato apresentado nesta seção, é uma das contribuições desta pesquisa. A Tabela 4.1 apresenta a classificação de práticas de usabilidade da comunidade de software livre, de acordo com as fases do DCU, e na sequência, cada uma das práticas são descritas. 
Tabela 4.1: Principais práticas de usabilidade utilizadas no desenvolvimento de software livre.

\begin{tabular}{|l|l|}
\hline \multicolumn{1}{|c|}{ Fases do DCU } & \multicolumn{1}{|c|}{ Software Livre } \\
\hline Especificar contexto de uso & $\begin{array}{l}\text { Modelo de pesquisa de usuário } \\
\text { Fórum de usuários } \\
\text { Questionários }\end{array}$ \\
\hline Especificar requisitos & $\begin{array}{l}\text { Registro de soluções de desenvolvedores } \\
\text { Registro de brainstorm de usuários } \\
\text { Visão online do sistema }\end{array}$ \\
\hline Criar soluções de design & $\begin{array}{l}\text { Design por blog } \\
\text { Diretrizes de Interface com Humanos } \\
\text { Envolvimento de especialistas em design de interface } \\
\text { Design cedo e frequente }\end{array}$ \\
\hline Avaliar designs & $\begin{array}{l}\text { Lançamento cedo para feedback do usuário } \\
\text { Reuniões de usabilidade } \\
\text { Relatos de erros } \\
\text { Testes de usabilidade remotos }\end{array}$ \\
\hline
\end{tabular}

\subsubsection{Especificar contexto de uso}

\section{Modelo de Pesquisa de usuário}

Contexto: Equipe-núcleo de um projeto disponibiliza modelos de como realizar pesquisas de usabilidade durante o desenvolvimento. Desse modo, novos contribuidores precisam antes entender como aplicar pesquisas de usabilidade para depois realizá-las, caso deseje. Essa técnica tem a vantagem de ensinar as práticas de usabilidade adotadas pela comunidade e impede que sejam utilizadas opções que não estejam de acordo com as definidas no modelo, o qual é definido por membros da equipe-núcleo do projeto juntamente com especialistas em usabilidade participantes da equipe. Tal prática é encontrada em grandes projetos e é realizada remotamente, uma vez que o conhecimento das técnicas é disponibilizado no site do projeto, para acesso remoto dos atuais membros e dos possíveis contribuidores.

Problema: Falta de conhecimento e/ou experiência com métodos para realizar pesquisa de usabilidade. Principais forças envolvidas:

- Força 1: Desenvolvedores podem entrar ou sair em qualquer momento do processo de desenvolvimento.

- Força 2: Todos os desenvolvedores precisam conhecer como realizar as pesquisas de usabilidade no projeto.

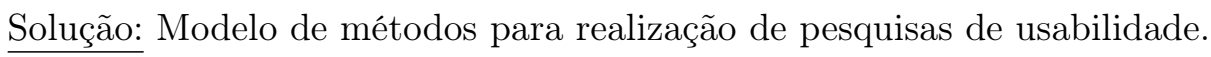

Exemplos: O modelo de pesquisa de usuário da KDE [For09] tem a proposta de fornecer um local para documentar as informações de pesquisa de usuários da aplicação para referenciar durante 
o desenvolvimento. O modelo é composto de itens categorizados por meio de uma hierarquia de importância, na qual os itens de nível superior contêm informações que todos no projeto devem estar cientes.

\section{Fórum de usuários}

Contexto: Grandes projetos costumam disponibilizar fóruns online para comunicação dos usuários, onde eles podem fazer perguntas uns aos outros, de modo a se ajudarem mutuamente durante o uso do sistema. Tais fóruns, por sua vez, são monitorados por membros da equipe-núcleo do projeto, de modo a identificar funcionalidades úteis para o sistema e/ou problemas comuns encontrados pelos usuários. Essa técnica também é aplicada remotamente, pois os membros da equipe acompanham as discussões que ocorrem nos fóruns online.

Problema: Identificar novas funcionalidades e/ou problemas encontrados pelos usuários durante o uso do sistema. Principais forças envolvidas:

- Força 1: Usuários precisam de um meio de comunicação de modo a se ajudarem mutuamente.

- Força 2: Equipe precisa identificar novas funcionalidades e/ou problemas comuns encontrados durante o uso do sistema.

Solução: Fórum para comunicação de usuários que são utilizados por desenvolvedores para levantamento das necessidades de usuários.

Exemplos: O projeto Debian disponibiliza um fórum online para discussão de seus usuários [Com07], que é dividido em Novidades e Anúncios, Ajuda, Documentação e Discussão. As divisões servem para melhor direcionar os assuntos tratados em cada fórum.

\section{Questionários}

Contexto: Questionários são aplicados para obter informações sobre os usuários do sistema e suas necessidades. São aplicados em meio online, de modo que possam atingir usuários de diversas partes do mundo. Alguns projetos que o aplicam já passaram por experiências ruins de usabilidade ou de priorização de funcionalidades e enxergaram os questionários como uma forma de melhor levantar o perfil dos usuários típicos do sistema.

Problema: Obter mais informações sobre os usuários do sistema. Principais forças envolvidas:

- Força 1: Equipe necessita levantar o perfil de usuários típicos do sistema.

- Força 2: Usuários típicos encontram-se dispersos geograficamente.

Solução: Aplicar questionários online para obter informações de perfil de usuários e suas atividades.

Exemplos: O site da Open Source Usability Labs apresenta as pesquisas de usabilidade realizadas para diversos projetos de software livre. O questionário realizado para Libre Office [Bal11a] apresentou objetivos e resultados esperados com a pesquisa. Após a análise dos dados coletados, os resultados [Bal11b] foram apresentados publicamente 13 dias após a conclusão da coleta de dados. $\mathrm{Na}$ pesquisa realizada por Paul [Pau09], para levantamento das principais práticas de usabilidade em software livre, foi percebido que alguns projetos aplicam questionários para melhor compreender seus usuários. 


\subsubsection{Especificar requisitos}

\section{Registro de soluções de desenvolvedores}

Contexto: Requisitos de software livre são articulados em várias maneiras que são expressas ou representadas na Web. Os requisitos podem aparecer dentro de uma mensagem de email ou dentro de uma thread de discussão postada em sites do projeto para revisão, elaboração, refutação ou refinamento. Recursos do sistema caracterizam-se por capacidades funcionais que já foram implementadas. Desenvolvedores interessados justificam seus requisitos por meio do esforço de código requerido para elaborar essas capacidades. Os membros da equipe-núcleo na comunidade votam ou concordam por meio de discussão para incluir a funcionalidade dentro da distribuição do sistema. $\mathrm{O}$ registro histórico pode existir dentro de arquivos de discussão de emails ou sites, para documentar quem fez a requisição, o que, onde, quando, por quê e como, não necessariamente contendo todas essas informações. Contudo, uma vez tendo sido aceita, não existe, geralmente, nenhum esforço aparente para documentar, formalizar, ou comprovar tal capacidade como um requisito do sistema, salvo em projetos maiores [Sca02]. Sendo assim, funcionalidades aceitas tornam-se invisíveis ou transparentes, tomadas por requisitos concedidos que podem ser tratados como óbvios, isto é, fazem parte de uma consciência compartilhada para aqueles familiares com o desenvolvimento do sistema.

Problema: Desenvolvedores que usam o sistema encontram necessidades que não são atendidas por ele. Principais forças envolvidas:

- Força 1: Participantes de comunidades de software livre podem estar distantes geograficamente ou estão impossibilitados de realizar encontros presenciais.

- Força 2: Desenvolvedores do sistema desejam compartilhar soluções para necessidades e/ou problemas encontrados por eles durante a utilização, assim como a equipe-núcleo espera obter soluções de participantes da comunidade que possuem conhecimento técnico.

Solução: Sistema online onde desenvolvedores apresentam a implementação de soluções que atendam suas necessidades e as submetem para aprovação da equipe-núcleo do projeto, que por sua vez, realiza votação e discussões para decidir se a funcionalidade implementada pode ser incluída dentro da distribuição do sistema.

Exemplos: Vários exemplos podem ser encontrados no site do sistema KDE, por exemplo, (www.kde.org), dentro de alguma comunidade, onde requisitos confirmados são exibidos dentro de threads de discussão. Os requisitos são confirmados sem referências a outros documentos ou padrões. São requisitos porque alguns desenvolvedores precisavam dessas capacidades no sistema [Sca02]. A Figura 4.1 exibe um exemplo de apresentação de uma funcionalidade implementada por um desenvolvedor para aprovação dos demais membros da comunidade.

\section{Registro de brainstorm de usuários}

Contexto: Usuários de um sistema percebem melhorias ou novas funcionalidades que poderiam ser implementadas para resolver ou facilitar o uso para suas necessidades. Esses usuários podem ser desenvolvedores ou não, mas apenas descrevem a ideia sem enviar um componente já implementado. As ideias são então submetidas a votação e se aprovadas são implementadas por desenvolvedores e incluídas na distribuição do sistema.

Problema: Obter feedback de usuários do sistema, que ao utilizá-lo percebem melhorias ou novas características que poderiam melhor atender às suas necessidades. Principais forças envolvidas:

- Força 1: Participantes de comunidades de software livre podem estar distantes geograficamente ou estão impossibilitados de realizar encontros presenciais. 


\section{Option to listen to microhpone/line-in in KMix}

$\square$ by Chemtox $»$ Mon Nov 07, 2011 3:02 am • Status: $\oplus$ Validated

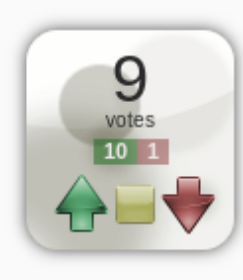

Howdy,

Currently I have to load/unload PulseAudio's loopback module by hand to be able to listen to my microhpone/line-in:

pulseaudio-loopback.sh

Code: Select all

$\# ! /$ bin/bash

if pactl list short/grep module-loopback 1\&gt; /dev/null

then

echo Disabling loopback

4 pactl unload-module pactl list short |perl -ne 'print $\$ 1$ and exit if

/^(d@kb_sc)s@kb_scmodule-loopback/; '

else

(4) echo Enabling loopback for the preferred input device

4 pactl load-module module-loopback

fi

Surely this vital function (for us karaoke lovers, amongst others $*$ ) should be available in KMix?

P.S: can't get the script to display properly. If interested, you can get it here: http://randomtechtail.blogspot.com/ 2011/11/escuchar-el-microfono-o-linea-de.html.

Figura 4.1: Apresentação de funcionalidade implementada por desenvolvedor para aprovação da comunidade KDE [For11a].

- Força 2: Usuários do sistema desejam compartilhar suas ideias para melhorias e/ou novas funcionalidades, para resolver ou facilitar o uso de acordo com suas necessidades. A equipe do projeto precisa conhecer as ideias de melhorias vindas a partir da utilização do sistema.

Solução: Sistema online para usuários submeterem novas ideias para melhoria ou criação de novas características. As ideias são submetidas à votação e discussão dos membros do projeto e se aceitas são implementadas e incluídas na distribuição do sistema.

Exemplos: A Figura 4.2 exibe registros para solicitação de novas funcionalidades realizadas por membros do sistema KDE. Cada registro é rotulado com seu estado (submetido, em progresso, feito, pré-existente, não corrigir, duplicado, inválido, validado), que contém também o autor da solicitação, a descrição com o porquê da necessidade e a data da solicitação.

\section{Visão online do sistema}

Contexto: Um documento online é disponibilizado no site do projeto com a visão geral do sistema e do funcionamento da comunidade, incluindo papeis e atividades. As principais características do sistema são definidas, bem como a evolução para os próximos passos. O documento não contém detalhes de implementação e design, apenas os conceitos fundamentais para compreensão do que é e como está sendo desenvolvido o projeto.

Problema: Apresentar o propósito do sistema, quais são as principais características e os próximos passos. Principais forças envolvidas:

- Força 1: Participantes de comunidades de software livre podem estar distantes geograficamente ou estão impossibilitados de realizar encontros presenciais.

- Força 2: Equipe precisa apresentar os principais objetivos da comunidade e do sistema em desenvolvimento, de modo a atrair novos membros e usuários para o projeto. Usuários precisam 


\section{Storage of additional meta information in KWallets}

. 98272

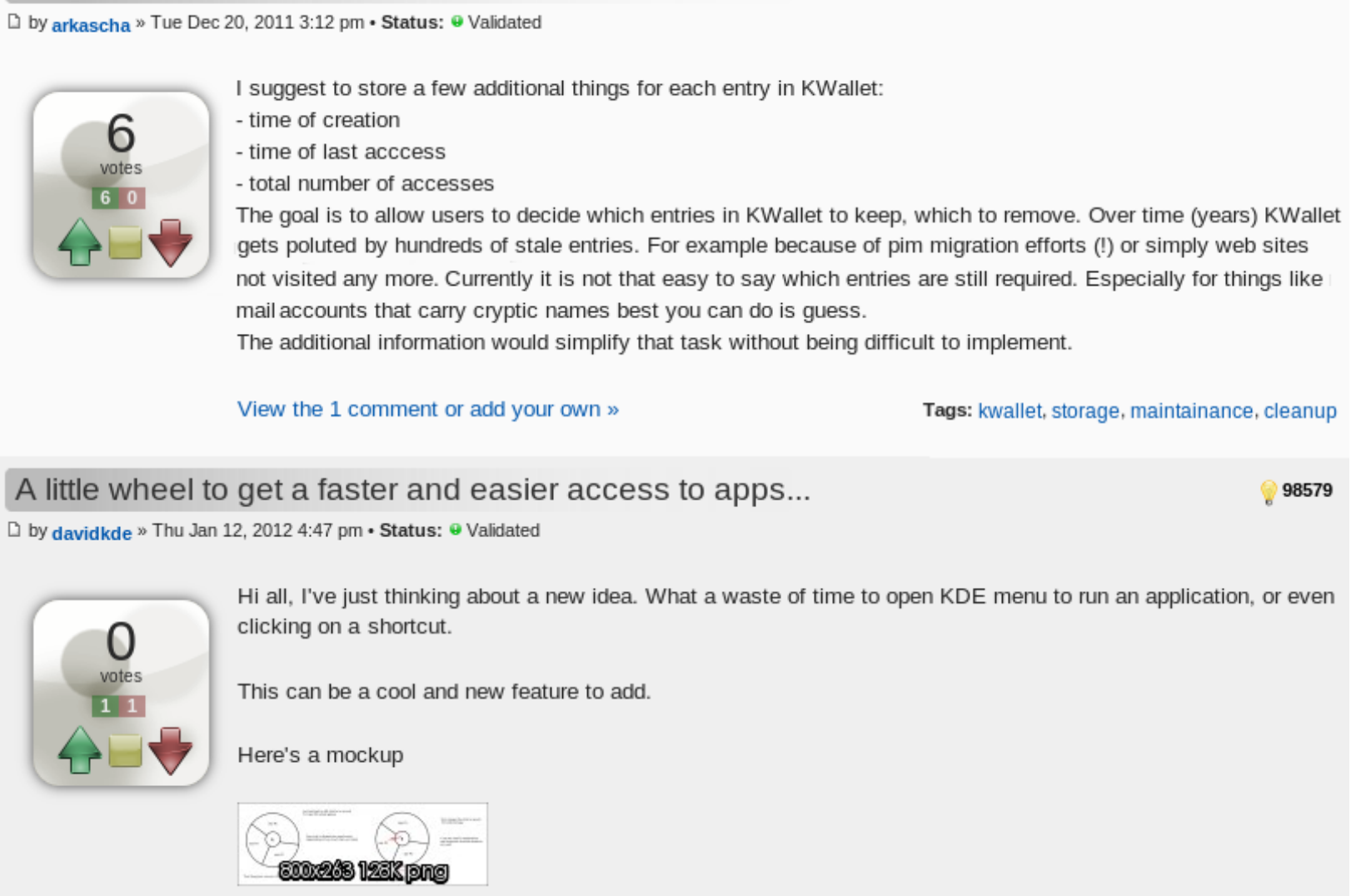

Figura 4.2: Registros para solicitação de novas características feitas por usuários do sistema KDE [For11b].

conhecer as principais características de um projeto para avaliar se serão úteis para suas necessidades. Além disso, os valores de uma comunidade influenciam na escolha de um projeto para utilização e/ou participação.

Solução: Página no site do projeto apresentando a visão geral do que é e como é desenvolvido o sistema.

Exemplos: A Figura 4.3 apresenta a página do site do ArgoUml, na qual é apresentada a visão geral do projeto.

\subsubsection{Criar soluções de design}

\section{Design por blog}

Contexto: Versões de interfaces do sistema são disponibilizadas em um blog do projeto. O blog funciona como um meio de documentação de novas funcionalidades e principais correções, bem como apresenta designs possíveis para uma interface, de modo que usuários, desenvolvedores e especialistas em design possam avaliar a interface e propor novas opções. Essa prática explora a colaboração entre os participantes e possibilita a inovação. Também é aplicada remotamente porque as interfaces são disponibilizadas para avaliação e inserção de novas propostas por meio do blog e não presencialmente.

Problema: Limitações para proximidade física de usuários reais. Principais forças envolvidas:

- Força 1: Participantes de comunidades de software livre podem estar distantes geograficamente ou estão impossibilitados de realizar encontros presenciais. 


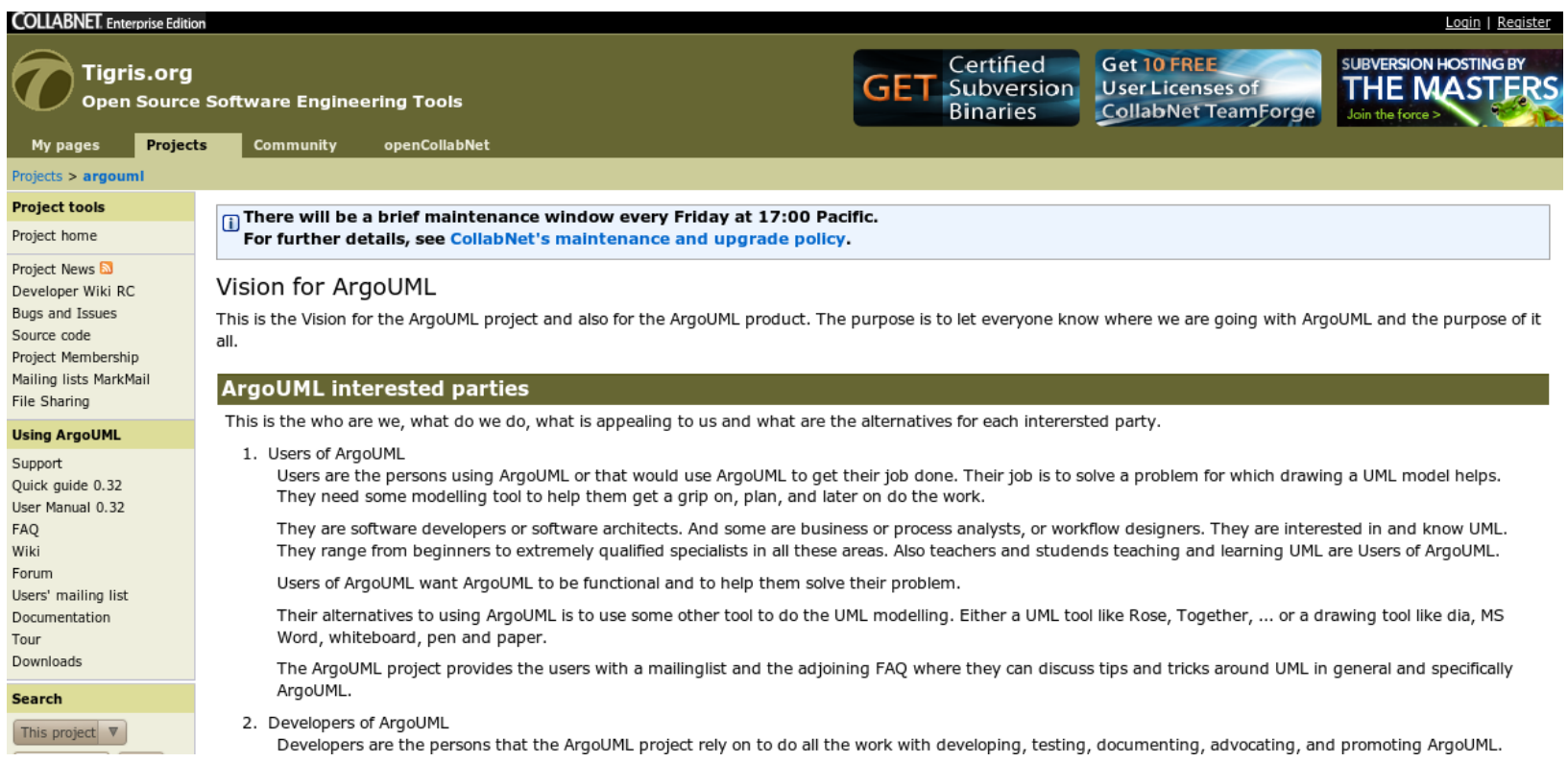

Figura 4.3: Visão geral do sistema ArgoUML [Colo9].

- Força 2: Usuários desejam compartilhar suas ideias, críticas e sugestões para o design de interfaces do sistema. A equipe de desenvolvimento deseja receber feedback dos usuários sobre o design de interfaces.

Solução: Liberação de versões de interfaces do sistema em um blog do projeto, de modo que usuários, desenvolvedores e especialistas em design possam avaliar a interface.

Exemplos: O blog da Canonical apresenta a descrição de novas funcionalidades e possibilidades de interfaces que são comentadas pelos leitores [Tea10]. Já em um blog que tem como autora uma designer e pesquisadora de experiência do usuário que contribui com projetos de software livre [Pau10], é possível ver os protótipos com a descrição passo-a-passo de cada interface para facilitar a análise dos demais usuários. Também o blog de design da Gnome [Com10] fornece os protótipos de interface para avaliação, onde é possível visualizar para cada tópico de design, sua descrição, interfaces e comentários vindos dos demais usuários.

\section{Diretrizes de Interface com Humanos}

Contexto: As diretrizes de interfaces com humanos são utilizadas como forma de adequar o projeto aos padrões de design de interface. Ainda dentro do contexto de poucos ou nenhum especialista em usabilidade ou design, as diretrizes direcionam membros da comunidade a manterem as interfaces dentro de um padrão estabelecido inicialmente pela equipe-núcleo do projeto. Dessa forma, garante-se que novos contribuidores não entreguem interfaces que não estejam de acordo com o padrão definido. As diretrizes são disponibilizadas como parte da documentação para novos desenvolvedores através de sites, blogs ou listas de discussão do projeto, o que também caracteriza uma prática realizada remotamente.

Problema: Ausência de especialistas em design de interface. Principais forças envolvidas:

- Força 1: Equipe-núcleo do projeto deseja manter as interfaces de sistema padronizadas de acordo com heurísticas de design.

- Força 2: Desenvolvedores que contribuem com o projeto podem não conhecer métodos de design para aplicar durante o desenvolvimento.

Solução: Participantes seguem diretrizes bem definidas para criar soluções de design. 
Exemplos: O projeto KDE fornece uma página com diretrizes de interface, de modo a facilitar as atividades de membros do projeto [Com11]. A página apresenta as diretrizes ordenadas em ordem alfabética.

\section{Envolvimento de especialistas em design de interface}

Contexto: Equipes utilizam estratégias de divulgação do sistema e de envio de convites para participação de especialistas em design ou usabilidade para contribuirem com o projeto, salientando o valor de sua contribuição para o sistema. Alguns grupos de designers e especialistas em usabilidade formaram-se, como por exemplo, o Open Usability que atualmente possui um site para cadastro de projetos que gostariam da contribuição de design e/ou usabilidade. Os projetos são apresentados com uma breve descrição e quais são os desafios para as interfaces que desejam resolver. A aplicação dessa técnica também ocorre de modo remoto, uma vez que a divulgação dos projetos e o contato entre membros da equipe-núcleo e os especialistas se dá através de sites ou troca de emails.

Problema: Equipe-núcleo não possui especialistas em design de interfaces. Principais forças envolvidas:

- Força 1: Equipe-núcleo gostaria de ter a participação de especialistas em design e/ou usabilidade no processo de desenvolvimento.

- Força 2: Especialistas em design e/ou usabilidade encontram-se distantes do desenvolvimento.

- Força 3: Especialistas em design e/ou usabilidade não costumam participar voluntariamente de projetos de software livre.

Solução: Utilizar estratégias de divulgação do sistema e chamadas para participação de especialistas em UX ou usabilidade.

Exemplos: O projeto Open Usability possui como principal objetivo fornecer uma plataforma para unir desenvolvedores de software livre e contribuidores de usabilidade. A ideia é estabelecer uma relação de longo prazo entre desenvolvimento e usabilidade e promover o estabelecimento de processos de design orientado a usuários [Usa10].

\section{Design cedo e frequente}

Contexto: Design de interfaces desde cedo e ocorrendo diversas vezes durante o processo de desenvolvimento do sistema. O design começa antes da implementação do código, mas continua em paralelo com as definições de design, por isso as atividades de design precisam ser frequentes durante todo o desenvolvimento do sistema.

Problema: Encontrar e resolver questões de design cedo no projeto. Principais forças envolvidas:

- Força 1: Resolver problemas de design antes do sistema ser implementado.

- Força 2: Sistema começa a ser implementado em paralelo com definições de design.

Solução: Criação de design do sistema desde cedo e frequentemente.

Exemplos: Projetos como Gnome, KDE e Mozilla utilizam essa prática conforme o survey realizado por Celeste Lyn Paul [Pau09]. Alguns projetos perceberam a necessidade da prática após problemas com a usabilidade da interface. 


\subsubsection{Avaliar designs}

\section{Lançamento cedo para feedback do usuário}

Contexto: Em desenvolvimento de software livre, são liberadas versões do sistema gradualmente para uso, de modo a coletar novos requisitos e perceber problemas diretamente por meio do uso do sistema em situações reais. Dessa forma, os membros da equipe-núcleo do projeto percebem a necessidade de novas funcionalidades através dos relatos dos usuários e notam problemas tanto na interface quanto na lógica de funcionamento do sistema. A partir desse entendimento, novas versões são criadas baseadas no uso real. Tanto o sistema é testado por meio do uso em situações reais, quanto novas funcionalidades são levantadas. Esta também é uma técnica aplicada de modo remoto, uma vez que o sistema é lançado para uso e os comentários dos usuários são utilizados para reconhecer problemas e novas funcionalidades para o sistema.

Problema: Receber feedback do usuário o mais cedo possível durante o desenvolvimento. Principais forças envolvidas:

- Força 1: Receber feedback de uso real do sistema de modo a definir novas características e/ou melhorias.

- Força 2: Impossibilidade de reunir usuários típicos e desenvolvedores presencialmente para realização de testes. Além disso, os testes podem não ser fiéis à realidade, se não ocorrerem durante o uso normal do sistema.

Solução: Liberação de versões do sistema o mais cedo possível para obter feedback do uso por usuários reais.

Exemplos: Release early, release often é uma filosofia de desenvolvimento que tem por objetivo enfatizar a liberação cedo e frequente de versões de um sistema, de modo a criar um ciclo de feedback entre desenvolvedores e usuários. Esta filosofia foi popularizada por Eric Raymond em seu famoso artigo "The Cathedral and the Bazaar", onde Raymond declara: "Release early. Release often. And listen to your customers" [Ray99].

\section{Reuniões de usabilidade}

Contexto: Membros da equipe-núcleo podem convocar reuniões de design de interfaces, abertas para os contribuidores do projeto, para que sejam discutidas opções para telas complexas e críticas do sistema. As discussões levam em conta as opiniões dos participantes e problemas referentes à implementação de um determinado design são analisados de modo a escolher a melhor opção tanto em termos de design quanto em termos de implementação do código. As reuniões são finalizadas com uma definição do design e os resultados são disponibilizados para todos os envolvidos. Esse tipo de reunião costuma ser realizada presencialmente, mas seus resultados são disponibilizados de modo online.

Problema: Resolver problemas de usabilidade e/ou design complexos. Principais forças envolvidas:

- Força 1: Membros de equipe precisam encontrar boas soluções para problemas de design complexos.

- Força 2: Necessidade de levar em consideração problemas de implementação.

Solução: Reunião de membros do projeto para discussão e solução de problemas complexos de design e/ou usabilidade. 
Exemplos: O projeto KDE realiza reuniões com a proposta de resolver problemas de usabilidade. As reuniões são livres para todos que desejam participar, contudo, a maioria dos participantes é composta de designers e desenvolvedores [Com09]. Antes da reunião ocorrer, os participantes podem inserir os tópicos que gostariam que fossem discutidos na página de reuniões de usabilidade do projeto.

\section{Relatos de erros}

Contexto: Utilização de um sistema de bug tracking ou acompanhamento de erros para que usuários possam relatar problemas que encontrem durante o uso do sistema. Esse tipo de sistema segue um formato pré-definido para relato de um bug, o que implica em maiores conhecimentos por parte do usuário para que possa relatar satisfatoriamente um bug, como é desejado pelo sistema. Esse fato pode inibir a participação de usuários com menos conhecimento técnico. A técnica é realizada de modo remoto, uma vez que os relatos são inseridos em um sistema online, que é acompanhado remotamente por membros da equipe-núcleo.

Problema: Encontrar problemas em funcionalidades e de usabilidade em situações reais de uso. Principais forças envolvidas:

- Força 1: Usuários encontram erros durante o uso do sistema e desejam solicitar soluções.

- Força 2: Impossibilidade de reunir desenvolvedores e usuários típicos presencialmente para que sejam apresentados os erros encontrados durante o uso.

Solução: Sistema de Bug Tracking para que usuários informem problemas que encontrem durante o uso do sistema. O envio de um bug segue um formato pré-definido.

Exemplos: O sistema Bugzilla (www.bugzilla.org) é um sistema de bug tracking utilizado pela comunidade de usuários e desenvolvedores de projetos como o núcleo do Linux (bugzilla.kernel.org), Gnome (bugzilla.gnome.org), KDE (bugs.kde.org), Apache Project (issues.apache.org/bugzilla), Open Office (www.openoffice.org/issues/query.cgi), Eclipse (bugs.eclipse.org/bugs), além da própria Mozilla (bugzilla.mozilla.org). Seu principal objetivo é permitir que desenvolvedores acompanhem os relatórios de erros em seu produto de forma eficaz.

\section{Testes de usabilidade remotos}

Contexto: Existem diversas ferramentas online, livres ou não, disponíveis para realização de testes de usabilidade remotos. Desde simples ferramentas que fazem o $\log$ das ações dos usuários no sistema, até mesmo testes de usabilidade com ou sem moderadores ${ }^{3}$, com usuários reais realizando tarefas no sistema. Sistemas de software livre utilizam-se dessas ferramentas para realizar testes com usuários remotamente. Dessa forma, envolve-se nos testes um número maior de usuários, que podem estar dispersos em vários locais simultaneamente.

Problema: Testar usabilidade de sistemas em ambientes que equipe, contribuidores e usuários encontram-se dispersos geograficamente. Principais forças envolvidas:

- Força 1: Necessidade de realização de testes de usabilidade com usuários reais durante o desenvolvimento do sistema.

- Força 2: Usuários reais encontram-se distantes da equipe de desenvolvimento e/ou existe a impossibilidade de realizar testes presenciais.

- Força 3: Realizar testes com um número maior de usuários.

\footnotetext{
${ }^{3}$ Papel utilizado em testes de usabilidade, que tem o objetivo de acompanhar os usuários durante o teste, informando as tarefas a serem realizadas, respondendo dúvidas dos usuários e auxiliando a manter o foco no teste que está sendo realizado
} 
Solução: Utilizar ferramentas online para realização de testes de usabilidade.

Exemplos: Resultados de testes de usabilidade remotos realizados pelo KDE podem ser obtidos em blogs.kde.org/node/1845. Ao acessar os resultados, o leitor pode incluir seus comentários através de um link de wikipedia para os resultados do teste. A iniciativa de teste piloto da Mozilla (testpilot. mozillalabs.com) tem o objetivo de construir uma amostra representativa de usuários Firefox, que são recrutados para avaliar novos conceitos e características de interfaces; a ideia é formar um laboratório de usabilidade global para Firefox. Dependendo dos testes necessários, usuários são selecionados para participar em diferentes experimentos e são questionados para fornecer feedback em uma base regular. Todas as informações coletadas são disponibilizadas publicamente.

\subsection{Notas do capítulo}

Neste capítulo foram apresentadas as principais características de comunidades de software livre, bem como o seu contexto de desenvolvimento. Em seguida, descreve-se as principais práticas de usabilidade utilizadas por equipes de software livre, por meio do formato-padrão: nome, contexto, problema, solução e exemplos. As práticas que foram descritas neste capítulo são utilizadas na comunidade de software livre, mas não indicam padrões de uso da comunidade. Isso ocorre porque são práticas isoladas e que se concentram em grandes equipes, algumas com patrocínio de empresas. Mas, não representam a realidade da maioria dos projetos da comunidade de software livre. No próximo capítulo serão apresentados os padrões de uso de práticas de usabilidade da comunidade de métodos ágeis, de modo a possibilitar a análise das práticas de ambas as comunidades em capítulos posteriores. 


\section{Capítulo 5}

\section{Práticas de usabilidade utilizadas na comunidade de métodos ágeis}

Neste capítulo, são definidos os principais conceitos relacionados a métodos ágeis, bem como, seus valores, princípios e práticas, de modo a delinear o contexto no qual são aplicadas práticas para melhoria de usabilidade nesta comunidade. A dois métodos ágeis foi dada especial atenção neste capítulo, pois são os utilizados nos projetos de estudo de caso ou de pesquisa-ação, são eles Scrum e XP.

Após a definição dos principais conceitos relacionados a métodos ágeis que são aplicáveis a esta dissertação, apresenta-se as principais práticas de usabilidade que são utilizadas na comunidade de métodos ágeis, bem como a identificação de padrões de uso de práticas de usabilidade nesse contexto.

\subsection{Métodos ágeis}

No período de 11 a 13 de fevereiro de 2001, em Utah, ocorreu uma reunião de 17 especialistas em desenvolvimento de software, que resultou no Manifesto do Desenvolvimento Ágil de Software [BBvB01], que se tornou a base filosófica para definição de métodos ágeis e possui os quatro seguintes valores:

- Indivíduos e Interações mais do que Processos e Ferramentas;

- Software Funcionando mais do que Documentação Abrangente;

- Colaboração do Cliente mais do que Negociação de Contratos; e

- Responder a Mudanças mais do que Seguir um Plano.

Isto é, existe valor nos itens à direita, mas valoriza-se mais os itens destacados à esquerda. Métodos ágeis possuem como meta a simplicidade, com o intuito de realizar somente o necessário para entregar sistemas de software com qualidade, sem a utilização de métodos ou artefatos que apenas consomem tempo da equipe e que possuem como objetivo a documentação de planos ou requisitos, que podem mudar a qualquer momento, ao invés de produzir valor ao cliente.

Em métodos ágeis existe documentação, mas não de centenas de páginas que raramente serão usadas ou mantidas atualizadas. Valoriza-se o planejamento, mas reconhece-se os seus limites, pois, em métodos ágeis, a mudança faz parte do processo normal do desenvolvimento de software.

Métodos ágeis possuem 12 princípios por trás dos seus valores, são eles [SG07]:

1. A maior prioridade é a satisfação do cliente por meio da entrega rápida e contínua de software que traga valor. 
2. Mudanças nos requisitos são aceitas, mesmo em estágios avançados de desenvolvimento. Processos ágeis aceitam mudanças que trarão vantagem competitiva para o cliente.

3. Software que funciona é entregue frequentemente, em períodos que variam de semanas a meses, quanto menor o tempo entre uma entrega e outra, melhor.

4. As pessoas relacionadas ao negócio e os desenvolvedores devem trabalhar juntos no dia a dia do projeto.

5. Construa projetos formados por indivíduos motivados, fornecendo o ambiente e o suporte necessário e confiando que realizarão o trabalho.

6. O modo mais eficiente e eficaz de transmitir informações dentro e fora do time de desenvolvimento é a comunicação face a face.

7. A principal medida de progresso é software funcionando.

8. Processos ágeis promovem o desenvolvimento em um ritmo sustentável. Os investidores, desenvolvedores e usuários devem ser capazes de manter um ritmo constante.

9. Cuidar continuamente da excelência técnica e do bom design ajuda a aprimorar a agilidade.

10. Simplicidade - a arte de maximizar a quantidade de trabalho não necessário - é essencial.

11. Os melhores requisitos, arquiteturas e design surgem de equipes autogerenciadas.

12. Em intervalos regulares, o time reflete sobre como se tornar mais eficiente, refinando e ajustando seu comportamento apropriadamente.

Métodos ágeis possuem planejamento adaptativo e processo iterativo. Possuir um processo iterativo significa que subdivide um projeto em subconjuntos de funcionalidades, ao contrário do estilo em cascata que subdivide um projeto com base nas atividades: análise de requisitos, projeto, codificação e teste [Fow05]. No estilo iterativo, o ciclo de desenvolvimento é composto por uma série de pequenas releases incrementais. Cada release é criada em intervalos regulares, geralmente de duas a quatro semanas, que são chamados sprints ou iterações, nos quais realiza-se o ciclo de vida do software completo para um subconjunto de requisitos.

Enquanto métodos de usabilidade possuem como foco principal os usuários típicos do sistema, que realmente o utilizarão, métodos ágeis preocupam-se com o cumprimento das necessidades dos clientes, mais relacionadas com os valores de negócio do sistema. A preocupação com os usuários, portanto, está presente em ambos, mas diferem com relação ao tipo de usuário considerados. Sendo assim, a integração dessas áreas beneficiará os usuários, seja qual for o tipo ou o perfil a que eles pertençam.

Em 2011, foi realizada uma reflexão sobre o aniversário de 10 anos de métodos ágeis (Agile Manifesto Anniversary) e, a partir dela, Beedle (www.infoq.com/articles/agile-10-contradiction), que participou do primeiro Manifesto e é um dos primeiros praticantes de Scrum, reescreve o manifesto ágil com os seus valores atuais, conforme sua percepção.

De acordo com a Figura 5.1, nota-se que a relação próxima que métodos ágeis já possuíam com métodos de usabilidade, foi intensificada ainda mais nesse novo manifesto, após dez anos de prática, o que reforça a ideia de que métodos ágeis e métodos de usabilidade podem ser bons aliados na entrega de software com qualidade que atende seus reais usuários. Contudo, é necessário sempre considerar o contexto em que um projeto é desenvolvido antes de se utilizar qualquer metodologia de desenvolvimento, porque o contexto importa tanto no nível de características do projeto quanto em nível de organização, conforme a Figura 5.2 ilustra.

O questionário aplicado pela Version One em 2010 (www.versionone.com/state_of_agile_ development_survey/10/default.asp), no qual se obteve 4770 respondentes e a participação de 91 países, trouxe como principal resultado uma visão geral do estado da prática de métodos ágeis em 


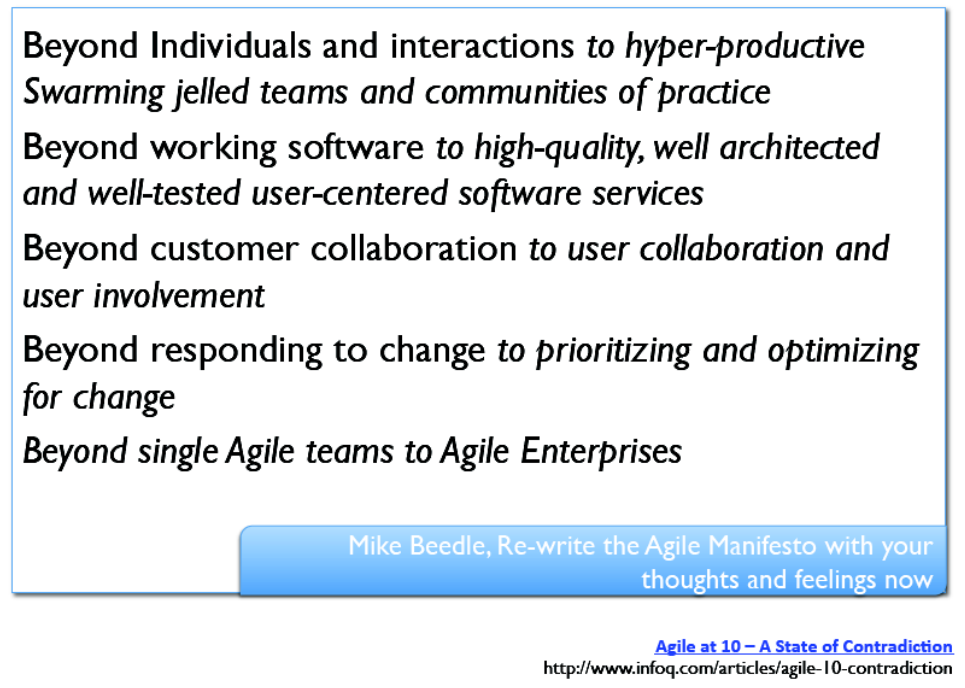

Figura 5.1: Manifesto Ágil II por Mike Beedle

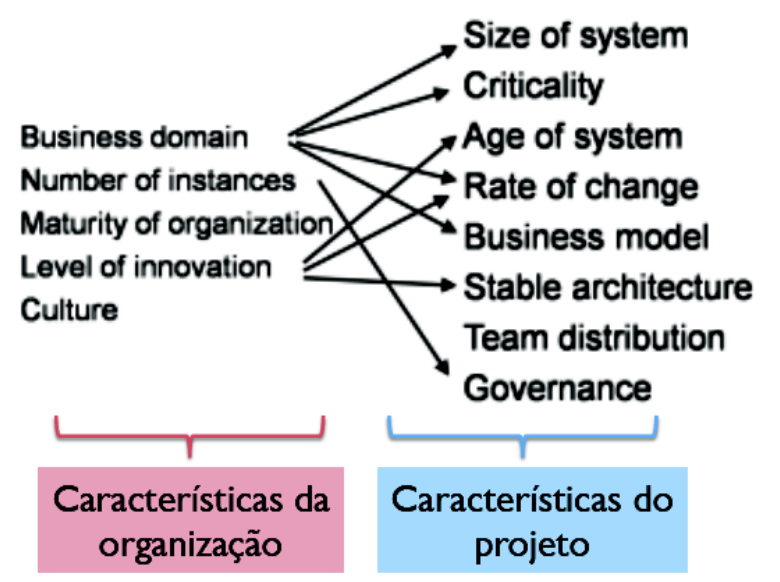

Kruchten, P. 2008. Situated Agility - Context does matter, a lot. Keynote XP'2008.

Figura 5.2: Contexto: Características do projeto e da organização são importantes.

nível mundial. No período entre maio e outubro de 2011, pesquisadores do IME-USP [CGK $\left.{ }^{+} 11\right]$ aplicaram o mesmo questionário, com o objetivo de levantar o estado da prática no Brasil, com o qual foram obtidas 471 respostas completas e a participação de 21 estados. São Paulo, Rio de Janeiro, Distrito Federal e Minas Gerais possuem a maioria das empresas nas quais trabalham os respondentes.

Os resultados obtidos no Brasil assemelham-se aos resultados da pesquisa da VersionOne e com ambos foi possível aprender que em métodos ágeis foram criados alguns mitos, como por exemplo, pensar que Ágil é feito apenas para projetos pequenos / co-localizados / não críticos. Outro ponto semelhante percebido pelas duas pesquisas é a necessidade de compreensão de fatores humanos e mudanças organizacionais como sendo os principais desafios para fortalecer e sustentar métodos ágeis na indústria.

\subsubsection{Scrum}

Scrum é um método ágil desenvolvido por Schwaber, Sutherland e Beedle [SB01, Sch04], em meados da década de 1990. Seu foco é na aplicação da filosofia ágil para o gerenciamento de desenvolvimento de software, sendo, portanto, menos voltado a aspectos técnicos. Por esse motivo, em muitas equipes, costuma ser utilizado junto com XP, explicado na Seção 5.1.2, para tratar melhor 
dos aspectos técnicos. A Figura 5.3 ilustra o funcionamento do processo do Scrum.

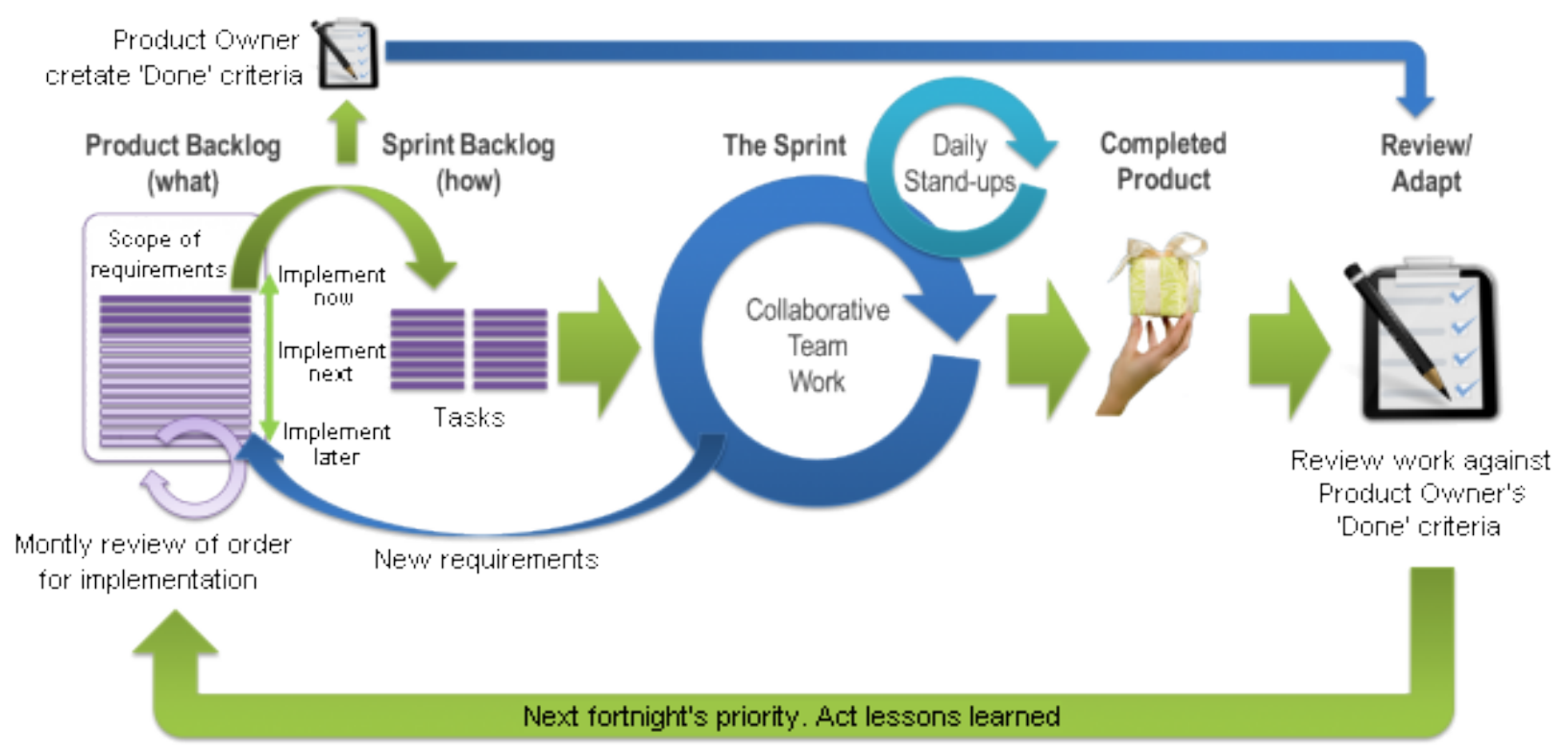

Figura 5.3: Processo do Scrum [Blo11].

Mais especificamente, Scrum é um arcabouço de processo que tem sido usado para gerenciar o desenvolvimento de produtos complexos. Sendo assim, Scrum não é um processo ou técnica para construir produtos, é mais um arcabouço dentro do qual se pode empregar processos e técnicas variadas. O Scrum torna clara a eficácia relativa das práticas de gerenciamento e desenvolvimento de produtos, para que seja possível melhorá-las [SS11].

\subsubsection{Programação extrema (XP)}

As principais características da Programação Extrema (eXtreme Programming ou XP) [BA04, Bec99], são as seguintes [SG07]: (1) XP é um método leve. O time só deve fazer o que for necessário para trazer valor para o cliente; (2) XP é um método que enfatiza o desenvolvimento de software. Apesar de ter implicações em áreas como marketing, vendas ou operações, XP não tenta resolver os problemas diretamente ligados a elas; (3) XP funciona para times de qualquer tamanho. Apesar de as práticas de XP funcionarem melhor em times pequenos, seus valores e princípios podem ser aplicados em qualquer escala; e (4) XP adapta-se a requisitos vagos ou em constante mudança.

A Figura 5.4 exibe as relações existentes entre valores, princípios e práticas de XP. Valores justificam as práticas, sendo aplicáveis em qualquer situação durante o desenvolvimento de um sistema. Um exemplo de valor em XP é a comunicação. As práticas são técnicas utilizadas diariamente por integrantes de uma equipe XP, que são aplicáveis em contextos específicos do processo de desenvolvimento; por exemplo, Test Driven Development (TDD) só faz sentido no contexto de programação. Os princípios, por sua vez, traduzem os valores em práticas, constituindo-se em pontes entre os dois. Como as práticas são específicas por contexto, os princípios ajudam a trazer o valor de uma determinada prática para outros contextos. A Figura 5.5 apresenta o fluxo de trabalho em projetos que utilizam XP para o desenvolvimento de software.

\subsection{Métodos de usabilidade utilizados durante o desenvolvimento com métodos ágeis}

Os valores do Manifesto Ágil estão de acordo com os princípios fundamentais de desenvolvimento centrado no usuário (DCU), descrito na Seção 3.4.2: foco nos indivíduos e interações e colaboração com cliente. Sendo assim, DCU Ágil é a prática do design centrado no usuário quando conduzida dentro de uma metodologia ou filosofia de desenvolvimento ágil de software. 


\section{Programação eXtrema}

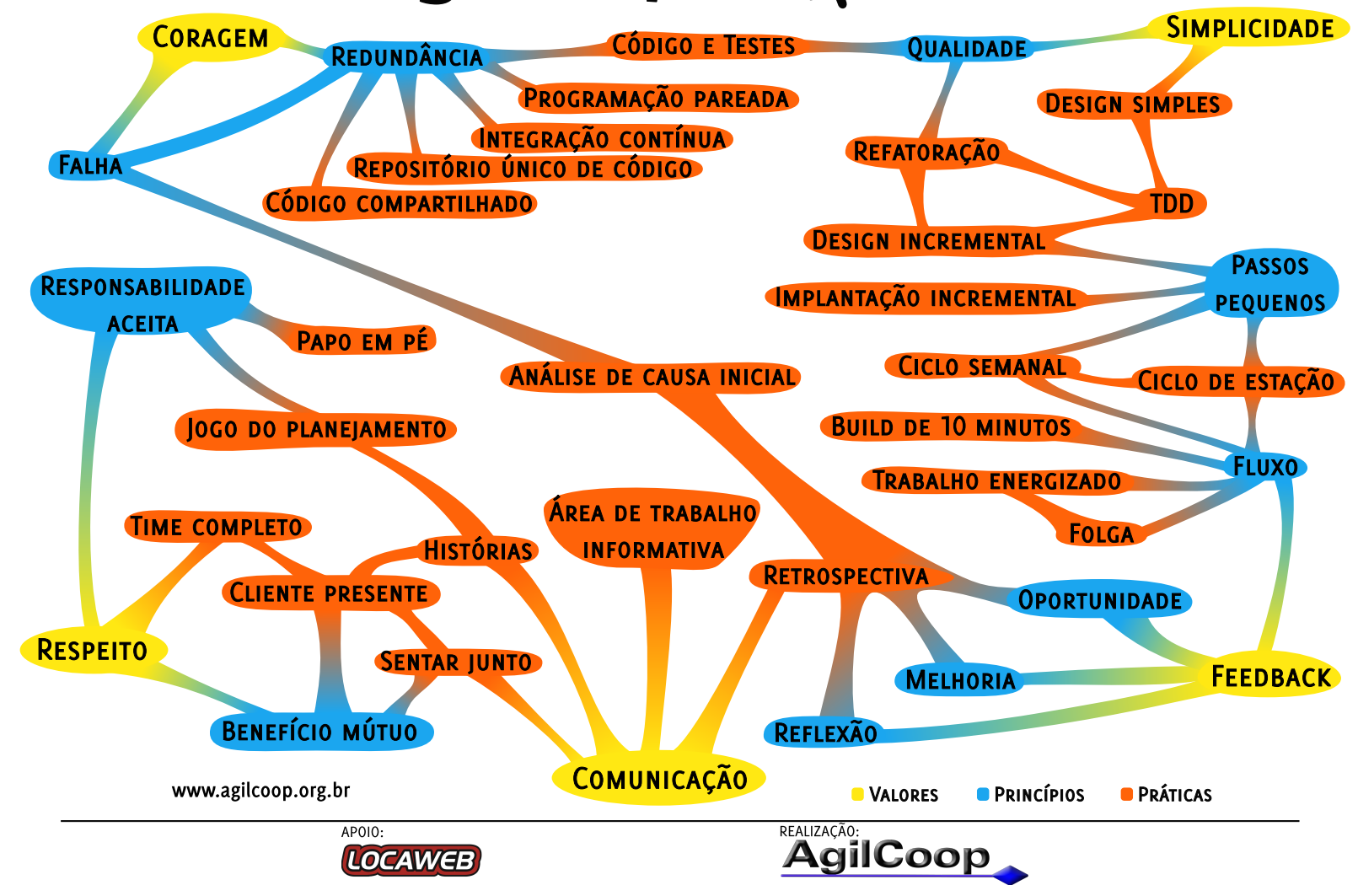

Figura 5.4: Relacionamento entre valores, princípios e práticas de XP [BG11].
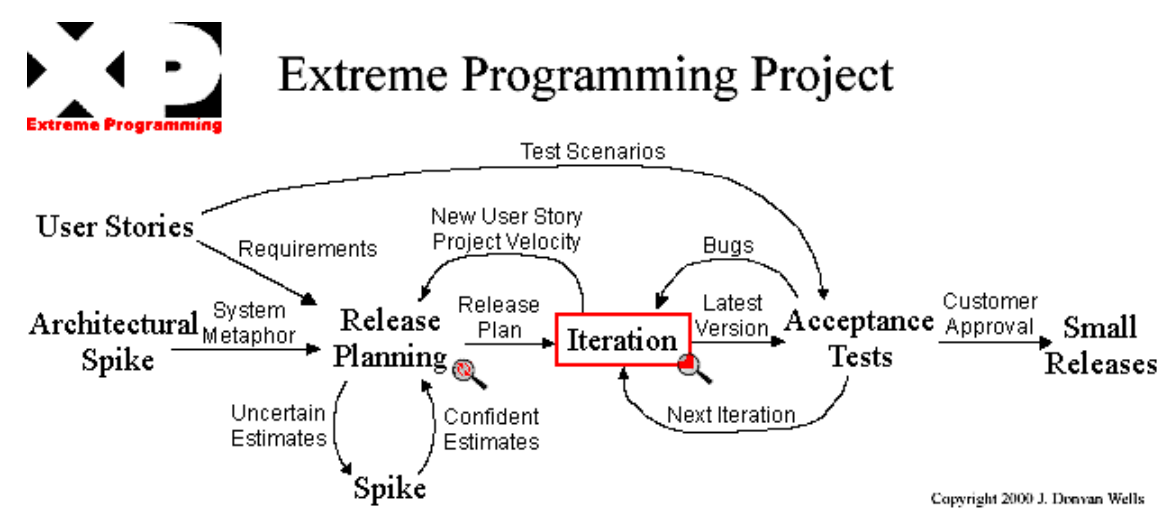

Figura 5.5: Fluxo de projetos XP [Welogb].

O desafio da área de DCU Ágil resume-se em encontrar a melhor maneira de realizar as atividades de pesquisa de usuário, design de versões que atendam às necessidades do usuário, construção de versões interativas e realização de testes de usabilidade, dentro de um ambiente de desenvolvimento com métodos ágeis, tendo a participação de usuários típicos em todas as atividades. A Figura 5.6 exibe o ciclo de DCU ágil proposto por Sy [SY07] que integra tanto as atividades de DCU, quanto as de desenvolvimento em apenas um único ciclo, exibindo a interação destas atividades.

Equipes que trabalham nesse contexto de desenvolvimento [SY07, MM05] relatam suas experiências na adaptação de investigações de usabilidade para ambientes ágeis (DCU Ágil), indicando que adaptações são realmente necessárias, principalmente no que diz respeito à granularidade da pesquisa, no tempo gasto com ela e na maneira de relatar as descobertas de usabilidade. Além disso, informam que o valor da comunicação presente em equipes ágeis facilita a realização de mudanças, diante das descobertas de usabilidade e que em ambientes baseados no modelo de cascata, a 


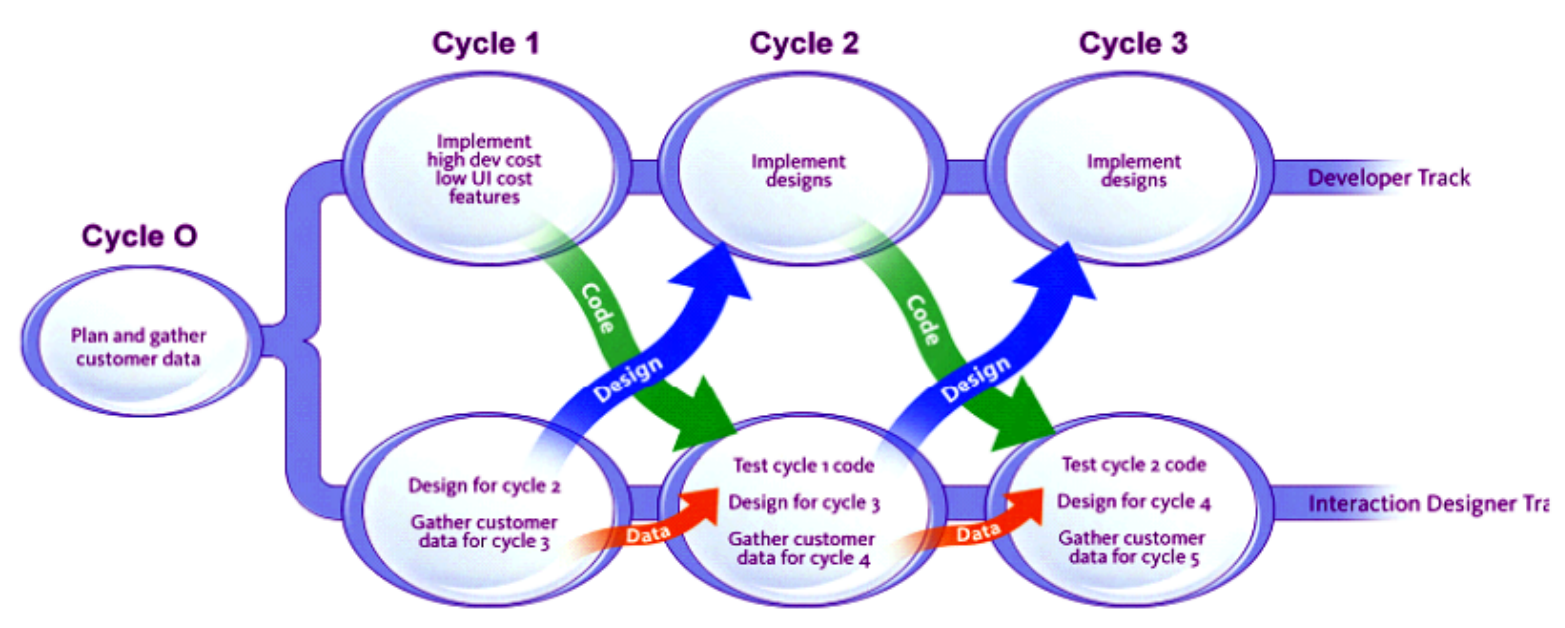

Figura 5.6: Ciclo do DCU ágil [SYO]].

distância entre a especificação do design e a sua implementação era, muitas vezes, de meses. Em projetos ágeis, a equipe focaliza em poucas características por vez e, portanto, a equipe de UX (User eXperience) também não precisa trabalhar em todos os designs de uma só vez e nem antes do início do desenvolvimento. Durante todo o ciclo de desenvolvimento ágil, pode-se realizar investigações de usabilidade com foco nos designs-chave de cada iteração. Dessa forma, atividades de DCU e de desenvolvimento trabalham juntas nas mesmas características, garantindo que as investigações de usabilidade serão tratadas durante a iteração, além de disseminar os dados das pesquisas por toda a equipe e através de todas as iterações do sistema [UW08].

Os praticantes de UX que passaram a trabalhar em ambientes ágeis também relatam que, em média, as equipes levam de 6 a 12 meses para se adaptarem ao novo ambiente de desenvolvimento, mas, uma vez que tenham conseguido fazer o processo funcionar, não querem mais retornar ao antigo método de desenvolvimento baseado no modelo em cascata. Além disso, os praticantes de UX relatam maior influência do seu trabalho no desenvolvimento pela diminuição do intervalo entre as descobertas de usabilidade e implementação de mudanças para atendê-las. Também aumenta-se a probabilidade de entregar a solução que o cliente quer pois, em cada sprint, apenas as funcionalidades mais importantes e priorizadas pelo cliente são entregues já com o código funcionando, o que possibilita avaliar o sistema com usuários reais para verificar se suas necessidades foram cumpridas. Dessa forma, rapidamente pode-se realizar mudanças que entrarão na próxima iteração.

Embora existam várias vantagens na integração das áreas de métodos ágeis e usabilidade, praticantes de UX levantaram alguns problemas e possíveis soluções para resolvê-los, conforme a Figura 5.7, retirada do artigo de Sy e Miller [MS09].

Em um workshop realizado entre profissionais da área de UX que trabalham em ambientes ágeis, também foram levantadas algumas soluções para desafios encontrados na integração das duas áreas. Abaixo, descreve-se as soluções exibidas na revista User Experience [LRM10].

1. Desafio: Recursos Distribuídos (vários membros de equipe, vários projetos, várias localizações geográficas);

Solução: Sala de Equipe Virtual com Cartões Online.

Criação de uma sala de equipe virtual com cartões online representando histórias no backlog. O backlog online ajuda a registrar priorização e planejamento da sprint. Todos os metadados da história são também monitorados por esse log. Equipes distribuídas têm um trabalho maior para se comunicar e a colaboração pode precisar ser um pouco mais formal e documentada.

2. Desafio: Sem tempo suficiente para escrever especificações da interface de usuário, por este 


\begin{tabular}{|c|c|c|}
\hline Problem & Symptoms & Pussible Solutions \\
\hline Not enough design time. & $\begin{array}{l}\text { - Developers waiting on designs } \\
\text { - Design quality drop } \\
\text { - Designs not verified with customers }\end{array}$ & \multirow{3}{*}{$\begin{array}{l}\text { - Separate and parallel UX Design/Developer tracks }[1,2,9,12,13] \\
\text { - Scope UX activities to be small, incremental }[1,2] \\
\text { - RITE formative usability testing }[3,4] \\
\text { - Rapid contextual design [5] } \\
\text { - } \quad \text {-Design studio" }[6] \\
\text { - Design chunking }[1,14] \\
\text { - Combine đifferent UX activities into one session [7] } \\
\text { - Bring user (and data) to you [7] } \\
\text { - Lighten requirements gathering process }[1,2,9,11,12]\end{array}$} \\
\hline Sprints are too short & $\begin{array}{l}\text { - Designs cant be finished in time } \\
\text { - No time for usability testing } \\
\text { - No time to set up customer contact }\end{array}$ & \\
\hline Not enough user kedback & $\begin{array}{l}\text { - Feedback not earty enough } \\
\text { - No data to act on - opinions rule } \\
\text { - Product isn't validated }\end{array}$ & \\
\hline Weak Agile "customer" [6] & $\begin{array}{l}\text { - End-users and clients won't participate } \\
\text { - Can't get buy-in from rest of team } \\
\text { - Non informed decisions are made }\end{array}$ & \multirow{4}{*}{$\begin{array}{l}\text { - UX person can act as Agile customer role }[8] \\
\text { - Each UX person works on one scrum team }[8] \\
\text { - Choose which scrum teams to work with wisely }[11] \\
\text { - Validated designs are passed to developers to implement }[1,2] \\
\text { - UX participates in cycle planning }[2,15] \text {, bringing appropriate } \\
\text { - } \text { - No features go in unless something comes out }[11]\end{array}$} \\
\hline $\begin{array}{l}\text { UX is not full-time on one } \\
\text { Agile team }\end{array}$ & $\begin{array}{l}\text { - UX time spent in many meetings instead } \\
\text { of on designs and iterations } \\
\text { - Demoralized by UX quality drop }\end{array}$ & \\
\hline No sprint/cycle planning & $\begin{array}{l}\text { - Large backlog of features/bugs } \\
\text { - Prioritization feedback ignored } \\
\text { - No control over timing of designs }\end{array}$ & \\
\hline User feedback is ignored & $\begin{array}{l}\text { - Feature set is cast in stone } \\
\text { - No time to incorporate changes } \\
\text { - No re-ordering of features is allowed }\end{array}$ & \\
\hline Missing the "big picture" & $\begin{array}{l}\text { - No shared vision or end goal } \\
\text { - Too much focus on details } \\
\text { - Hard to prioritize/make design decisions }\end{array}$ & $\begin{array}{l}\text { - Persuade Agile team to adopt Cycle Zero }[1,2,9,10,12] \\
\text { - Consider design goals from different levels of detail (product, } \\
\text { release, capability, design chunk) [14] }\end{array}$ \\
\hline Poor communication. & $\begin{array}{l}\text { - Misundersood designs } \\
\text { - Agile team doesn't bury-into designs } \\
\text { - Important information is lost }\end{array}$ & $\begin{array}{l}\text { - Include developers in design process }[1,2] \\
\text { - Usability included in acceptance criteria }[1,2] \\
\text { - Daily contact to check progress }[1,2] \\
\text { - Design cards for stand-up meetings }[1] \\
\text { - Issue cards for usability reporting }[1] \\
\text { - Documents are for design team [1] }\end{array}$ \\
\hline Team isn't co-located & $\begin{array}{l}\text { - No sense of team - lack of trust } \\
\text { - Language and/or time barriers } \\
\text { - Not enough communication }\end{array}$ & $\begin{array}{l}\text { - Telecommuting tools (phone and web-based replacements) } \\
{[11,12]} \\
\text { - Co-locate for cycle plaming }[11,12]\end{array}$ \\
\hline Dependency issues & $\begin{array}{l}\text { - Requiring input from non-Agile teams } \\
\text { (e.g.,marketing sign-offs, lawyers) }\end{array}$ & $\begin{array}{l}\text { - A scrum leader or facilitat or with strong persuasion skills can } \\
\text { move things along quickly. [11] }\end{array}$ \\
\hline
\end{tabular}

Figura 5.7: Principais problemas durante a aplicação de DCU ágil [MS09].

motivo a implementação pode desviar dos designs.

Solução: Passagem de design a quente

Ao passar do design para o desenvolvimento, postar documentação onde a equipe possa acessála e fazer uma reunião para discuti-la com a equipe, de modo a manter a comunicação entre os envolvidos. Ficar em contato com a equipe de desenvolvimento, de modo a detectar qualquer mudança no design durante a implementação. Alguns profissionais acompanham regularmente como a implementação está ocorrendo.

3. Desafio: Falhas no design e melhorias desejadas são notadas durante a implementação, mas não há tempo para corrigi-las durante o sprint; ou as falhas são tão pequenas que não são realmente consideradas relevantes.

Solução: Cartões para "coisas pequenas" (The Little Things Card).

Se o produto for lançado com inconsistências, registra-se os problemas e melhorias desejados em cartões para coisas pequenas, também chamados de log de mudanças de interface de usuário (UI change log). Por meio dos cartões, cria-se uma nova feature no próximo sprint, com a combinação de várias coisas, ou, tarefas pequenas, de modo a resolvê-las.

\subsubsection{DCU e XP}

Alguns estudos para exploração dos processos de usabilidade ágil descrevem a integração entre instrumentos de IHC e práticas de Programação Extrema. Os instrumentos de IHC são estudos de usuários, avaliação de usabilidade por especialistas, testes de usabilidade, avaliações automáticas de usabilidade e personas extremas. Esta última é uma variação da abordagem de personas, que 
consiste na realização de uma técnica para modelagem de pessoas com o objetivo de comunicar as características de perfil de usuário de um produto [FAS ${ }^{+} 05$, JTF08]. Pela combinação de XP e DCU pode-se encontrar vantagens para ambas as abordagens.

McInerney e Maurer mostraram que o casamento destas duas abordagens é possível [MM05]. Segundo Wolkerstorfer et al., a ideia para o processo de usabilidade ágil é integrar os instrumentos de IHC dentro dos processos clássicos de XP $\left[\mathrm{WTS}^{+}\right.$08]. Cada instrumento é trabalhado na prática através de especialistas de IHC, baseados no processo de XP e intervindo de três maneiras:

- criação de histórias de usuários;

- contribuição pela escrita de testes; e

- expansão de métodos do XP.

Wolkerstorfer et al. usam o processo de usabilidade ágil desde 2007. Eles relatam que até o momento não tiveram qualquer experiência com problemas culturais e que os especialistas de IHC do projeto estão bem integrados com a equipe de desenvolvimento. Também a união entre experiências diferentes tem levado a uma alta motivação entre os membros do projeto. Desenvolvedores ganharam conhecimento em DCU, especialistas em IHC aprenderam a entender as origens de alguns dos problemas de usabilidade. Sendo assim, ocorre a disseminação de conhecimento das áreas envolvidas entre os membros da equipe.

\subsection{Padrões de uso de práticas de usabilidade na comunidade de métodos ágeis}

Nesta seção serão descritas as melhores práticas de usabilidade que são utilizadas na comunidade de métodos ágeis, no formato contexto, problema, solução e exemplos conforme a definição de um padrão [AIS ${ }^{+} 77$, Fow97, Cru01, CK09]. A seleção das práticas como padrões de uso levou em consideração a preocupação em descrever apenas práticas que foram utilizadas por pelo menos três grupos diferentes.

Na comunidade ágil é muito comum usar o termo Experiência do Usuário para qualquer atividade relacionada com pesquisa de usuário, DCU, usabilidade, design de interfaces e até mesmo Experiência do Usuário, como definido na Seção 3.2. Por esse motivo, os padrões abaixo descritos usam essa nomenclatura, mas ressalva-se que o termo não necessariamente indica que todas as atividades de UX são realmente realizadas, mas sim atividades relacionadas à melhoria da usabilidade, atendimento das reais necessidades dos usuários, design e avaliação de interfaces.

Os padrões foram divididos em categorias de acordo com a fase de Design Centrado em Usuário em que se encontram, conforme a Seção 3.4.2 do Capítulo 3, de modo a facilitar o entendimento do objetivo de cada padrão descrito. A seleção e classificação das melhores práticas de usabilidade da comunidade de métodos ágeis encontradas na literatura, por meio do formato apresentado nesta seção, é uma das contribuições desta pesquisa. A Tabela 5.1 apresenta a classificação dos padrões de uso de práticas de usabilidade da comunidade de métodos ágeis, de acordo com as fases do DCU, e na sequência, cada um dos padrões de uso são descritos.

\subsubsection{Identificar necessidades para design centrado em humano}

\section{Um Sprint na frente}

Contexto: As atividades de UX incluem pesquisas de usuários, levantamento de requisitos, prototipação e avaliação de interfaces de usuário por meio de testes com usuários reais, entre outras. O tempo de uma iteração é considerado curto para realizar todas essas atividades e ainda implementar os resultados delas. Dessa forma, os profissionais de UX precisam trabalhar um sprint na frente dos demais membros da equipe, de modo que possam realizar pesquisas e criar designs para a próxima iteração de desenvolvimento, enquanto avaliam as funcionalidades já implementadas da 
Tabela 5.1: Padrões de uso de práticas de usabilidade da comunidade de métodos ágeis.

\begin{tabular}{|c|c|}
\hline \multicolumn{2}{|r|}{ Métodos Ágeis } \\
\hline Fases do DCU & Práticas de Usabilidade \\
\hline \multirow{6}{*}{$\begin{array}{l}\text { Identificar necessidades para } \\
\text { design centrado em humano }\end{array}$} & Um Sprint na frente \\
\hline & Sprint Zero \\
\hline & Especialistas em UX como Donos do Produto \\
\hline & Tempo do usuário é valioso \\
\hline & Caminhos paralelos \\
\hline & $100 \%$ de compromisso UX \\
\hline \multirow[t]{2}{*}{ Especificar contexto de uso } & Pouco design antecipado \\
\hline & Plano de contato de usuários \\
\hline \multirow[t]{3}{*}{ Especificar requisitos } & Histórias de usuários \\
\hline & Mais colaboração, menos documentos \\
\hline & Tratar protótipo como especificação \\
\hline \multirow[t]{3}{*}{ Criar soluções de design } & Prototipação \\
\hline & Estúdio de Design \\
\hline & Design Colaborativo e Participativo \\
\hline \multirow[t]{4}{*}{ Avaliar designs } & Testes com usuários \\
\hline & Avaliação por Inspeção \\
\hline & Método RITE (Rapid Iterative Testing and Evaluation ) \\
\hline & Testes de aceitação \\
\hline
\end{tabular}

iteração anterior. Nesse contexto, existem duas frentes de trabalho dentro do projeto, uma de UX e outra de desenvolvimento, conforme o padrão Caminhos paralelos. O trabalho de UX geralmente é realizado por especialistas da área, que comunicam seus resultados para a equipe.

Problema: Acertar o passo entre equipe de desenvolvimento e de UX, para que uma alimente o fluxo de trabalho da outra. Principais forças envolvidas:

- Força 1: Desenvolvedores necessitam das definições de design e de requisitos do sistema para análise e implementação de funcionalidades.

- Força 2: Equipe de UX precisa avaliar designs implementados por desenvolvedores de acordo com as necessidades dos usuários.

- Força 3: Equipe de UX precisa interagir com usuários e clientes de modo a definir requisitos e soluções de design.

- Força 4: Uma iteração geralmente possui pouco tempo para realizar as atividades descritas nas três primeiras forças.

Solução: Equipe de UX trabalha no mínimo uma iteração à frente da equipe de desenvolvimento.

Exemplos: O padrão "Um Sprint na frente" é reconhecido em práticas como "Separar design e desenvolvimento", de Nielsen, no qual ele destaca a necessidade de que design e desenvolvimento andem separados, de modo que a equipe de interface de usuário progrida um passo na frente da 
equipe de desenvolvimento [Nie09]. Quando chega o momento de construção de alguma parte do sistema, esta já foi projetada e testada. O design e teste podem ser realizados em uma semana ou duas por utilizar protótipos em papel e testes de desconto com usuários, os quais referem-se aos testes realizados no contexto da engenharia de usabilidade de desconto, descrita na Seção 3.5.

Patton é um desenvolvedor e projetista de software com mais de 12 anos de experiência, que tem se especializado na aplicação de técnicas de DCU para melhorar requisitos, planejamento e produtos ágeis. Em 2008, ele publicou 12 práticas emergentes, decorrentes de seu conhecimento de práticas comuns entre pessoas, inclusive ele, que praticam UX em ambientes ágeis [Pat08]. O padrão Um Sprint na frente é reconhecido na sua prática "Pesquisar, modelar e realizar design na frente do desenvolvimento, mas somente o suficiente", onde entre outras atividades, nota-se a preocupação com que a equipe de UX ou usabilidade trabalhe na frente da equipe de desenvolvimento.

Na revisão sistemática realizada em 2011 sobre Design Centrado em Usuário e métodos ágeis [SMMS11], foram descritos oito artigos de autores diferentes [CSM06, NT08, SM08, WF07, UW08, BJK09, IM09, Cho09] que utilizavam a prática de um sprint na frente do desenvolvimento, que pode ser resumida em especialistas em usabilidade ou UX realizando atividades relacionadas a pesquisa de usuário, design e avaliação de interfaces de usuário, enquanto a equipe de desenvolvimento implementa o código das histórias de usuário projetadas no Sprint anterior e corrige problemas encontrados pela equipe de UX. A prática ocorre a partir do Sprint 0 até o Sprint n-1.

Govella é designer de Experiência do Usuário por mais de dez anos e também publicou suas impressões sobre o trabalho de UX em ambientes ágeis, que resultaram em seis estratégias para integrar as duas áreas [Gov08]. Ele também cita, na sua lista de estratégias de integração de UX com métodos ágeis, a prática de "Sincronização de UX com o desenvolvimento", que tem o objetivo de executar a iteração de UX à frente do desenvolvimento.

\section{Sprint Zero}

Contexto: Sprint Zero é uma prática que tem o objetivo de melhor definir uma visão geral das necessidades do projeto a ser desenvolvido. É uma fase única antes do início da implementação do sistema e antes de começar os caminhos paralelos. Pode ser resumida em um Sprint curto pré-implementação para definir visão do produto, metas gerais, planejar superficialmente sprints futuros, definir princípios de design, esclarecer papeis de membros da equipe e métodos de comunicação. É também um sprint crítico para realizar algum trabalho de User eXperience (UX) ou usabilidade antes da produção de código começar. O foco é sobre quem, o que e o que será e é possível construir sobre pesquisa de usuário anterior, quando puder [LRM10]. Geralmente na comunidade ágil, é realizado por uma equipe de Experiência do Usuário ou usabilidade, composta por analistas de usabilidade, designers, gerentes de UX, entre outros, que realizam um breve estudo de usuário e desenham algumas telas para comunicar as ideias levantadas com o estudo. O trabalho geralmente é realizado presencialmente entre os membros da equipe de UX e, embora algumas equipes envolvam os demais membros, como desenvolvedores, geralmente essa prática envolve apenas os membros relacionados às atividades de UX. Para realizar essa prática, métodos de usabilidade para levantamento das necessidades dos usuários são utilizados.

Problema: O problema descrito por especialistas em UX caracteriza-se pela não existência de uma "grande figura" do sistema no início do desenvolvimento com métodos ágeis, além de prioridades não claras ou trabalho em coisas erradas, por não conhecer quais são as reais prioridades. Sendo assim, relatam trabalho desnecessário que não é usado. Além disso existe pouco tempo para trabalho de design na frente (upfront design). Principais forças envolvidas:

- Força 1: Necessidade de visão geral do sistema pela equipe de UX.

- Força 2: Pouco tempo para buscar entendimento da visão geral do sistema durante a Sprint, na qual ocorre fluxo paralelo de atividades de desenvolvimento e UX.

Solução: Curto Sprint antes da implementação do código para definir visão do produto, metas 
gerais, planejar superficialmente os próximos sprints, definir princípios de design.

Exemplos: A revisão sistemática de Silva et al. aponta alguns autores que utilizam o Sprint Zero para pesquisas contextuais com usuários e relatam a utilização dos seguintes métodos [SMMS11]: investigação contextual (Contextual Inquiry) e entrevistas com usuários [Hod05, KSB09, CSM06, NT08, FSM08]. Também Chamberlain et al. sugerem que o Sprint Zero seja feita antes do Planning Game, reunião de planejamento ágil, para que aspectos de usabilidade sejam discutidos durante o Planning Game [CSM06]. Najafi e Toyoshiba sugerem a criação de personas no Sprint Zero [NT08] e Wolkerstorfer sugere o uso de Personas Extremas, que seriam uma extensão de histórias de usuários de XP [WTS ${ }^{+} 08$ ]. Também Belchev e Baker relatam a realização de investigação contextual como entrevistas um-a-um conduzidas no local de trabalho dos usuários, que focam sobre observações do trabalho em andamento [BB09]. Detweiler [Det07] e Williams e Ferguson [WF07] declaram que atividades relacionadas a interface de usuário devem ser realizadas antes do início oficial do projeto.

Algumas práticas descritas como casos de sucesso de equipes de experiência do usuário em ambientes de desenvolvimento com métodos ágeis [SY07, MM05] resultaram em um conjunto de melhores práticas, que foram descritas no primeiro volume da revista User Experience, de 2010 [LRM10]. A revista descreve a prática Sprint Zero como sendo necessária para resolver o problema do sentimento de não possuir uma "grande figura" do projeto. Existem também sugestões [Ent11] de ter um designer que, desde o início do projeto, tenha em mente a grande figura, assim mesmo que em cada iteração ou sprint seja priorizado apenas um subconjunto de funcionalidades para desenvolvimento, este designer manterá em mente o que ou como as novas funcionalidades afetam o todo, a grande figura do projeto.

Janet Six relata o planejamemto rápido, dizendo que nem sempre eles possuem uma reunião de planejamento face-a-face. Ao invés disso, eles enviam uma lista de coisas que necessitam saber sobre as metas de estudo, tarefas, personas e problemas. A partir disso, eles podem iniciar o planejamemto dos elementos, onde alguns são escritos e outros rascunhados pelos clientes para revisão. Troca-se vários e-mails, às vezes muitos em um mesmo dia, até que eles obtenham o protocolo de estudo mapeado. A autora declara: "Uma maneira de assegurar que você está construindo o produto certo para seu público-alvo é fazer pesquisa de usuário geradora, então definir perfis de usuários ou personas e cenários baseados em sua pesquisa. As atividades de pesquisa de usuário e análise tipicamente ocorrem durante a iteração, ou sprint 0 , e fornecem entradas úteis para definição de requisitos na forma de épicos e histórias de usuários" [Six11].

\section{Especialistas em UX como Donos do Produto}

Contexto: Dono do Produto ou Product Owner é um papel em equipes ágeis, que utilizam Scrum para gerenciamento de desenvolvimento de software, o qual tem a responsabilidade de representar os interesses dos stakeholders ou clientes, além de definir e priorizar as funcionalidades do Product Backlog. Este, por sua vez, é uma lista principal de todas as funcionalidades desejadas do sistema. Os clientes geralmente trazem para o sistema os requisitos de negócio que precisam ser atendidos. Quando são usadas versões híbridas, compostas por Scrum e XP, os itens do Product Backlog são descritos como User Stories. Incluir especialistas em UX como Product Owners, significa também considerar os interesses dos usuários que realmente utilizarão o sistema, além dos interesses de clientes, de modo a gerar uma lista de funcionalidades baseada também nas necessidades dos usuários reais. O Product Owner compartilha as necessidades dos usuários com a equipe e a equipe define quais funcionalidades consegue concluir para o próximo Sprint, que é um período de tempo onde um conjunto de atividades deve ser executado. O desenvolvimento de software com métodos ágeis é iterativo, ou dividido em iterações ou sprints. Em XP, costuma-se utilizar o termo iteração e, em Scrum, o termo Sprint. A função do Dono do Produto geralmente é desempenhada presencialmente, já que utiliza-se de contato face a face com clientes e usuários.

Problema: Integrar requisitos de negócio com requisitos de usabilidade. Principais forças envolvidas: 
- Força 1: Trazer para o ambiente de desenvolvimento a necessidade de usuários reais sem esquecer dos requisitos de negócio.

- Força 2: Integrar necessidades de clientes e de usuários reais.

Solução: Praticantes de UX fazem parte da equipe de Donos do Produto Product Owners.

Exemplos: Patton relata entre suas práticas a necessidade de "Guiar: praticantes de UX fazem parte da equipe de Product Owners ou clientes" e "Profissionais de UX devem ser facilitadores de design" [Pat08]. As duas práticas concordam com o padrão de que especialistas em UX ou usabilidade são representantes dos clientes ou usuários dentro da equipe. Gothelf é um designer de Experiência do usuário e autor do livro Lean UX: Getting Out of the Deliverables Business que relata em seu blog sua experiência atuando como Product Owner em uma equipe ágil que utiliza Scrum [Got11]. Ele considera que o trabalho de designer de UX é uma ponte para a ligação entre negócios e o cliente e que essas informações sendo tratadas juntas sob o papel de Product Owner, permite conceber ideias de design cedo que já estão em conformidade com os requisitos de negócios. McCoy, diretor de desenvolvimento de produtos integrados na Cooper, uma empresa de design e estratégia localizada em São Francisco, escreveu no diário online da empresa [McC11] como eles integram os papeis de especialistas em UX ou usabilidade com o papel de Product Owner, através do papel de Product Stewardship, que se relaciona com o gerente de produto (Product Manager), de modo a equilibrar necessidades dos usuários e negócios da empresa, dessa forma, os dois papeis juntos formam o papel de Product Owner. U-Scrum, proposto por Singh, prescreve a criação de um Product Owner específico para aspectos de usabilidade, com a escrita de histórias de usuários que contemplam critérios de usabilidade [Sin08]. Em [Six11] declara-se que praticantes de UX são missionários, não ditadores, por isso, gastar mais tempo facilitando o trabalho de UX pela equipe inteira reduz problemas e libera os especialistas para dar enfoque sobre problemas de UX mais difíceis. Grosjean também afirma, em seu artigo, a necessidade de ser um facilitador e engajar pessoas (de negócios, desenvolvimento e usuários finais) em workshops colaborativos para design e avaliação do sistema [Gro10].

\section{Tempo do usuário é valioso}

Contexto: Em métodos ágeis todas as atividades são realizadas para um subconjunto de funcionalidades em cada iteração ou sprint. Logo, para as pesquisas de usuário é necessário alocar tempo para coleta de requisitos para as próximas iterações e avaliação das anteriores. Assim, em uma única visita do usuário utiliza-se o tempo para várias atividades. Geralmente, as atividades com os usuários e clientes são realizadas presencialmente e apenas por membros da equipe relacionados com as atividades de UX.

Problema: Pouco tempo para realização de testes de usabilidade e pesquisas de usuário. Principais forças envolvidas:

- Força 1: Atividades de UX são realizadas durante sprints ou iterações.

- Força 2: Sprints ou iterações são curtas para dividir cada encontro com o usuário em um tipo específico de atividade (avaliação, design ou pesquisa).

Solução: Cada encontro com usuários típicos é utilizado para várias atividades como testes de usabilidade do design desenvolvido na iteração anterior e pesquisa de usuário para definição de requisitos para próxima iteração.

Exemplos: Patton declara que a prática de "Aproveitar o tempo do usuário para múltiplas atividades" é uma das melhores práticas na integração de UX em ambiente com métodos ágeis, uma vez que, neste ambiente, há pouco tempo para dedicação a aprofundamento de pesquisas de usuários e avaliação [Pat08]. Em [Ent11], descreve-se a prática de incorporar uma variedade de 
técnicas rápidas para solicitar feedback de usuários finais em uma base regular, tais como curtos surveys e chamadas de feedback informais semanalmente. Six descreve a realização de recrutamento e agendamento de participantes, por meio da definição de datas e do tempo para o primeiro estudo, de acordo com o perfil de usuários [Six11]. Só após essa definição, inicia-se o recrutamento a partir de uma base de dados de possíveis participantes potenciais.

\section{Caminhos paralelos}

Contexto: Em comunidades ágeis que realizam pesquisas de UX ou usabilidade é normal existir uma equipe responsável por atividades relacionadas a UX, uma equipe responsável por atividades de desenvolvimento e líderes de equipe, como Product Owner e Scrum Master em Scrum, e Coach em XP, responsáveis, entre outras funções, por verificar se a comunicação entre as equipes está sendo eficiente. Nesse contexto, uma equipe alimenta a outra através da entrega dos resultados do seu trabalho em uma iteração. A equipe de UX compartilha os resultados de pesquisas com usuários, prototipação de novas telas e avaliação de interfaces, enquanto a equipe de desenvolvimento compartilha o código integrado com a interface entregue pela equipe de UX, de modo que testes de usabilidade sobre interfaces com código implementado possam ser realizados. Dessa forma, existem caminhos paralelos ocorrendo entre as equipes de UX e desenvolvimento, cada uma responsável por suas atividades, mas com a comunicação ocorrendo durante o ciclo. A maioria dos casos relatados de aplicação desse ciclo de desenvolvimento [SY07] ocorrem presencialmente, quando todos os membros da equipe trabalham no mesmo local.

Problema: Resolver fluxo de design em ciclos ágeis e confusão sobre entregas de design; conseguir finalizar trabalho de design em uma iteração ou sprint e validar designs. Principais forças envolvidas:

- Força 1: Realização de atividades de UX sincronizadas com funcionalidades em desenvolvimento.

- Força 2: Implementação de funcionalidades já definidas por pesquisa e design de UX e correção de funcionalidades baseada em avaliações.

Solução: Equipe de UX ou usabilidade trabalha em caminho paralelo sincronizado com o ciclo $\overline{\text { sprint }}$ de desenvolvimento.

Exemplos: Patton aponta a prática "Usar desenvolvimento de caminho paralelo para trabalhar na frente e seguir atrás" em sua lista de melhores práticas para integração de UX com métodos ágeis, que descreve a realização do trabalho de design, da equipe de UX ou usabilidade, sendo realizado na frente do desenvolvimento e a avaliação sendo realizada após a implementação [Pat08]. Tal descrição concorda com o ciclo de DCU ágil proposto por Sy [SY07]. Federoff sugere que as equipes de UX e desenvolvimento precisam trabalhar em paralelo [Fed08]. Nas melhores práticas descritas na revista User Experience Magazine de 2010, a prática Caminhos paralelos tem o objetivo de sincronizar as atividades de UX com os ciclos/sprints de desenvolvimento, onde a equipe de UX pode conduzir pesquisa de usuário um ou dois ciclos à frente da equipe de desenvolvimento e conduzir avaliações de usabilidade para a iteração anterior ou a atual [LRM10].

\section{$100 \%$ de compromisso UX}

Contexto: Tradicionalmente, as equipes de UX ou usabilidade são alocadas para atender vários projetos ao mesmo tempo, ou seja, não pertencem à equipe de um projeto em desenvolvimento e sim funcionam como consultoras de projetos. Em equipes ágeis, esse modo de realizar o trabalho de UX distanciava-se da ideia de ter uma equipe unida e sincronizada, diante da necessidade de realizar várias atividades de desenvolvimento e UX em cada iteração. Nesse contexto, a equipe de UX passou a perder dados importantes que surgem ou são atualizados durante uma iteração. Também o sentimento de equipe real não existe nesse tipo de organização, pois não há o convívio e comunicação diária que ocorrem em equipes. Além disso, os profissionais de UX tinham pouco tempo 
para se dedicar a cada projeto e realizar atividades de design. Por esses motivos, os especialistas em UX passaram a ser alocados apenas a um projeto, de modo a reforçar que todos os membros pertencem a mesma equipe e estão envolvidos integralmente com a qualidade do sistema. Dessa forma, os participantes de um projeto passam a trabalhar próximos fisicamente um do outro, de modo que problemas ou dúvidas possam facilmente ser solucionadas.

Problema: Equipe de UX sente-se fora do ciclo ou perdendo informações cruciais; sem tempo suficiente para design. Principais forças envolvidas:

- Força 1: Em métodos ágeis, o sentimento de equipe e convivência diária são importantes para reforçar a comunicação.

- Força 2: Equipes de UX podem atender vários projetos ao mesmo tempo, o que dificulta a comunicação diária com membros de cada um dos projetos acompanhados.

Solução: Praticantes são membros em tempo integral de uma única equipe ágil e não atribuídos a múltiplos produtos. Também é comum a utilização de design pareado como ocorre em programação pareada.

Exemplos: O artigo escrito por Sy na revista User Experience Magazine, com as melhores práticas na integração de UX e métodos ágeis, descreve a prática de $100 \%$ de compromisso UX como a participação em tempo integral de um praticante de UX em uma única equipe ágil. Também utilizam o design pareado, considerando mais do que um membro de UX realizando o design em conjunto [LRM10]. No relatório de Nielsen, ele descreve a prática "Queda do departamento de UX centralizado" como resultado de suas experiências, onde relata que todos os seus estudos de caso indicam que pessoas de UX devem ficar co-localizadas com desenvolvedores e outros membros da equipe de projeto, de modo que a equipe de UX seja considerada parte da equipe do projeto e não um departamento fora dele. Porém reforça que ter praticantes de UX distribuídos pelos projetos não significa que a empresa precisa abandonar os benefícios de um grupo centralizado ou especializado. Por exemplo, os praticantes de UX podem estar alocados em projetos individuais, mas ainda permitindo alguma coordenação de toda a empresa. Ou seja, ainda poderiam ser gerenciadas as atividades de UX por meio de especialistas da área que podem avaliar se o trabalho de UX foi bem empregado e não apenas relatar atividades para um gerente de desenvolvimento que tem pouco conhecimento em UX [Nie09]. Patton relata na prática "Profissionais de UX devem ser facilitadores de design" que profissionais de UX coletam e modelam informações a partir de vários grupos de pessoas, trabalhando com usuários e desenvolvedores para escrever cenários de usuários e criar esboços da interface de usuário. Além de sessões de design, também precisam comunicar os resultados de testes ou de visitas em campo. Ou seja, os membros da equipe precisam estar próximos, em contato frequente, para que seja possível a realização das atividades de forma colaborativa e a comunicação dos resultados para todos os membros [Pat08], o que sugere que o praticante de UX está alocado como membro da equipe de um projeto. Em [Six11], também se declara que praticantes de UX estão embutidos dentro da equipe. A abordagem ágil de entregas incrementais exige informações de design continuamente (grupos de design isolados não podem fazer isso tão bem quanto pessoas dentro da equipe).

\subsubsection{Especificar contexto de uso}

\section{Pouco design antecipado}

Contexto: O design antecipado que ocorre em pesquisas de UX não está de acordo com os valores de métodos ágeis. Nestes, considera-se que as mudanças nos requisitos são parte do processo de desenvolvimento e que portanto não é necessário gastar muito tempo com planejamento e design de requisitos que ainda estão distantes de serem implementados, pois eles podem mudar. Sendo assim, apenas as funcionalidades que serão implementadas na próxima iteração precisam ser detalhadas 
com maior profundidade, de modo que possam ser compreendidas, mas não todas as funcionalidades do sistema. Ou seja, todas as atividades necessárias para que o conjunto de funcionalidades a ser implementado em uma iteração seja bem compreendido por todos os membros da equipe são realizadas, mas apenas no momento em que as funcionalidades serão implementadas e não no início do projeto. Por isso a necessidade de pouco design antecipado ao desenvolvimento, para que apenas o trabalho necessário para uma iteração seja realizado, minimizando o trabalho que pode não ser utilizado porque mudanças nos requisitos ocorreram. Nesse contexto, participantes relacionados às atividades de UX realizam seu trabalho apenas sobre o conjunto de funcionalidades de uma iteração e compartilham seus resultados com a equipe de desenvolvimento, de acordo com o padrão Caminhos paralelos.

Problema: Tradicionalmente, as pesquisas de usuário são realizadas antes do início do desenvolvimento, o que é incompatível com valores de métodos ágeis. Principais forças envolvidas:

- Força 1: Em métodos ágeis, apenas as funcionalidades que serão implementadas na próxima iteração precisam ser detalhadas com maior profundidade.

- Força 2: Pesquisas de usuário e seu contexto e análises dos dados coletados que resultam em definições de requisitos e de design geralmente são realizadas antes do início do desenvolvimento em equipes de UX.

Solução: Realização de pesquisa com menor granularidade de detalhes, enfoque apenas sobre um conjunto de funcionalidades essencial para a próxima iteração, ou seja, quebra-se o trabalho de design em pedaços menores.

Exemplos: A revisão sistemática de Silva et al. levantou artigos [JA04, CL02, AMC09, FNB07] que mencionam que Grande Design antecipado (Big Design Upfront) não está de acordo com o contexto de métodos ágeis [SMMS11]. Williams e Ferguson sugerem o uso de cartões de histórias de usuários e a existência de ao menos dois papeis na equipe de especialistas em Design Centrado no Usuário: um pesquisador de DCU e um prototipador de DCU [WF07]. Cho menciona que menos tempo deve ser gasto com a criação de designs de alta fidelidade em isolamento e enfoque deve ser dado na definição de problemas e facilitação de soluções de forma colaborativa. Antes de começar o ciclo de sprint, no caso descrito por Cho o ciclo é composto de três semanas, a equipe de especialistas em UX prepara-se para a próxima sprint por meio da condução de sessões de definição de problemas e desenvolvimento de soluções, isto acontece na semana final da sprint anterior. Dessa forma, a equipe levanta uma lista de funcionalidades que requerem design de interface de usuário para o próximo sprint [Cho09]. Em artigo presente na revista User Experience Magazine, enfatiza-se a ideia de começar pequeno, prototipar mais e continuar testando, onde as autoras afirmam que na profissão de UX vem existindo um esforço por anos em mover-se mais para frente no ciclo de desenvolvimento e fazer mais prototipação e avaliação iterativa. O enfoque, segundo as autoras, deve ser "sobre quem, o que, e o que será, realizando design na frente e validando o protótipo atual" [LRM10]. Também reforça este padrão a prática descrita por Patton "Quebrar o trabalho de design em pedaços menores", pois esta tem como objetivo permitir que o trabalho de design seja dividido de modo a caber em iterações ou sprints ágeis [Pat08].

\section{Plano de contato de usuários}

Contexto: Realizar pesquisa com usuários reais depende de primeiro saber quem são os usuários típicos de um sistema e então encontrar usuários dispostos a participar de pesquisas, design e testes. Além disso, para que essas atividades sejam realizadas em cada iteração, não é possível pensar em quais usuários chamar no momento em que deveria ser realizada a atividade com eles. Por isso, tornou-se necessário ter um plano de contato de usuários, onde uma lista de usuários que atendam ao perfil do sistema, com seus dados de contato e possibilidades de participação é mantida atualizada, de modo que um breve planejamento de quais usuários convidar para as atividades e 
seu respectivo agendamento possam ser realizados, para o caso de pesquisas presenciais, antes que a atividade precise ser realizada. Esse planejamento precisa considerar não chamar sempre os mesmos participantes, para que os testes não fiquem viciados, mas também para não se tornar um incômodo para os usuários. Geralmente essas atividades de planejamemto são realizadas por membros relacionados às atividades de UX.

Problema: Não ser apto para encontrar usuários rápido o suficiente; não obter feedback cedo no processo; depender de beta-users; e design não ser avaliado. Principais forças envolvidas:

- Força 1: Necessidade de participação de usuários típicos em atividades de levantamento de requisitos, design e avaliação.

- Força 2: Conciliar a disponibilidade de usuários para participar de atividades de acordo com o planejamento de coleta de feedback com usuários típicos para pesquisa, design e avaliação do sistema em desenvolvimento.

Solução: Criar um canal de comunicação adiantado com usuários finais (e responsáveis) para fornecer suprimento estável de feedback.

Exemplos: Em [Ent11] é exposta a prática de planejar o feedback futuro de usuários durante o desenvolvimento, em uma base regular. Segundo os autores, é possível que o praticante de UX não saiba ainda exatamente o que será questionado em duas semanas para frente, pode ser feedback de um protótipo, ou uma sessão de perguntas e respostas com usuários típicos, mas é necessário agendar tempo com usuários em uma base regular para obter feedback que possa ser rapidamente levado de volta à equipe. Na lista de melhores práticas da revista User Experience também aparece o plano de contato de usuários como uma tarefa necessária desde o início do projeto. A ideia é agendar avaliações em uma base regular e testar o que estiver pronto na época [LRM10]. Também na prática "Agendar pesquisa de usuário contínua em um caminho separado do desenvolvimento" definida por Patton percebe-se mais uma vez a importância do uso dessa prática em ambientes ágeis. O autor ressalta que investigações sobre o usuário ocorrem em um caminho separado do desenvolvimento e geram compartilhamento dos resultados de forma leve com a equipe, como, por exemplo, em vez de documentos extensos, histórias em quadrinhos ou apresentações dos resultados [Pat08].

\subsubsection{Especificar requisitos}

\section{Histórias de usuários}

Contexto: As histórias de usuários utilizadas em métodos ágeis possuem a mesma função dos casos de uso, ou seja, capturar requisitos, porém não são iguais. A maior diferença está no nível de detalhes, pois devem fornecer apenas o suficiente para fazer uma estimativa do tempo que será necessário para implementar a história [Wel09a, Gro11, Gro09]. No momento de implementar de fato a história, os desenvolvedores recebem maiores detalhes diretamente do cliente. Idealmente, as histórias possuem de uma a três semanas, onde mais do que três indica que a história precisa ser quebrada em outras histórias e, menos do que uma, indica que pode combinar-se a uma ou mais histórias. Outra grande diferença entre histórias de usuários e documentos de requisitos, como casos de uso, é o enfoque apenas nas necessidades dos usuários, ao invés de detalhes técnicos como detalhes de uma tecnologia específica, ou de banco de dados, ou ainda de algoritmos. Em XP, as histórias de usuários são escritas pelos clientes, como requisitos que o sistema precisa realizar para eles. São similares a cenários de uso, mas não possuem apenas a descrição do funcionamento de uma interface de usuário. Possuem o formato de algo em torno de três sentenças de texto escritas pelo cliente em um cartão de história de usuário, na linguagem do cliente, sem termos técnicos, conforme Figura 5.8. As histórias de usuários servem de base para a criação de testes de aceitação, que podem ser descritos no verso do cartão ou ainda serem automatizados no ambiente de desenvolvimento. $\mathrm{O}$ objetivo é verificar se a história de usuário foi implementada corretamente. 
O enfoque da escrita de histórias de usuários em equipes ágeis está nas necessidades dos usuários, mas não em especificar interfaces de usuário. Porém quando integra-se atividades de UX e métodos ágeis, além de se inserir o ponto de vista de usuários reais do sistema e não apenas do cliente, que tem um foco maior em requisitos de negócio, também é comum incluir rascunhos de interfaces nos cartões de histórias de usuários, que são utilizados para melhor compreensão das ideias discutidas e na criação dos protótipos. Também as personas são utilizadas para melhor descrever o perfil do usuário presente em cada história e questões de usabilidade podem ser inseridas nos critérios de aceitação da história. Geralmente, a escrita de histórias de usuários envolve clientes e coach em XP, ou Product Owner e Scrum Master em Scrum e as reuniões para determinar as estimativas de tempo envolvem todos os membros da equipe. Quando usa-se as histórias de usuário em ambientes com UX, também envolve-se usuários reais.

Problema: Tradicionalmente, os requisitos de usabilidade seriam definidos em documentos detalhados contendo a análise de tarefas, personas, visão geral e cenários de uso, contudo, documentação extensa não está de acordo com valores de métodos ágeis. Principais forças envolvidas:

- Força 1: Em métodos ágeis, a documentação extensa e detalhada é vista como uma atividade que demanda muito tempo e que pode ficar desatualizada rapidamente devido às mudanças de requisitos.

- Força 2: Definição de requisitos com métodos de UX ou de usabilidade costumam definir em detalhes as necessidades dos usuários de acordo com os perfis de usuário levantados.

Solução: Inclusão de requisitos de usabilidade em histórias de usuários, definindo critérios de aceitação para cada história.

Exemplos: A Figura 5.8 ilustra um exemplo de história de usuário retirado do site blog.scrumhalf. com.br/2011/10/user-stories-o-que-sao-como-usar, que é mantido pela GPE, uma empresa incubada do Instituto Alberto Luiz Coimbra de Pós-Graduação e Pesquisa de Engenharia da Universidade Federal do Rio de Janeiro (Coppe/UFRJ).

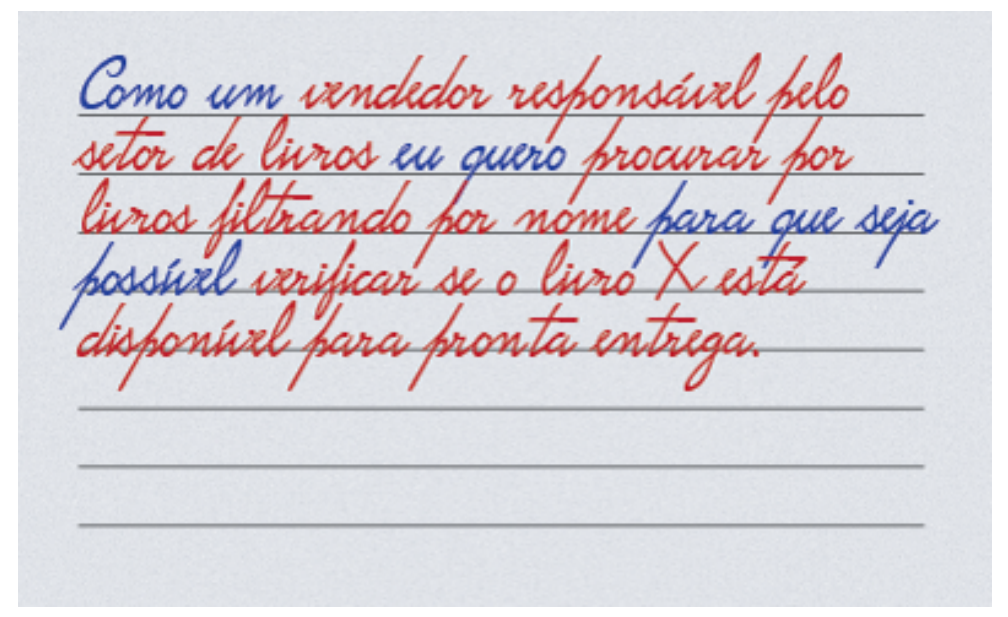

Figura 5.8: Um exemplo de cartão de história de usuário [Pri11].

A revisão sistemática de Silva et al. demonstra que diversas equipes ágeis ao integrar a preocupação com a usabilidade no desenvolvimento passam a também capturar requisitos de usabilidade para o projeto, definir critérios de aceitação e fornecer detalhes para a construção de protótipos, por meio das histórias de usuários [SMMS11]. Alguns autores afirmam que as histórias podem ser originadas a partir de cenários de usabilidade [BM10, LM07]. Outros ainda declaram que as histórias podem ser originadas a partir de testes de usabilidade com protótipos em papel [MA06]. A história também serve como insumo para a criação de protótipos [Hus08b, FSM08] e podem ser utilizadas como tarefas para testes de usabilidade com usuários reais [HES $\left.{ }^{+} 05\right]$, além de poderem 
ser alimentadas com os resultados de testes com usuários realizados no fim de cada sprint [FNB07]. Budwig et al. relatam que poderia existir um product backlog específico para aspectos de usabilidade [BJK09]. Hussain et al. declaram que estudos de usuários podem ser usados para desenvolver histórias de usuários [Hus09].

Sohaib e Khan relatam que histórias de usuários devem ser integradas com design baseado em cenário [SK10] e Jokela e Abrahamsson informam que atividades como Análise de Tarefas de usuários podem contribuir para o desenvolvimento de histórias de usuários [JA04]. Broschinsky e Baker declaram a integração de protótipos e histórias de usuários [BB08], enquanto Duchting et al. descrevem Product Backlog e histórias de usuários como os melhores lugares para registrar requisitos de usabilidade [DZN07]. Singh defende que histórias de usuários podem conter questões de usabilidade em seus critérios de aceitação [Sin08].

Alguns autores também defendem que protótipos de interfaces de usuário podem ser parte da definição da história de usuário e dos critérios de testes de aceitação [BHB04]. Hussain et al. descreve a importância de praticantes de UX serem treinados em escrita de histórias XP, relatando os problemas de usabilidade na forma de pontos principais, os quais então são convertidos em histórias de usuário rapidamente ao invés de um grande relatório de um teste de usabilidade formal [Hus09].

Dickinson, principal consultor da Consultoria Accolade, que tem como objetivo ajudar as organizações a melhorar o software que oferecem através de técnicas de desenvolvimento ágil e Kumana, líder de Experiência do Usuário e de propriedade de Produto da Isotrak Ltd, que trabalha para garantir que as abordagens ágeis de desenvolvimento de software continuem fundamentadas em uma compreensão dos objetivos, necessidades e desejos das pessoas reais, escreveram juntos um artigo intitulado "How User-Centered Design Can Put User Stories in Proper Context" [DK10]. Nesse artigo defendem que as histórias de usuários integradas com valores de DCU ajudam a definir melhor o contexto das histórias, pois definem uma história de usuário como um mecanismo "leve" para a coleta e verificação de requisitos de usuário em projetos ágeis, mas que infelizmente, é fácil perder o contexto de histórias e usando técnicas de DCU é possível evitar este problema.

DCU possui uma série de ferramentas e técnicas para realização de pesquisa de usuário e, segundo Dickinson e Kumana, a chave para integração de DCU com métodos ágeis é assegurar que os resultados da pesquisa de usuário são comunicados e entendidos de forma eficaz dentro de uma equipe ágil. Eles reforçam que não é necessário comunicar todos os resultados da investigação, mas apenas a essência do núcleo. Os autores aindam destacam que a essência pode ser resumida por meio da definição de Stephen P. Anderson: "É tudo sobre pessoas, suas atividades e o contexto de suas atividades" [And09]. Dickinson e Kumana então descrevem personas e cenários como sendo ferramentas de DCU que podem ser bem empregadas em ambientes ágeis, onde personas ajudam a comunicar pessoas e cenários ajudam a comunicar atividades e o contexto. Os autores também descrevem um acrônimo, definido por William Wake, que identifica um boa história de usuário, INVEST [Wak03]:

Independent

Negotiable

Valuable

Estimable

Small

Testable

Em [Six11], Pabini Gabriel-Petit, editor-chefe e colunista da revista UX Matters, arquiteto de UX diretor da BMC Software e diretor fundador da Interaction Design Association (IxDA), descreve a prática de criar documentação leve, onde sugere: "Definição de requisitos é uma parte integral de um processo de desenvolvimento ágil, e escrever histórias de usuários é uma maneira rápida e eficaz de capturar requisitos e estimar nível de esforço. 


\section{Mais colaboração, menos documentos}

Contexto: Mais colaboração e menos documentos referem-se a valores que já são bem difundidos em ambientes que utilizam métodos ágeis, porém ampliados para as atividades de UX ou usabilidade. Nesse contexto, o compartilhamento de resultados de pesquisa são informados oralmente e através de protótipos de baixa fidelidade, como desenhos feitos com papel e lápis, de modo a rapidamente comunicar uma ideia e validá-la. Também nesses casos, os protótipos de baixa e média fidelidade são usados como especificação junto com as histórias de usuários, que também seguem o mesmo valor de apenas o necessário para o entendimento. Com maior convívio e comunicação de todos os membros da equipe, sejam os relacionados às atividades de UX ou os de desenvolvimento, o conhecimento obtido com as pesquisas de usuário é disseminado por toda a equipe e problemas encontrados durante a implementação podem ser resolvidos mais rapidamente pela facilidade de resolver dúvidas e questões mal compreendidas. Uma grande vantagem é a melhor compreensão das tarefas de UX e desenvolvimento por profissionais de ambas as áreas.

Problema: Designs não compreensíveis; design à deriva durante implementação; equipe ágil não compreende atividades de UX. Principais forças envolvidas:

- Força 1: Resultados de pesquisas e avaliações precisam ser disseminados pela equipe o mais cedo possível no processo de desenvolvimento.

- Força 2: Descrições com maiores detalhes dos resultados obtidos com a pesquisa de UX ou usabilidade dependem de maior tempo com a produção de documentos.

Solução: Atualizações frequentes no design e no processo de design; comunicação contínua durante implementação e teste. Também algumas equipes utilizam profissionais de UX como facilitadores de design coletando informações entre os envolvidos, como usuários, clientes e desenvolvedores e compartilhando-as entre todos os membros do projeto.

Exemplos: Esta prática é descrita na lista de melhores práticas da revista UX Magazine para facilitar a compreensão das atividades de UX por todos os membros da equipe por meio de comunicação contínua entre todos os membros [LRM10]. Patton também descreve a prática "Profissionais de UX devem ser facilitadores de design", onde é necessário coletar informações a partir de vários grupos de pessoas, trabalhando com usuários e desenvolvedores, de modo a realizar as atividades de forma colaborativa e disseminando o conhecimento entre os envolvidos por meio de conversas informais e trabalho próximo [Pat08]. Nielsen descreve duas práticas para melhorar a colaboração entre os membros do projeto, "Porteiro" e "Pessoa-âncora" [Nie09]. O porteiro tem a função de acompanhar requisitos e comunicações entre equipes de UX e as outras equipes do projeto, para manter todos no caminho (mesmo quando caminhos são paralelos). Uma pessoa-âncora seria designada para cada comunicação de UX do projeto. Quando novos especialistas em UX são necessários em um projeto, eles paream com o âncora. O princípio do âncora também suporta comunicação cruzada a longo prazo entre equipes, quando pessoas-âncora são periodicamente alternadas. Six informa que praticantes de UX precisam adaptar suas entregas, pois quando se trabalha com toda a equipe, é possível responder questões diretamente aos interessados ao invés de escrever um guia de estilo, por exemplo. Também podem ser abordados os problemas imediatamente após um teste de usabilidade ao invés de escrever um relatório de 90 páginas. Sendo assim, menos tempo é gasto com documentação desnecessária, o que significa mais tempo para ajudar a fazer um produto melhor [Six11]. A autora também destaca que como os praticantes de UX estão mais envolvidos com tarefas fora da sua área imediata de especialidade, como desenvolvimento e testes, eles encontram novas formas de aplicar seu conhecimento de UX, o que também ajuda a fazer um produto melhor. Grosjean afirma que confiança e colaboração são as chaves e praticantes de UX devem ser co-locados com a equipe de desenvolvimento: artefatos visuais, storyboards, mockups e wireframes servem ao projeto e permitem que equipes de desenvolvimento e negócios construam a melhor experiência do usuário [Gro10]. 


\section{Tratar protótipo como especificação}

Contexto: Como parte da ideia descrita no padrão Mais colaboração, menos documentos, muitas equipes utilizam os protótipos como especificação, ao invés de extensos documentos, com o objetivo de trazer os requisitos dos usuários e clientes para a discussão, tão rápido quanto possível. Nesse contexto, os protótipos desenvolvidos são usados para rapidamente comunicar e validar ideias referentes aos requisitos de interfaces de usuários. Geralmente são produzidos pelos especialistas em UX e, juntamente com as histórias de usuários, compõem as principais fontes de especificação de requisitos do sistema.

Problema: Compartilhar os requisitos de interface, que atendem as necessidades dos usuários, de forma mais rápida do que com documentos de especificação de requisitos. Principais forças envolvidas:

- Força 1: Disseminar conhecimento sobre as necessidades do usuário, que precisam ser atendidas pelo sistema, de forma mais rápida e desde cedo no processo de desenvolvimento.

- Força 2: Necessidade de registro dos requisitos definidos e compartilhados com a equipe.

Solução: Utilizar protótipos para especificar requisitos de interface de usuário.

Exemplos: Patton define a prática "Tratar protótipo como especificação" [Pat08], como uma das melhores práticas para se integrar métodos ágeis e UX, porque é melhor discutir sobre protótipos do que sobre documentos extensos. Na revisão sistemática de Silva et al. também foi levantada a prototipação como meio para especificar requisitos [SMMS11]. Em [BB08], os protótipos de interface de usuário são usados para tornar os requisitos do cliente conhecidos dentro da discussão tão rápido quanto for possível e servir como um template para o desenvolvimento. Para [BLB08], os sketches (ou protótipos de baixa fidelidade) juntos com histórias de usuário podem ser usados como meios de revelar erros, informações temporais tais como sequência de tarefas, informações contextuais etc.

\subsubsection{Criar soluções de design}

\section{Prototipação}

Contexto: Os protótipos utilizados para comunicar e validar uma ideia geralmente são os de baixa fidelidade, que são rápidos de serem desenvolvidos e corrigidos. Para especificar o leiaute, equipes que contém especialistas em design de interface geram o protótipo que serve de base para a implementação. São usadas técnicas presenciais, como colocar protótipos de telas importantes para o sistema em quadros no ambiente de trabalho ou técnicas online como compartilhar acesso a versões do protótipo na Web. A principal diferença entre técnicas de prototipação tradicionais e as realizadas em ambientes com métodos ágeis caracteriza-se pelo fato de que os protótipos são criados sobre o subconjunto de funcionalidades de uma iteração e não para todo o sistema antes do início do desenvolvimento. Os protótipos de alta fidelidade são partes do sistema que está evoluindo a cada iteração, já com código funcional. Em uma iteração, a equipe de UX cria o design de interface e na próxima iteração a equipe de desenvolvedores implementa o código sobre o design projetado na iteração anterior.

Problema: Obter feedback do cliente e usuários sobre a interface tão cedo quanto possível. Principais forças envolvidas:

- Força 1: Necessidade de feedback de clientes e usuários sobre a interface.

- Força 2: Definir design de interface de acordo com as funcionalidades de uma iteração.

Solução: Realizar prototipação de baixa fidelidade nas fases iniciais do sistema. Quando o sistema passa a ser construído, é avaliado como protótipo de alta fidelidade que vai evoluindo conforme 
os requisitos das iterações vão sendo desenvolvidos.

Exemplos: A revisão sistemática de Silva et al. apontou a prototipação como uma prática muito comum em equipes ágeis que integram UX ou usabilidade [SMMS11]. Para vários autores, a prototipação ocorre nos estágios iniciais do desenvolvimento e é usada para avaliações de usabilidade tanto por inspeção quanto por teste com usuários [SK10, FSM08, MA06, HES ${ }^{+}$05, Det07, WF07, CSM06, Mil05]. Além disso, equipes de UX devem desenvolver protótipos de interface de usuário um sprint adiante da equipe de desenvolvimento. Para Chamberlain et al. e Williams e Ferguson, os protótipos evoluem para protótipos de alta fidelidade [CSM06, WF07] e para Hellmann et al. e Hussain et al. os protótipos podem ser derivados a partir de histórias de usuários [HHKM10, Hus08a]. Haikara aponta a construção de protótipos a partir de personas [Hai07] e Hussain também aponta o uso de protótipos em papel de baixa fidelidade e protótipos de alta fidelidade para realizar avaliações por inspeção e testes de usabilidade com o cliente [Hus09, Hus08b]. Patton define a prática "Prototipar em baixa fidelidade" [Pat08], informando que o protótipo só precisa ser bom o suficiente para entender, aprender, comunicar rapidamente, depois disso, pode ser jogado fora. São materiais consumíveis para o desenvolvimento ágil e não distribuíveis, ou seja, não são itens de entrega.

Six informa que uma equipe de UX que inclui desenvolvedores Web de interface, pode prototipar ou mesmo construir uma interface de usuário real da aplicação ao invés de escrever especificações de design de UX detalhadas [Six11]. Mas ressalta que, se o trabalho ocorre em uma equipe distribuída e não é possível criar protótipos, será necessário criar mais documentação de design detalhada. Porém, apenas o mínimo de documentação que com eficiência comunica o design e assegura uma implementação de alta qualidade é desejável.

\section{Estúdio de Design}

Contexto: Alguns trabalhos de UX precedem os estúdios de design, geralmente na forma de entrevistas de usuários e/ou observações para obtenção de requisitos. O resultado dessas investigações iniciais tornam-se arquitetura de informação ou mais objetivos de projeto. As informações das atividades iniciais são compartilhadas com a equipe.

No estúdio, cada esboço de design é apresentado pelo autor para a equipe, a qual pode envolver desenvolvedores e especialistas em UX. A equipe, então, tem um tempo para críticas. No fim do estúdio, um conceito de design é definido e desenvolvido. O design escolhido reflete as partes boas de ideias apresentadas durante o estúdio. Depois do estúdio, a equipe de experiência do usuário produz cenários da sessão colaborativa. Como o estúdio de design facilita o entendimento compartilhado de quais necessidades devem ser construídas, o trabalho de desenvolvimento pode prosseguir imediatamente [UW08]. Membros da equipe de desenvolvimento podem ser alocados para atividades de design de interface de usuário. Geralmente, as atividades de estúdio de design são realizadas presencialmente com membros reunidos em uma sala para criação de versões de design.

Problema: Possibilitar a criação de versões de design alternativas para o sistema, de modo a manter a inovação; fomentar o entendimento para a equipe inteira, construir somente o que é entendido e o que possui valor mais alto para os negócios e o usuário final. Principais forças envolvidas:

- Força 1: Possibilitar a proposta de soluções inovadoras.

- Força 2: Possibilitar a compreensão compartilhada das funcionalidades do sistema entre membros da equipe.

Solução: Participantes geram diversas versões de design alternativas para uma interface durante um tempo pré-determinado que, ao terminar, abre-se para discussão e seleção de um design para o sistema. 
Exemplos: Dubakov descreve a metodologia de Estúdio de design como uma forma simples e eficiente de realizar reuniões ágeis [Dub11]. O autor relata que existem várias variações para o estúdio de design, mas ele utilizou um conjunto simples que contém os seguintes cinco passos: (1) definir um problema; (2) rascunhar cinco ideias individualmente, sem exceder 5 minutos por ideia; (3) apresentar e categorizar as ideias para a equipe; (4) discutir pontos positivos e negativos das ideias; e (5) selecionar as ideias interessantes e criar duas versões para cada solução final. A Figura 5.9 apresenta os resultados de um estúdio de design.

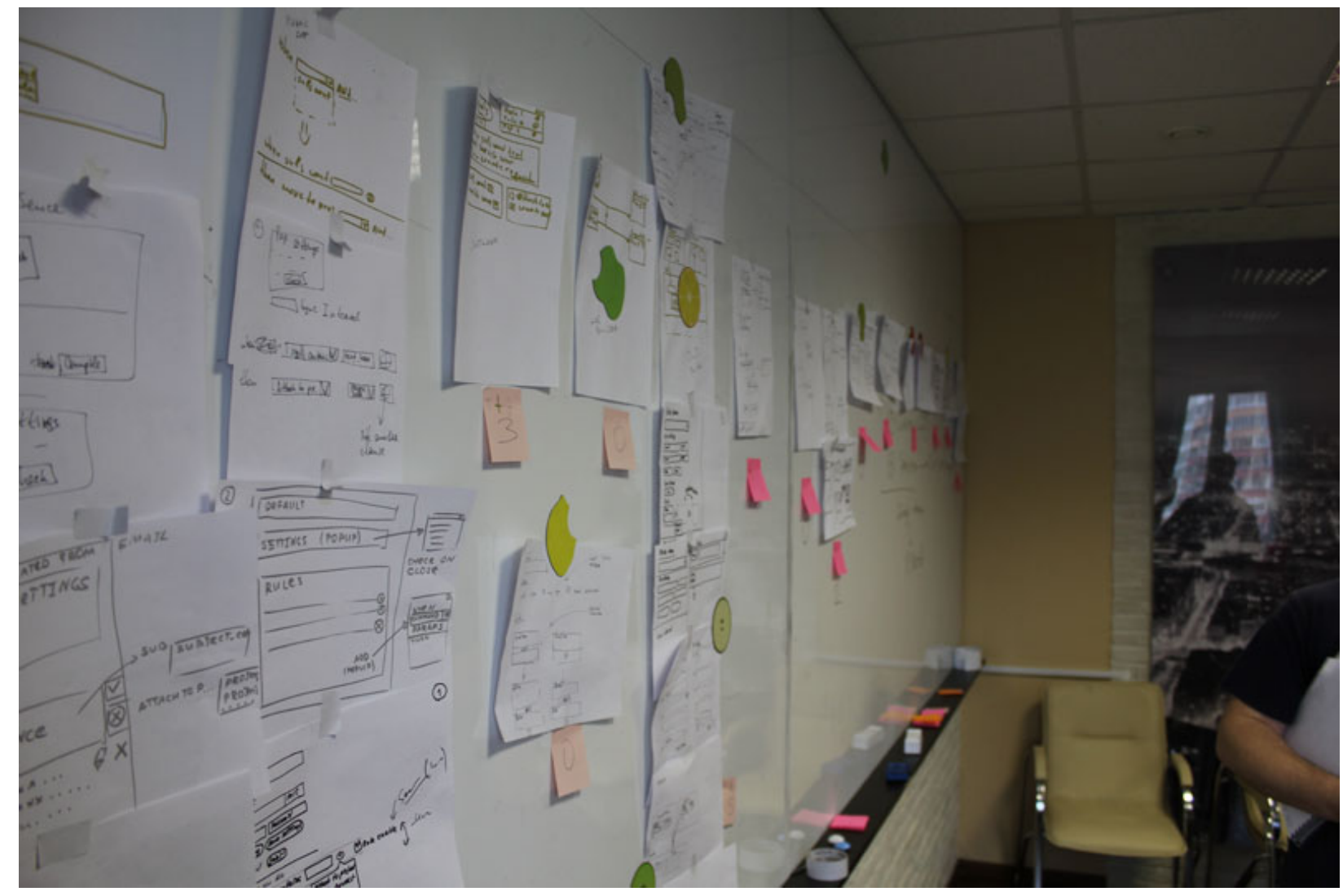

Figura 5.9: Lousa contendo ideias dos participantes do estúdio [Dub11].

Segundo [UW08], o estúdio de design possui quatro componentes principais: (1) Pesquisa: o estúdio de design é guiado pela pesquisa de usuário; (2) Design: também dito pré-trabalho, onde muitos projetos e ideias são gerados rapidamente; (3) Estúdio: uma oficina de um dia inteiro para avaliar alternativas, tomar decisões e consolidar um design e (4) Participantes: uma equipe de projetistas ou profissionais de UX que estão dispostos a aprender e crescer dentro do processo de design.

Evans e Gothelf descrevem em um artigo sobre estúdios de design e UX ágil que a saída de uma sessão de estúdio de design pode gerar muitas iterações sobre o design e que existem muitas variações do estúdio que podem ser empregadas com bons efeitos para espaços de problemas menores dentro de processos ágeis [EG11]. Os autores exemplificam que, em uma equipe Scrum, pode ser necessário explorar um espaço de problema mais específico, que é identificado durante o planejamento da iteração, antes de um sprint. Eles relatam também que não usam estúdios de design em sprints zero ou iteração zero, embora não vejam razão para não serem usadas. Eles reforçam ainda que resolvem problemas como equipes Scrum completas e trazem as fases de ideação, design e desenvolvimento mais próximas quanto possível do mesmo ponto inicial, de modo que os conceitos possam informar sessões de escritas de histórias e estimativas. Três atividades são importantes para organizar as sessões de estúdio: (1) Definição do problema e seu escopo; (2) seleção de quem será envolvido e (3) determinação de quais stakeholders são aptos para fornecer maior insight e direção. Geralmente, essas decisões envolvem o diretor de produto ou um gerente de produto e um designer de UX, que 
também decidem se existe ou não necessidade para um estúdio de design. Existem vários usos dos estúdios e os autores citam como exemplo: esforços de escopo maior, esforços de escopo médio e esforços de escopo menor. Os esforços de escopo maior, acontecem antes do início de um produto completamente novo, onde o primeiro dia tem o enfoque sobre várias técnicas de brainstorm, de modo a ajudar stakeholders e membros do projeto a explorar a natureza e escopo do projeto para gerar muitas ideias sobre o mercado potencial, a audiência e metas de negócio.

Para esforços de escopo médio, como no caso onde uma solução necessite somente de duas iterações para ser finalizada, um estúdio de design de meio-dia é sugerido por Evans e Gothelf para alcançar as seguintes metas primárias: (1) trabalhar colaborativamente para entender o espaço do problema; (2) permitir ideias a partir de várias perspectivas; (3) transformar ideias e hipóteses não declaradas em rascunhos que possam ser discutidos; (4) criar uma cultura de propriedade compartilhada; (5) gerar várias ideias em um prazo muito rápido; (6) permitir crítica aberta e honesta e (7) conseguir algum entendimento compartilhado de soluções potenciais. Para esforços de escopo menor, declaram que a experiência deles demonstrou que estúdios rápidos e pequenos de três horas podem ser usados para explorar um problema que a equipe Scrum irá enfrentar em sua próxima iteração. Imediatamente após, segue-se a escrita de histórias e definição de estimativas. Geralmente isso significa que a equipe pode realizar dois ciclos de prototipação de baixa fidelidade (esboços) e críticas, selecionar uma solução potencial e assim estimar o escopo.

\section{Design Colaborativo e Participativo}

Contexto: Semelhante ao estúdio de design, porém o design colaborativo envolve a contribuição de vários tipos de stakeholders, como membros da equipe de desenvolvimento, de UX e clientes, entre outros. Possui o objetivo de criar e observar novos processos de design. Já o design participativo tem como objetivo envolver os usuários finais ou usuários típicos durante o desenvolvimento, os quais são classificados de acordo com o perfil de uso do sistema em que se encaixam. O objetivo de ambos os tipos de design é colocar a perspectiva de cada um desses participantes no processo de design de interfaces, ou seja, cada um exibe a sua visão para solucionar um problema de design com base nas suas necessidades com o sistema e no seu entendimento. Assim como o estúdio de design, é uma atividade que favorece a inovação. Também possibilita que novos requisitos possam ser levantados durante as sessões. Por envolver usuários reais, é necessário utilizar o padrão Plano de contato de usuários para agendamento prévio. O envolvimento dos desenvolvedores é muito benéfico para a qualidade do sistema, interna e externa, além de possibilitar que todos os membros da equipe sejam envolvidos na fase de definição de requisitos. Também o design colaborativo contribui para a criação de uma visão compartilhada entre todos os participantes.

Problema: Possibilitar a criação de versões de design alternativas para o sistema, de modo a manter a inovação e entender a perspectiva de usuários e clientes, e compartilhar o entendimento entre os membros do projeto. Principais forças envolvidas:

- Força 1: Envolver usuários típicos e clientes no processo de design para coleta e avaliação de informações para o sistema.

- Força 2: Aproximar membros da equipe de desenvolvimento e de UX desde o início do processo de design e desenvolvimento, durante a realização de suas atividades, de modo a possibilitar uma visão compartilhada do funcionamento do sistema e seu contexto de uso.

Solução: Sessões para criação de versões de design de forma colaborativa, ou seja, participantes criam juntos cada design, mostrando sua visão a respeito das necessidades que devem ser atendidas pela interface de usuário, e de forma participativa, através do envolvimento de usuários reais do sistema.

Exemplos: Govella inclui o design colaborativo em sua lista de estratégias para experiência do usuário mais ágil, onde membros da equipe de design, juntos desenham, conversam e interagem para 
chegar a um consenso de design [Gov08]. Só necessita da documentação de detalhes que podem ser esquecidos, como o que acontece se existir um erro, mas todos entendem a visão geral, por terem trabalhado juntos.

Em [Bel11], o design colaborativo resume-se em deixar desenvolvedores fazerem parte do processo de ideação e designers fazerem parte do processo de desenvolvimento. Os desenvolvedores podem ajudar a encontrar boas soluções que são tecnicamente viáveis e a evitar falhas conceituais devido a limitações técnicas. Também Beltrame aponta alguns benefícios do envolvimento de desenvolvedores no processo de ideação, como: maior identificação com usuários, cliente e projeto, menor necessidade de transferência de conhecimento e maior aceitação, porque eles podem ajudar e contribuir. Os designers podem revisar o design, podem realizar coaching e design pareado e definir e verificar entregas de design. O autor declara como benefícios do envolvimento de designers, a garantia da qualidade do design, quando desenvolvedores podem ter um coach de design, pois menos refatoração ocorre devido a implementação de interface ruim. O autor também sugere possibilidades para envolvimento dos desenvolvedores desde cedo no processo de ideação, como assistir a criação do projeto e participar de grupos focais. Também sugere o envolvimento de desenvolvedores na criação de personas e definição de suas tarefas, tão bem quanto na definição da estrutura do projeto, como na priorização dos fluxos de trabalho, quando tarefas relevantes e custosas são avaliadas. Além de revisar e assistir sessões de testes dos protótipos e revisar design visual. Quanto as possibilidades para envolvimento de designers no processo de desenvolvimento, destacam-se a participação na definição de feito, história completa, onde leva-se em conta a visão de DCU e UX. No planejamento do sprint, ter um designer que revisa as histórias de usuário e na escrita de histórias de usuários, ter um designer participando e rotulando as histórias de usuários, tanto para quadros virtuais quanto físicos. Diariamente os designers participam, de modo a saberem o que está acontecendo e podendo ajudar com impedimentos, além de poderem revisar trabalhos feitos, configurarem e realizarem testes de usabilidade. Em resumo, Beltrame declara que DCU ágil tem a propriedade do design coletivo e que é necessário informar, envolver e motivar os participantes do projeto [Bel11].

Furnell define um guia passo-a-passo para facilitar oficinas de design colaborativo [Fur10]. Os passos são: (1) Reunião inicial, onde são expostas a agenda da oficina e quais processos serão utilizados, exibindo exemplos. Para a agenda da oficina, define-se tempo de duração, sobre o qual o autor sugere oficinas de $2 \times 2$ horas por dia; (2) Entender os objetivos e direções de negócios; (3) entender a jornada do cliente, entendendo a experiência do mundo real e o seu contexto; e (4) Projetar a experiência em conjunto, utilizando um design Sketchboard.

Tyne descreve design participativo em três tarefas principais: (1) rascunhar ideias; (2) apresentar ideias à equipe; e (3) criticar apresentação com base em soluções. O processo é repetido três vezes, cada ciclo aumenta a fidelidade dos esboços [Tyn11]. Em [Six11], Pabini sugere que "desenvolvimento ágil é fundamentalmente um processo colaborativo, então a partir de um ponto de partida de UX, o sucesso de um processo de desenvolvimento ágil depende da associação de uma equipe de produto ágil e desenvolvedores para trabalharem em colaboração próxima com profissionais de UX".

\subsubsection{Avaliar designs}

\section{Testes com usuários}

Contexto: Realizar testes com usuários é o núcleo de Design Centrado em Usuário, pois apenas podemos saber se as reais expectativas dos usuários são atendidas quando os assistimos enquanto utilizam o sistema sob teste. A ideia central é fornecer atividades para que o usuário realize no sistema, com o objetivo de avaliar se as tarefas são facilmente realizadas ou se eles encontram dificuldades para encontrar o caminho certo, ou mesmo, se não conseguem realizar a tarefa solicitada. O protocolo "Pense em voz alta" tem como objetivo pedir ao usuário que vá falando em voz alta o que ele pretende fazer para realizar a tarefa, o que ele está pensando sobre a interface e o que ele pensou sobre o caminho que realizou para cumprir determinada tarefa. O objetivo é obter a impressão espontânea do usuário enquanto está utilizando o sistema e unir à análise dos resultados de cumprimento da tarefa (conseguiu realizar do modo esperado, conseguiu realizar mas de modo 
alternativo, demorou muito tempo para encontrar o caminho certo, mas conseguiu realizar ou não conseguiu realizar). Todos esses dados, ajudam a perceber problemas de usabilidade no sistema, que são identificados pelos usuários típicos, porque eles trazem para a interação com o sistema, suas expectativas de acordo com o conhecimento que possuem. Logo, problemas que podem não ser perceptíveis para desenvolvedores, podem ser percebidos facilmente por usuários específicos de uma determinada área. O teste com usuários reais do sistema é considerado por especialistas em usabilidade, a melhor forma de verificar se as reais necessidades dos usuários do sistema são atendidas. Geralmente, em equipes ágeis, o teste com usuários é realizado com o cliente do projeto e envolve especialistas em usabilidade na condução dos testes. Os resultados obtidos com a análise dos testes são compartilhados com a equipe. Quando usuários reais são envolvidos, também participam especialistas em usabilidade como mediadores do teste. Contudo, existem relatos de projetos que envolveram demais membros da equipe como observadores do teste e notaram que existiram ganhos na percepção dos desenvolvedores ao assistirem como os usuários reais entendem o sistema. Os testes com usuários em equipes ágeis são realizados, em sua maioria, de modo presencial, embora existam relatos de testes remotos realizados com sucesso. Geralmente, os resultados do teste com usuários são corrigidos pelos desenvolvedores no próximo sprint.

Problema: Avaliar um sistema com seus usuários reais. Principais forças envolvidas:

- Força 1: Avaliar o sistema com usuários reais e desde cedo no processo de desenvolvimento.

- Força 2: Conciliar testes de usabilidade de acordo com as funcionalidades desenvolvidas em uma iteração ou sprint ágil.

Solução: Aplicação de testes de usabilidade utilizando o protocolo "Pense em voz alta".

Exemplos: Em [Ent11] é relatado que quando se conduz testes com usuários como parte de um processo ágil, os testes devem ocorrer antes ou durante o desenvolvimento e devem empregar tarefas de usuários que levam em conta a "grande figura" mais do que o escopo limitado da próxima release. Afirmam também que outro aspecto único de testes com usuários dentro de ambientes ágeis está em assegurar que as mudanças recomendadas a partir de estudos de usuários encontrem sua solução em uma release apropriada. Isto pode significar o planejamento de uma release para vários meses no futuro. Os autores ainda reforçam que testes com usuários ainda devem absolutamente serem conduzidos e não se deve somente resolver problemas no próximo ciclo de desenvolvimento só porque os ciclos de desenvolvimento são mais rápidos do que se pode esperar por feedback pós-entrega. Frequentemente a equipe de desenvolvimento realiza mudanças em características e funcionalidades. Também feedback em campo ou dados de Web analytics podem sugerir onde existem problemas, mas a maioria das vezes essas fontes de dados sozinhas não dizem por que usuários estão se comportando de uma certa maneira ou qual deve ser a solução de design certa.

Na revisão sistemática de Silva et al. [SMMS11] foram encontrados vários relatos de uso de testes com usuários com o principal objetivo de refinar o protótipo de interface de usuário para a próxima iteração [MA06, LM07, FSM08, OF08, Hus08b, HES ${ }^{+}$05, WF07, Fed08]. Najafi e Toyoshiba e Wolkerstorfer recomendam a execução de testes com usuários sempre que possível [NT08, WTS ${ }^{+} 08$ ], mas Duchting et al. declara que testes com usuários devem ser realizados durante as Sprint Reviews [DZN07]. Najafi e Toyoshiba também informam que realizam testes com o cliente [NT08]. Lee e McCrickard e Benigni et al. usam os testes com usuários para validar a interface com usuário [LM07, BGPK10] e Illmensee e Muff [IM09] conduzem testes de usabilidade de forma leve e não dentro de um laboratório de usabilidade.

Ainda na mesma revisão sistemática, relata-se artigos que realizam testes com usuários sobre protótipos em papel [MA06, LM07, FSM08, OF08, Hus08b, HES $\left.{ }^{+} 05\right]$, enquanto que outros artigos realizam testes com usuários sobre software funcionando [LM07, DZN07, BGPK10, SK10, FNB07, Det07, Kan03]. Holzinger et al. relata o uso do método Pensando em voz alta [HES $\left.{ }^{+} 05\right]$ e Obendorf e Finckem usam cenários para guiar o teste com usuários [OF08]. Belchev e Baker relatam o uso de testes de usabilidade leves, que consistem da captura de telas e movimentos de mouse, o uso do 
método Pensando em voz alta e registro dos comentários dos usuários [BB09]. Benigni et al. e Kane afirmam que testes de usabilidade devem ser integrados em testes de aceitação [BGPK10, Kan03] e Detweiler sugere a realização de testes com usuários remotos no fim da release, porque acredita que código gerado dentro de uma iteração é muito instável para realizar testes com usuários [Det07]. Beyer et al. esclarece que a interface de usuário é testada com usuários usando papel, com protótipos de baixa fidelidade (esboços) e entrevistas, porque histórias de usuários são definições bastante refinadas de funcionalidades do sistema e elas podem ser cobertas em um único teste com protótipo em papel [BHB04]. Também sugerem testar com uma interface de usuário mais detalhada se tiver tempo e recursos.

\section{Avaliação por Inspeção}

Contexto: A avaliação por inspeção é realizada por especialistas em usabilidade que utilizam cenários, regras ou heurísticas de usabilidade para averiguar se a interface de usuário sob teste encontra-se adequada às regras ou caminhos esperados para os cenários. Geralmente, é realizada por dois ou três especialistas, onde cada um faz a sua análise individual e depois discutem juntos o que foi encontrado para consolidar os resultados. O principal objetivo da avaliação por inspeção é avaliar a interface mesmo em fases iniciais do sistema, sem o envolvimento de usuários. Dessa forma, realiza-se testes com usuários em interfaces já avaliadas por avaliações internas, sem expor, idealmente, problemas graves aos usuários reais do produto. Os especialistas compartilham os resultados com a equipe de desenvolvimento, para que os problemas encontrados sejam corrigidos. Algumas equipes relatam o envolvimento de desenvolvedores e nesse caso descrevem como positiva tal participação, pois facilita o compartilhamento do conhecimento de usabilidade com a equipe. Também as reuniões para consolidação dos resultados encontrados por cada análise individual são realizadas presencialmente na maioria das vezes, e, geralmente os problemas encontrados na avaliação por inspeção são corrigidos pelos desenvolvedores na mesma iteração ou sprint.

Problema: Realizar avaliações de usabilidade sem o envolvimento de usuários. Principais forças envolvidas:

- Força 1: Avaliação de cenários de uso do sistema por meio da interface de usuário desde cedo e frequentemente durante o desenvolvimento.

- Força 2: Não expor problemas graves a usuários reais.

Solução: Inspecionar interfaces de usuário, de protótipos de baixa ou alta fidelidade, por meio de cenários, regras ou heurísticas de usabilidade.

Exemplos: Assim como ocorre com os testes com usuários, na revisão sistemática de Silva et al. [SMMS11], também levantou-se como objetivo da avaliação por inspeção o refinamento da interface de usuário para a próxima iteração, conforme relatado em [WF07, FSM08, Hus08b, UW08, Mil05], mas também é apontada a validação de interfaces de usuário [Det07, WTS ${ }^{+}$08, SM08, NT08, BGPK10]. Duchting et al. sugere que as avaliações por inspeção podem ser realizadas durante as Sprint Reviews [DZN07] e Obendorf e Finck declaram que é possível utilizar cenários para guiar a avaliação por inspeção de protótipos em papel [OF08]. Vários autores declaram que as inspeções podem ser realizadas sobre protótipos em papel [WF07, FSM08, Hus08b, UW08, Mil05] ou sobre interfaces de usuário já implementadas [Det07, $\mathrm{WTS}^{+}$08, SM08, NT08, BGPK10] com o objetivo de validação, ou ainda, sobre protótipos interativos [Fed08]. Benigni et al. e Kane apontaram claramente o uso do método de avaliação heurística para avaliação por inspeção [BGPK10, Kan03]. Hussain et al. também sugerem que avaliações por inspeção sobre protótipos de baixa e alta fidelidade podem ajudar a escrever histórias relacionadas a interface de usuário [Hus09]. Albisetti comenta que desenvolvedores podem fazer revisões de interfaces de usuário e declara que, em sua experiência, esse envolvimento muda a maneira que os desenvolvedores enxergam o trabalho de DCU, pois mudam a perspectiva focada no código para ver o que está sendo usado pelas pessoas [Alb10]. 


\section{Método RITE}

Contexto: RITE (Rapid Iterative Testing and Evaluation) enfatiza mudanças e verificações da eficácia dessas mudanças de forma rápida. Suas metas são identificar e resolver quantos problemas forem possíveis e verificar a eficácia das soluções no menor tempo possível, ou seja, testes de usabilidade e correção mais rápida dos erros encontrados. Geralmente, é realizado pelos especialistas em UX ou usabilidade, e seus resultados são passados para correção dos demais membros da equipe.

Problema: Sem tempo para iterações de design e validação de soluções; poucos testes de usabilidade. Principais forças envolvidas:

- Força 1: Receber feedback das correções o mais perto possível da aplicação dos testes.

- Força 2: Diminuir a distância entre descoberta de problemas de usabilidade e a correção dos mesmos no sistema.

Solução: Identificar e resolver problemas encontrados por meio de testes com usuários típicos do sistema e verificar a eficácia das soluções no menor tempo possível.

Exemplos: Esta prática está na lista de melhores práticas da revista UX Magazine com o enfoque em enfatizar mudanças e verificações da eficácia dessas mudanças rapidamente [LRM10]. Para Patton, usa-se RITE para iterar a interface de usuário antes do desenvolvimento [Pat08].

Wixon et al. descrevem a essência do método RITE como sendo as melhorias rápidas e a criação de um ambiente colaborativo [WMF07]. Informam que o método é parecido com um teste de usabilidade tradicional, mas a principal diferença é que as mudanças ocorrem tão logo um problema seja identificado. Também, na sequência, a interface corrigida é testada com usuários.

Em [Leg08] define-se RITE como uma variação dos testes de usabilidade tradicionais que foi documentado por pesquisadores da Microsoft em 2002, sendo creditado a Medlock. Em suma, testase um design com cinco usuários no primeiro dia; no segundo dia, melhora-se o design baseado no feedback; testa-se de novo no terceiro dia; itera-se no quarto dia; e então testa-se o design final no quinto dia com oito usuários. Os autores declaram ainda que RITE não é sempre apropriado, por exemplo, quando existem muitas tarefas ou se o design está bem resolvido, mas sempre que possível acreditam ser altamente recomendável, porque promovem colaboração na equipe, satisfação do cliente e economia de tempo.

Douglass e Smith descrevem esta metodologia como sendo primariamente qualitativa, exploratória e conceitual [DS10]. É mais apropriada para coleta de requisitos cedo e fases de design de produção onde wireframes iniciais podem ser usados para validar arquitetura de informação e obter feedback sobre a funcionalidade proposta. Os autores descrevem como visão geral do RITE, a utilização de um protótipo clicável (geralmente um PDF), que é criado pela equipe de UX. Então, os participantes são recrutados para realizar tarefas representativas e a equipe de UX obtém feedback qualitativo de usuário (ações + comentários). O protótipo é atualizado de um a dois dias, baseado no feedback e no conhecimento dos especialistas da equipe de UX. A nova versão do protótipo é testada com os participantes nos próximos dias. As principais vantagens na utilização do método decorrem de facilmente modificar os protótipos e obter feedback rápido.

\section{Testes de aceitação}

Contexto: Testes de aceitação são comuns na comunidade de métodos ágeis, para avaliar com o cliente se o sistema em desenvolvimento cumpre as necessidades por ele desejadas. Em ambientes ágeis que integram métodos de usabilidade, os testes de aceitação incluem a validação não apenas de clientes, mas também de usuários típicos do sistema. A escrita dos testes envolvem usuários e clientes e é realizada por meio de linguagem natural, que é tranformada em código automaticamente testado pelas ferramentas de desenvolvimento. Sendo assim, praticantes de UX, clientes, usuários e demais membros da equipe conseguem escrever os testes mesmo sem conhecimento técnico de programação, seguindo um formato padrão, o que possibilita que os arquivos descritos em liguagem 
natural sejam inseridos no ambiente de desenvolvimento. Ao executar os testes automáticos, a partir da prática de Test Driven Development (TDD), um relatório é gerado exibindo o status dos testes definidos. No caso de um teste recém descrito, este será exibido como pendente, indicando que ainda não foi implementado código para tratamento deste teste. Por esse motivo, apenas quando um desenvolvedor do sistema implementar o código que resolva esse teste de aceitação, o relatório informará que o teste foi desenvolvido e se a característica em teste foi corretamente implementada no sistema, caso contrário, o status do teste aparecerá no relatório com falha, indicando que o sistema ainda não atende ao teste definido. Por exibir um relatório com o status de todos os testes de aceitação do sistema, essa prática ajuda a validar as necessidades dos usuários e cria uma documentação atualizada de tudo que o sistema faz, quais funcionalidades já possuem testes e se esses testes são executados com sucesso.

Problema: Manter documentação atualizada em ambientes com métodos ágeis e validar com clientes e usuários típicos se suas necessidades estão sendo cumpridas pelo sistema. Principais forças envolvidas:

- Força 1: Manter documentação atualizada de necessidades dos usuários que foram implementadas.

- Força 2: Facilitar a validação do sistema com clientes e usuários típicos.

Solução: Criação de testes de aceitação automáticos, aproveitando a prática de TDD já existente em métodos ágeis. Os testes são criados com a participação de clientes e/ou usuários típicos, por meio de um formato padrão definido em linguagem natural, de modo que qualquer pessoa não técnica seja capaz de descrever suas necessidades.

Exemplos: Dyba et al. [TTB10] descrevem a prática de testes de aceitação automáticos como uma boa prática para validar design de interface de usuário.

A comunidade ágil abraçou a importância dos testes de aceitação, tendo construído arcabouços como Fit (Framework for Integrated Test), fit.c2.com, e JBehave jbehave.org, para ajudar a automatizá-los. Os testes automatizados são executados frequentemente, ao menos diariamente, se não várias vezes por dia. Testes manuais com usuários, por outro lado, são tipicamente feitos uma iteração atrás. No fim de uma iteração, muitas equipes ágeis implantam o sistema funcionando em um ambiente de teste/QA (Quality assurance) onde testes do sistema e com usuários são realizados. A equipe continua desenvolvendo a versão $\mathrm{N}+1$ do sistema, enquanto obtém relatórios de defeitos pertencentes à versão N. Relatórios de defeitos são tratados como qualquer outro requisito: eles são estimados, priorizados, e colocados em uma lista de requisitos para serem tratados no futuro [Amb09].

Segundo Rice [Ric09], várias definições tem sido aplicadas para testes de aceitação de usuários ou User Acceptance Testing (UAT). Seu sucesso em validar que um sistema ou aplicação está pronto para uso por usuários típicos, depende de como é definida essa fase de teste. Os autores declaram que não se deve tratar esses testes apenas como testes funcionais baseados em requisitos de usuários, pois são perdidos os mesmos elementos que foram perdidos na definição dos requisitos, e também não se deve tratá-los como testes ágeis automatizados, pois perde-se a avaliação "em mãos" dos usuários reais, para determinar como a aplicação realmente reúne as suas necessidades. O autor reforça ainda que não está dizendo que se deve usar a sua definição de UAT, mas sim que existe uma variedade de visões de UAT que podem ou não reunir suas necessidades e que para fazer o melhor para cada caso, se deve estar certo de conhecer as diferenças nas formas que UAT é definido. Rice sugere que quem deve realizar UAT são os usuários reais, sugerindo que usuários reais atuais e futuros façam o planejamento, testes e avaliação para aceitação. Ele declara que algumas pessoas preferem ter testadores com o papel de usuários, outros ainda possuem uma equipe de UAT composta de usuários primários que realizam os testes. Ainda em outras organizações, UAT pode ser realizado por analistas de negócios, mas Rice reforça que gosta de ter usuários reais realizando UAT porque: "(1) eles usarão o sistema eventualmente de qualquer jeito; (2) eles conhecem as maneiras atuais 
de realizar suas tarefas e portanto podem dizer quando alguma coisa não funciona bem para eles; e (3) eles sabem o que esperam em termos de características e qualidade do sistema" [Ric09].

\subsection{Notas do Capítulo}

Neste capítulo foram apresentadas as principais características de comunidades de métodos ágeis, bem como seus valores princípios e práticas. Na sequência, são descritos os padrões de uso de práticas de usabilidade utilizados na comunidade de métodos ágeis seguindo o mesmo formatopadrão utilizado no capítulo anterior: contexto, problema, solução e exemplos. Finaliza-se a parte conceitual que pretendia trazer o estado da arte das práticas de usabilidade das comunidades de métodos ágeis e de software livre. O próximo capítulo apresenta como algumas das práticas apresentadas neste e nos capítulos anteriores foram aplicadas em projetos do Centro de Competência em Software Livre do IME-USP. 


\section{Capítulo 6}

\section{Pesquisas qualitativas}

Para melhor entendimento da aplicação de práticas de usabilidade em ambientes de desenvolvimento de software livre, foram realizadas pesquisas qualitativas em projetos do Centro de Competência em Software Livre do IME-USP. Os projetos utilizavam métodos ágeis e portanto a exploração de práticas de usabilidade ágil também foi possível.

O projeto Arquigrafia-Brasil foi utilizado como pesquisa-ação de práticas de usabilidade durante o desenvolvimento de um software livre. As práticas aplicadas durante o projeto eram analisadas após sua aplicação, de modo a refletir sobre melhorias a serem realizadas no próximo ciclo de pesquisa e desenvolvimento.

O projeto Mezuro foi utilizado como estudo de caso sobre práticas de usabilidade em ambiente que utiliza Programação Extrema (XP) para desenvolvimento de software livre. Nos projetos Borboleta, Balcão de Dúvidas, CogrOO e AgilCoop foram aplicados métodos de usabilidade pontuais durante o desenvolvimento dos sistemas ou avaliações somativas para testes de usabilidade finais do software.

\subsection{Pesquisa-ação no projeto Arquigrafia-Brasil}

O projeto Arquigrafia-Brasil (ccsl.ime.usp.br/project/arquigrafia) foi utilizado como pesquisaação, definida na Seção 2.3.1, de práticas de usabilidade em desenvolvimento de software livre que utiliza uma versão híbrida dos métodos ágeis Scrum e Programação Extrema (XP), que foram descritos no Capítulo 5, nas Seções 5.1 .1 e 5.1.2, respectivamente.

O projeto consiste na criação de uma rede social na Web 2.0 denominada Arquigrafia-Brasil (arquigrafia.org.br), a qual está concentrada sobre imagens digitais da arquitetura brasileira, possibilitando, assim, a construção colaborativa de um acervo específico de imagens, ainda inexistente. O projeto se pauta pelo movimento internacional de Acesso Aberto (OA) a seu conteúdo e seu desenvolvimento envolve uma equipe multidisciplinar de pesquisadores da FAU-USP, IME-USP e ECA-USP para concepção, construção, monitoramento e aperfeiçoamento permanente da rede na Web 2.0. Sobre este acervo digital georeferenciado e regido pelo Creative Commons quanto às licenças de direitos autorais, a equipe de pesquisadores desenvolve uma investigação sobre como a construção do conhecimento individual se relaciona com a construção do conhecimento coletivo, compartilhando subjetividades sobre experiências interativas e comunicativas relativas a um acervo coletivo online de imagens digitais da arquitetura brasileira. Dessa forma, o principal objetivo do projeto Arquigrafia é ampliar a cultura visual arquitetônica, promovendo maior interação entre estudantes de arquitetura, professores, profissionais da área e, numa instância mais ampla, entre todos os interessados no tema.

O projeto Arquigrafia-Brasil, conforme descrito por Rozestraten et al. (FAU-USP) [Roz10] pretende complementar o esforço de digitalização e livre acesso ao conjunto de slides da Biblioteca da FAU-USP, o maior acervo de imagens fotográficas de arquitetura da América Latina, com cerca de 82 mil fotografias, sendo que destas 38.429 já estão digitalizadas. Da mesma forma que esse acervo físico foi constituído coletivamente ao longo das décadas de 1960 a 1980, por meio de fotografias 
cedidas por alunos, professores e colaboradores, o projeto Arquigrafia propõe a construção coletiva e colaborativa de um novo acervo fotográfico digital. A partir desse acervo espera-se o estabelecimento de comunidades e conexões sociais para o estudo iconográfico da arquitetura brasileira. Até este momento, o projeto tem se concentrado em imagens fotográficas, porém, em um próximo passo, serão incorporados desenhos e vídeos.

O Arquigrafia-Brasil oferece a todos os interessados no assunto, um ambiente Web no qual é possível construir coletivamente um acervo iconográfico digital da arquitetura brasileira e interagir para discutir e estudar esse acervo. Nessa rede é possível navegar sobre conjuntos temáticos de imagens de arquiteturas de diferentes períodos históricos e contextos geográficos do Brasil e interpretar cada imagem quanto às palavras-chave (tags) que a identificam. Os componentes de software do arcabouço Groupware Workbench definido por Gerosa (IME-USP) [Ger06] encapsulam as funcionalidades colaborativas, como avaliação, comentários, formação de comunidades, tagcloud etc., formando a base para a construção da rede social.

Em meados de março de 2010, foi definido que seriam aplicadas práticas de usabilidade durante o desenvolvimento do sistema e seria analisado como ocorreu a aplicação no contexto do projeto, que utiliza uma abordagem híbrida dos métodos ágeis Scrum e XP. O processo de usabilidade definido por Martinez (ECA-USP) [Mar02], exibido na Figura 6.1, foi utilizado como base para os métodos de usabilidade aplicados no sistema. Inicialmente pensou-se em aplicar práticas mais tradicionais de usabilidade no primeiro ciclo e somente depois adaptá-las, com base nas práticas de usabilidade ágil. Sendo assim, os ciclos iniciais apresentam métodos mais tradicionais da engenharia de usabilidade, enquanto que os ciclos posteriores apresentam práticas de usabilidade das comunidades de métodos ágeis. Contudo, em todos os ciclos foi considerado que se tratava de um contexto de desenvolvimento de software livre, levando-se em consideração todas as características específicas desse tipo de ambiente. As adaptações para práticas ágeis ocorreram de acordo com os ciclos da pesquisa onde, para cada ciclo, a etapa de reflexão serviria para a definição de adaptações para ciclos futuros. Os ciclos da pesquisa-ação seguiram a definição descrita na Seção 2.3.1.

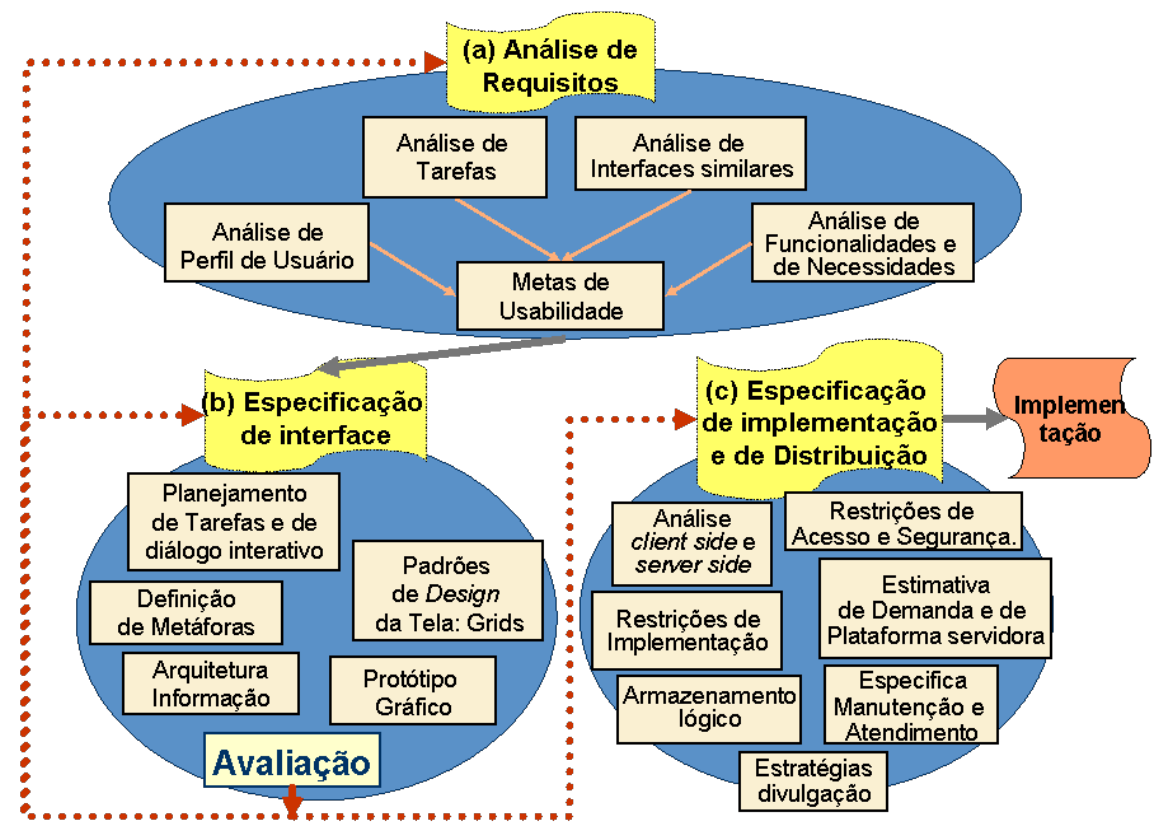

Figura 6.1: Método de usabilidade proposto por Martinez [Mar02].

Quando a pesquisa-ação de práticas de usabilidade começou no projeto Arquigrafia, um protótipo inicial das principais telas havia sido definido e apresentado para clientes e membros da equipe. Porém, ainda não haviam sido realizadas avaliações do protótipo e dos requisitos com usuários típicos, além dos próprios clientes, pois em métodos ágeis as validações ocorrem, geralmente, apenas com os clientes do sistema. A equipe de desenvolvimento trabalhava de forma distribuída, reunindo-se semanalmente para acompanhamento presencial do projeto, no qual os clientes parti- 
cipavam sempre que possível, contribuindo com percepções sobre o protótipo e as funcionalidades a serem desenvolvidas.

Os alunos de pós graduação do IME-USP, orientados por Gerosa, desenvolvendo pesquisas sobre inteligência coletiva, sistemas colaborativos, entre outros, utilizaram o projeto como estudo de caso para suas pesquisas, enquanto compunham a equipe de desenvolvedores. Inicialmente, um membro da equipe de desenvolvimento teve o papel de Web Designer e criou as interfaces com a ajuda dos demais desenvolvedores. Os requisitos inicialmente coletados foram levantados com base em reuniões com os clientes do projeto e o feedback dos clientes era obtido através da apresentação do protótipo da interface do sistema.

Também uma equipe da Universidade Federal do Espírito Santo (UFES) estava desenvolvendo uma versão móvel do sistema de modo que, entre outras características, os usuários pudessem compartilhar imagens de arquitetura em tempo real, por meio de celulares ou smartphones, durante seus passeios ou viagens.

A pesquisa-ação realizada durante o desenvolvimento do projeto Arquigrafia-Brasil possibilitou a realização de seis ciclos iterativos, cada um deles será explicado nas próximas subseções:

1. Aplicação de métodos de usabilidade tradicionais;

2. Primeiro teste de usabilidade;

3. Workshop de usabilidade e Card Sorting;

4. Redesign de interfaces e testes de usabilidade remotos;

5. Avaliação e nova coleta de requisitos; e

6. Integração do HTML com o código.

\subsubsection{Ciclo 1: Aplicação de métodos de usabilidade tradicionais}

O ciclo 1 foi marcado pela aplicação de métodos de usabilidade mais tradicionais. Porém, devido a consideração do contexto de desenvolvimento do projeto, algumas adaptações foram necessárias. As adaptações ocorreram sobre o tipo de projeto, o ambiente em que o sistema estava sendo desenvolvido e o estágio atual em que se encontrava o desenvolvimento, porém ainda utilizando métodos de usabilidade tradicionais e não práticas ágeis. Os seguintes métodos de usabilidade foram aplicados:

- análise do perfil de usuário: aplicação de questionário online; realização de três sessões de grupos focais; definição de personas;

- análise de tarefas;

- análise da aplicação: análise de interfaces similares; análise de funcionalidades e necessidades;

- análise de requisitos: definição e priorização das funcionalidades; definição de metas de usabilidade;

Um questionário disponível na Web foi utilizado para levantamento das principais características contextuais dos usuários típicos, de modo a compreender quem são, qual o conhecimento ou experiência com Internet, como a utilizam para realizar seu trabalho (acadêmico ou profissional), quais são os sites que utilizam sobre imagens de arquitetura, entre outras informações.

Foram recebidas 175 respostas completas entre os aproximadamente 500 usuários que viram o questionário. Deste total, foram eliminadas 10 respostas, sendo 4 por não estar na condição alvo (i.e., os respondentes disseram que não usam e nem estão interessados em fotografias de arquitetura), 5 por conteúdo vazio e 1 por conteúdo replicado. Tal procedimento resultou em 165 respostas na condição alvo. 
Por meio da análise do questionário foi possível levantar a predominância de estudantes de arquitetura, arquitetos, fotógrafos e professores de arquitetura como principais usuários típicos do sistema. Também existem as editoras de revistas de arquitetura e/ou fotografia de arquitetura, além de interessados em imagens de arquitetura como hobby. A maioria são jovens acostumados com Internet e com o uso de sites para realizar pesquisas sobre assuntos relacionados à arquitetura como Google, GoogleMaps e Vitruvius (vitruvius.com.br), site muito citado entre arquitetos e estudantes de arquitetura participantes da pesquisa devido à sua importância na área.

Foram realizadas três sessões de grupos focais (técnica para discussão aberta sobre algum tema específico, com um grupo homogêneo de participantes) com usuários típicos predominantes do sistema: uma sessão com arquitetos profissionais, uma com fotógrafos profissionais e uma com estudantes de arquitetura. O objetivo era explorar como eram realizadas as tarefas com imagens de arquitetura como parte de sua rotinas no trabalho, estudo ou lazer. Participaram da realização das sessões de grupos focais, alguns desenvolvedores do projeto e clientes, o que se mostrou muito benéfico para o compartilhamento de informações coletadas com o restante da equipe e até mesmo para passar a enxergar o sistema do ponto de vista de um usuário típico.

Foram definidos os temas para os encontros dos grupos focais e realizada a distribuição de convites para 6 usuários de cada perfil, 18 usuários no total, para participarem presencialmente assinando um "termo de consentimento livre e esclarecido" para uso de som e imagem. As sessões dos grupos focais contaram com 5 arquitetos, 6 fotógrafos especializados em arquitetura e 4 estudantes de graduação em arquitetura e urbanismo, com registro audiovisual, registro fotográfico e anotações da equipe ao longo do diálogo de $1 \mathrm{~h} 30 \mathrm{~m}$ com cada grupo de usuários, completando um total de $4 \mathrm{~h} 30 \mathrm{~m}$ de bate-papo. A Figura 6.2 apresenta fotografias de cada uma das sessões.
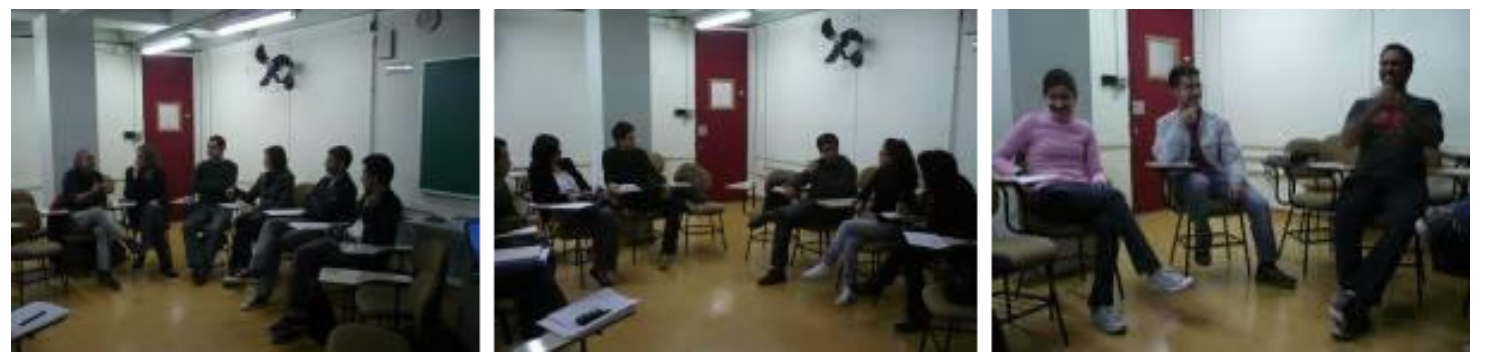

Figura 6.2: Registro fotográfico dos grupos focais presenciais de fotógrafos, arquitetos e estudantes

Por meio da análise das sessões de grupos focais, ficou mais clara a maneira que usuários típicos utilizam as imagens de arquitetura. As imagens podem ser referências para um projeto de estudo ou pesquisa sobre arquitetura, ou para o início de um nova obra arquitetônica, ou para lembrar de detalhes técnicos da arquitetura. Para os arquitetos, os detalhes construtivos da obra presentes na imagem são importantes. Para os fotógrafos, os detalhes plásticos da fotografia são importantes. Ou seja, no contexto diário de trabalho de um profissional ou estudante da área, as imagens são usadas para referenciar projetos de qualidade ou de autores que se deseja seguir, ou para guardar os resultados de uma visita em campo, possibilitando análises posteriores. A imagem também pode contar a história da evolução da obra, para isso incluem anotações sobre elas. As imagens geralmente são classificadas por data ou por lugar e, entre os profissionais, é comum colocarem o nome do autor da obra (arquiteto) como nome da pasta onde estão as imagens.

Além disso, os participantes dos grupos focais concordavam que a fotografia pode ser utilizada para valorizar ou desvalorizar um determinado aspecto da obra de acordo com o ângulo, luz e cenário que se escolha retratar e essa é a preocupação de fotógrafos e editoras de revistas de imagens de arquitetura. Outra preocupação compartilhada por todos os profissionais e considerada fundamental são os direitos autorais de cada imagem. Entre os estudantes pesquisados, essa não é uma informação necessária porque enxergam o compartilhamento de arquivos na rede como algo natural.

A análise dos dados coletados no questionário e nos grupos focais, mesmo com a preocupação de reduzir o nível de detalhes a serem pesquisados para não consumir muito tempo dado o contexto de desenvolvimento do projeto, ainda necessitou de três meses de análise. Todas as sessões de grupos 
focais foram registradas em vídeo e áudio e a análise dos vídeos foi a tarefa mais onerosa em tempo, pois tinha o objetivo de compreender as tarefas atuais dos participantes com imagens de arquitetura e relacioná-las com tarefas possíveis no sistema. Foi criada uma planilha com os resultados sendo classificados por objetivos dos usuários, tarefas típicas e perfil predominante de usuário, o que resultou em 25 macro-objetivos de usuários.

Por meio do levantamento de 17 sites apontados pelos participantes do questionário como importantes fontes de pesquisa de imagens de arquitetura, foi realizada uma análise dos sites, com o objetivo de levantar características que fossem importantes para o compartilhamento, acesso e utilização de imagens de arquitetura. Ao todo foram levantadas 38 características presentes nos sites pesquisados. Em paralelo, a equipe de desenvolvimento também realizou a análise de 15 redes sociais de modo a levantar características de comunicação, coordenação e cooperação de sistemas colaborativos, levantando 21 características que estão relacionadas ao compartilhamento de conteúdo em redes sociais. Após a análise de tarefas e de características levantadas nos sites similares, foi possível a criação de personas e a definição de requisitos e metas de usabilidade para o sistema.

Foram criadas 5 personas, incluindo cenários para cada uma delas, que representavam os principais perfis de usuários típicos do sistema e tarefas principais com imagens de arquitetura para cada um deles. A criação de personas foi rápida após o conhecimento dos usuários típicos e suas tarefas. A Figura 6.3 exibe as principais características das personas levantadas para o sistema. Os cenários mais detalhados foram descritos em documentos separados que também foram compartilhados com a equipe.

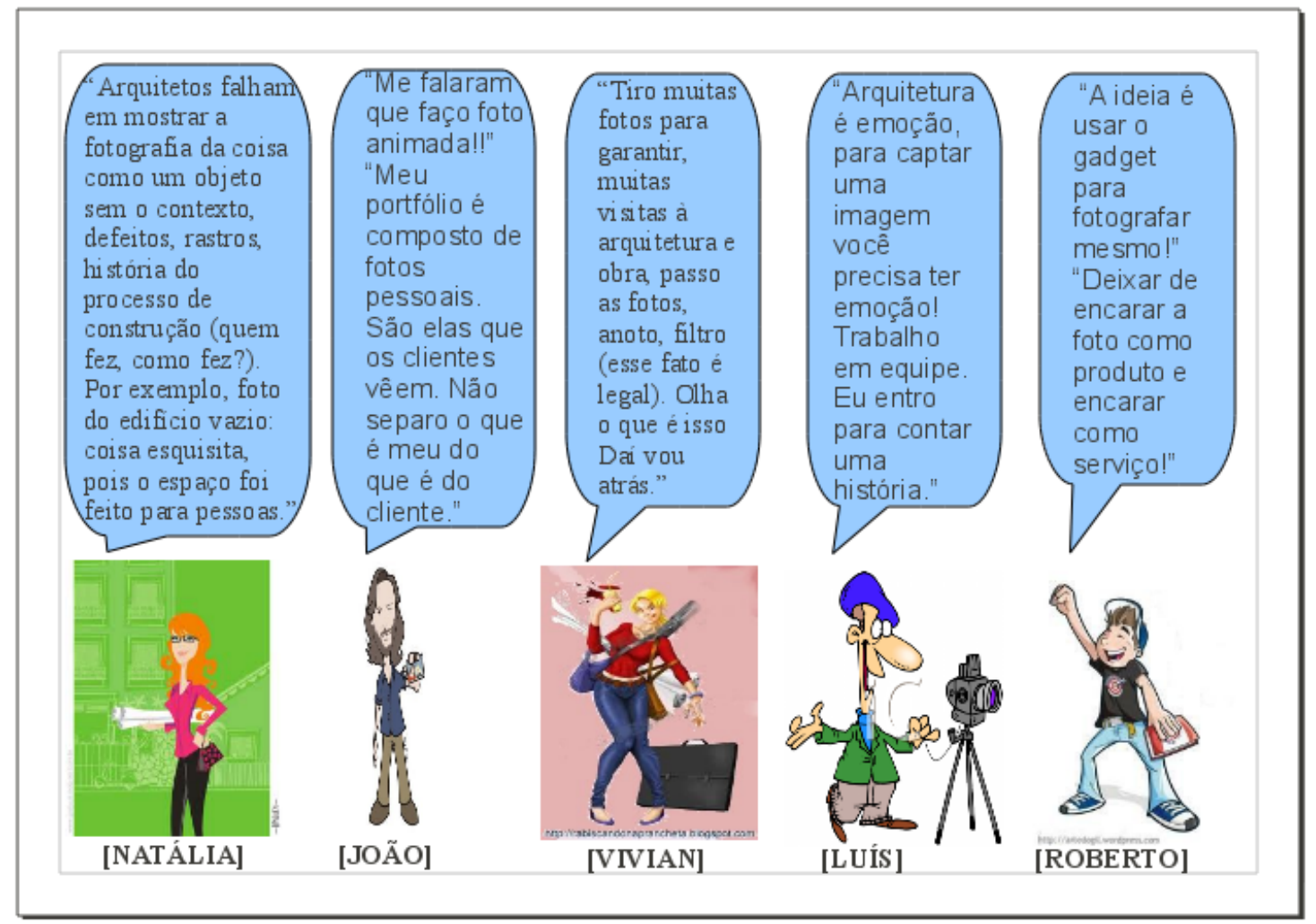

Figura 6.3: Personas definidas para o sistema Arquigrafia-Brasil.

A definição de requisitos foi realizada levando-se em consideração os requisitos levantados no brainstorm inicial do projeto, antes da pesquisa de usabilidade iniciar, e a análise de grupos focais, questionário, sites similares e personas. O resultado foi uma planilha contendo 57 funcionalidades para o sistema, as quais continham o mapeamento de onde elas foram levantadas e para qual perfil de usuário.

A definição de metas de usabilidade baseou-se nos objetivos dos usuários e nas funcionalidades priorizadas para o sistema, o que resultou em métricas qualitativas e métricas quantitativas. As mé- 
tricas quantitativas são as possíveis de automatização por meio de testes diretamente no ambiente de desenvolvimento, por exemplo, por meio de testes de aceitação automáticos. Já as metas qualitativas são as que dependem de avaliação subjetiva do usuário e portanto não se pode automatizá-las, são as que necessitam ser avaliadas por meio de testes de usabilidade com usuários do sistema. Foram definidas 15 metas de usabilidade com base nos atributos de usabilidade definidos por Nielsen, conforme descrito na Seção 3.1.

Todos os resultados obtidos com as análises foram compartilhados com a equipe por meio de emails. As funcionalidades, personas e metas de usabilidade definidas foram apresentadas em uma reunião para a equipe, incluindo clientes, de modo a priorizar quais seriam as funcionalidades importantes para a primeira versão do sistema. A priorização de cada funcionalidade seguiu a seguinte classificação: desnecessária, muito baixa, baixa, relevante, alta, muito alta. Foi então decidido entre desenvolvedores e cliente que para a primeira versão entrariam as funcionalidades com prioridade muito alta, que totalizavam em 17 das 57 funcionalidades levantadas.

O método de personas demonstrou ser um meio divertido de apresentar características e objetivos importantes dos usuários, que o sistema precisa comportar. Para clientes e desenvolvedores que participaram das sessões de grupo focal, a definição de personas foi uma forma de lembrar pontos ressaltados por participantes e situações engraçadas que ocorreram durante as sessões, que justificam os cenários descritos para cada persona. As metas de usabilidade foram apresentadas de modo a explicar como seriam acompanhadas por meio de métricas quantitativas e qualitativas e de modo a validá-las com a equipe.

\section{Reflexão do Ciclo 1 da pesquisa-ação}

Enquanto eram realizados os métodos de análise dos dados coletados, a implementação do sistema seguiu em paralelo, sem incluir os resultados da análise, o que demonstra problemas na integração de métodos de pesquisa mais detalhados com a dinâmica de desenvolvimento de métodos ágeis. O principal problema foi o tempo gasto, aproximadamente três meses, para realização da análise com base nos registros em vídeo.

As principais percepções de quem eram os usuários típicos do sistema e quais eram seus objetivos foram comentadas pelos membros da equipe, que participaram das sessões de grupos focais, inclusive clientes, após o término das sessões. Após a análise dos dados coletados, notou-se que as percepções obtidas no dia das sessões de grupos focais, refletiram-se em funcionalidades priorizadas como muito altas para o sistema. A análise do vídeo possibilitou o levantamento de 40 funcionalidades a mais do que poderíamos ter percebido com a análise superficial, mas para isso necessitou de muito tempo. Além disso, a análise tinha como objetivo levantar o máximo de requisitos para o sistema, de preferência antes do início do desenvolvimento, como ocorre em métodos de usabilidade tradicionais. Porém, em métodos ágeis levanta-se apenas o necessário para entregar valor ao cliente na próxima iteração.

Sendo assim, uma lição aprendida com essa experiência é que no contexto de métodos ágeis não há necessidade de realização de uma análise detalhada dos registros em vídeo, e para dar continuidade logo em seguida, para os resultados obtidos com pesquisas como nas sessões de grupos focais, poderia ser realizado um brainstorm com os membros da equipe participantes das sessões. Dessa forma, as principais percepções, anotadas por cada membro da equipe durante a sessão, seriam discutidas, de modo a validar as impressões compartilhadas e obter uma lista dos principais requisitos necessários no mesmo dia em que se realiza o grupo focal. Se esta prática tivesse sido aplicada, o desenvolvimento que continuou em paralelo à análise, teria incluído os resultados do grupo focal, por meio de histórias de usuários a serem implementadas. Na escrita de histórias de usuários para a próxima iteração, pode surgir a necessidade de levantamento de mais detalhes para a compreensão da história por completo. Apenas nesse momento, haveria justificativa para mais análises ou coletas de dados para possibilitar o entendimento.

Quanto à análise do questionário, os resultados principais ficaram disponíveis no primeiro dia em que foi finalizado, já que este foi criado em uma ferramenta online chamada Survey Gizmo que possibilita a geração de um relatório de análise. Porém, o cruzamento com os dados coletados nos 
grupos focais, bem como a criação de gráficos mais detalhados, consumiram mais tempo. Notou-se que a análise detalhada dos resultados obtidos com o questionário, gerou muitos dados que não foram plenamente utilizados para o desenvolvimento do sistema.

A definição de personas, que foi realizada após a análise dos dados coletados, poderia ser realizada no dia seguinte após os grupos focais, sendo compartilhada logo em seguida com a equipe. Neste ponto, poderia ser utilizada a área de trabalho informativa, uma prática de equipes que utilizam XP, de modo a colocar no ambiente de trabalho da equipe de desenvolvimento a figura em tamanho grande das personas do sistema. Sendo assim, passa a fazer parte do dia-a-dia da equipe a lembrança de como são os usuários típicos do sistema que estão desenvolvendo. Essa já é uma prática utilizada em algumas equipes de XP, denominada Personas Extremas [WTS ${ }^{+} 08$ ].

No caso de desenvolvimento aberto, apenas a equipe núcleo que compartilha o mesmo local de trabalho poderia utilizar a área de trabalho informativa, para o caso de equipes em que todos os membros encontram-se distribuídos, seria utilizado o compartilhamento por e-mail ou por meio de ferramentas online.

Em seguida, as metas de usabilidade poderiam ser definidas, mas ao contrário de descrevêlas em documentos, poderiam ser diretamente relacionadas aos testes que as validariam. Além disso, as metas definidas seriam relacionadas apenas às próximas histórias de usuários a serem implementadas, levando-se em consideração metas gerais para todo o sistema. Desse modo, as metas quantitativas seriam descritas por meio de testes de aceitação automáticos, que também já fazem parte das práticas de algumas equipes que utilizam TDD em XP. E as metas qualitativas poderiam ser relacionadas aos cenários de teste de usabilidade que seriam aplicados aos usuários típicos.

A análise de tarefas poderia ser substituída por testes de aceitação automáticos no ambiente de desenvolvimento, o que além de documentar a forma correta de comportamento do sistema, também valida os testes que foram implementados com sucesso. De modo que o relatório textual seria tranformado em testes automatizados, que funcionam como relatórios atualizados do que está implementado no sistema. Portanto, os resultados da pesquisa seriam documentados nos testes de aceitação e nas histórias de usuários, o que permite que fiquem próximos do desenvolvimento durante todo o ciclo e facilitam o entendimento de novos desenvolvedores que possam entrar durante o processo de desenvolvimento, o que pode ocorrer com frequência em equipes de software livre. Além disso, cada teste de aceitação escrito pode ser liberado imediatamente aos desenvolvedores, por meio de ambientes de desenvolvimento com integração contínua, o que diminui o tempo entre descobertas de pesquisas de usabilidade e a aplicação delas no desenvolvimento.

O ponto positivo que pode ser destacado neste primeiro ciclo é o envolvimento de desenvolvedores e clientes na realização do questionário e grupos focais. Este envolvimento trouxe como benefício direto a disseminação de conhecimento sobre usabilidade e o conhecimento de quem eram os usuários. Foi possível perceber a surpresa dos membros da equipe que participaram dos grupos focais, com as respostas de usuários para descrever suas tarefas, fazendo-os notar a diferença de ponto de vista de pessoas de áreas diferentes. Sendo assim, não houve nenhum problema em se realizar esses métodos neste contexto de desenvolvimento, apenas ajustes são necessários com relação à granularidade da análise dos dados coletados.

De forma geral, podemos citar os seguintes problemas decorrentes da demora em se apresentar os resultados da análise dos dados coletados: (1) distanciamento do resultado coletado na pesquisa de usuário e sua aplicação no projeto; (2) implementação continuou sem os resultados da pesquisa; (3) relatório com muitas páginas descrevendo a análise dos resultados, o que implica em não ser lido ou ser lido apenas parcialmente; e (4) reunião para apresentação dos resultados necessitou de aproximadamente 5 horas, tornando-se onerosa em tempo pela grande quantidade de requisitos sendo analisados de uma só vez.

\subsubsection{Ciclo 2: Primeiro teste de usabilidade}

No período em que foi realizada a análise dos resultados de usabilidade, a equipe de desenvolvimento integrou o protótipo inicial do sistema com o código de implementação do Groupware 
Workbench. Dessa forma, a pesquisa de usabilidade não pôde ser aproveitada nesta primeira versão do sistema, conforme descrito anteriormente. A partir desse cenário, foi necessária adaptação ao contexto atual do projeto e optou-se por realizar um teste de usabilidade na versão implementada do sistema. O teste tinha como um dos objetivos exibir os problemas de usabilidade existentes por meio da "voz" dos usuários típicos.

Sendo assim, envolveu-se membros da equipe como participantes do teste com usuários, 2 desenvolvedores e 1 cliente, de modo a perceberem os problemas de usabilidade existentes através da observação dos usuários utilizando o sistema. Os problemas de usabilidade encontrados foram apresentados através de um relatório contendo cada uma das tarefas definidas para o teste e apontando como cada um dos cinco usuários participantes do teste se comportou na realização da atividade, exibindo se realizou com sucesso a operação ou se não realizou e descrevendo porque o problema ocorreu. No fim de cada tarefa, propostas de soluções para o problema foram definidas.

Os testes presenciais de usabilidade sobre o primeiro protótipo funcional contou com a participação de 2 arquitetos, 2 estudantes de graduação em arquitetura e urbanismo e 1 fotógrafo. Após o teste de usabilidade, os usuários preencheram um questionário para descrever suas impressões do sistema, de modo a avaliar metas qualitativas de usabilidade, como por exemplo, se gostou de utilizar o sistema, relacionado ao atributo de usabilidade satisfação subjetiva. A Figura 6.4 apresenta registros fotográficos dos testes com usuários.
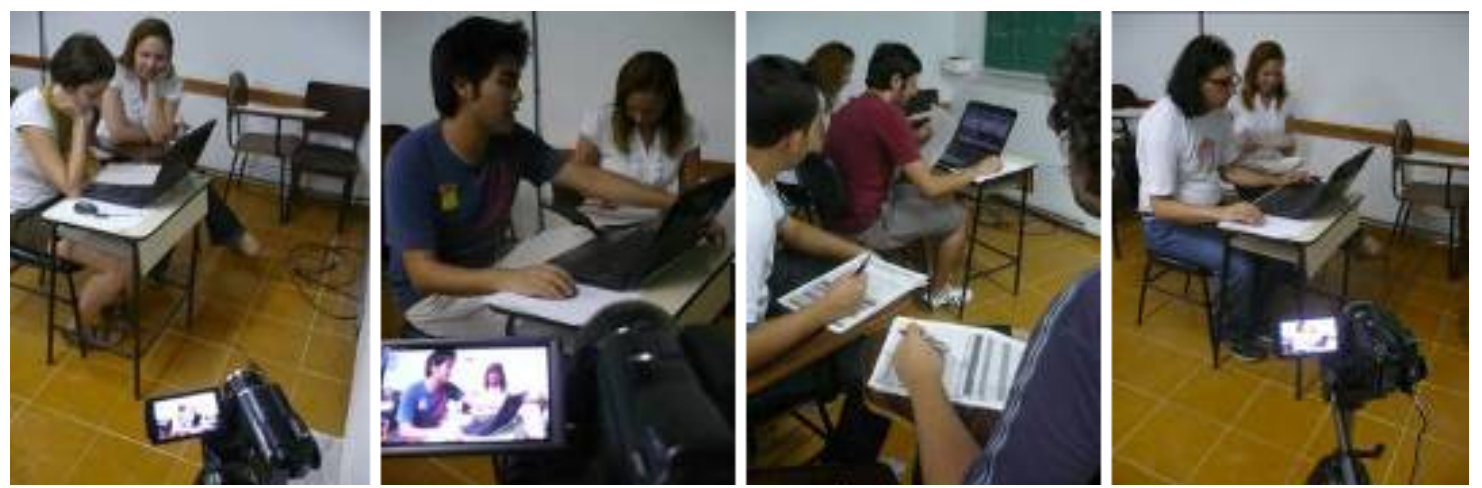

Figura 6.4: Teste presencial de usabilidade sobre a Versão Alfa do primeiro protótipo funcional

Os principais problemas de usabilidade encontrados no teste com usuários foram corrigidos pela equipe de desenvolvimento de modo a apresentar o projeto em um congresso e realizar o lançamento da versão beta do sistema. Todos os problemas graves, que impediam a utilização de tarefas essenciais, foram corrigidos antes do lançamento.

\section{Reflexão do Ciclo 2 da pesquisa-ação}

O teste de usabilidade mostrou-se muito eficaz tanto na descoberta de problemas de usabilidade quanto na mudança de perspectiva dos membros da equipe que participaram do teste, pois puderam notar os erros que os usuários cometiam simplesmente por terem modelos mentais diferentes dos projetistas ou desenvolvedores. Contudo, alguns problemas ocorreram: (1) não foram todos os membros da equipe que participaram, sendo assim, notou-se que apenas os participantes do teste puderam compreender adequadamente os problemas encontrados; (2) alguns erros graves foram expostos a usuários potenciais; (3) o teste foi realizado com 11 tarefas propostas aos usuários para serem executadas pelo sistema, o que resultou em sessões de teste extensas.

Como soluções de melhorias para os próximos ciclos, poderiam ser quebradas as tarefas de testes de usabilidade em testes menores com o foco em atividades específicas. Cada teste envolveria uma parte da equipe ( 2 ou 3 membros) como observadores, porém a cada novo teste, outros desenvolvedores que não participaram do teste anterior seriam envolvidos, de modo que todos os membros da equipe pudessem participar dos testes de usabilidade que ocorrem durante o desenvolvimento do sistema. Ao dividir em testes menores, consequentemente o tempo é reduzido. 
Quanto à exposição dos usuários a erros graves, poderia ser realizada uma "limpeza" dos maiores erros através de uma avaliação heurística, ou também não incluindo tarefas que estivessem no fluxo que contém erros graves. De qualquer forma, os usuários participantes do teste foram informados de que se tratava de um protótipo inicial que ainda continha erros.

\subsubsection{Ciclo 3: Workshop de usabilidade e Card Sorting}

Após os resultados dos testes de usabilidade, os problemas existentes nas interfaces indicaram a importância da melhoria da usabilidade e do leiaute do sistema. Por esse motivo, foi contratada uma empresa especialista em leiaute de interfaces, Benchmark Design Total, que ficou responsável pelo redesign de interfaces, explicado no próximo ciclo.

Por esse motivo, foi realizado um workshop de usabilidade para todos os membros da equipe de desenvolvimento, clientes e novos membros da empresa de design, de modo a apresentar todos os resultados da pesquisa de usabilidade, destacando as funcionalidades priorizadas para a primeira versão do sistema, as metas de usabilidade e as personas definidas. Os documentos relatando os resultados obtidos foram compartilhados com a nova equipe e os próximos passos para o desenvolvimento do projeto foram planejados durante o encontro. Ideias para melhorias de leiaute foram discutidas entre todos os participantes. A Figura 6.5 apresenta registros fotográficos do workshop.
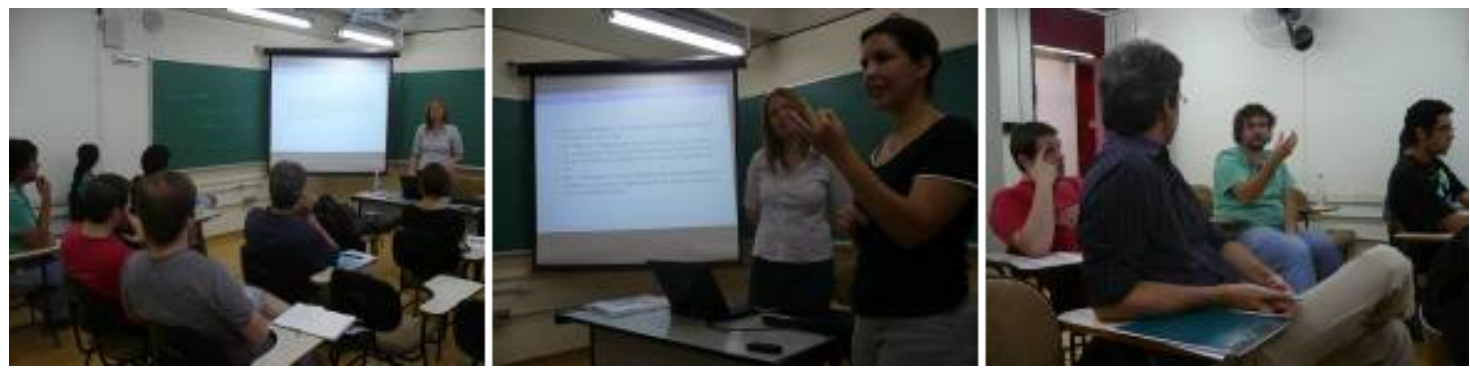

Figura 6.5: Registro fotográfico do Workshop de usabilidade

Para melhor definição da nova organização das informações na interface, optou-se pela aplicação do método card sorting [MW04] ou ordenação de cartões. Essa técnica consiste em classificar as informações de acordo com o modelo mental dos usuários típicos do sistema. Foi aplicada por meio da ferramenta WebSort.net (websort.net/s/025185), que possibilita a realização online da técnica. A Figura 6.6 exibe a interface utilizada pelos usuários para realização da ordenação de cartões. Do lado direito da interface estão as possíveis categorias para organização das funcionalidades apresentadas do lado esquerdo. O usuário também tem a possibilidade de criar novas categorias, se julgar necessário.

\section{Reflexão do Ciclo 3 da pesquisa-ação}

A apresentação dos principais resultados da pesquisa para a equipe e novos membros possibilitou reforçar dados importantes coletados e abrir a discussão de novas possibilidades de leiaute a serem implementadas pela equipe de design.

A técnica de ordenação de cartões foi realizada sem maiores problemas com relação à análise dos seus resultados, uma vez que, foi percebido com o primeiro ciclo que a análise detalhada não foi interessante para o contexto de desenvolvimento do projeto. Sendo assim, os resultados obtidos através do relatório gerado pela própria ferramenta foi compartilhado com a equipe, de modo a ser um insumo para o redesign da organização de conteúdo nas interfaces do sistema.

\subsubsection{Ciclo 4: Redesign de interfaces e testes de usabilidade remotos}

A nova equipe de design, responsável por realizar o redesign do leiaute do sistema, utilizou como base as funcionalidades priorizadas, as metas de usabilidade, as personas, os testes com usuários e a ordenação de cartões de acordo com a perspectiva de usuários típicos do sistema. 


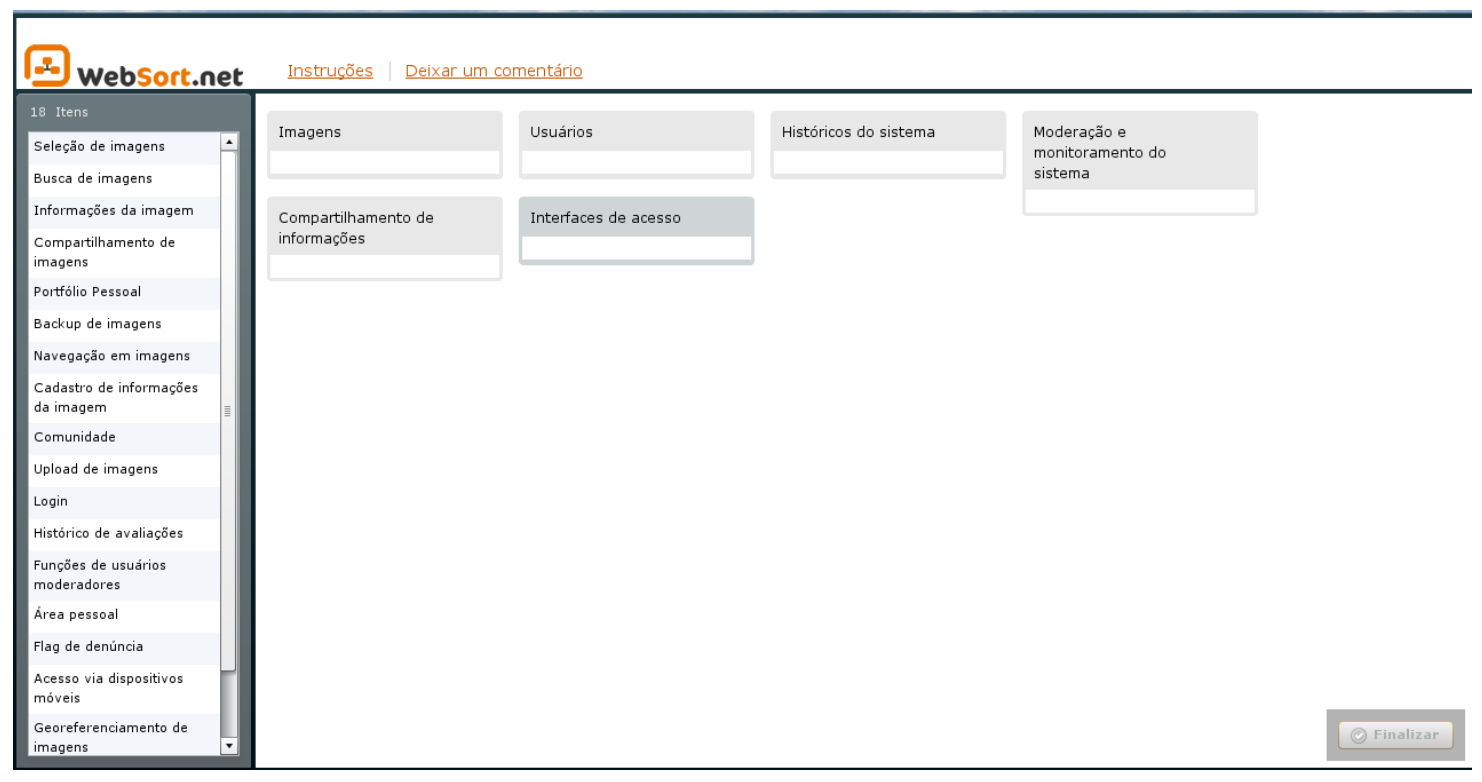

Figura 6.6: Interface da ferramenta WebSort.net utilizada para ordenação de cartões.

O primeiro passo foi a criação de wireframes especificando a organização do conteúdo na interface e o fluxo básico de tarefas no sistema, onde algumas reuniões presenciais foram marcadas para melhor compreensão de requisitos e rascunhos de ideias iniciais para o leiaute, onde todos os envolvidos participavam, inclusive clientes.

Em seguida, iniciou-se um processo iterativo de criação de wireframes, apresentação deles em reuniões presenciais para equipe e clientes, onde problemas percebidos eram corrigidos e na sequência a realização de testes de usabilidade remotos através da ferramenta Usabilla e a correção dos problemas encontrados nos testes. Cada teste continha tarefas a serem realizadas e no fim o usuário era encaminhado para o questionário para avaliação do cumprimento de metas de usabilidade qualitativas através da ferramenta Survey Gizmo.

A ferramenta Usabilla também fornece um relatório dos problemas encontrados, sendo possível visualizar um mapeamento com cores destacando as partes da tela mais clicadas. A Figura 6.7 exibe um exemplo de imagem gerada pela ferramenta, no relatório de resultados para o teste do wireframe da interface Home, contendo os pontos clicados e anotações textuais dos usuários para a atividade de acessar informações pessoais. Cada anotação é enumerada e descrita na próxima página do relatório.

Durante as reuniões para apresentação dos wireframes e dos resultados dos testes de usabilidade, novas ideias de leiaute e requisitos eram levantadas e testadas por meio de desenhos na lousa ou papel. Para acompanhamento posterior, foram registradas fotografias das lousas ou papeis rascunhados. A Figura 6.8 apresenta alguns registros fotográficos de reuniões para discussão sobre os protótipos e os resultados dos testes remotos de usabilidade com usuários típicos do sistema.

Quando as principais telas do sistema haviam sido desenvolvidas no wireframe e testadas com usuários típicos, passou-se para a criação de leiaute de interface, que também seguiu o mesmo ciclo iterativo realizado para os wireframes. Novos testes foram realizados, também com a utilização da ferramenta Usabilla e os problemas eram corrigidos na sequência pela equipe de design. A Figura 6.9 exibe um exemplo de imagem gerada para o resultado de um teste de usabilidade sobre o leiaute da interface Home.

\section{Reflexão do Ciclo 4 da pesquisa-ação}

No ciclo 4, o trabalho foi realizado de modo a definir a interface, apresentá-la, avaliá-la e corrigi-la, o que se mostrou muito eficaz na melhoria da usabilidade das interfaces do sistema. O envolvimento de usuários típicos e a presença constante do cliente em todas as atividades foram fundamentais para se alcançar melhores resultados. 


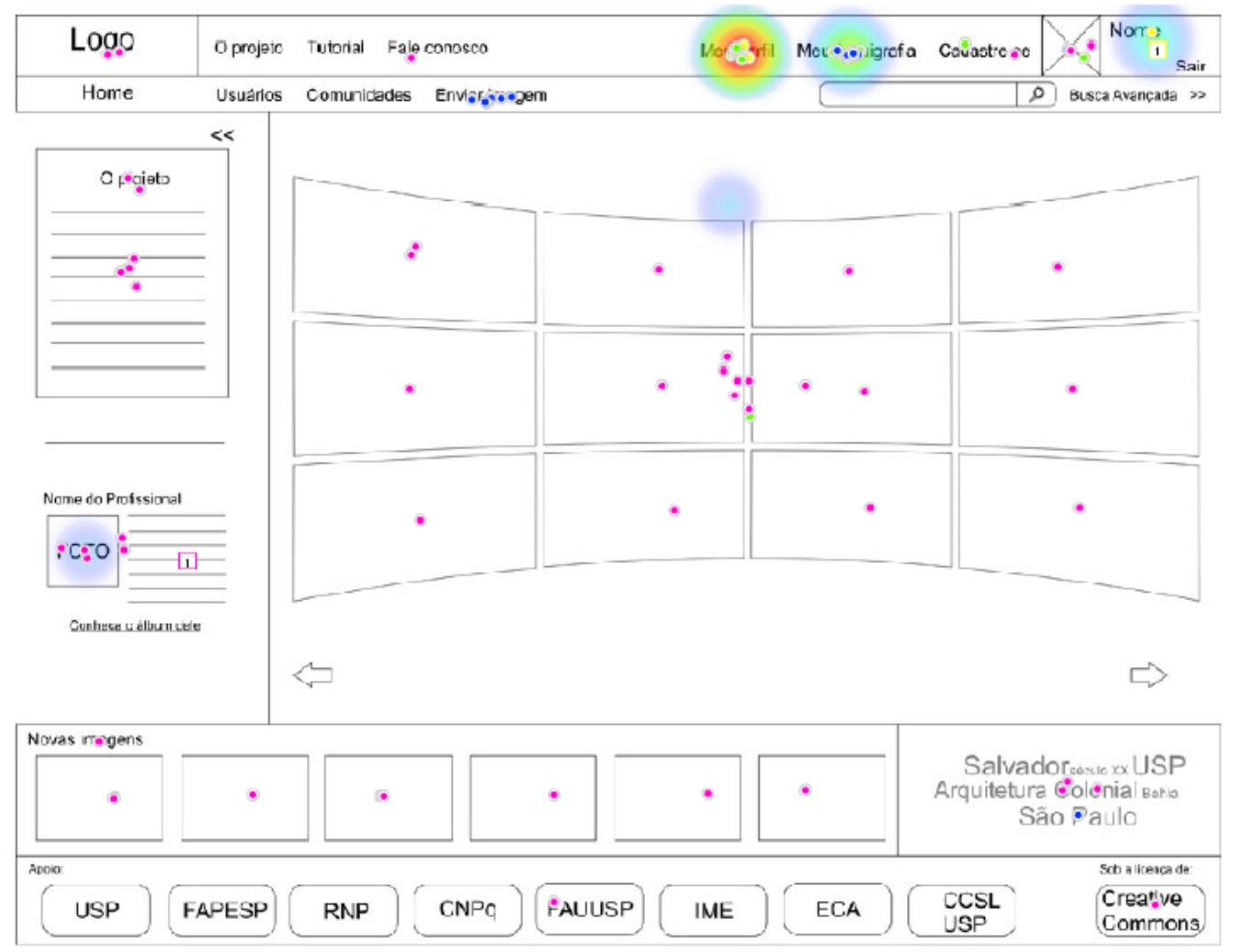

Figura 6.7: Relatório com resultados do teste sobre o wireframe da interface Home.
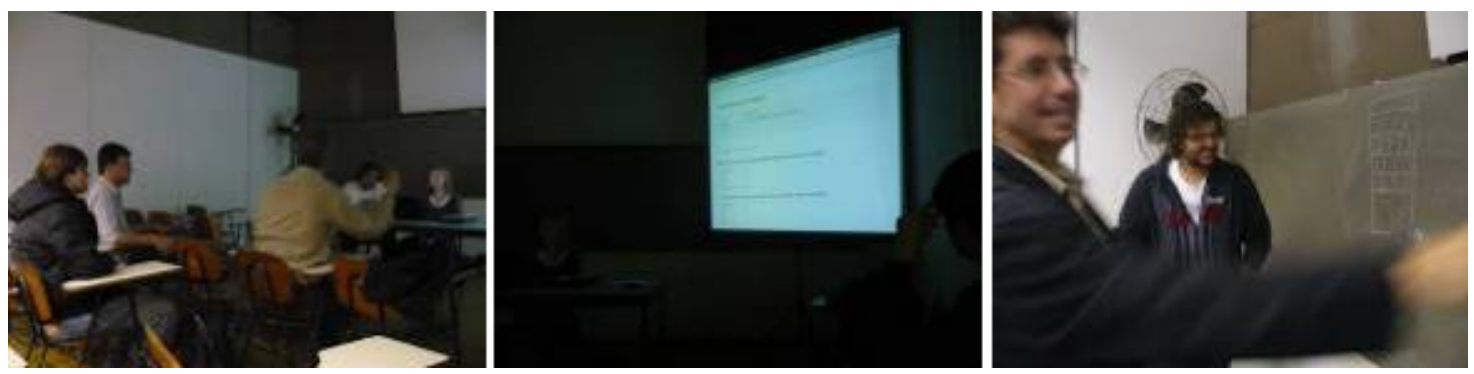

Figura 6.8: Reuniões para discussão sobre os protótipos e resultados de testes remotos de usabilidade com usuários típicos.

A única ressalva relaciona-se ao fato do desenvolvimento do código ficar separado do desenvolvimento da interface. Enquanto a equipe de design trabalhava exclusivamente com a interface do sistema, a equipe de desenvolvimento cuidava do código e questões relacionadas a ele. Em comunidades de métodos ágeis que utilizam práticas de usabilidade é comum possuir caminhos paralelos, de design e desenvolvimento, como descrito na Seção 5.3. Porém, essa prática dificulta o compartilhamento de conhecimento entre todos os membros da equipe. Além disso, como o trabalho andou em linhas separadas, foi necessário, ao final da definição do leiaute, realizar a integração do código, descrito no ciclo 6 .

\subsubsection{Ciclo 5: Avaliação e nova coleta de requisitos}

A tarefa mais crítica do sistema, do ponto de vista da usabilidade, é a avaliação de uma imagem de arquitetura, que consiste em avaliar a arquitetura apresentada em uma imagem de acordo com seus aspectos plástico-espaciais, que são apresentados na interface por meio de binômios como opaco/transparente ou claro/escuro. Essa tarefa é um objetivo específico da equipe de pesquisadores da FAU-USP, que desejam obter resultados vindos a partir da inteligência coletiva de diversos 

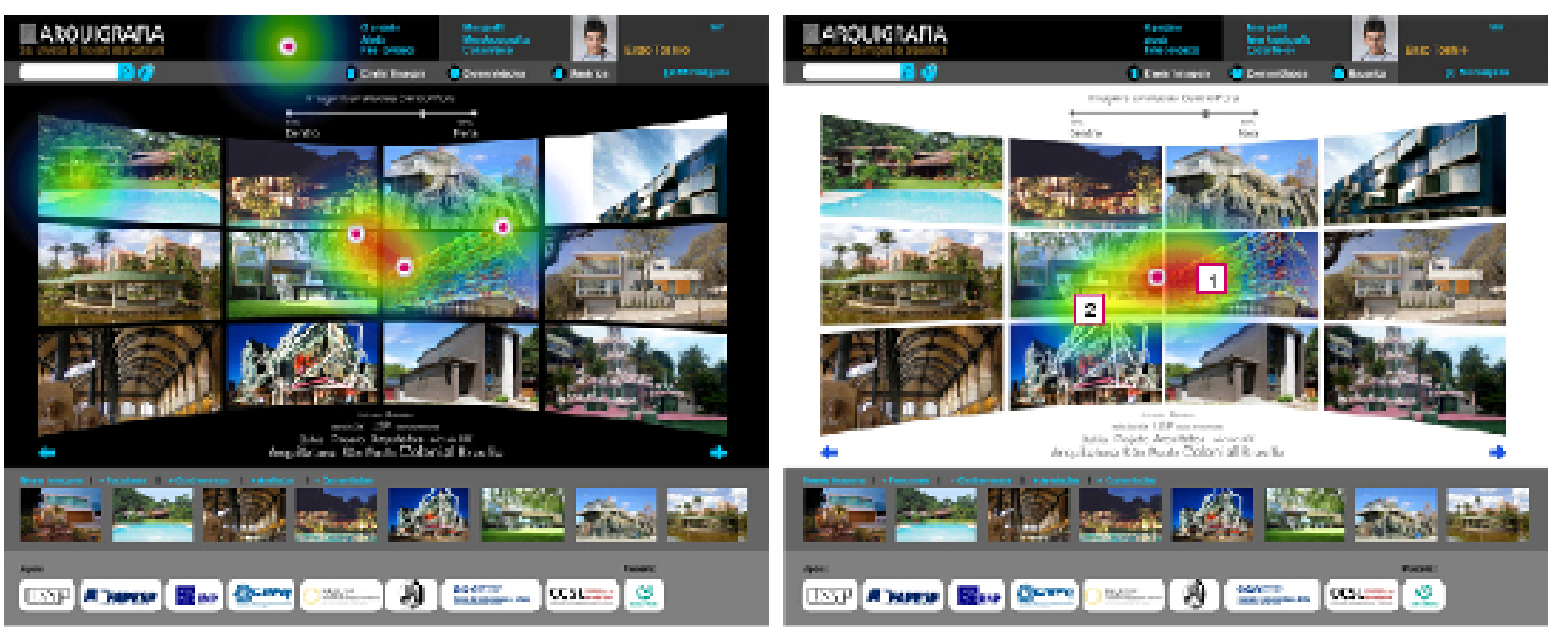

Figura 6.9: Exemplo de imagem gerada com os resultados do teste para comparação do leiaute de uma interface com o fundo escuro e com o fundo claro.

usuários interagindo e avaliando informações de imagens de arquitetura.

Foi realizado um teste sobre o último leiaute para a interface de avaliação e os resultados obtidos não foram satisfatórios. A maioria dos usuários não conseguiu compreender para que ou como realizar a avaliação. A Figura 6.10 apresenta uma versão de leiaute para interface de Avaliação de imagens por meio dos binômios de qualidades plástico-espaciais (tela à esquerda na figura), que foi utilizada como base para o teste remoto com usuários. O mesmo teste foi utilizado para avaliar a melhor localização de botões interativos para uma imagem (tela à direita), os quais permitem visualizar detalhes da imagem, fazer download, entre outras funções.
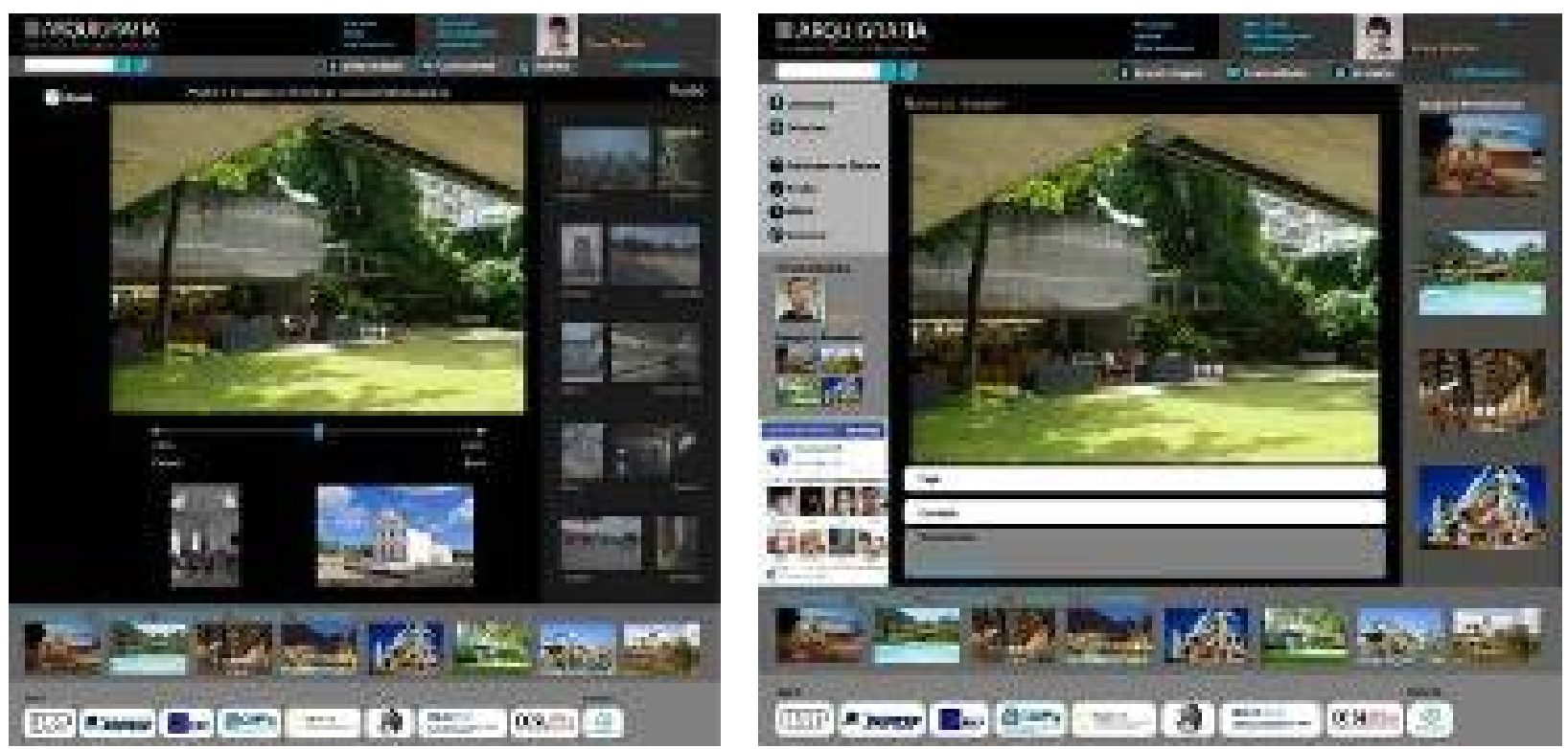

Figura 6.10: Exemplos de telas usadas no teste remoto de usabilidade com usuários típicos.

Durante a reunião, para discussão dos resultados dos testes remotos com usuários sobre as interfaces exemplificadas na Figura 6.10, notou-se a necessidade de aprofundamento de requisitos para a funcionalidade de avaliação de imagens por meio de binômios, de modo a entender como apresentar da melhor forma possível essa tarefa aos usuários, tornando-a compreensível e fácil de utilizar. A Figura 6.11 apresenta registros fotográficos da reunião. Sendo assim, foram corrigidos os problemas encontrados no último teste desta interface e, em seguida, foram realizadas duas sessões 
de grupos focais, uma realizada remotamente e outra presencialmente, além de uma entrevista remota.
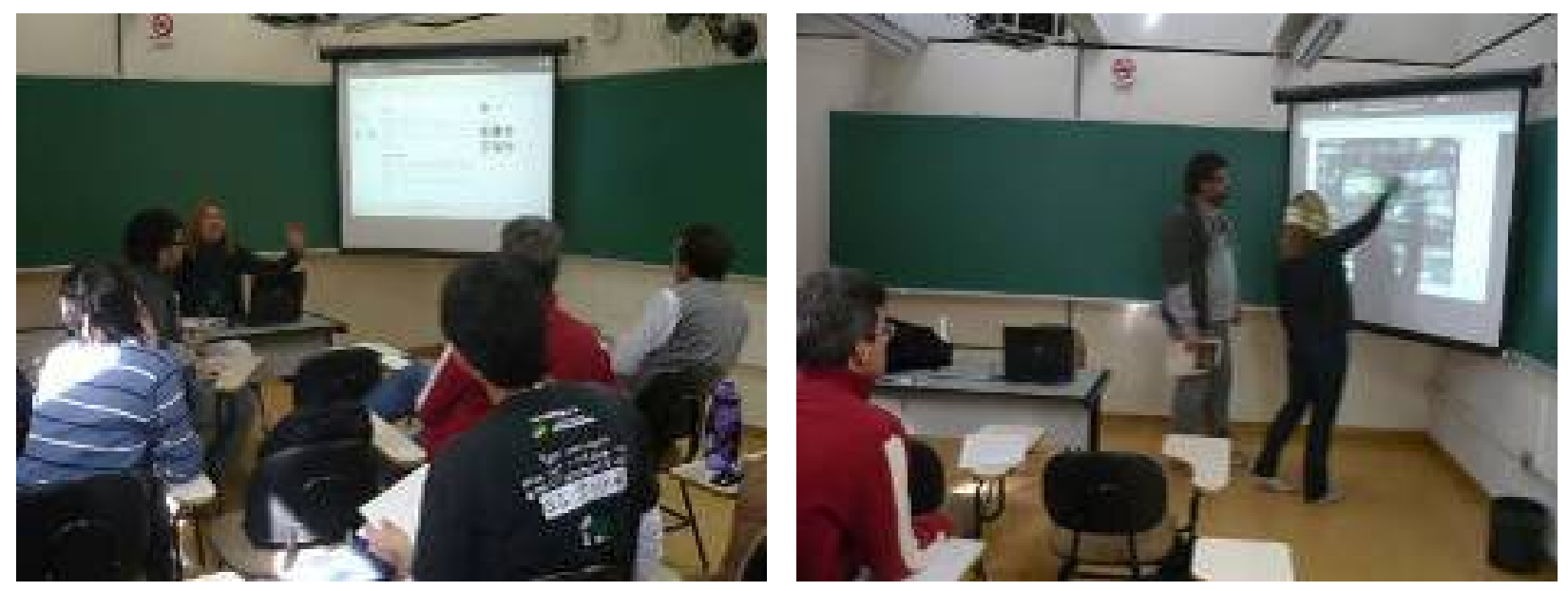

Figura 6.11: Reunião para apresentação da análise dos testes remotos

De acordo com o aprendizado obtido no ciclo 1, a análise foi realizada na sequência da realização dos grupos focais e compartilhada com todos os membros da equipe. Embora todas as sessões tenham sido gravadas em vídeo e áudio, como ocorreu no ciclo 1, o processo de análise foi realizado com base no brainstorm online entre membros da equipe participantes das sessões, inclusive clientes, após a saída dos usuários. A ferramenta utilizada para a sessão de grupo focal e entrevista remota foi o Google+, onde todos os usuários estavam com câmeras ligadas e foi possível simular uma roda de discussão de forma distribuída.

Os grupos focais específicos sobre os binômios, presenciais e remotos, contaram com usuários dos 3 perfis predominantes (arquitetos, fotógrafos especializados em arquitetura, estudantes de graduação em arquitetura), com registro audiovisual, registro fotográfico e anotações da equipe ao longo do diálogo de cerca de 1 hora com cada grupo de usuários.

A Figura 6.12 e a Figura 6.13 apresentam, respectivamente, registros fotográficos do grupo focal presencial com arquitetos e do grupo focal remoto com fotógrafos de arquitetura, além da entrevista remota com uma estudante de arquitetura. É importante destacar que as sessões envolveram usuários que são referências na fotografia de arquitetura e arquitetura nacionais.
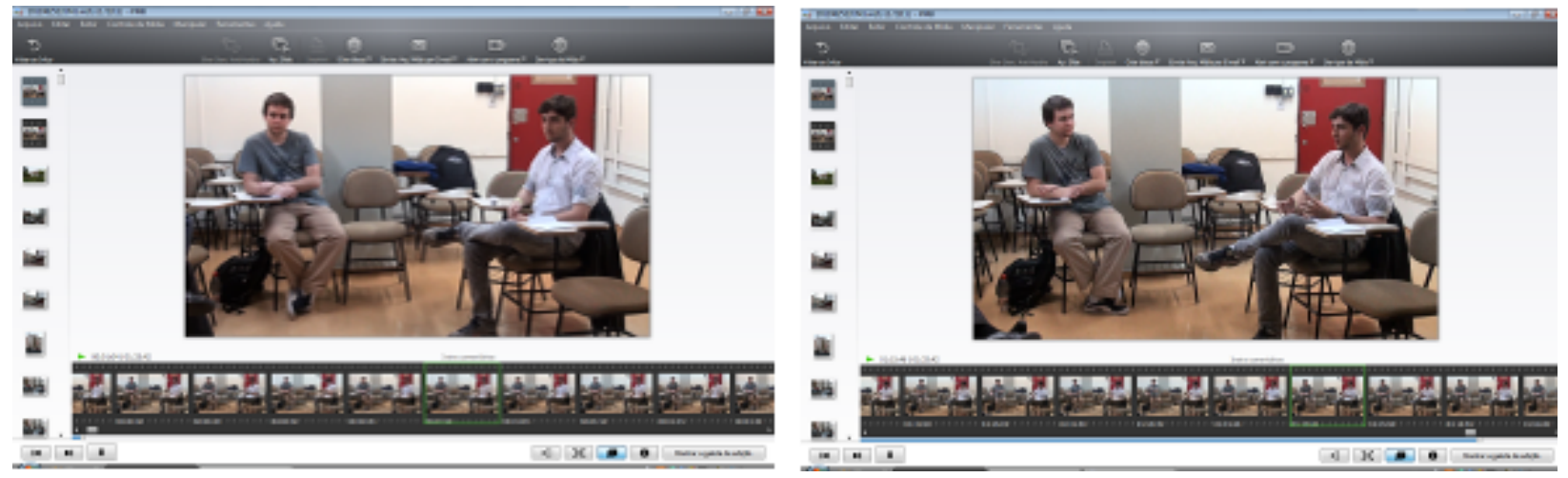

Figura 6.12: Grupo focal presencial específico para discussão de avaliação de imagens por meio de aspectos plástico-espaciais

Durante as sessões remotas, grupo focal e entrevista, todos os membros da equipe participantes, inclusive clientes, acompanhavam a discussão com um roteiro contendo as principais questões a serem investigadas. Em seguida, foi realizada uma reunião para revisão do leiaute, usabilidade e programação, a partir dos resultados obtidos nas sessões de entrevista e grupos focais. 

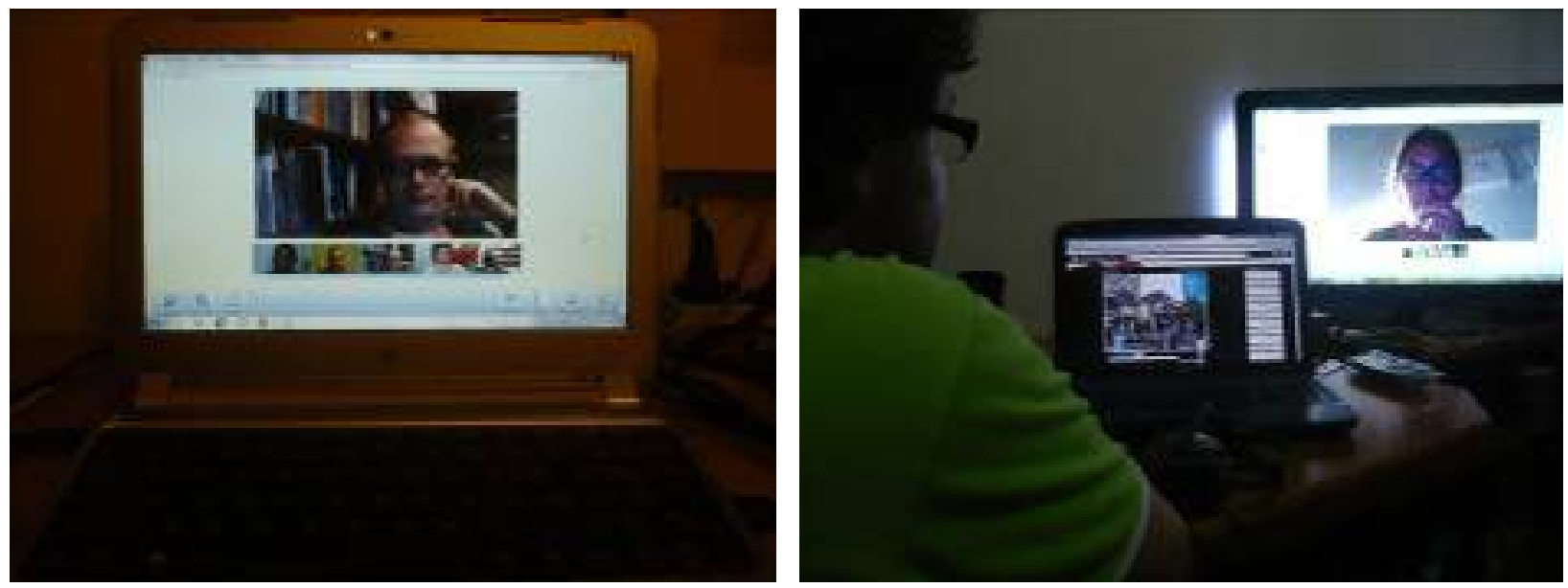

Figura 6.13: Grupo focal remoto e entrevista remota com usuários típicos do sistema.

\section{Reflexão do Ciclo 5 da pesquisa-ação}

O ciclo 5 possibilitou colocar em prática a análise dos dados coletados em grupos focais e entrevista por meio da solução indicada no ciclo 1 e mostrou-se eficiente para o contexto do projeto, uma vez que os resultados foram rapidamente compartilhados com membros da equipe possibilitando que ações fossem tomadas para melhoria da interface.

Durante as novas sessões de grupos focais, foi possível avaliar a utilização do método de grupos focais remotos, em comparação com a técnica realizada presencialmente. Nas sessões presenciais, é possível criar um ambiente acolhedor, por exemplo, servindo lanches para os participantes, de modo a definir um bate-papo informal sobre as questões estudadas, inclusive, com a possibilidade de organização das cadeiras de forma circular. Na versão online, não contamos com essas possibilidades, porém os resultados obtidos foram muito positivos para o aprofundamento de questões relacionadas à avaliação de imagens, sendo responsável por novo refinamento da lista de binômios considerando eixos artísticos e técnicos na interpretação de uma imagem de arquitetura. Quanto à entrevista remota, notou-se que a entrevistada sentiu-se à vontade para falar sobre diversos assuntos relacionados à arquitetura, tendo inclusive mostrado imagens em livros sobre assuntos que lembrava durante a conversa.

\subsubsection{Ciclo 6: Integração do HTML com o código Java}

Novos designers de interface, que pertencem à empresa Brz Comunicações, passaram a fazer parte da equipe de design. O código html com o leiaute das interfaces começou a ser refinado com melhorias de Web design e na sequência o html será integrado ao código Java do sistema. Foi necessária maior integração entre a equipe de desenvolvimento e a equipe de design para tornar a comunicação mais rápida. As melhorias de design são compartilhadas com todos os membros da equipe por meio da troca de emails, onde os membros da equipe, clientes e usuários típicos, avaliam as telas e apontam suas impressões a respeito do leiaute, que é então corrigido pela equipe de design.

As metas de usabilidade, definidas na última sessão de grupos focais, serão descritas por meio de testes de aceitação automáticos no ambiente de desenvolvimento. Atualmente, apenas alguns testes de aceitação foram criados para o projeto. Os testes basearam-se no arcabouço JBehave, para criação de testes de aceitação baseados em Behaviour-Driven Development (BDD), com o objetivo de avaliar se o comportamento esperado para determinados cenários do sistema alcançaram as metas de usabilidade definidas. A escolha desse arcabouço se deve à linguagem de programação utilizada para o sistema, Java, e pela facilidade de inclusão no ambiente de desenvolvimento do projeto, Eclipse.

Inicialmente, no sistema Arquigrafia, foram criados os arquivos usability_goals.story e a classe UsabilityGoals.java. O arquivo .story, exemplificado na Figura 6.14, contém a descrição textual no 


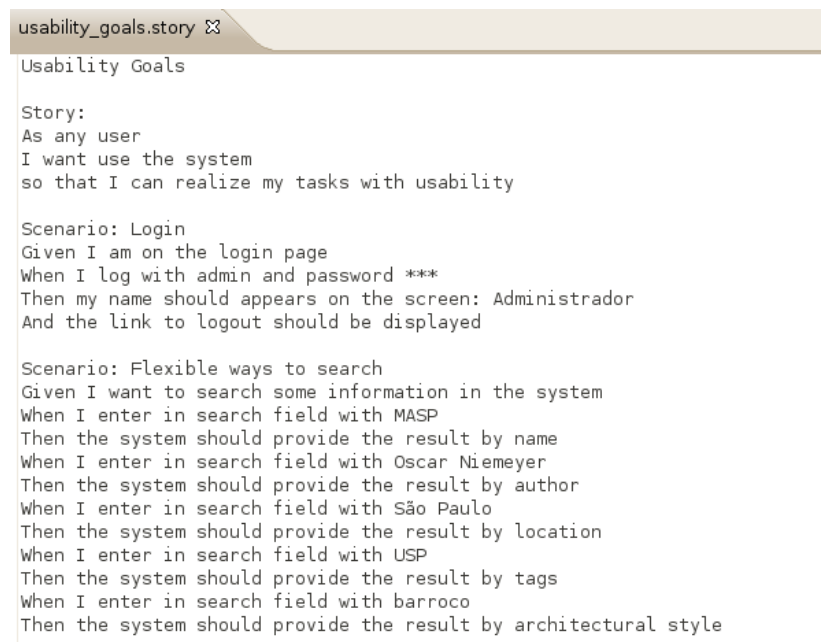

Figura 6.14: Arquivo usability_goals.story que contém as metas de usabilidade definidas para o projeto

formato de uma história de usuário, conforme apresentado na Seção 5.3, contendo uma história para cumprimento das metas de usabilidade do sistema. Ou seja, neste arquivo foram descritas as metas de usabilidade que podem ser verificadas automaticamente pelo sistema. Cada meta é um novo cenário, ou comportamento, esperado para a história. A classe UsabilityGoals, conforme apresentado na Figura 6.15 é uma classe de configuração que associa cada cenário textual descrito no arquivo .story a uma classe java que será responsável pela sua implementação, a qual utiliza anotações específicas do Jbehave que associam cada linha de texto, presente na descrição do cenário no arquivo .story e iniciadas pelas palavras-chave Given, When, Then e And, a um método da classe que implementa este cenário.

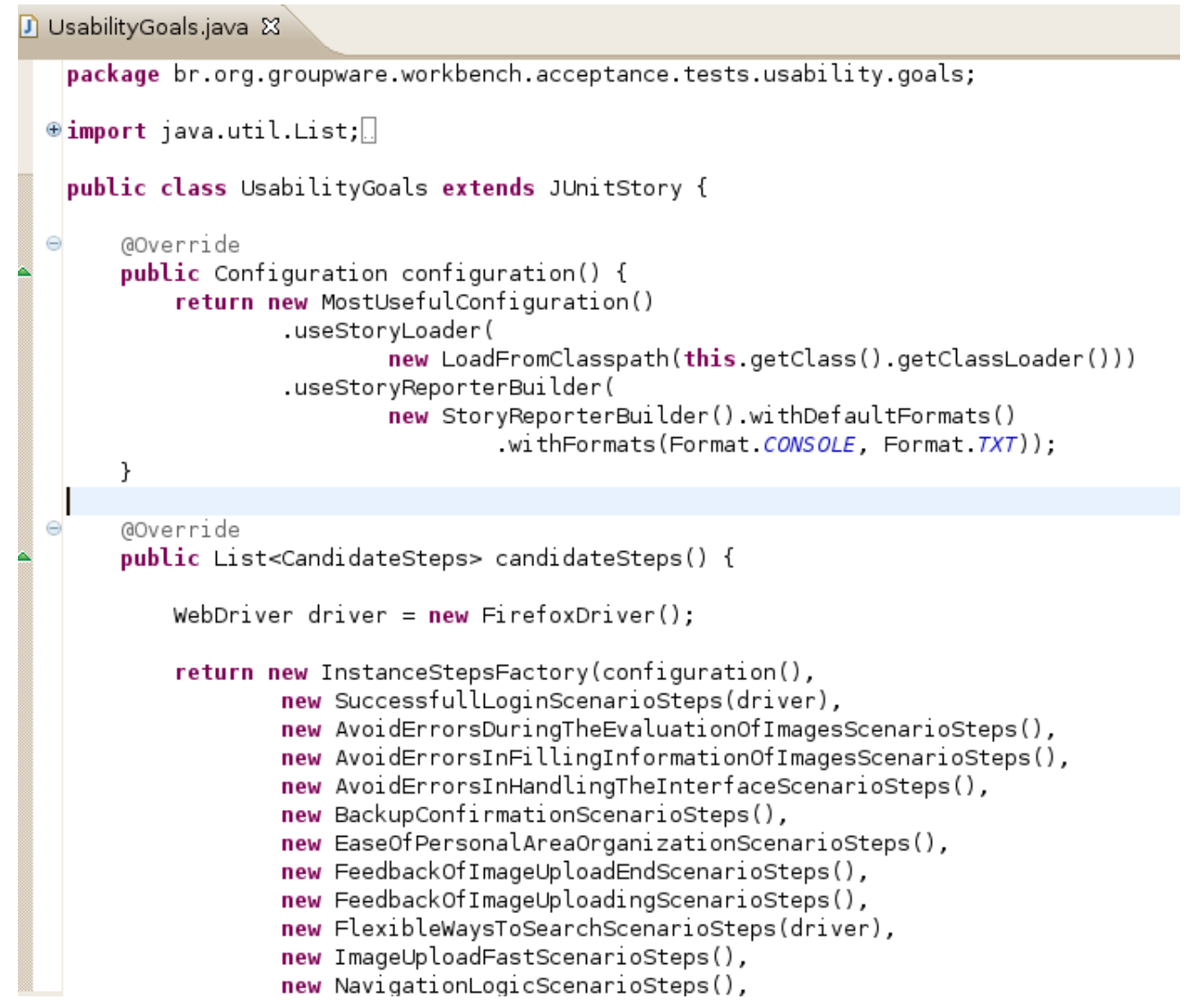

Figura 6.15: Classe UsabilityGoals.java que associa cada cenário descrito no arquivo .story a uma classe java que o implementa 
De modo a melhor integrar a definição de metas de usabilidade, em ambientes que utilizam métodos ágeis e em comunidades de software livre, as metas precisam ser definidas para cada história de usuário e não para todo o sistema. Sendo assim, seria necessário um arquivo com as metas de usabilidade para cada história de usuário. Então, por exemplo, para o cenário de "Login realizado com sucesso", conforme Figura 6.16, teremos um arquivo .story contendo as metas de usabilidade a serem cumpridas para a história de usuário "Realizar login", onde um dos cenários será o "Login realizado com sucesso", no qual espera-se cumprir a meta de usabilidade "feedback de fim de submissão", que por sua vez, está associada ao atributo de usabilidade "Minimizar erros", definido por Nielsen e descrito na Seção 3.1. A justificativa para esta meta é garantir que o usuário consiga realizar as ações que deseja no sistema e que será informado se obteve ou não sucesso em suas atividades. Nesse caso tem-se um arquivo "login_usability_goals.story", associado a um arquivo "LoginUsabilityGoals.java" que conecta cada cenário descrito no arquivo .story a uma classe que o implementa. Para o caso do cenário "Login realizado com sucesso", a classe "SuccessfulLoginScenarioSteps" é responsável pela implementação. A classe "UsabilityGoals" passa agora a ser uma fábrica para instanciar histórias de usuários. Cada classe representando uma história de usuário, como "LoginUsabilityGoals", passa a ser a classe de configuração para todos os cenários possíveis desta história.

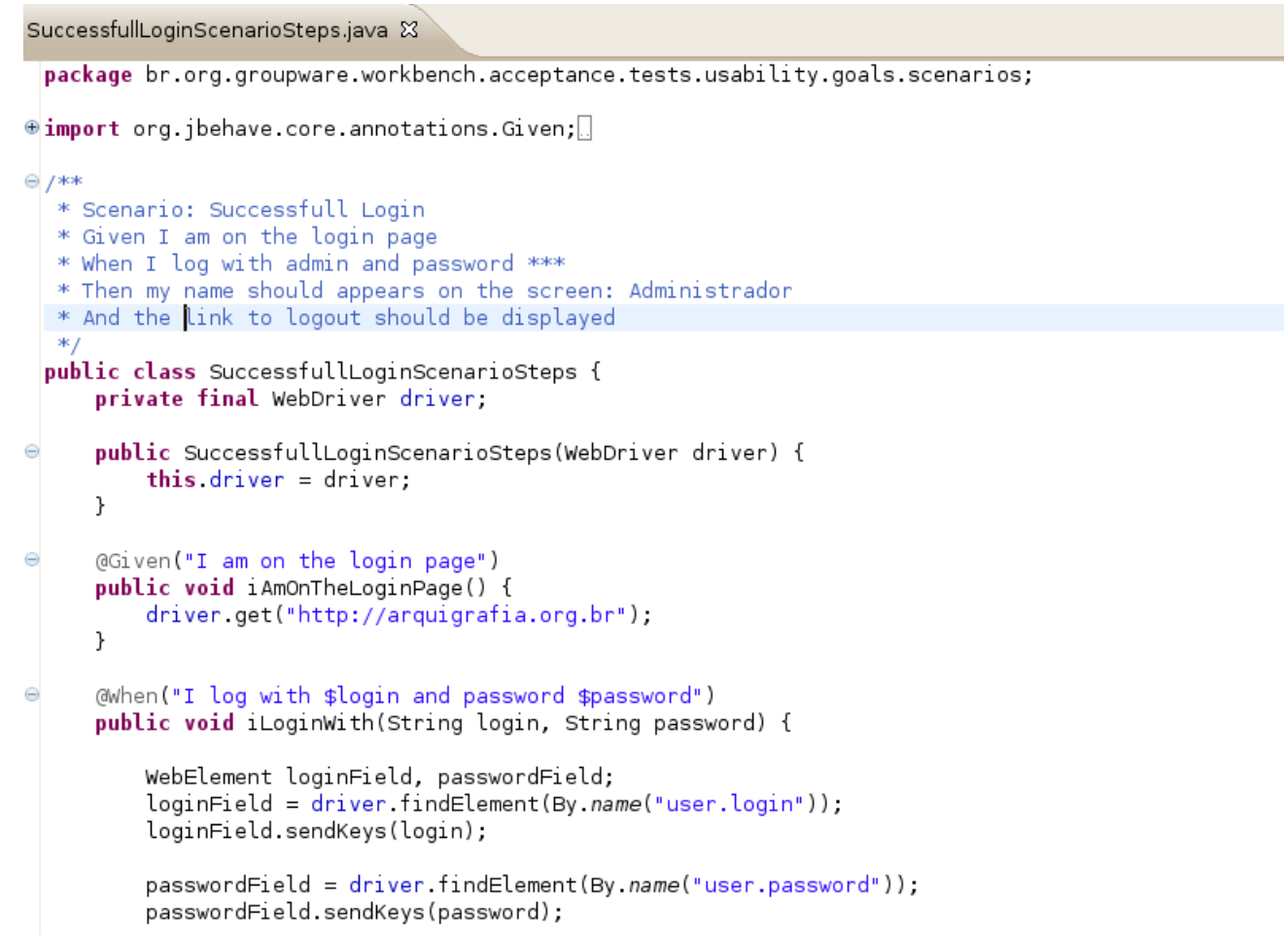

Figura 6.16: Exemplo de classe que implementa o cenário Login realizado com sucesso descrito em um arquivo .story, que contém as metas de usabilidade da história de usuário Realizar login

\section{Reflexão do Ciclo 6 da pesquisa-ação}

O ciclo 6 está em uma fase de integração entre o código HTML e o código Java, e posteriormente, serão realizados novos testes de usabilidade na interface integrada, de modo a avaliar metas de usabilidade e a corretude das tarefas realizadas pelos usuários no sistema.

Os testes de aceitação automáticos têm o objetivo de documentar os requisitos de comportamento para o sistema e gerar um relatório atualizado das funcionalidades que estão implementadas de acordo com os requisitos levantados. Os testes de usabilidade com usuários e os testes de aceitação, possibilitam a avaliação de metas de usabilidade qualitativas e quantitativas respectivamente. No próximo capítulo, serão apresentadas propostas de adaptações de práticas de usabilidade ágil 
para o contexto de comunidades de software livre, que levam em consideração a experiência obtida durante o desenvolvimento do projeto Arquigrafia-Brasil.

\subsection{Estudo de caso no Projeto Mezuro}

O projeto Mezuro é uma aplicação Web para que os líderes e desenvolvedores de projetos de software livre possam monitorar características de código-fonte, através de métricas de acoplamento, coesão, tamanho, encapsulamento, entre outras. Isso proporcionará um acompanhamento do quanto o software está crescendo e se tornando mais complexo em relação a ele mesmo e à média dos projetos avaliados pelo Mezuro. O Mezuro (mezuro.org) é a evolução das funcionalidades fornecidas pelas ferramentas Kalibro [Fil09] e Analizo [ $\left.\mathrm{TCM}^{+} 10\right]$. O objetivo é possuir recursos de visualização semelhantes ao GitHub, Heroku e GoogleAnalytics para métricas de código-fonte. Nesse estudo de caso, participei durante um semestre, como desenvolvedora do projeto e com o papel de tracker de usabilidade, no qual são realizados processos para melhorar a usabilidade do sistema e encontrar maneiras eficazes de apresentar as informações encontradas nas análises de usabilidade para toda a equipe. Os clientes do projeto estavam distantes da equipe de desenvolvimento sendo, portanto, uma oportunidade de explorar a aplicação de práticas de usabilidade ágil de maneira distribuída. O projeto Mezuro segue a metodologia XP para desenvolvimento de software.

Durante o acompanhamento do projeto Mezuro, foram aplicadas as seguintes práticas de usabilidade: testes de usabilidade com cinco usuários, seguidos de uma entrevista; uma avaliação heurística; e prototipação de baixa e média fidelidade. Além disso, foram realizadas atividades com o papel de tracker de usabilidade para coletar informações relevantes obtidas com as práticas de usabilidade e apresentá-las aos membros da equipe.

Nesse momento, as práticas de XP Papo em pé, Retrospectiva, Área de trabalho informativa e Cliente presente ajudaram a perceber o valor da comunicação e do compartilhamento de informações entre membros da equipe. Dessa forma, a observação participativa durante a construção do sistema, contribuiu para essa percepção, possibilitando a definição de propostas de adaptações às práticas de usabilidade para melhor adequação a um determinado contexto. Por exemplo, a proposta de prática Definir metas de usabilidade automáticas, que será apresentada na Seção 7.2, é um exemplo de adaptação de uma prática de usabilidade, Definir metas de usabilidade, por meio da integração com uma prática ágil comum em equipes que utilizam XP, a prática de TDD, que nesse caso, passa a também considerar as metas de usabilidade do sistema.

Os resultados obtidos com as práticas de usabilidade foram apresentados para a equipe por meio das práticas Área de trabalho informativa e Papo em pé, as quais possibilitaram discussões a respeito dos dados coletados e das suas implicações para o desenvolvimento. Por exemplo, a prototipação de baixa e média fidelidade de interfaces do sistema, eram compartilhadas na área de trabalho, de modo a facilitar a definição de interfaces para histórias que seriam implementadas na iteração. A figura 6.17 apresenta protótipos de baixa fidelidade definidos para interfaces do sistema referentes a histórias de usuário a serem implementadas na próxima iteração. Os protótipos foram apresentados por meio do Papo em pé, onde contribuições da equipe e clientes, permitiram avaliá-lo e corrigi-lo.

Durante a escrita de Histórias de usuários e a realização da prática Jogo do planejamento a prototipação de baixa fidelidade era utilizada para melhor explicar os requisitos que deveriam ser tratados pela funcionalidade, para apresentar ideias de design que seriam mais adequadas para o contexto e para validar fluxos de cenários de uso. Por meio dos protótipos era possível estimar melhor a dificuldade de implementação de cada história e o tempo para desenvolvê-la. Os membros da equipe utilizavam uma lousa para rascunhar e validar ideias para interfaces do sistema durante encontros presenciais. Os protótipos de média fidelidade definidos pela equipe com a ajuda dos clientes foram evoluindo ao longo do projeto para o sistema com código implementado. As reuniões com os clientes do projeto eram realizadas presencialmente ou por meio do Skype, pois algumas vezes os clientes encontravam-se distantes geograficamente. Nas reuniões apresentava-se as interfaces e funcionalidades implementadas durante a semana.

Antes da aplicação dos testes de usabilidade com usuários típicos do sistema, realizou-se uma 


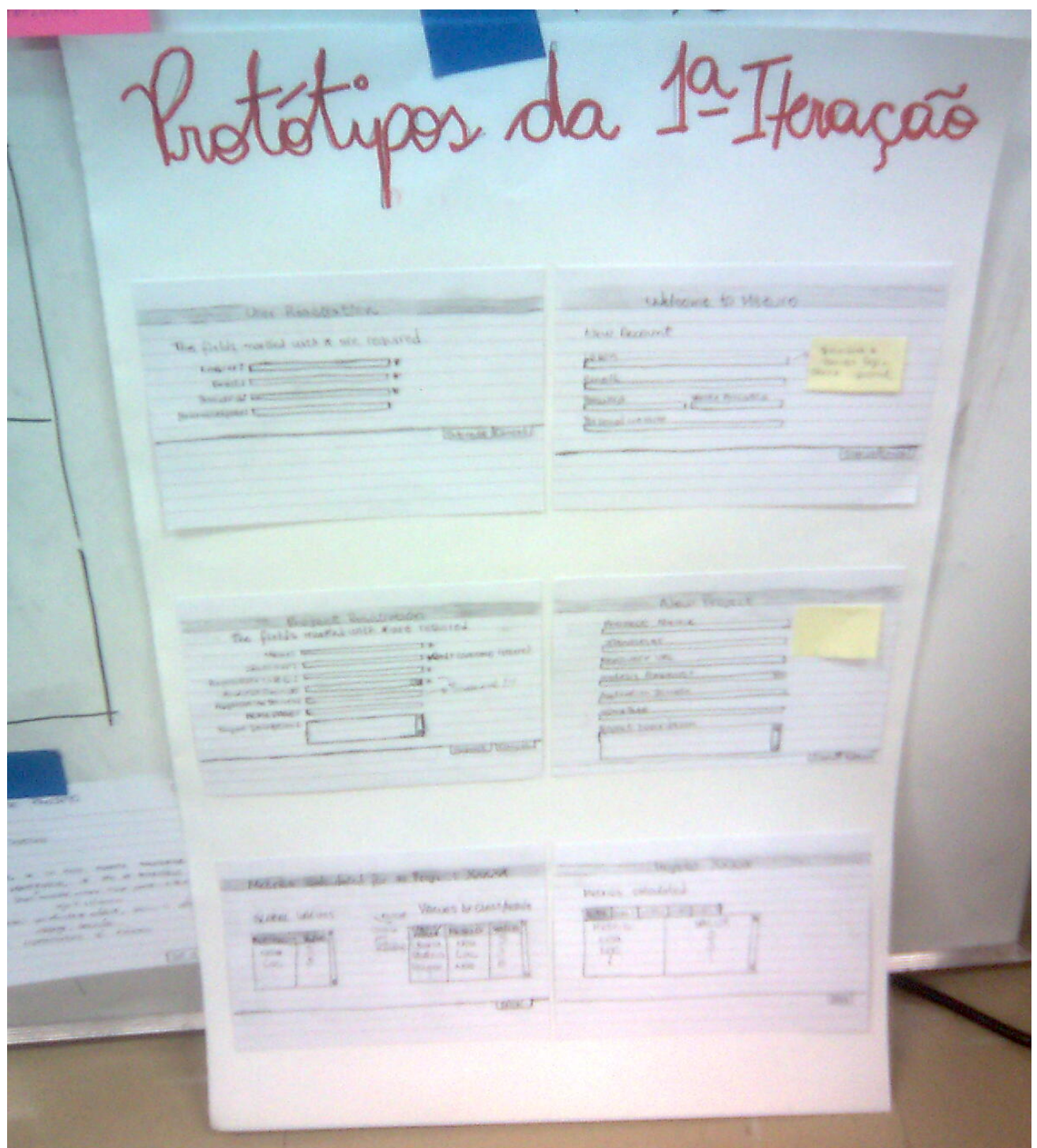

Figura 6.17: Protótipos de baixa fidelidade expostos na Área de trabalho informativa do projeto.

avaliação heurística. Um relatório foi produzido com os resultados, descrevendo o significado de cada grau de severidade dos problemas encontrados e uma lista contendo os problemas de usabilidade, uma proposta de solução e o grau de severidade. O relatório foi compartilhado por email com a equipe, inclusive clientes. Além disso, os resultados foram compartilhados por meio das práticas Papo em pé e Área de trabalho informativa. Uma iteração foi utilizada para a correção dos problemas encontrados, seguindo a ordem de priorização a partir de problemas mais graves, que poderiam afetar a utilização do sistema.

Após as correções dos problemas encontrados com a avaliação heurística, um teste de usabilidade foi aplicado com cinco usuários típicos. Para realização do teste utilizou-se a ferramenta gtkRecordMyDesktop para registro em vídeo das ações que o usuário realizava no sistema. O teste composto de 9 tarefas foi realizado presencialmente. Cada usuário recebeu um roteiro do teste de usabilidade, explicando como o teste funcionava e apresentando as tarefas a serem realizadas no sistema. O usuário poderia tirar dúvidas antes de começar o teste sobre qualquer item que não compreendesse. O teste foi cronometrado e foi utilizado o protocolo Pensando em voz alta. Após cada teste de usabilidade, foi realizada uma entrevista para obter as impressões do usuário sobre o sistema. Os resultados foram compartilhados com a equipe por meio do Papo em pé e Área de trabalho informativa.

A prática Retrospectiva possibilitava a reflexão, ao fim de cada iteração, das ações realizadas com sucesso e as que precisavam ser melhoradas. Todos os membros participavam com ideias de melhorias 
e fornecendo seu ponto de vista a respeito das atividades realizadas. As atividades de usabilidade aplicadas durante o desenvolvimento do sistema também foram beneficiadas pelas contribuições da equipe em como melhor adequá-las ao contexto do projeto.

O projeto Mezuro proporcionou a vivência do dia a dia de desenvolvimento em equipes que utilizam o método ágil XP e a exploração de práticas de usabilidade nesse contexto, o que contribuiu com a definição de propostas de adaptações de práticas de usabilidade descritas no Capítulo 7.

\subsection{Aplicação de práticas de usabilidade em projetos de software livre}

Foram aplicadas práticas de usabilidade específicas em projetos do Centro de Competência em Software Livre (CCSL) do IME-USP. O método de observação participativa foi utilizado para aplicação das práticas. O objetivo era a visualização dos resultados obtidos em contextos reais de desenvolvimento de sistemas de software livre.

\subsubsection{Projeto Borboleta}

O projeto Borboleta (ccsl.ime.usp.br/borboleta) é um sistema de software livre para suporte a atendimento domiciliar de saúde. O objetivo do Projeto Borboleta é investigar ferramentas e metodologias inovadoras em TI para dar suporte a programas de atendimento domiciliar em saúde pública; utilizando-se de ferramentas avançadas de Computação Móvel para contribuir com a melhoria dos serviços de saúde prestados à população de baixa renda. O projeto é uma iniciativa do CCSL do IME-USP.

Durante o desenvolvimento do projeto Borboleta percebeu-se a necessidade de redesign das interfaces do dispositivo móvel utilizado para atendimento domiciliar. Sendo assim, foi aplicado o método de usabilidade de Design Participativo presencial, envolvendo membros da equipe de desenvolvimento do projeto e o cliente, que é médico do Centro de Saúde Escola do Butantã da Faculdade de Medicina da USP.

Em uma reunião presencial, requisitos do sistema foram discutidos e rascunhos de telas do sistema foram desenhados entre clientes e desenvolvedores do projeto, de modo a definir melhorias para as interfaces. Em aproximadamente uma hora e trinta minutos foram definidas as principais interfaces, incluindo o fluxo correto esperado pelo cliente para cada uma das tarefas. No fim da sessão, uma série de rascunhos da interface, ou protótipos de baixa fidelidade, havia sido definida.

Após a sessão colaborativa entre clientes e desenvolvedores, as telas desenhadas foram colocadas na parede do laboratório de trabalho da equipe, seguindo a ordem do fluxo de navegação no sistema. O redesign possibilitou melhorias de usabilidade na interface móvel, o que gerou um novo diagrama de navegação, conforme apresentado na Figura 6.18.

\subsubsection{Projeto Balcão de Dúvidas}

O projeto Balcão de Dúvidas (ccsl.ime.usp.br/duvidas) é um software livre, no qual internautas acessando o site do CCSL, poderão enviar perguntas sobre software livre ou sobre projetos do CCSL para serem respondidas por especialistas voluntários.

Foi aplicada uma avaliação heurística somativa, ou seja, após o desenvolvimento do sistema, para o sistema Balcão de Dúvidas. Os problemas encontrados foram apresentados por meio de um relatório, enviado por email aos membros da equipe de desenvolvimento, descrevendo o problema e a solução proposta para resolvê-lo. Cada problema foi descrito indicando o seu grau de severidade, por isso uma definição para cada grau de severidade foi apresentada no relatório. Os problemas mais graves foram corrigidos pelos desenvolvedores do sistema e aplicados no sistema em produção. 


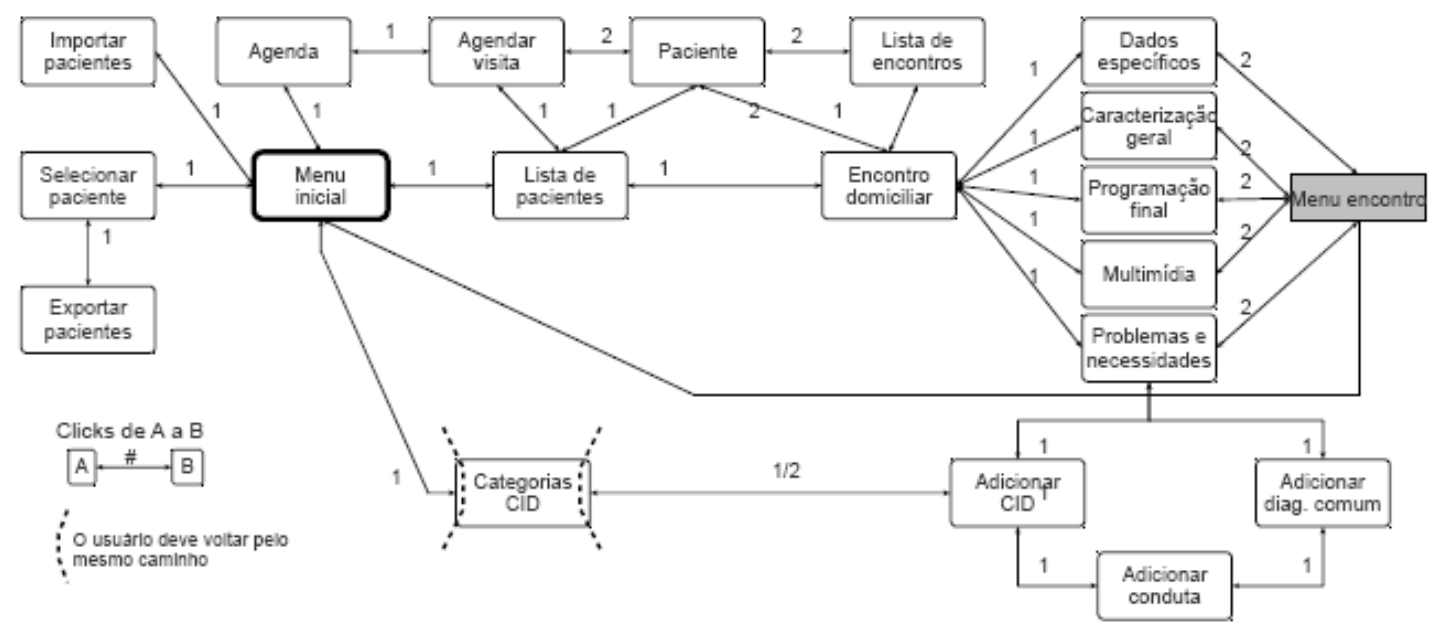

Figura 6.18: Diagrama de navegação do Borboleta [Gí1].

\subsubsection{Projeto CoGrOO}

O projeto CoGrOO é um corretor gramatical acoplável ao LibreOffice, com o objetivo de detectar erros nas relações entre as palavras, por exemplo, na sentença "Os menino estudam demais.", o corretor gramatical detecta o erro na concordância entre o artigo "os" e o substantivo "menino". E também sugere uma medida corretiva, como a substituição da palavra "menino" pela mesma palavra flexionada no plural, que é "meninos".

Sendo assim, conforme o site do projeto, (ccsl.ime.usp.br/cogroo), o CoGrOO é capaz de detectar diversos tipos de erros gramaticais, sendo os mais importantes listados a seguir: (1) colocação pronominal; (2) concordância nominal; (3) concordância entre sujeito e verbo; (4) concordância verbal; (5) uso de crase; (6) regência nominal; (7) regência verbal; e (8) erros comuns da língua portuguesa escrita.

Também para o projeto CoGrOO, foi aplicado uma avaliação heurística somativa. Os problemas encontrados foram apresentados por meio de um relatório, enviado por email aos membros da equipe de desenvolvimento, contendo as mesmas informações definidas para o relatório de resultados da avaliação heurística do projeto Balcão de Dúvidas, conforme descrito anteriormente. Os problemas de usabilidade foram corrigidos pelos desenvolvedores e aplicados no sistema em produção, que encontra-se disponível em cogroo.sourceforge.net.

\subsubsection{AgilCoop}

A AgilCoop (Cooperativa de Desenvolvimento Ágil de Software) (agilcoop.org.br) é composta por professores, alunos e ex-alunos do IME/USP e visa manter-se na vanguarda do desenvolvimento de software e promover inovações nas empresas e instituições brasileiras públicas e privadas. Um dos exemplos disso foi a intensa promoção de métodos ágeis nos últimos anos, meta alcançada com sucesso pela cooperativa $\left[\mathrm{CGK}^{+} 11\right]$.

Foi notada a necessidade por membros da AgilCoop, de melhoria da organização das informações no portal Web da cooperativa, para que este possa atrair novos usuários. Em consequência disso, foi realizado em algumas horas, o método de Design Colaborativo remoto, por meio de pareamento. As ideias de design eram compartilhadas por meio da ferramenta Skype e em seguida eram aplicadas no sistema, que foi sendo atualizado em tempo real. A organização do conteúdo das páginas foi modificada de modo a dar mais destaque para informações mais importantes e links desatualizados foram retirados. A nomenclatura de títulos e links também foi alterada para versões mais convidativas para os usuários. Após as mudanças, o link do site foi compartilhado por email para avaliação dos demais membros do projeto. O foco do redesign foi sobre a organização de conteúdo e não sobre melhorias de design gráfico. 
A diferença aqui entre o método de design participativo presencial realizado no projeto Borboleta e o design colaborativo remoto realizado no portal da AgilCoop é que no design participativo envolveu-se usuários típicos do sistema na sessão de design e os protótipos foram definidos em papel para posterior aplicação no sistema. Enquanto, no portal da AgilCoop, as ideias de design foram levantadas e aplicadas imediatamente no sistema em produção, disponibilizando para avaliação o próprio sistema já modificado.

\subsection{Notas do Capítulo}

Neste capítulo foram apresentadas as experiências com a aplicação de práticas de usabilidade em projetos de software livre. As lições aprendidas serão utilizadas como base para as propostas de práticas de usabilidade descritas no próximo capítulo. Todos os projetos descritos pertencem ao Centro de Competência em Software Livre do IME-USP. 


\section{Capítulo 7}

\section{Práticas de Usabilidade Ágil em Software Livre}

São necessárias adaptações em métodos de usabilidade para aplicação em ambientes distribuídos, abertos e colaborativos, como em comunidades de software livre. Isso ocorre porque em comunidades de desenvolvimento de software livre, não se pode garantir a existência de um indivíduo especialista em usabilidade ou de uma equipe dedicada a essas atividades. A distância física de membros que contribuem com o projeto também dificulta a utilização de métodos de usabilidade que dependem de comunicação face a face. Mesmo assim, a usabilidade deve ainda ser considerada, afinal ela é muito importante para a criação de um sistema de qualidade, em qualquer ambiente.

A usabilidade deve fazer parte do desenvolvimento, não apenas em busca de produtos usáveis, mas também de práticas usáveis e de modo a envolver todos os membros de uma equipe considerando o contexto em que as práticas serão aplicadas. Dessa forma, não se tem uma equipe de acordo com os valores de métodos ágeis e de métodos de usabilidade se apenas alguns se preocupam em atender as necessidades dos usuários típicos e clientes, pois todos os membros precisam entender a importância de atendê-las.

No sentido de métodos ou práticas usáveis, métodos ágeis são considerados mais leves [CG11], ou seja, possuem maior usabilidade. Em contrapartida, DCU traz a importância do usuário real no desenvolvimento de sistemas. Sendo assim, o encontro das duas áreas traz benefícios para ambas. Afinal, desenvolve-se software com pessoas e para pessoas.

Todos os participantes envolvidos na construção de um sistema são usuários de métodos ou práticas para desenvolvimento de software. Por esse motivo, ao pensar em um método para desenvolvimento de software, é necessário pensar em seus usuários, quem são, quais são suas necessidades, como realizam hoje suas tarefas e em que contexto, de modo a valorizar o ser humano envolvido. Ou seja, aplicando as mesmas tarefas utilizadas para entendimento dos usuários finais de um sistema, para os usuários dos métodos para desenvolvê-lo.

\subsection{Síntese de práticas de usabilidade ágil em contexto de software livre}

Com o levantamento dos principais padrões de uso de práticas de usabilidade no desenvolvimento de software com métodos ágeis e das principais práticas em comunidades de software livre, foi possível conhecer as soluções propostas por cada comunidade para resolver problemas de integração de métodos de usabilidade no ciclo de desenvolvimento. Esta pesquisa, estudou a possibilidade de facilitar a aplicação de métodos de usabilidade em comunidades de software livre, compostas por equipes que possuem apenas desenvolvedores e que não têm o suporte de grandes organizações, por meio da inclusão de valores de métodos ágeis na integração de métodos de usabilidade.

Essa reflexão será descrita por meio do formato fase-aplicação-integração. A fase faz referência a uma das cinco fases do DCU, descritas na Seção 3.4.2 do Capítulo 3. A aplicação refere-se a 
uma reflexão de como esta fase do DCU está sendo realizada em comunidades de software livre atualmente, conforme práticas descritas na Seção 4.2 do Capítulo 4. A integração contém a síntese de padrões de práticas de usabilidade da comunidade de métodos ágeis, descritas na Seção 5.3 do Capítulo 5, integradas às práticas de usabilidade da comunidade de software livre e, quando necessário, uma proposta de adaptação de uma prática de usabilidade da comunidade de métodos ágeis, para melhor adequação ao contexto de software livre. Para cada proposta de adaptação, será feita a referência ao nome de uma prática adaptada definida na Seção 7.2.

\subsubsection{Fase: Identificar necessidades para design centrado em humano}

Aplicação: Não foram encontradas práticas específicas para identificar necessidades para design centrado em humano em comunidades de software livre.

Integração: As práticas de usabilidade ágil, Um Sprint na frente, Sprint Zero, Especialistas em UX como Donos do Produto, Caminhos Paralelos e 100\% de Compromisso UX, descritas na Seção 5.3 poderiam ser utilizadas por equipes da comunidade de software livre que podem contar com especialistas em usabilidade ou com pessoas dedicadas a atividades relacionadas à usabilidade, como UX. Dessa forma, existiriam dois grupos de trabalho na equipe, o de desenvolvimento e o de usabilidade. Para que as práticas sejam realizadas de acordo com o padrão de comunidades de métodos ágeis, seria necessário que uma parte da equipe de usabilidade fizesse parte da equipe-núcleo do software livre. O compartilhamento de informações com os demais membros ocorreria por meio de listas de emails, blogs ou ferramentas de acesso online. Contudo, para uma equipe da comunidade de software livre, onde existem apenas desenvolvedores e sem a presença de especialistas, seria necessário envolver toda a equipe-núcleo na aplicação da prática Sprint Zero, com o subsequente compartilhamento dos resultados. A prática Especialistas em UX como Donos do Produto poderia ser adaptada para a proposta de prática Equipe-Núcleo como Donos do Produto. A prática Caminhos Paralelos poderia ser adaptada para a proposta de prática Caminhos Completos. A prática Tempo do usuário é valioso pode ser aplicada em qualquer contexto, pois necessita que cada contato com o usuário seja aproveitado para realização de várias atividades. A proposta de prática Especialista-generalista pode ser um meio de adaptar a aplicação de práticas de usabilidade em equipes de desenvolvimento de software livre, compostas apenas por desenvolvedores.

\subsubsection{Fase: Especificar contexto de uso}

Aplicação: Foram levantadas as práticas Modelo de Pesquisa de Usuário, Fórum de usuários e Questionários, as quais possuem o objetivo de especificar o contexto de uso de sistemas. A prática Modelo de Pesquisa de Usuário ajuda a compartilhar com os demais contribuidores como se deve realizar e documentar resultados de pesquisa com usuários. Contudo, o modelo é criado com a ajuda de especialistas em usabilidade, o que equipes menores dificilmente possuem. O Fórum de usuários é uma boa maneira de conhecer as necessidades dos usuários no contexto de comunidades de software livre e pode ser utilizado por qualquer equipe, uma vez que o fórum é disponibilizado na Web para discussão entre os usuários. A ressalva se deve ao fato de que esses fóruns costumam ser frequentados por usuários mais técnicos ou experientes, o que impossibilita o conhecimento das necessidades de usuários novatos ou menos experientes. Além disso, os fóruns são criados a partir de sistemas já funcionando, mesmo que com poucas funcionalidades, e não sobre sistemas em fases iniciais de desenvolvimento. A prática de levantamento através de Questionários é uma técnica adequada para o contexto de desenvolvimento de software livre, mas ainda é pouco utilizada. Geralmente, é realizada por projetos maiores, os quais apresentam usabilidade superior a de projetos menores da comunidade.

Integração: A utilização da prática Pouco design antecipado, utilizada com métodos ágeis, poderia resolver o problema de não ouvir todos os perfis de usuários típicos através de fóruns, uma vez que práticas como grupos focais e entrevistas poderiam ser utilizadas, presencialmente ou remotamente, 
de acordo com o contexto, porém sobre pequenos grupos de requisitos, o que torna a execução mais rápida. A entrevista e os grupos focais remotos aplicados no projeto Arquigrafia ajudaram a compreender melhor requisitos específicos. Na segunda aplicação de sessões de grupo focal, remoto e presencial, e da entrevista remota, utilizou-se a prática Pouco design antecipado, com enfoque apenas em uma atividade que foi o alvo das discussões. A análise foi realizada por meio de brainstorm logo após as sessões, o que demonstrou ser mais adequado para o contexto de uma equipe de software livre que utiliza métodos ágeis. Para equipes com membros distribuídos, poderia ser usada uma adaptação da prática Pouco design antecipado, como a proposta de prática Pouco design antecipado e distribuído.

O Plano de Contato de usuários, da comunidade de métodos ágeis, poderia ser utilizado sem alterações no contexto de desenvolvimento de software livre. Para essa prática, é necessário possuir uma lista de usuários com os quais seja possível contar com a participação quando uma história de usuário ou funcionalidade necessitar de mais detalhes para ser melhor compreendida, por exemplo, antes do início de uma nova iteração ou sprint. Ou ainda, quando é necessário obter feedback de usuários reais sobre interfaces ou funcionalidades implementadas, por meio de avaliações de usabilidade. A prática de Questionário poderia ser aplicada sobre pequenos grupos de requisitos, com menor granularidade de detalhes, de modo a também utilizar a prática Pouco design antecipado. No projeto Arquigrafia, o questionário online possibilitou definir o perfil de usuários típicos do sistema, por meio da divulgação do questionário em listas de emails relacionadas a arquitetura ou fotografia de arquitetura, sites especializados em arquitetura e fotografia de arquitetura, como Vitruvius, bem como pela divulgação entre pessoas da área. Também envolveu-se a equipe de desenvolvimento nos testes-piloto do questionário e na sua divulgação.

\subsubsection{Fase: Especificar requisitos}

Aplicação: Foram levantadas as práticas Registro de soluções de desenvolvedores, Registro de brainstorm de usuários e Visão online do sistema, as quais possuem o objetivo de especificar requisitos de projetos. A prática Registro de soluções de desenvolvedores traz para o sistema a visão de funcionalidades pensadas e implementadas por contribuidores, que são usuários do sistema que também são desenvolvedores. Ou seja, a funcionalidade é definida por usuários experientes e técnicos. O Registro de brainstorm de usuários é semelhante ao registro de soluções de desenvolvedores, porém as ideias de melhorias ou novas funcionalidades são submetidas por usuários típicos não técnicos. As duas práticas mostram-se adequadas na criação de novas funcionalidades para sistemas de software livre, onde um núcleo de funcionalidades básicas é disponibilizado em uma versão do sistema para uso e novas características ou melhorias são implementadas a partir dos comentários de utilização. Contudo, os registros geralmente ocorrem em projetos com alta atratividade para usuários e desenvolvedores. A prática Visão online do sistema apresenta uma visão geral do sistema, sem maiores detalhes das funcionalidades. De modo geral, a especificação de requisitos em comunidades de software livre tende a ser uma documentação de funcionalidades já implementadas ou registros de discussões para solicitação de novas funcionalidades.

Integração: A prática da comunidade de métodos ágeis Mais colaboração, menos documentos pode ser utilizada localmente pela equipe-núcleo e compartilhada entre os demais membros do projeto por meio de listas de emails, de um blog do sistema ou de ferramentas para acesso online. A prática Tratar protótipo como especificação também ajudaria a novos membros ingressantes durante o desenvolvimento, de modo a possibilitar a compreensão do fluxo de telas e o comportamento esperado. Na comunidade de métodos ágeis, utiliza-se a prática de Histórias de usuários para especificação dos requisitos do sistema. Para equipes de projetos de software livre onde apenas membros co-localizados fazem parte do processo de desenvolvimento, essa poderia ser uma prática utilizada para especificação de requisitos, pois ainda seria mantido o enfoque, de comunidades de software livre, sobre um núcleo de funcionalidades para uma versão do sistema. Porém em ambientes distribuídos, a solução Sala de Equipe Virtual com Cartões Online, descrita para o desafio de possuir vários recursos distribuídos no projeto, na Seção 5.2, seria uma boa solução para manter todos os 
membros atuais e possíveis ingressantes informados do que está sendo desenvolvido. A definição de metas de usabilidade quantitativas poderia ser realizada por meio da proposta de prática Definir metas de usabilidade automáticas, conforme foi experimentado no projeto Arquigrafia.

\subsubsection{Fase: Criar soluções de design}

Aplicação: Foram levantadas as práticas Design por blog, Diretrizes de Interface com Humanos, Envolvimento de especialistas em design de interface e Design cedo e frequente, as quais possuem o objetivo de criar soluções de design para o sistema. A prática Design por blog explora a possibilidade de envolver indivíduos de diversos locais, colaborando para definição da interface do sistema. É uma prática semelhante à prática Design Colaborativo e Participativo da comunidade de métodos ágeis, porém realizada de forma distribuída ao invés de presencialmente. Contudo, ainda é pouco utilizada. A prática Diretrizes de Interface com Humanos é uma boa aliada do desenvolvimento distribuído, uma vez que possibilita manter a padronização do design de interfaces mesmo à distância e com a entrada e saída de desenvolvedores do projeto. A padronização de design possibilita a criação de interfaces que são mais fáceis de aprender a utilizar, porque uma vez tendo realizado uma ação em uma parte do sistema, a mesma ação em outro local, seguirá o mesmo comportamento. Porém, se as diretrizes forem utilizadas sem aplicar práticas que envolvam o feedback de usuários típicos, dificulta-se a abertura de espaço para inovação e melhorias de usabilidade vindas a partir das necessidades de usuários reais.

A prática Envolvimento de especialistas em design de interface utiliza a mesma abordagem de convidar contribuidores para qualquer tarefa do ciclo de desenvolvimento de um software livre, onde espera-se que pessoas motivadas a colaborar participem. É uma prática adequada para o contexto de software livre e que depende da atratividade do sistema, como ocorre normalmente neste contexto. A prática Design cedo e frequente é uma prática iterativa de criação de design de interfaces, que assemelha-se à prática de Prototipação, descrita na comunidade de métodos ágeis. É uma prática que pode ser aplicada em qualquer contexto de desenvolvimento, sendo possível apoiar-se tanto em protótipos de baixa fidelidade, quanto em protótipos de alta fidelidade.

Integração: Em projetos menores da comunidade de software livre, a prática Design Colaborativo e Participativo, poderia ser aplicada pela equipe-núcleo sobre pequenos conjuntos de funcionalidades, priorizando as interfaces mais complexas. As novas ideias de design e melhorias podem ser compartilhadas e definidas em conjunto por meio do Design por blog. Porém, para que sejam aplicadas, é necessário que existam pessoas na equipe-núcleo que possam analisar as contribuições de design antes que elas sejam aceitas na versão de distribuição do sistema, assim como ocorre com o código, de modo a filtrar e selecionar apenas as contribuições relevantes e de acordo com o padrão de design adotado pela equipe. As interfaces mais básicas, como telas de cadastro, podem ser definidas por meio da utilização das Diretrizes de interface com humanos. A prática Estúdio de design, da comunidade de métodos ágeis, poderia ser utilizada por meio de ferramentas que permitam a conversa em tempo real entre os participantes, mesmo os que encontram-se distantes da equipe-núcleo. Também pode ser realizada apenas com membros da equipe-núcleo de modo a tomar decisões de design mais complexas em conjunto. A prática Design cedo e frequente poderia ser utilizada por meio do envolvimento de usuários tipícos, o que poderia ocorrer remotamente através do convite à participação na criação ou avaliação do design de interfaces.

\subsubsection{Fase: Avaliar designs}

Aplicação: Foram levantadas as práticas Lançamento cedo para feedback do usuário, Reuniões de usabilidade, Relatos de erros e Testes de usabilidade remotos, as quais possuem o objetivo de avaliar o design do sistema. A prática Lançamento cedo para feedback do usuário está inserida na cultura de software livre onde os requisitos, melhorias e inovações são resultantes do uso real de versões do sistema. Sendo assim, é um meio de coletar informações para o desenvolvimento de novas funcionalidades e receber feedback de usuários reais. A prática Reuniões de usabilidade assemelha-se 
à prática Estúdio de design, porém com a diferença principal que a primeira ocorre sobre interfaces já implementadas que possuem problemas de usabilidade, enquanto que em Estúdio de Design, são levantadas ideias para o design de interfaces para depois serem implementadas as escolhidas. A prática Relatos de erros é o meio mais comum em comunidades de software livre para conhecimento dos problemas encontrados durante o uso do sistema. Porém, normalmente, a interface utilizada para descrição do bug, costuma ser voltada para usuários com perfil experiente, como descrito na Seção 3.4.2. Além disso, os campos para descrição do problema encontrado solicitam informações detalhadas do problema, o que usuários novatos podem não saber como fornecer. Por fim, a prática Testes de usabilidade remotos costuma ser aplicada por especialistas e em caminhos separados do desenvolvimento do projeto. Também podem ocorrer sobre versões do sistema e não durante o seu desenvolvimento.

Integração: As práticas Lançamento cedo para feedback do usuário e Relatos de erros funcionam bem em meios onde os usuários típicos são experientes e acostumados com tecnologia. Nesse caso, se encontram problemas no uso, sabem que o problema está no produto, e não com eles, e muitas vezes podem dar ideias de como corrigir. Não é o que ocorre com usuários novatos ou aprendizes. Estes quando encontram problemas durante o uso de um sistema, frequentemente, pensam que o problema está com eles, porque eles não sabem utilizar. Por isso, não apontam o problema, porque acreditam que seria algo que deveriam saber. Para esse perfil de usuário, não seria possível esperar comentários de melhoria. Mesmo em testes de usabilidade, é preciso deixar claro que trata-se de um protótipo e que o teste é sobre ele e não sobre o usuário. Por esse motivo, apenas esperar o lançamento para ouvir feedback de usuários com esse perfil não é suficiente, sendo necessária a utilização de testes de usabilidade para atender esse objetivo. De preferência, devem ser realizados testes moderados, onde o moderador deixa claro ao usuário que ele precisa apontar todos os problemas que encontrar. Os testes podem ser realizados tanto remotamente quanto presencialmente dependendo do contexto do projeto; por exemplo, com a equipe-núcleo reunida no mesmo local de trabalho, é possível a realização de teste de usabilidade presencial, que pode envolver desenvolvedores com o papel de moderador ou observador do teste. Também os papeis podem ser trocados entre os membros da equipe a cada novo teste, de modo que todos possam compreender o objetivo de cada papel envolvido. Além disso, por se tratar de sistemas abertos, os testes de usabilidade podem levar em consideração a localização dos membros do projeto, de modo que cada participante possa ajudar na divulgação de testes de usabilidade remotos na sua região, ou mesmo, realizar na sua cidade o mesmo teste de usabilidade aplicado pela equipe-núcleo presencialmente. Os resultados dos testes podem ser analisados de modo a avaliar a usabilidade global [DL11], que atenda os usuários de várias localidades e culturas diferentes, ou ainda, compreender quais são as particularidades de cada lugar.

Ferramentas para coletar dados de usabilidade do sistema são muito úteis nesse ambiente, uma vez que possibilitam o registro das ações do usuário em seu contexto real de utilização. Porém, testes com usuários ainda são a melhor forma de se obter feedback de usuários reais. Sendo assim, a utilização do método RITE, descrito na comunidade de métodos ágeis na Seção 5.3, pode ser uma boa solução no contexto de software livre, principalmente em meios nos quais a equipe é composta apenas por desenvolvedores, sem a presença de especialistas em usabilidade ou UX. Também seria adequada a utilização de testes de aceitação para documentar os problemas encontrados, o que poderia ser realizado pelos próprios desenvolvedores da equipe, conforme descrito na proposta de prática RITE para desenvolvedores de software livre. A Avaliação por inspeção, descrita na comunidade de métodos ágeis, poderia ser aplicada para recuperar problemas maiores de uma interface antes de apresentá-la a clientes e usuários típicos e também poderia ser realizada por desenvolvedores da equipe. 


\subsection{Adaptação de práticas de usabilidade ágil para o contexto de software livre}

Esta seção apresenta propostas de adaptação dos padrões de práticas de usabilidade ágil, descritos na Seção 5.3 do Capítulo 5, para o contexto de software livre. A descrição das práticas utiliza o formato composto de nome, contexto, problema e solução, que foi apresentado em capítulos anteriores. Os exemplos não serão descritos, por se tratar de uma proposta de adaptação de práticas existentes e não um levantamento de práticas já utilizadas.

As lições aprendidas com a aplicação de práticas de usabilidade nos projetos descritos no Capítulo 6, de modo a melhor adequar algumas práticas ao contexto de desenvolvimento de software livre, também foram insumos para a descrição das propostas de adaptações. Especificamente, o contexto de enfoque é formado por equipes compostas apenas por desenvolvedores, que não possuem especialistas em usabilidade ou UX, que são distribuídas, abertas e colaborativas. É importante ressaltar que as adaptações foram propostas porque boa parte dos projetos de software livre encontram-se em desenvolvimento sob o contexto descrito acima, sendo esse o motivo principal de muitas das práticas de usabilidade levantadas em comunidades de software livre não serem aplicadas em projetos menores, e sim, apenas em projetos maiores, que podem contar com a participação de especialistas.

As práticas propostas também são classificadas de acordo com as fases do DCU, conforme a descrição das práticas de usabilidade das comunidades de métodos ágeis e de software livre. Para a fase do DCU Criar soluções de design, não foram identificadas propostas de adaptações, sendo portanto, descritas propostas para as fases: Identificar necessidades para design centrado em humano, Especificar contexto de uso, Especificar requisitos e Avaliar Designs. A Tabela 7.1 apresenta a classificação das propostas de práticas de usabilidade ágil para a comunidade de software livre, de acordo com as fases do DCU, e na sequência, cada uma das propostas são descritas.

Tabela 7.1: Propostas de práticas de usabilidade ágil para a comunidade de software livre.

\begin{tabular}{|l|l|}
\hline \multicolumn{2}{|c|}{ Práticas Propostas } \\
\hline \multicolumn{1}{|c|}{ Fases do DCU } & \multicolumn{1}{c|}{ Práticas de Usabilidade } \\
\hline $\begin{array}{l}\text { Identificar necessidades para } \\
\text { design centrado em humano }\end{array}$ & $\begin{array}{l}\text { Equipe-Núcleo como donos do produto } \\
\text { Caminhos completos } \\
\text { Especialista-generalista }\end{array}$ \\
\hline Especificar contexto de uso & Pouco design antecipado e distribuído \\
\hline Especificar requisitos & Definir metas de usabilidade automáticas \\
\hline Avaliar designs & RITE para desenvolvedores de software livre \\
\hline
\end{tabular}

\subsubsection{Identificar necessidades para design centrado em humano}

\section{Equipe-Núcleo como Donos do Produto}

Contexto: Equipe de desenvolvimento de software livre composta por desenvolvedores e que não possui especialistas em usabilidade ou UX como membros. Contudo, a equipe-núcleo do projeto percebe a necessidade de compreender melhor os requisitos de negócios e de usabilidade, levando em consideração a visão de clientes e usuários típicos.

Problema: Integrar requisitos de negócio com requisitos de usabilidade em um ambiente que não possui especialistas em usabilidade. Principais forças envolvidas: 
- Força 1: Necessidade de levantamento de requisitos de negócios com clientes e requisitos de usabilidade com usuários típicos, de modo a integrá-los para o desenvolvimento do sistema.

- Força 2: Não existe garantia de que especialistas em usabilidade ou UX participarão voluntariamente do projeto e/ou não é possível contratá-los. Também não é possível garantir que desenvolvedores-voluntários queiram participar dessas atividades.

Solução: Uma adaptação da prática Especialistas em UX como Donos do Produto, da comunidade de métodos ágeis, na qual a equipe-núcleo de um projeto de software livre assumiria o papel de Proprietários do Produto, que levam em consideração a usabilidade do sistema. Dessa forma, podem controlar as contribuições para o projeto, com a visão das necessidades de usuários típicos e clientes. A definição e priorização de funcionalidades, para o sistema em desenvolvimento, pode ser realizada através de ferramentas online, como por exemplo, utilizando a Sala de Equipe Virtual com Cartões Online, descrita na Seção 5.2, de modo a registrar as funcionalidades em histórias de usuários e o comportamento esperado para cenários em testes de aceitação automáticos.

\section{Caminhos Completos}

Contexto: Equipe de desenvolvimento de software livre composta por desenvolvedores e que não possui especialistas em usabilidade ou UX como membros. Contudo, a equipe-núcleo do projeto precisa empregar práticas de usabilidade durante o desenvolvimento do sistema.

Problema: Realizar práticas de usabilidade em projetos de software livre que não possuem especialistas em usabilidade ou UX. Principais forças envolvidas:

- Força 1: Necessidade de realizar práticas de usabilidade para pesquisa de usuários, levantamento de requisitos e metas de usabilidade, definição de design e avaliações com usuários e clientes.

- Força 2: Não existe garantia de que especialistas em usabilidade ou UX participarão voluntariamente do projeto e/ou não é possível contratá-los.

- Força 3: Desenvolvimento distribuído e participação esporádica de membros.

Solução: Ao invés de caminhos paralelos entre equipe de desenvolvimento e de UX, como ocorre na prática Caminhos paralelos da comunidade de métodos ágeis, a equipe de desenvolvimento executa o ciclo completo de DCU para um conjunto específico de funcionalidades, utilizando-se de Pouco design antecipado ou Pouco design antecipado e distribuído para coletar informações. A prática pode ser executada apenas pela equipe-núcleo do projeto ou mesmo com a participação dos demais contribuidores que desejem participar.

\section{Especialista-generalista}

Contexto: Equipes de desenvolvimento de software livre, que não possuem especialistas em usabilidade ou UX como membros do time, compostas por desenvolvedores que desejam desenvolver sistemas com melhor usabilidade para usuários típicos.

Problema: Ausência de especialistas em usabilidade ou UX na equipe de desenvolvimento do projeto. Principais forças envolvidas:

- Força 1: Não existe garantia de que especialistas em usabilidade ou UX participarão voluntariamente do projeto e/ou não é possível contratá-los.

- Força 2: Desenvolvimento distribuído e participação esporádica de membros.

Solução: Os desenvolvedores da equipe-núcleo do projeto aplicam práticas de usabilidade para entender quem são os usuários típicos do sistema, quais são as suas necessidades e em que contexto o sistema seria utilizado, de modo a incluir essas considerações nos requisitos da aplicação. As 
pesquisas têm baixa granularidade, ou seja, realiza-se apenas o necessário para o entendimento das funcionalidades da próxima iteração. Os requisitos podem ser definidos por meio da escrita de cartões de histórias de usuários, que são validados com o cliente conforme ocorre em comunidades de métodos ágeis, ou ainda, por meio da Sala de Equipe Virtual com Cartões Online, descrita na Seção 5.2. A documentação detalhada dos requisitos pode ser encontrada nos testes de aceitação, que podem ser acessados por qualquer desenvolvedor do sistema, conforme a prática Testes de aceitação de comunidades de métodos ágeis, o que mantém um relatório atualizado das funcionalidades do sistema que atendem ao comportamento esperado. As metas de usabilidade do sistema também podem ser descritas por meio da proposta de prática Definir metas de usabilidade automáticas.

\subsubsection{Especificar contexto de uso}

\section{Pouco design antecipado e distribuído}

Contexto: Equipe de desenvolvimento de software livre composta por desenvolvedores e que não possui especialistas em usabilidade ou UX como membros. Membros da equipe-núcleo do projeto e contribuidores encontram-se distribuídos em diversas localidades. Contudo, existe a necessidade de realização de pesquisas presenciais com usuários típicos para melhor compreensão do contexto de uso do sistema.

Problema: Utilizar práticas de usabilidade, em ambiente de desenvolvimento de software livre, para especificar contexto de uso de um sistema, onde membros da equipe estão dispersos em vários locais diferentes. Principais forças envolvidas:

- Força 1: Distância física entre membros de uma comunidade de desenvolvimento de software livre.

- Força 2: Necessidade de realização de pesquisas de usabilidade para definição de perfil de usuários típicos e o contexto de uso do sistema.

- Força 3: Possibilitar a participação de voluntários de diversas culturas.

Solução: Equipe-núcleo do projeto é responsável por definir quais são as práticas de usabilidade a serem utilizadas para especificação do contexto de uso de um sistema e também por realizar as práticas presenciais na sua cidade. Membros da equipe, que encontram-se dispersos em locais distintos, poderiam aplicar a mesma prática em sua localidade, de modo a obter feedback de usuários com culturas diferentes; por exemplo, replicando testes, sessões de grupos focais ou entrevistas presenciais, em sua região ou país. Desse modo, possibilita-se a obtenção da percepção cultural de vários locais distintos, de modo a explorar o contexto de projetos abertos, no qual podem existir desenvolvedores, usuários, membros da equipe-núcleo e contribuidores em diversas localidades.

\subsubsection{Especificar requisitos}

\section{Definir metas de usabilidade automáticas}

Contexto: Desenvolvimento aberto, distribuído e colaborativo, onde desenvolvedores podem entrar e sair do projeto durante o processo de desenvolvimento. Também não existe uma equipe de usabilidade trabalhando em conjunto com a equipe de desenvolvimento.

Problema: Definir metas de usabilidade de modo que todos os desenvolvedores que contribuam com um projeto aberto possam conhecer as metas definidas. Principais forças envolvidas:

- Força 1: Necessidade de definição de metas de usabilidade que atendam às necessidades de usuários típicos.

- Força 2: Possibilitar que todos os desenvolvedores tenham contato diário com as metas de usabilidade definidas. 
- Força 3: Desenvolvimento distribuído e participação esporádica de membros.

- Força 4: Manter documentação atualizada das metas de usabilidade tratadas pelo sistema.

Solução: Escrita de testes de aceitação automáticos baseados em Behaviour Driven Development (BDD) para definição de metas de usabilidade. Para o contexto de desenvolvimento livre, seria mais eficiente escrever as metas de usabilidade diretamente no ambiente de desenvolvimento do que em documentos separados, que correm o risco de não serem lidos. Sendo assim, conforme grupos de funcionalidades são selecionados para desenvolvimento, descreve-se as metas de usabilidade que precisam ser cumpridas para essas funcionalidades. Membros da equipe-núcleo do projeto podem escrever testes de aceitação automáticos, envolvendo usuários típicos e/ou clientes, o que possibilita documentar o comportamento esperado para a funcionalidade, e também gerar um relatório do funcionamento do sistema, exibindo quais funcionalidades e quais cenários são implementados de acordo com as necessidades dos usuários reais. Um exemplo da descrição de metas de usabilidade por meio de testes de aceitação automáticos é descrito no ciclo 6 , da pesquisa-ação realizada no projeto Arquigrafia-Brasil, na Seção 6.1.

\subsubsection{Avaliar designs}

\section{RITE para desenvolvedores de software livre}

Contexto: Equipes de desenvolvimento de software livre que não possuem especialistas em usabilidade ou UX como membros do time, mas que tem a necessidade de realizar testes de usabilidade com usuários típicos do sistema de modo a desenvolver sistemas com melhor usabilidade.

Problema: Possibilitar a identificação e correção de problemas de usabilidade no menor tempo possível durante o desenvolvimento de software livre. Principais forças envolvidas:

- Força 1: Diminuir a distância entre a identificação e a correção de problemas de usabilidade encontrados em testes com usuários.

- Força 2: Não existe garantia de que especialistas em usabilidade ou UX participarão voluntariamente do projeto e/ou não é possível contratá-los.

Solução: O método RITE pode ser aplicado por membros da equipe-núcleo do projeto, não sendo necessário utilizar laboratórios de usabilidade com a aplicação de testes formais. Os desenvolvedores da equipe-núcleo podem observar os usuários utilizando um pequeno conjunto de funcionalidades do sistema e solicitar que falem em voz alta o que estão pensando, enquanto o utilizam (Protocolo Pensando em voz alta). Não seria necessária a criação de relatórios e análises de vídeo dos testes, pois os desenvolvedores que estarão envolvidos na correção dos problemas encontrados podem participar do teste como moderadores ou observadores, de modo que possam obter o conhecimento das melhorias necessárias que precisam ser implementadas. Para documentar problemas referentes a um comportamento esperado do sistema, os testes de aceitação automáticos, utilizados pela comunidade de métodos ágeis, podem servir como forma de documentação, como também, para verificar se o sistema está realizando a tarefa do modo que se espera. Nesse caso, o relatório de teste de usabilidade seria substituído por testes de aceitação automáticos. A criação dos testes de aceitação, nesse caso, seria feita pelos próprios desenvolvedores que participaram do teste e conhecem o problema a ser resolvido. Um breve brainstorm após a sessão de teste serviria para consolidar as impressões dos membros da equipe envolvidos, possibilitando definir como os problemas serão corrigidos. A correção dos problemas encontrados seria realizada na sequência da realização do teste. Dessa forma, os testes de aceitação serviriam para registrar como corrigir um problema de usabilidade, detectado no teste com usuários típicos, para um determinado cenário de uso do sistema. 


\subsection{Notas do Capítulo}

Este capítulo apresentou uma síntese das práticas de usabilidade propostas para comunidades de software livre, quando integradas a práticas da comunidade de métodos ágeis. Uma reflexão para cada prática de usabilidade levantada em projetos de software livre, foi realizada de acordo com as fases de DCU e as propostas de adaptações, quando necessárias, foram indicadas de acordo com as práticas de usabilidade da comunidade de métodos ágeis ou práticas de usabilidade ágil. 


\section{Capítulo 8}

\section{Conclusões}

O levantamento de práticas de usabilidade da comunidade de métodos ágeis, práticas de usabilidade ágil, e das práticas de usabilidade da comunidade de software livre, foi realizado com o objetivo de refletir como práticas de usabilidade ágil poderiam ser aplicadas em comunidades de software livre.

Notou-se que as práticas descritas na comunidade de software livre eram aplicadas em projetos maiores, que geralmente possuem o patrocínio de grandes empresas. Já em projetos menores, raramente alguma prática de usabilidade é utilizada. Contudo, a maioria dos projetos de software livre são desenvolvidos por equipes pequenas, compostas geralmente, apenas por desenvolvedores e que não possuem especialistas em usabilidade ou áreas relacionadas como participantes do projeto. Ainda assim, a usabilidade é importante neste contexto.

Algumas práticas de usabilidade ágil podem ser aplicadas sem nenhuma modificação em ambientes de desenvolvimento de software livre, onde seja possível a realização de práticas presencialmente. Em outras, seria necessário realizar a prática de forma remota, por meio de acesso à Internet, tornando possível a obtenção de bons resultados. Para adaptações mais específicas, para equipes compostas apenas por desenvolvedores e que são distribuídas, abertas e colaborativas, foram descritas propostas de adaptações, levando em consideração o contexto de software livre, as práticas de usabilidade ágil e a experiência obtida com as lições aprendidas durante o desenvolvimento dos projetos do CCSL do IME-USP.

Com isso, percebe-se que se existe a vontade de construir um produto com melhor qualidade e usabilidade, basta adequar as práticas ou métodos existentes ao contexto específico de cada projeto, de modo a colher os bons resultados que as práticas trazem tanto para o desenvolvimento, quanto para o produto final. Para melhoria da usabilidade é necessário envolver usuários típicos, para isso, é preciso entender quem serão os reais usuários do sistema a ser desenvolvido e incluí-los, assim como ocorre com o envolvimento de clientes em equipes de métodos ágeis, no processo de desenvolvimento.

Não é necessário utilizar-se de métodos com grande formalidade para aplicação ou documentação, mas é necessário um ambiente colaborativo onde todos os envolvidos possam compartilhar o conhecimento obtido por meio do contato próximo de usuários reais e de modo a compartilhar o conhecimento necessário para a criação do produto; desde a coleta de dados para especificação do contexto de uso, até desenvolvimento e testes. Nesse contexto, cada membro do projeto, beneficiase do conhecimento existente em toda a equipe, permitindo maior compreensão do processo de desenvolvimento de software como um todo. Dessa forma, torna-se possível tanto a melhoria da usabilidade do produto quanto do processo de desenvolvimento.

Em ambientes de desenvolvimento de software livre, práticas de usabilidade realizadas por desenvolvedores e que possam ser aplicadas remotamente são necessárias. A documentação de comportamentos esperados para o sistema, metas de usabilidade e resultados de testes são mais adequados, nesse contexto, quando descritos no próprio ambiente de desenvolvimento, por meio de testes de aceitação, que podem ser baseados em BDD. Sendo assim, a entrada e saída de desenvolvedores do projeto não impede a disseminação do conhecimento levantado com base nas pesquisas de usabilidade, envolvendo usuários reais. 


\subsection{Artigos publicados}

Durante este mestrado foram publicados 4 artigos sobre a pesquisa. O primeiro artigo intitulado "Adaptação de metodologias de usabilidade para o contexto de desenvolvimento de software livre" foi publicado no Workshop de Teses e Dissertações do Simpósio Brasileiro de Engenharia de Software (SBES 2009, Fortaleza-Ceará). O artigo, escrito em conjunto com o orientador desta dissertação, descreve que o modelo colaborativo e aberto do software livre possibilita uma maior exploração de um dos conceitos-chave de métodos de usabilidade - a aceitação de várias ideias de design e interação - promovido pela possibilidade de abertura à contribuição para qualquer pessoa interessada em participar. Dessa forma, o processo não é limitado a especialistas da área de Computação, pois a dinâmica das comunidades livres facilita a melhor exploração desta abertura [SK09].

O segundo artigo intitulado "Rede social Arquigrafia-Brasil: estudos iconográficos da arquitetura brasileira na Web 2.0" foi publicado no Seminário Nacional de Documentação do Patrimômio Arquitetônico com o uso de Tecnologias Digitais (ArqDoc2010, Salvador-Bahia). O artigo, escrito em conjunto com professores membros do Arquigrafia-Brasil, descreve o que o projeto se propõe a investigar e o problema que pretende resolver, considerando a carência de acervos iconográficos específicos, organizados e disponíveis para amplo acesso público na Internet. Também descreve-se o envolvimento de uma equipe multidisciplinar para a concepção e a construção da rede social na Web 2.0 concentrada sobre imagens digitais da arquitetura $\left[\mathrm{RMG}^{+} 10\right]$.

O terceiro artigo intitulado "Applying usability and user experience goals in Agile Software Development" foi publicado no Workshop Dealing with Usability in an Agile Domain da $12^{\text {a }}$ Conferência Internacional sobre desenvolvimento de software ágil (XP2011, Madrid-Espanha). O artigo, escrito em conjunto com o orientador desta dissertação, descreve uma maneira de conectar as metas de usabilidade e de experiência do usuário em ambientes de desenvolvimento com métodos ágeis. De acordo com o entendimento de quem são os usuários típicos, suas necessidades e o contexto de uso do sistema, descreve-se uma abordagem para definir e validar as metas, de usabilidade e UX, por meio de testes de aceitação baseados em BDD e testes de usabilidade envolvendo usuários e clientes [SK11].

O quarto artigo intitulado "Da coleta de dados ao conhecimento obtido durante o desenvolvimento do projeto Arquigrafia-Brasil" foi publicado no $5^{\circ}$ Congresso Internacional de Design de Informação (CIDI 2011, Florianópolis-Santa Catarina). O artigo, escrito em conjunto com membros do projeto Arquigrafia, descreve a evolução dos dados coletados para a definição de requisitos do sistema, passando pelo estágio de informação até a obtenção de conhecimento aplicado ao projeto $\left[\mathrm{SMK}^{+} 11\right]$.

\subsection{Premiação do projeto Arquigrafia-Brasil na Olimpíada USP de inovação}

A Olimpíada USP de inovação (www.inovacao.usp.br/olimpiada2011/pdf/Regulamento_OUI_ 2011.pdf), "tem como objetivo: estimular, reconhecer, premiar e divulgar as atividades de inovação com foco em tecnologias desenvolvidas por toda a comunidade USP (alunos de graduação e pósgraduação, pós-doutorandos, docentes e funcionários)".

A olimpíada foi composta por duas etapas e, na primeira etapa, os projetos seriam inscritos segundo duas categorias, conforme regulamento da competição:

- "Livre: destinada a projetos bem estruturados e exeqüíveis baseados em ideias/conceitos inovadores. A Comissão Julgadora, indicada pela Coordenação da Olimpíada, selecionará um único projeto para a $2^{\mathrm{a}}$ Etapa"; e

- "Centros de Inovação (CI): categoria destinada a projetos bem estruturados e exeqüíveis baseados em pesquisas científicas fundamentadas e inovadoras, nas Unidades de Ensino e Pesquisa, Núcleos de Apoio a Pesquisa, e nos Institutos Nacionais de Ciência e Tecnologia do CNPq da USP". 
O projeto Arquigrafia adequava-se na categoria Centros de inovação (CI) e portanto para sua inscrição foi necessária a entrega de um resumo com a ideia central do produto ou processo e a descrição da tecnologia. O resumo deveria responder as seguintes questões: "a) Que problema será resolvido? b) Quem será o cliente atendido pela solução proposta? e c) Como o produto ou serviço resolveria o problema de modo inovador?".

Os projetos selecionados na $1^{\mathrm{a}}$ Etapa desenvolveram um plano de produto, "caracterizado como uma solução técnica com viabilidade de se transformar em negócio", conforme descrito no regulamento da olimpíada. Uma comissão selecionou os 5 melhores projetos em cada uma das áreas que participaram da arguição. Após a arguição, selecionou primeiro, segundo e terceiro colocados em cada uma das áreas. A arguição resultou na conquista do $1^{\circ}$ lugar na categoria Tecnologias Sociais Aplicadas e Humanas na Olimpíada USP de Inovação de 2011. A olimpíada teve 641 projetos inscritos em 4 categorias diferentes, dos quais 52 foram selecionados para a segunda etapa.

Os seguintes sites trazem notícias dos resultados da Olimpíada USP de inovação 2011: ccsl.ime. usp.br/news/11/12/06/olimpiada-usp-de-inovacao-premia-projeto-do-ccsl e www.inovacao.usp.br/ olimpiada2011.

\subsection{Trabalhos Futuros}

Em trabalhos futuros, as práticas de usabilidade ágil poderiam ser realizadas em contexto de software livre, inclusive as propostas de adaptação, de modo a avaliar sua aplicação durante o desenvolvimento de vários projetos de software livre. O objetivo seria coletar dados resultantes da aplicação em diversos projetos diferentes para avaliar como as práticas influenciaram na melhoria de usabilidade.

Também pode-se explorar práticas para melhoria de design gráfico de interfaces (cores, botões, arte) em contexto de software livre. Nesta dissertação, o enfoque foi em práticas para melhoria da usabilidade, levando-se em consideração o cumprimento das necessidades dos usuários no sistema. De forma complementar, pesquisas poderiam ser desenvolvidas para aplicação de técnicas de melhoria de design gráfico nesse contexto.

Portanto, muito ainda pode ser explorado na aplicação de práticas para melhoria da usabilidade e/ou qualidade do design gráfico de acordo com o contexto de desenvolvimento. O importante é que essa preocupação faça parte do dia a dia de qualquer tipo de sistema, com o objetivo de facilitar a interação para todos os perfis de usuários, contribuindo dessa forma para a inclusão digital e disseminação de conhecimento. 


\section{Referências Bibliográficas}

[AIS $\left.{ }^{+} 77\right]$ C. Alexander, S. Ishikawa, M. Silverstein, M. Jacobson, I. Fiksdahl-King, e S. Angel. A Pattern Language: Towns, Buildings, Construction. Oxford University Press, 1977. 46

[Alb10] M. Albisetti. Launchpadś quest for a better and agile user interface. in Agile Processes in Software Engineering and Extreme Programming, 2010. 64

[Amb09] S. W. Ambler. Introduction to agile usability user experience activities on agile development projects - user testing on an agile project, 2009. Available on-line at: http://www.agilemodeling.com/essays/agileUsability.htm\#AcceptanceTesting Acessed on: December 2011. 66

[AMC09] S. Adikari, C. McDonald, e J. Campbell. Little design up-front: A design science approach to integrating usability into agile requirements engineering. Em Proceedings of the 13th International Conference on Human-Computer Interaction. Part I, páginas 549-558, 2009. 53

[And09] S. P. Anderson. The fundamentals of experience design, March 2009. Available on-line at: http://www.poetpainter.com/thoughts/article/ia-summit-2009-thefundamentals-of-experience-design- Acessed on: December 2011. 56

[Ass10a] Usability Professionals Association. What is usability?, 2010. Available on-line at: http://www.usabilityprofessionals.org/usability_resources/about_usability/ definitions_of_usability.html. 13

[Ass10b] Usability Professionals Association. What is usercentered design?, 2010. Available online at: http://www.usabilityprofessionals.org/usability_resources/about_usability/ what_is_ucd.html. xiii, 18, 19, 28

[BA04] K. Beck e C. Andres. Extreme Programming Explained: Embrace Change. AddisonWesley Professional, 2 edição, 2004. 42

[Bal11a] B. Balazs. First libreoffice user research survey closed, 2011. Available on-line at: http://www.opensource-usability-labs.com/opensource-usabilitylabs/2011/08/05/first-libreoffice-user-research-survey-closed/ Acessed on: December 2011. 30

[Bal11b] B. Balazs. Libreoffice user research - results vol.1, 2011. Available online at: http://www.opensource-usability-labs.com/kde/2011/08/18/libreoffice-userresearch-results-vol-1/ Acessed on: December 2011. 30

[BB03] G. Booch e A. Brown. Collaborative development environments. Vol. 59, August 2003. 26

[BB08] D. Broschinsky e L. Baker. Using persona with xp at landesk software, an avocent company. Em Agile 2008 Conference, páginas 543-548, 2008. 56, 58 
[BB09] B. Belchev e P. Baker. Improving obama campaign software: Learning from users. Em Agile 2009 Conference, páginas 395-399, 2009. 49, 64

[BBvB01] K. Beck, M. Beedle, e A. et al. van Bennekum. Manifesto for agile software development, 2001. Available on-line at: http://www.agilemanifesto.org. 39

[BDG08] M. Besten, J. M. Dalle, e F. Galia. The allocation of collaborative efforts in open-source software. Information Economics and Policy, 20(4):316 - 322, 2008. 23

[Bec99] K. Beck. Extreme Programming Explained: Embrace Change. Addison-Wesley, Reading, PA., 1 edição, 1999. 42

[Bel11] M. Beltrame. Just married: User centered design and agile, May 2011. Available on-line at: http://www.memibeltrame.ch/slides/ Acessed on: December 2011. 62

[Ben04] Professional usability in open source projects: GNOME, OpenOffice.org, NetBeans, 2004. 6

[BG11] M. Bravo e A. Goldman. Programação extrema, 2011. Available on-line at: http://www.agilcoop.org.br/files/cartaz.pdf Acessed on: December 2011. xiii, 43

[BGPK10] G. Benigni, O. Gervasi, F. L. Passeri, e T. H. Kim. Usabagile_web: A web agile usability approach for web site design. ICCSA (2) - Lecture Notes in Computer Science (LNCS), 2010. 63,64

[BHB04] H. Beyer, K. Holtzblatt, e L. Baker. An agile customercentered method: Rapid contextual design. Em in Extreme Programming and Agile Methods - XP/Agile Universe 2004, 2004. 56, 64

[BJK09] M. Budwig, S. Jeong, e K. Kelkar. When user experience met agile: A case study. Em CHI 09: Proceedings of the 27th international conference extended abstracts on Human factors in computing systems, páginas 3075-3084, 2009. 48, 56

[BLB08] J. Brown, G. Lindgaard, e R. Biddle. Stories, sketches, and lists: Developers and interaction designers interacting through artefacts. Em Agile 2008 Conference, páginas 39-50, 2008. 58

[Blo11] Zen Ex Machina Company Blog. Tips on how ux can become agile by using scrum, 2011. Available on-line at: zenagile.wordpress.com/tag/ixd Acessed on: December, 2011. xiii, 42

[BM10] J. T. Barksdale e D. S. McCrickard. Concept mapping in agile usability: A case study. Em CHI EA 10: Proceedings of the 28th of the international conference extended abstracts on Human factors in computing systems, 2010. 55

[CG11] H. Corbucci e A. Goldman. Métodos ágeis e software livre: um estudo da relação entre estas duas comunidades. dissertação de mestrado. são paulo, brasil. departamento de ciência da computação do instituto de matemática e estatística, universidade de são paulo (usp), 2011. 5, 23, 91

$\left[\mathrm{CGK}^{+} 11\right]$ H. Corbucci, A. Goldman, E. T. Katayama, F. Kon, C. O. Melo, e V. Santos. Genesis and evolution of the agile movement in brazil - perspective from academia and industry. Em SBES 2011, 2011. 41, 88

[Cho09] L. Cho. Adopting an agile culture: A user experience teamś journey. Em Agile 2009 Conference, páginas 416-421, 2009. 48, 53 
[CK09] D. Cukier e F. Kon. Padrões para introduzir novas ideias na indústria de software. dissertação de mestrado. são paulo, brasil. departamento de ciência da computação do instituto de matemática e estatística, universidade de são paulo (usp), Maio 2009. 9, 46

[CL02] L. L. Constantine e L. A. D. Lockwood. Usage-centered engineering for web applications. IEEE Softw., 19:42-50, 2002. 53

[Col09] Inc. CollabNet. Vision for argouml, 2009. Available on-line at: http://argouml.tigris.org/vision.html Acessed on: December, 2011. xiii, 34

[Com07] Debian Community. Debian user forums, 2007. Available on-line at: http://forums.debian.net/ Acessed on: December 2011. 30

[Com09] KDE Community. Kde usability project meetings, 2009. Available on-line at: http://techbase.kde.org/Projects/Usability/Meetings Acessed on: December 2011. 37

[Com10] The Gnome Community. Planet ux, 2010. Available on-line at: http://planet.gnome.org/ux/ Acessed on: December 2011. 34

[Com11] KDE Community. Hig - human interface guidelines, 2011. Available on-line at: http://techbase.kde.org/Projects/Usability/HIG Acessed on: December 2011. 35

[Coo88] H. M. Cooper. Organizing knowledge synthesis: A taxonomy of literature reviews. Knowledge in society, 1:104-126, 1988. 10

[Cru01] J. Crupi. Core j2ee patterns, 2001. Available on-line at: http://java.sun.com/developer/technicalArticles/J2EE/corepatterns/ Acessed on: December 2011. 46

[CSM06] S. Chamberlain, H. Sharp, e N. Maiden. Towards a framework for integrating agile development and user-centred design. Extreme Programming and Agile Processes in Software Engineering, páginas 143-153, 2006. 48, 49, 59

[DDBS08] J. M. Dalle, P. A. David, M. Besten, e W. E. Steinmueller. Empirical issues in open source software. Information Economics and Policy, 20(4):301 - 304, 2008. 23

[Des11] J-M. Desharnais. Software measurement - analysis of isoiec 9126 and 25010, 2011. Available on-line at: http://www.cmpe.boun.edu.tr/courses/cmpe58V/fall2009/06aAnalysis\%20of\%209126-2,3,4short.pdf Acessed on: April, 2012. 13

[Det07] M. Detweiler. Managing ucd within agile projects. Interactions, 14:40-42, 2007. 49, 59, 63,64

[DFAB93] A. Dix, J. Finlay, G. Abowd, e R. Beale. Human-Computer Interaction. Prentice-Hall Europe, 2 edição, 1993. 19

[Dic93] B. Dick. You want to do an action research thesis?, 1993. Available online at: http://www.scu.edu.au/schools/gcm/ar/art/arthesis.html. Acessed on: November 2011. 7

[DK10] J. Dickinson e D. Kumana. How user-centered design can put user stories in proper context, 2010. Available on-line at: http://www.devx.com/architect/Article/42270/1954. Acessed on: December 2011. 56

[DL11] I. Douglas e Z. Liu. Global Usability. Springer, 2011. 13, 15, 95

[DS10] R. Douglass e C. Smith. Rapid iterative testing and evaluation (rite), May 2010. Available on-line at: https://www.usabilityprofessionals.org/upa_conference/app/schedule/show_detail/10831/for:2010 Acessed on: December 2011. 65 
[Dub11] M. Dubakov. Ux meets agile: Design studio methodology, May 2011. Available on-line at: http://www.targetprocess.com/blog/2011/05/ux-meets-agile-design-studiomethodology.html Acessed on: December 2011. xiii, 60

[DWA04] PA. David, A. Waterman, e S. Arora. Floss-us: The free/libre/open source software survey for 2003. Stanford Institute for Economic Policy Research, 20, 2004. 1, 2, 6

[DZN07] M. Düchting, D. Zimmermann, e K. Nebe. Incorporating user centered requirement engineering into agile software development. Em HCIÓ\%: Proceedings of the 12th international conference on Human-computer interaction, 2007. 56, 63, 64

[EG11] W. Evans e J. Gothelf. Design studio and agile ux : Process and pitfalls, November 2011. Available on-line at: http://uxmag.com/articles/design-studio-and-agile-uxprocess-and-pitfalls Acessed on: December 2011. 60

[Ent11] Expero Enterprise. Incorporating user-centered design into an agile development process, December 2011. Available on-line at: http://experoinc.com/incorporating-usercentered-design-into-an-agile-development-process/. Acessed on: December 2011. 49, $50,54,63$

$\left[\right.$ FAS $^{+}$05] L. Filgueiras, P. Aquino, R. Sakai, A. G. Filho, C. Torres, e I. Barbarian. Personas como modelo de usuários de serviços de governo eletrônico. Em Proceedings of the 2005 Latin American conference on Humancomputer interaction CLIHC 05 (2005). ACM Press, Pages: 319-324, 2005. 46

[Fed08] M. et al. Federoff. Extreme usability: Adapting research approaches for agile development. Em CHIÓ8: CHIó8 extended abstracts on Human factors in computing systems, páginas 2269-2272, 2008. 51, 63, 64

[FF08] D. Filippo e H. Fuks. Suporte à coordenação em sistemas colaborativos: uma pesquisaação com aprendizes e mediadores atuando em fóruns de discussão de um curso a distância. tese de doutorado. rio de janeiro, departamento de informática, pontifícia universidade católica do rio de janeiro. 281p., 2008. 7, 8

[Fil09] C. M. O. Filho. Kalibro: Uma ferramenta de configuração e interpretação de métricas de código-fonte. iniciação científica. (graduando em ciência da computação). orientador: Fabio kon, 2009. 85

[FN08] S. B. L. Ferreira e R. R. Nunes. e-Usabilidade. LTC Livros Técnicos e Científicos Editora S.A., Agosto 2008. 14

[FNB07] J. Ferreira, J. Noble, e R. Biddle. Agile development iterations and ui design. Em Proceedings of the AGILE 200\%, páginas 50-58, 2007. 53, 56, 63

[For09] KDE Community Forum. Project user research template, 2009. Available on-line at: http://techbase.kde.org/Projects/Usability/Project_User_Research_Template Acessed on: December 2011. 29

[For11a] KDE Community Forums. Kde brainstorm, 2011. Available on-line at: forum.kde.org/brainstorm.php\#idea97665 Acessed on: December 2011. xiii, 32

[For11b] KDE Community Forums. Kde brainstorm, 2011. Available on-line at: forum.kde.org/brainstorm.php\#idea98272 Acessed on: December 2011. xiii, 33

[Fou10] Free Software Foundation. What is free software?, 2010. Available on-line at: http://www.gnu.org/philosophy/free-sw.html Acessed on: December 2011. 24 
[Fow97] M. Fowler. Analysis Patterns: reusable object models. Addison-Wesley Professional, 1997. 46

[Fow05] M. Fowler. UML Essencial: Um breve guia para a linguagem-padrão de modelagem de objetos. Bookman, 3st edição, 2005. 40

[FSM08] D. Fox, J. Sillito, e F. Maurer. Agile methods and user-centered design: How these two methodologies are being successfully integrated in industry. Em Proceedings of the Agile 2008, páginas 63-72, 2008. 49, 55, 59, 63, 64

[Fur10] J. Furnell. Facilitating collaborative design workshops - a step by step guide for rapidly creating a shared vision for execution, December 2010. Available on-line at: http://jasonfurnell.wordpress.com/2010/12/01/facilitating-collaborative-designworkshops-a-step-by-step-guide-for-rapidly-creating-a-shared-vision-for-execution/

Acessed on: December 2011. 62

[Gí1] E. M. T. Gómez. Reconhecimento de fala para navegação em aplicativos móveis para português brasileiro - dissertação (mestrado em ciência da computação). orientador: Fabio kon, 2011. xiv, 88

[Gar08] R. Gardler. What is open development?, 2008. Available on-line at: http://osswatch.jiscinvolve.org/wp/2008/10/30/what-is-open-development Acessed on: December, 2011. 25

[Ger06] M. A. Gerosa. Desenvolvimento de groupware componentizado com base no modelo 3c de colaboração. tese de doutorado. rio de janeiro, brasil. departamento de informática, pontifícia universidade católica do rio de janeiro (puc-rio), 2006. 70

[Gho05] RA. Ghosh. Understanding free software developers: Findings from the floss study. páginas $23-45,2005.6$

[Gil06] A. C. Gil. Métodos e Técnicas de Pesquisa Social. 5.ed. São Paulo: Editora Atlas, 2006. 7

[Gil07] A. C. Gil. Como elaborar projetos de pesquisa - $4^{a}$ ed. São Paulo: Ed. Atlas, 2007. 8

[Got11] J. Gothelf. Ux designer as product owner, February 2011. Available on-line at: http://www.jeffgothelf.com/blog/ux-designer-as-product-owner/. 50

[Gov08] A. Govella. Agile + ux: six strategies for more agile user experience, 2008. Available on-line at: http://www.thinkingandmaking.com/view/agile-ux-six. 48, 62

[Gro09] J. C. Grosjean. Use cases - user stories: so precious but not the same!, 2009. Available on-line at: http://www.agile-ux.com/2009/01/23/use-cases-user-stories-so-preciousbut-not-the-same/ Acessed on: December 2011. 54

[Gro10] J. C. Grosjean. Agile ux in practice, November 2010. Available on-line at: http://www.agile-ux.com/2010/11/21/agile-ux-in-practice/ Acessed on: December 2011. 50,57

[Gro11] J. C. Grosjean. 10 strategies to split large user stories, 2011. Available on-line at: http://www.agile-ux.com/tag/user-stories/ Acessed on: December 2011. 54

[Hai07] J. Haikara. Usability in agile software development: Extending the interaction design process with personas approach. Em in XPÓ\%: Proceedings of the 8th international conference on Agile processes in software engineering and extreme programming, 2007. 
[Hed07] Assuring Quality and Usability in Open Source Software Development, 2007. 1

$\left[\mathrm{HES}^{+}\right.$05] A. Holzinger, M. Errath, G. Searle, B. Thurnher, e W. Slany. From extreme programming and usability engineering to extreme usability in software engineering education $(\mathrm{xp}+\mathrm{ue}=\mathrm{xu})$. Em COMPSAC 05: Proceedings of the 29th Annual International Computer Software and Applications Conference, páginas 169-172, 2005. 55, 59, 63

[HHKM10] D. T. Hellmann, A. Hosseini-Khayat, e F. Maurer. Supporting test-driven development of graphical user interfaces using agile interaction design. Em in Software Testing Verification and Validation Workshop, IEEE International Conference on, 2010. 59

[Hip05] E. v. Hippel. Democratizing Innovation. The MIT Press, Cambridge, Massachusetts, 2005. 27,28

[Hod05] P. Hodgetts. Experiences integrating sophisticated user experience design practices into agile processes. Em Proceedings of the Agile Development Conference, páginas 235-242, 2005. 49

[How08] J. Howison. Alone together: A socio-technical theory of motivation, coordination and collaboration technologies in organizing for free and open source software development. thesis of degree of doctor of philosophy in information science and technology, 2008. 1, 2,6

[Hus08a] Z. et al. Hussain. Agile user-centered design applied to a mobile multimedia streaming application. Em in USAB 0́8: Proceedings of the 4th Symposium of the Workgroup Human-Computer Interaction and Usability Engineering of the Austrian Computer Society on HCI and Usability for Education and Work, 2008. 59

[Hus08b] Z. et al. Hussain. User interface design for a mobile multimedia application: An iterative approach. Em in ACHI 0́8: Proceedings of the First International Conference on Advances in Computer-Human Interaction, 2008. 55, 59, 63, 64

[Hus09] Z. et al. Hussain. Integration of extreme programming and user-centered design: Lessons learned. Em in Agile Processes in Software Engineering and Extreme Programming 2009, 2009. $56,59,64$

[IM09] T. Illmensee e A. Muff. 5 users every friday: A case study in applied research. Em Agile 2009 Conference, páginas 404-409, 2009. 48, 63

[Ini11] Open Source Initiative. The open source definition, 2011. Available on-line at: http://opensource.org/docs/osd Acessed on: December 2011. 24

[IU10] ICMC-USP. Projeto qualipso, 2010. Available on-line at: http://qualipso.icmc.usp.br/. 5

[JA04] T. Jokela e P. Abrahamsson. Usability assessment of an extreme programming project: Close co-operation with the customer does not equal to good usability. Lecture Notes in Computer Science - Product Focused Software Process Improvement, 3009:393-407, 2004. 53,56

[JTF08] A. Junior, P. Thomaz, e L. Filgueiras. A expressão da diversidade de usuários no projeto de interação com padrões e personas. Proceedings of the VIII Brazilian Symposium on Human Factors in Computing Systems, páginas 1-10, 2008. 46

[Kan03] D. Kane. Finding a place for discount usability engineering in agile development: Throwing down the gauntlet. Em Proceedings of the Conference on Agile Development, 2003. 63,64 
[KM05] S. Kemmis e R. Mctaggart. Participatory Action Research: Communicative Action and the Public Sphere, Capitulo 23. Sage Publication Inc, EUA., 2005. 8

[KMS97] N.F. Kock, R.J. Mcqueen, e J.L. Scott. Can action research be made more rigorous in a positivist sense? the contribution of an iterative approach. Journal of Systems and Information Technology, v.1, n.1, p. 1-24, 1997, 1997. 7

[KS02] S. Koch e G. Schneider. Effort, co-operation and co-ordination in an open source software project: Gnome. Information Systems Journal, 12:27-42, 2002. 6

[KSB09] J. Kollmann, H. Sharp, e A. Blandford. The importance of identity and vision to user experience designers on agile projects. Em Proceedings of the 2009 Agile Conference, páginas 11-18, 2009. 49

[Leg08] N. Leggett. User research findings - analyzing the user research segment - the power of doing it rite, July 2008. Available on-line at: http://www.userresearchfindings.com/2008/07/power-of-doing-it-rite.html Acessed on: December 2011. 65

[LM07] J. C. Lee e D. S. McCrickard. Towards extreme(ly) usable software: Exploring tensions between usability and agile software development. Em Proceedings of the AGILE 2007, 2007. 55, 63

[LRM10] C. Lu, T. Rauch, e L. Miller. Agile teams: Best practices for agile development. 9(1):6 - 10, 2010. 44, 48, 49, 51, 52, 53, 54, 57, 65

[LW05] K. R. Lakhani e B. Wolf. Why hackers do what they do: Understanding motivation effort in free/open source software projects. 2005. 26

[MA06] G. Meszaros e J. Aston. Adding usability testing to an agile project. Em AGILE Conference, páginas 289-294, 2006. 55, 59, 63

[Mar02] M. L. Martinez. Um método de webdesign baseado em usabilidade. tese de doutorado. são paulo, brasil. escola politécnica, universidade de são paulo. 301p., 2002. xiii, 70

[McC11] T. McCoy. Lean ux, product stewardship, and integrated teams, February 2011. Available on-line at: http://www.cooper.com/journal/2011/02/lean_ux_product_stewardship_an.html. 50

[Mem09] Project Members. Qualipso project, 2009. Available on-line at: http://www.qualipso.org/. 5

[Mil05] L. Miller. Case study of customer input for a successful product. Em Agile 2005, 2005. 59,64

[MM01] J. Mckay e P. Marshall. The dual imperatives of action research. Information Technology \& People, v.14, n.1, páginas 46-59, 2001. 8

[MM05] P. McInerney e F. Maurer. Ucd in agile projects: Dream team or odd couple? 20(4):19 - 23, November/December 2005. 43, 46, 49

[MS09] L. Miller e D. Sy. Agile user experience sig. Em CHI '09: Proceedings of the 27th international conference extended abstracts on Human factors in computing systems, páginas 2751 - 2754, Boston, MA, USA, 2009. ACM. xiii, 44, 45 
[MW04] D. Maurer e T. Warfel. Card sorting: a definitive guide. boxes and arrows., 2004. Available on-line at: http://www.boxesandarrows.com/view/card_sorting_a_definitive_guide Acessed on: June 2011. 77

[Nie93] J. Nielsen. Usability Engineering. Academic Press, 1993. 20

[Nie94] J. Nielsen. Guerrilla hci: Using discount usability engineering to penetrate the intimidation barrier, 1994. Available on-line at: http://www.useit.com/papers/guerrilla_hci.html Acessed on: December 2011. 20

[Nie05] J. Nielsen. Ten usability heuristics, 2005. Available on-line at: http://www.useit.com/papers/heuristic/heuristic_list.html Acessed on: December 2011. 20

[Nie09] J. Nielsen. Agile user experience projects, 2009. Available on-line at: http://www.useit.com/alertbox/agile-user-experience.html. 48, 52, 57

[Nie9b] Usability engineering at a discount. In Salvendy, G., and Smith, M.J. (Eds.), 1989b. 20

[Nie0a] Big paybacks from 'discount' usability engineering, May 1990a. 20

[Nie2b] J. Nielsen. Evaluating the thinking aloud technique for use by computer scientists. Advances in Human-Computer Interaction, 3, 1992b. 20

[NL93] J. Nielsen e T. K. Landauer. A mathematical model of the finding of usability problems. Em Proc. ACM INTERCHI93 Conf, 24-29 April 1993. 20

[NL08] J. Nielsen e H. Loranger. Prioritizing Web Usability. Kindle, February 2008. 13

[NT03] D. M. Nichols e M. B. Twidale. The usability of open source software. First Monday, 8(1), January 2003. 2

[NT06] D. M. Nichols e M. B. Twidale. Usability processes in open source projects. Software Process Improvement and Practice, 11:149-162, 2006. 1, 2, 6, 23

[NT08] M. Najafi e L. Toyoshiba. Two case studies of user experience design and agile development. Em Proceedings of the Agile 2008, páginas 531-536, 2008. 48, 49, 63, 64

[OF08] H. Obendorf e M. Finck. Scenario-based usability engineering techniques in agile development processes. Em CHI 0́8: CHI 0́8 extended abstracts on Human factors in computing systems, 2008. 63, 64

[OLDB11] L. Olsina, P. Lew, A. Dieser, e Rivera B. Using web quality models and a strategy for purpose-oriented evaluations. Journal of Web Engineering, Vol. 10, N. 4, páginas 316-352, 2011. 13

[OO03] G. M. Olson e J. S. Olson. Human-computer interaction: Psychological aspects of the human use of computing. Annual Review of Psychology, 54:491-516, 2003. 15

[Pat08] J. Patton. Emerging best agile ux practice, 2008. Available on-line at: http://agileproductdesign.com/blog/emerging_best_agile_ux_practice.html. 48, 50, $51,52,53,54,57,58,59,65$

[Pau09] C. L. Paul. A survey of usability practices in free/libre/open source software. $C$. Boldyreff et al. (Eds.): OSS 2009, IFIP AICT 299, páginas 264-273, 2009. 7, 30, 35

[Pau10] C. L. Paul. Using tabs in the taskbar: Improving desktop-application integration, visual hierarchy, and usability in kde, 2010. Available on-line at: http://obso1337.org/2010/using-tabs-in-the-taskbar/ Acessed on: December 2011. 34 
[PH08] Runeson P. e M. Höst. Guidelines for conducting and reporting case study research in software engineering. Empirical Software Engineering, 14(2):131-164, 2008. 8

[Pri03] R. Prikladnicki. Munddos: Um modelo de referência para desenvolvimento distribuído de software. dissertação de mestrado, ppgcc - pucrs, 2003. 25

[Pri11] G. Primo. User stories - o que são? como usar?, 2011. Available on-line at: blog.scrumhalf.com.br/2011/10/user-stories-o-que-sao-como-usar Acessed on: December, 2011. xiii, 55

[Ran09] J. Randolph. A guide to writing the dissertation literature review. Practical Assesment, Research \& Evaluation, 14(13), 2009. Available on-line at: http:/ pareonline.net/getvn.asp? $\mathrm{v}=14 \& \mathrm{n}=13.10,11,12$

[Ray99] E. S. Raymond. The cathedral \& the bazaar. O'Reilly, 1999. 27, 36

[Raz11] A. Raza. A usability maturity model for open source software - thesis (doctor of philosophy)., 2011. 6

[Ric09] R. W. Rice. What is user acceptance testing?, 2009. Available on-line at: http://www.riceconsulting.com/articles/what-is-UAT.htm Acessed on: December 2011. 66,67

$\left[\mathrm{RMG}^{+} 10\right]$ A. S. Rozestraten, M. L. Martinez, M. A. Gerosa, F. Kon, e A. P. O. Santos. Estudos iconográficos da arquitetura brasileira na web 2.0. Em Seminário Nacional de Documentação do Patrimônio Arquitetônico com o Uso de Tecnologias Digitais (ARQ.DOC'2010). Anais do Seminário Nacional de Documentação do Patrimônio Arquitetônico com o Uso de Tecnologias Digitais, 2010, 2010. 102

[Rob03] J. E. Robbins. Adopting open source software engineering (osse) practices by adopting osse tools. Making Sense of the Bazaar: Perspectives on Open Source and Free Software, 2003. 5

[Roy70] W. Royce. Managing the development of large software systems. Em Proceedings of IEEE, August 1970. 5

[Roz10] M. L.; Michalsky S.; Silva V. W. S.; Munoz C. L. H.; Oliveira L. S.; Gerosa M. A. Rozestraten, A. S.; Martinez. Rede social arquigrafia-brasil: Design de um ambiente online baseado em transdisciplinaridade e colaboração. Em In: SIMPÓSIO BRASILEIRO DE SISTEMAS COLABORATIVOS, 7., Anais do Simpósio Brasileiro de Sistemas Colaborativos, 2010. 69

[SB01] K. Schwaber e M. Beedle. Agile Software Development with Scrum. Prentice Hall, 2001. 41

[Sca02] W. Scacchi. Understanding the requirements for developing open source software systems. páginas 24-39, 2002. 28, 31

[Sca10] W. Scacchi. The future of research in free/open source software development. ACM, 2010. 6

[Sch04] K. Schwaber. Agile Project Management with Scrum. Microsoft Press, 2004. 41

$\left[\mathrm{SFF}^{+} 06\right]$ W. Scacchi, J. Feller, B. Fitzgerald, S. Hissam, e K. Lakhani. Guest editorial: Understanding free/open source software development processes. 11:95-105, 2006. 1, 2, 6 
[SG07] D. T. Sato e A. Goldman. Uso eficaz de métricas em métodos ágeis de desenvolvimento de software, 2007. Available on-line at: http://www.teses.usp.br/teses/disponiveis/45/45134/tde-06092007-225914/. 39, 42

[Sin08] M. Singh. U-scrum: An agile methodology for promoting usability. Em Proceedings of the Agile 2008, páginas 555-560, 2008. 50, 56

[Six11] J. M. Six. Integrating ux into agile development, April 2011. Available on-line at: http://www.uxmatters.com/mt/archives/2011/04/integrating-ux-into-agiledevelopment.php Acessed on: December 2011. 49, 50, 51, 52, 56, 57, 59, 62

[SK09] A. P. O. Santos e F. Kon. Adaptação de metodologias de usabilidade para o contexto de desenvolvimento de software livre. Em $14^{\circ}$ Workshop de Teses e Dissertações em Engenharia de Software. Anais do $14^{\circ}$ Workshop de Teses e Dissertações em Engenharia de Software, 2009, 2009. 102

[SK10] O. Sohaib e K. Khan. Integrating usability engineering and agile software development: A literature review. Em International Conference on Computer Design and Applications (ICCDA), páginas V2-32-V2-38, 2010. 56, 59, 63

[SK11] A. P. O. Santos e F. Kon. Applying usability and user experience goals in agile software development. Em Proceedings of the 2nd workshop Dealing with Usabiliy in an Agile Domain, XP'2011 workshop, 2011. 102

[SM08] D. Sy e L. Miller. Optimizing agile user-centred design. CHI 0́8: CHI 0́8 extended abstracts on Human factors in computing system, páginas 3987-3900, 2008. 48, 64

$\left[\mathrm{SMK}^{+} 11\right]$ A. P. O. Santos, M. L. Martinez, F. Kon, M. A. Gerosa, S. Michalsky, e A. S. Rozestraten. Da coleta de dados ao conhecimento obtido durante o desenvolvimento do projeto arquigrafia-brasil. Em $5^{\circ}$ CIDI - Congresso Internacional de Design da Informação. Anais do $5^{\circ}$ Congresso Internacional de Design da Informação. Bauru, SP: SBDI, 2011. v.1., 2011. 102

[SMMS11] T. S. Silva, A. Martin, F. Maurer, e M. Silveira. User-centered design and agile methods: A systematic review. IEEE Computer Society, 2011. 48, 49, 53, 55, 58, 59, 63, 64

[SRP07a] H. Sharp, Y. Rogers, e J. Preece. Interaction Design: Beyond Human-Computer Interaction - 2nd edition. John Wiley \& Sons Ltd, 2007. xiii, 15, 18, 19

[SRP07b] H. Sharp, Y. Rogers, e J. Preece. Website for the book interaction design: beyond human-computer interaction (2nd edition), 2007. Available on-line at: http://www.idbook.com/secondedition/chapter1_teaching.htm Acessed on: August 2010. xiii, 16

[SS11] K. Schwaber e J. Sutherland. The scrum guide - the definitive guide to scrum: The rules of the game, July 2011. Available on-line at: http://www.scrum.org/storage/scrumguides/Scrum\%20Guide\%20-\%202011.pdf Acessed on: December 2011. 42

[SY07] D. SY. Adapting usability investigations for agile user centered design. Journal of Usability Studies, 2(3):112-132, May 2007. xiii, 43, 44, 49, 51

[TA08] T. Tullis e B. Albert. Measuring the User Experience: Collecting, Analysing, and Presenting Usability Metrics. Morgan Kaufmann, March 2008. 13

$\left[\mathrm{TCM}^{+} 10\right]$ A. Terceiro, J. Costa, J. Miranda, P. Meirelles, L. R. Rios, L. Almeida, C. Chavez, e F. Kon. Analizo: an extensible multi-language source code analysis and visualization toolkit. Sessão de Ferramentas do Congresso Brasileiro de Software: Teoria e Prática (CBSoft), setembro 2010. 85 
[Tea10] Design Team. Canonical design, 2010. Available on-line at: http://design.canonical.com Acessed on: December 2011. 34

[Tho08] M. P. Thomas. Why free software has poor usability, and how to improve it. Computing E Internet, Usability, August 2008. 1

[TTB10] Dyba T., Dingsoyr T., e Moe N. B. Agile Software Development - Current Research and Future Directions. Ed. Springer, 1st edição, 2010. 66

[Twi05] Exploring Usability Discussions in Open Source Development, 2005. 6

[Tyn11] S. V. Tyne. User experience design in agile development, 2011. Available on-line at: http://www.slideshare.net/sdeconf/sdec-2011-uxagilesvt Acessed on: December 2011. 62

[Usa10] Open Usability. Open usability - where open source meets usability, 2010. Available on-line at: http://www.openusability.org Acessed on: December 2011. 7, 35

[UW08] J. M. Ungar e J. A. White. Agile user centered design: Enter the design studio - a case study. Em Proceedings of CHI 2008: CHI '08 extended abstracts on Human factors in computing systems, páginas 2167-2178, April 2008. 44, 48, 59, 60, 64

[Wak03] B. Wake. Invest in good stories, and smart tasks, August 2003. Available on-line at: http://xp123.com/articles/invest-in-good-stories-and-smart-tasks/ Acessed on: December 2011. 56

[Wel09a] D. Wells. User stories, 2009. Available on-line at: http://www.extremeprogramming.org/rules/userstories.html Acessed on: December 2011. 54

[Wel09b] D. Wells. Xp flow chart, 2009. Available on-line at: www.extremeprogramming.org/map/project.html Acessed on: August, 2010. xiii, 43

[WF07] H. Williams e A. Ferguson. The ucd perspective: Before and after agile. Em Proceedings of the AGILE 2007, páginas 285-290, 2007. 48, 49, 53, 59, 63, 64

[Wik11] Wikipedia. Open source software development, 2011. Available on-line at: http://en.wikipedia.org/wiki/Open_source_software_development/.5

[WMF07] D. Wixon, M. Medlock, e M. Federoff. Rapide iterative testing and evaluation, December 2007. Available on-line at: http://www.slideshare.net/macieklipiec/rapid-iterativetesting-and-evaluation Acessed on: December 2011. 65

[WTS $\left.{ }^{+} 08\right]$ P. Wolkerstorfer, M. Tscheligi, R. Sefelin, H. Milchrahm, Z. Hussain, M. Lechner, e S. Shahzad. Probing an agile usability process. Em Proceedings of CHI 2008: CHI 0́8 extended abstracts on Human factors in computing systems, páginas 2151-2158, April 2008. 46, 49, 63, 64, 75

[Yin03] R. K. Yin. Case study research: design and methods. 3rd ed. London: Sage, 2003. 8 